\title{
Untersuchungen zur Expression, Funktion und Regulation ausgewählter Gene der Insulinfamilie
}

\author{
Dissertation \\ zur Erlangung des Doktorgrades \\ der Mathematisch-Naturwissenschaftlichen Fakultäten \\ der Georg-August-Universität zu Göttingen
}

vorgelegt von

Katayoon Shirneshan

aus Esfahan (Iran)

Göttingen 2005 
D 7

Referent:

Prof. Dr. W. Engel

Korreferent:

Prof. Dr. R. Hardeland

Tag der mündlichen Prüfung: 03.11.2005 


\section{INHALTSVERZEICHNIS}

ABKÜRZUNGSVERZEICHNIS.......................................... IX

1.1 Die Insulinfamilie. 1

1.2 Insl2/Insl3 transgene Mäuse. 5

1.3 Ziele der vorliegenden Arbeit.

2.1

Material.

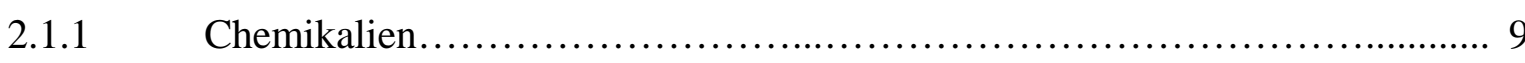

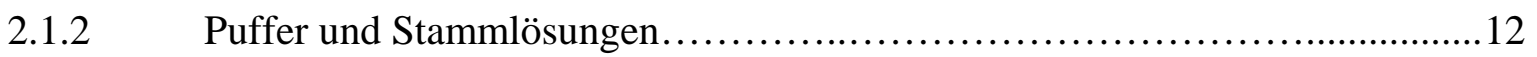

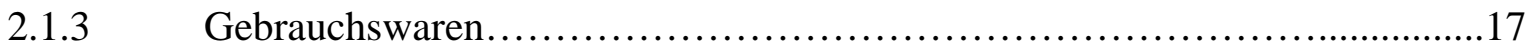

2.1.4 Sterilisation.......................................................... 17

2.1.5 Medien, Agarplatten und Antibiotika...................................... 18

2.1.5.1 Medien für Bakterien................................................... 18

2.1.5.2 Medien für die Zellkultur.............................................. 18

2.1.6 Antibiotika............................................................. 20

2.1.7 IPTG/X-Gal-Platten................................................... 20

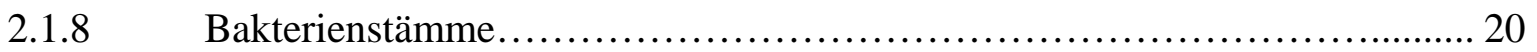

2.1.9 Eukaryotische Zelllinien.......................................... 21

2.1.10 Plasmide......................................................... 21

2.1.11 Synthetische Oligonukleotide.........................................21

2.1.12 cDNA-Proben......................................................... 23

2.1.13 Mausstämme......................................................... 23

2.1.14 Antikörper......................................................... 23

2.1.15 Kits...................................................... 24

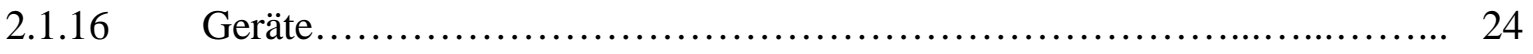


2.2.1 Methoden zur Isolierung von Nukleinsäuren............................ 26

2.2.1.1 Isolierung von Plasmid DNA.......................................... 26

2.2.1.1.1 Minipräparation von Plasmid-DNA.................................... 26

2.2.1.1.2 Endotoxin-freie Maxipräparation von Plasmid-DNA......................... 27

2.2.1.2 Isolierung genomischer DNA aus Geweben.............................. 27

2.2.1.3 Isolierung genomischer DNA aus ES-Zellen.......................... 27

2.2.1.4 Isolierung von Gesamt-RNA aus Geweben............................. 28

2.2.1.4.1 Isolierung von RNA durch Fällung ...................................... 28

2.2.1.4.2 Isolierung von RNA über die Säule........................................ 29

2.2.2 Konzentrationsbestimmung von DNA und RNA....................... 29

2.2.3 Enzymatische Modifikation von DNA................................. 30

2.2.3.1 Restriktionsenzymatische Spaltung von DNA......................... 30

2.2.3.2 Ligation eines DNA-Inserts in einen Plasmid-Vektor.........................30

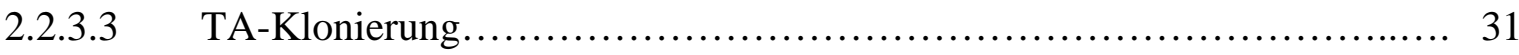

2.2.3.4 Dephosphorylierung von Plasmid-DNA mit alkalischer

Phosphatase (CIAP) .................................................. 31

2.2.3.5 Auffüllreaktion.................................................... 32

2.2.4 Plasmidtransformation in kompetente Bakterien....................... 32

2.2.5 Gelelektrophorese von Nukleinsäuren.................................... 33

2.2.5.1 Horizontalgelelektrophorese......................................... 33

2.2.5.2 Vertikalgelelektrophorese........................................... 33

2.2.5.3 Elektrophorese von RNA im Agarosegel................................ 34

2.2.6 Isolierung von DNA-Fragmenten aus Agarosegelen...................... 34

2.2.7 Methoden der Polymerasekettenreaktion (PCR)...................... 35

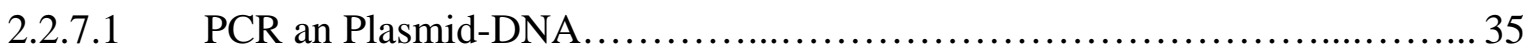


2.2.7.2 PCR an genomischer DNA .............................................. 36

2.2.7.2.1 Analytische PCR an genomischer DNA von knock-out und transgenen Mäusen.................................................... 37

2.2.7.3 Genotypisierung mittels quantitativer Real-Time-PCR .................... 39

2.2.7.4 Integrationszahlbestimmung des $\mathrm{I}_{2} \mathrm{I}_{3}$-Konstrukts mittels quantitativer Real-Time-PCR $\ldots \ldots \ldots \ldots \ldots \ldots \ldots \ldots \ldots \ldots \ldots \ldots \ldots \ldots \ldots, 43$

2.2.7.5 Kopienzahlbestimmung des $\mathrm{I}_{2} \mathrm{I}_{3}$-Konstrukts mittels quantitativer Real-Time-PCR ......................................... 43

2.2.7.6 "Reverse Transkriptions PCR" (RT-PCR) ..............................43

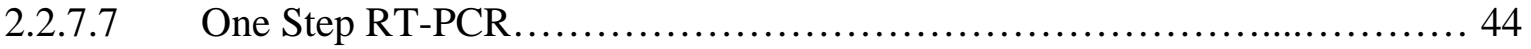

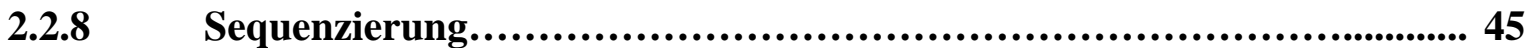

2.2.9 Protein- und biochemische Methoden.......................................... 46

2.2.9.1 Gesamtproteinisolierung aus Geweben................................ 46

2.2.9.2 Isolierung von Proteinen für Radio-Immunoassays (RIA) ................... 47

2.2.9.3 Bestimmung der Proteinkonzentration.................................. 47

2.2.10 Transfertechniken.............................................................. 48

2.2.10.1 Transfer von DNA-Fragmenten: Southern-Blotting.........................48

2.2.10.2 Transfer von RNA aus Agarosegelen: Northern-Blotting..................... 48

2.2.11 Radioaktive Markierung von DNA („random prime labelling“)........... 49

2.2.12 Hybridisierungsmethoden.............................................. 49

2.2.12.1 Radioaktive Hybridisierungstechniken.................................. 49

2.2.12.1.1 Hybridisierung von Southern- und Northern-Blots......................... 49

2.2.12.1.2 Hybridisierung der genomischen Cosmid-Bibliothek 129/Ola und PACs Macroarrays....................................................... 50

2.2.12.1.3 ,Strippen" von Filtern................................................ 50

2.2.13 Quantitative Bestimmung des humanen Insulins in Serum und Testis durch Fluoroimmunoassay.......................................... 51 


\subsubsection{4 Überprüfung der testikulären Insulinprozessierung mittels Radio}

Immunoassay für humanes C-Peptid........................................ 51

2.2.15 Histologische Techniken............................................... 52

2.2.15.1 Herstellung von Paraffinschnitten....................................... 52

2.2.15.2 Färbung der histologischen Schnitte mit alkalischer Phosphatase........... 53

2.2.15.3 Färbung der histologischen Schnitte mit Fluoreszenzfarbstoffen................ 53

2.2.15.4 Fotografische Auswertungen....................................... 53

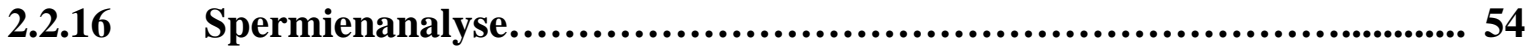

2.2.16.1 Spermienzahl und Motilitätsanalyse von Spermien......................... 54

2.2.16.2 Motilitätsanalyse von Spermien......................................... 54

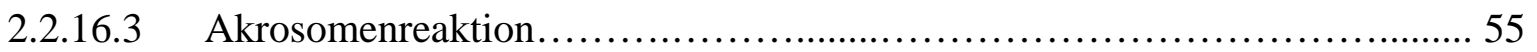

2.2.17 Erzeugung eines Diabetes mellitus bei Mäusen............................. 56

2.2.18 Glukosetoleranztest................................................. 56

2.2.19 Herstellung von mutanten Mäusen...................................... 57

2.2.19.1 Erzeugung von knock-out Mäusen.................................... 57

2.2.19.1.1 Routinekultur von ES-Zellen........................................... 57

2.2.19.1.2 Elektroporation und Selektion von ES-Zellen................................57

2.2.19.1.3 Isolierung und Kryokonservierung von ES-Zellklonen......................58

2.2.19.1.4 Herstellung und Identifizierung von Chimären.......................... 59

2.2.19.2 Methoden zur Erzeugung transgener Mäuse........................... 59

2.2.19.2.1 Vorbereiten der DNA zur Mikroinjektion................................ 60

3. ERGEBNISSE........................................................... 61

Insl5-Gen............................................................ 61

3.1.1 Expression des Insl5-Gens bei der Maus............................... 61

3.1.1.1 Amplifikation der Insl5-cDNA der Maus mittels RT-PCR......................61 
3.1.1.2 Untersuchung zur organspezifischen Expression des Insl5-Gens

3.1.1.3 Expressionsanalyse von Insl5 während der Embryonalentwicklung der Maus.

3.1.1.4 Untersuchung zur Expression des Insl5-Gens der Maus in postnatalen

Testes und bei verschiedenen Mausmutanten mit Keimzelldefekten. 65

3.1.2 Zur Funktion des Insl5-Gens. 66

3.1.2.1 Die Strategie zur Inaktivierung des Insl5-Gens............................66

3.1.2.2 Isolierung und Klonierung der 3'-flankierenden Region sowie der externen 3'-Sonde.................................................... 68

3.1.2.3 Isolierung und Klonierung der 5'-flankierenden Region....................69

3.1.2.4 Elektroporation der ES-Zellen mit dem Targeting Vektor Ins15 und Selektion homolog rekombinanter Insl5 ${ }^{+/}$-ES-Zellen.

3.1.2.5 Herstellung von Chimären durch Injektion der Blastocysten mit den Insl5 $^{+/-}$-ES-Zellen............................................... 71

3.1.2.6 Charakterisierung der Chimären...................................... 71

3.1.3 Die Analyse Insl5-defizienter Mäuse......................................... 72

3.1.3.1 Genotypisierung der Nachkommen..................................... 72

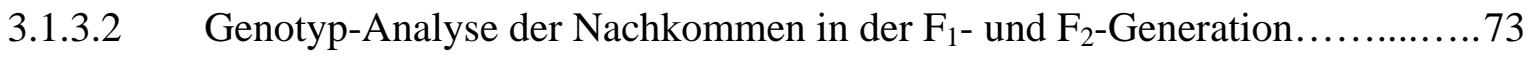

3.1.3.3 Kontrolle der Inaktivierung des Insl5-Gens durch Northern-

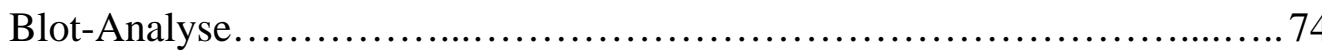

3.1.3.4 Histologische Darstellung und Alcian-Blau-Färbung von Kolon, Rektum und Thymus der Insl5-defizienten Mäuse......................... 75

3.1.3.5 Analyse der Spermien der Ins15 $5^{-/-}$-Mäuse................................. 77

3.1.3.5.1 Analyse der Spermienanzahl........................................ 77

3.1.3.5.2 Akrosomenreaktion................................................ 77

3.1.3.5.3 Analyse der Motilität von Spermien der Insl5-defizienten Mäuse............. 78

Insl6-Gen................................................................. 81

3.2.1 Expression des Insl6-Gens bei der Maus............................. 81

3.2.1.1 Herstellung der Insl6-cDNA der Maus mittels RT-PCR ..................... 81 
3.2.1.2 Analyse der Expression von Insl6 an RNA aus verschiedenen

Geweben der Maus

3.2.1.3 Expressionsanalyse von Insl6 durch RT-PCR an Gesamt-RNA der

embryonalen Maus

3.2.1.4 Untersuchungen zur Expression des Insl6-Gens während der

Testisentwicklung....

3.2.1.5 Analyse der Expression des Insl6-Gens in Testes verschiedener

Mausmutanten mit Keimzelldefekten. ...

3.2.2 Zur Funktion des Insl6-Gens.............................................. 87

3.2.2.1 Isolierung eines genomischen Klons für das Insl6-Gen der Maus........... 87

3.2.2.1.1 Screen einer Cosmid-Maus-Bibliothek.................................... 87

3.2.2.1.2 Screenen einer PAC-Bibliothek............................................ 87

3.2.2.2 Die Strategie zur Inaktivierung des Insl6-Gens............................ 88

3.2.2.3 Isolierung und Klonierung der 5'-flankierenden Region......................90

3.2.2.4 Isolierung und Klonierung der 3'-flankierenden Region sowie der externen 3'-Sonde............................................... 90

3.2.2.5 Linearisierung des Targeting-Vektors................................. 92

3.2.2.6 Elektroporation der ES-Zellen mit dem Targeting Vektor III/5 und Selektion homolog rekombinanter Insl6 ${ }^{+/-}$-ES-Zellen.................. 92

3.2.2.7 Herstellung von Chimären durch Injektion der Blastocysten mit

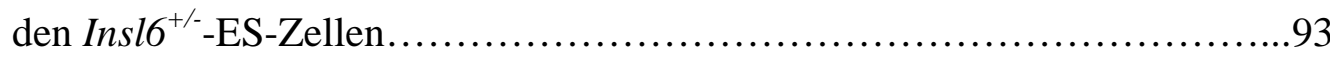

3.3 Untersuchung zur Funktion des testikulären Insulins in

$\mathbf{I}_{2} \mathbf{I}_{3}$-transgenen Mauslinien............................................94

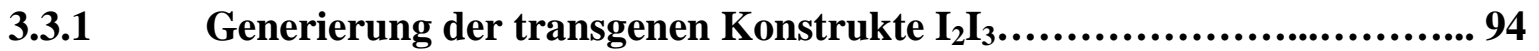

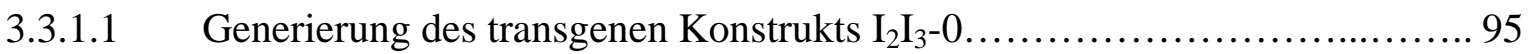

3.3.1.2 Generierung des transgenen Konstrukts $\mathrm{I}_{2} \mathrm{I}_{3}-1 \ldots \ldots \ldots \ldots \ldots \ldots \ldots \ldots \ldots \ldots$

3.3.1.3 Generierung des transgenen Konstrukts $\mathrm{I}_{2} \mathrm{I}_{3}-2 \ldots \ldots \ldots \ldots \ldots \ldots \ldots \ldots \ldots . \ldots \ldots$

3.3.2 Herstellung und Genotypisierung $\mathbf{I}_{2} \mathbf{I}_{3}$-transgener Mäuse................ 101

3.3.2.1 Analyse der Expression und Fertilität der $\mathrm{I}_{2} \mathrm{I}_{3}-0$ transgenen Mäuse..............102 
3.3.2.2 Analyse der Expression des transgenen Allels $\mathrm{I}_{2} \mathrm{I}_{3}-1$ und der

Fertilität der $\mathrm{I}_{2} \mathrm{I}_{3}-1$ transgenen Mäuse.

3.3.2.2.1 Analyse der Spermatogenese bei $\mathrm{I}_{2} \mathrm{I}_{3}-1$ transgenen Mäusen der

Linien 2 und 12

3.3.2.2.2 Untersuchung des Expressionsmusters des transgenen Allels

$\mathrm{I}_{2} \mathrm{I}_{3}-1$ in verschiedenen Geweben mittels Northern-Blot-Analyse.

3.3.2.2.3 Expression des transgenen Allels $\mathrm{I}_{2} \mathrm{I}_{3}-1$ in prä- und postnatalen

Entwicklungsstadien des Testis.

3.3.2.3 Analyse der Expression und Fertilität der transgenen Allele $\mathrm{I}_{2} \mathrm{I}_{3}-2$

3.3.2.3.1 Expressionsanalyse der Allele $\mathrm{I}_{2} \mathrm{I}_{3}-2$ in Testes der transgenen

Mauslinien

3.3.2.3.2 Analyse der Motilität von Spermien von Wildtyp- und $\mathrm{I}_{2} \mathrm{I}_{3}-2$ transgenen Mäusen der Linie 15

3.3.3 Analysen der Translation, Prozessierung und der Sekretion für

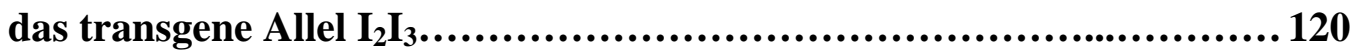

3.3.3.1 Immunhistochemische Analysen für das transgene Allel $\mathrm{I}_{2} \mathrm{I}_{3}-2 \ldots \ldots \ldots \ldots \ldots . \ldots \ldots$

3.3.3.2 Untersuchung über die Translation des transgenen Allels $\mathrm{I}_{2} \mathrm{I}_{3}-1$

mittels Fluoroimmunoassay.

3.3.3.3 Analyse der Sekretion prozessierten Insulins mittels Radio-

Immuno-Assay.

3.3.3.4 Expressionsanalyse der Proinsulin-prozessierenden Enzyme

PCSK1 und PCSK2

3.3.4 Rettungsexperimente und Glukose-Toleranz-Test diabetisierter

männlicher transgener Mäuse....................................... 126

3.3.4.1 Untersuchung zur Funktion des testikulären Insulins in vivo................... 126

3.3.4.2 Generierung transgener diabetischer Mäuse............................... 127

3.3.4.2.1 Analyse der Blutglukosekonzentration in mit Streptozotocin

behandelten $\mathrm{I}_{2} \mathrm{I}_{3}$-Mäusen..................................... 127

3.3.4.2.2 Glukosetoleranz................................................ 129 
4.1.1 Genomische Struktur des Insl5-Gens................................... 134

Expression von INSL5 $\quad$ E.1.2.

Funktionsanalyse des Insl5-Gens..................................... 136

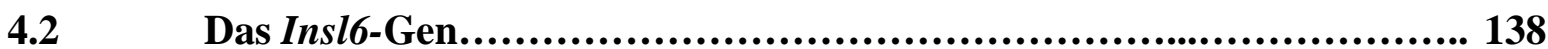

4.2.1 Genomische Struktur des Insl6-Gens................................... 139

4.2.2 Expression von INSL6........................................... 140

4.2.3 Funktionsanalyse des Insl6-Gens.................................. 142

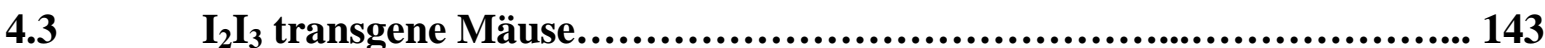

4.3.1 Erzeugung der Fusionskonstrukte $\mathrm{I}_{2} \mathrm{I}_{3}-0, \mathrm{I}_{2} \mathrm{I}_{3}-1$ und $\mathrm{I}_{2} \mathrm{I}_{3}-2 \ldots \ldots \ldots \ldots \ldots \ldots \ldots \ldots \ldots$

4.3.2 Erzeugung transgener Linien für die Konstrukte $\mathrm{I}_{2} \mathrm{I}_{3}-0, \mathrm{I}_{2} \mathrm{I}_{3}-1$

und $\mathrm{I}_{2} \mathrm{I}_{3}-2$

4.3.3 Vergleich der Transkribtion der Fusionskonstrukte für menschliches

Insulin mit der Transkribtion des endogenen Insl3-Gens im Testis

der transgenen Tiere.

4.3.4 Zur Frage der Translation der Insulinfusionstranskripte im Testis

der transgenen Mäuse.

4.3.5 Zur Prozessierung von Proinsulin in den $\beta$-Zellen des Pankreas und in den Leydigzellen der transgenen Tiere. ...

4.3.6 Hat das in den Leydigzellen produzierte Insulin auch einen biologischen Effekt? 148

4.3.7 Analyse der Fertilität $\mathrm{I}_{2} \mathrm{I}_{3}-1$ transgener Mäuse........................ 150

4.3.8 Letalität der homozygoten Mäuse für $\mathrm{I}_{2} \mathrm{I}_{3}-1$ der Linie 2 ...................151 


\section{ABKÜRZUNGEN}

$\begin{array}{ll}\text { Abb. } & \text { Abbildung } \\ \text { Ac } & \text { Acetat } \\ \text { ALH } & \text { Lateral Amplitude (Breite des Kopfausschlages) } \\ \text { Ampuwa } & \text { steriles pyrogenfreies Aqua ad iniectabilia } \\ \text { AS } & \text { Aminosäure } \\ \text { ATP } & \text { Adenosintriphosphat } \\ \text { BCF } & \text { Beat Frequency (Schlagfrequenz) } \\ \text { BCIP } & \text { 5-Brom-4-Chlor-3-Indolyl-Phosphat } \\ \text { bp } & \text { Basenpaare } \\ \text { BSA } & \text { Rinderserumalbumin } \\ \text { bzw. } & \text { beziehungsweise } \\ \text { ca. } & \text { circa } \\ \text { CAT } & \text { Chloramphenicolacetyltransferase } \\ \text { cAMP } & \text { zyklisches Adenosinmonophosphat } \\ \text { cDNA } & \text { komplementäre DNA } \\ \text { cGMP } & \text { zyklisches Guaninmonophospat } \\ \text { CIAP } & \text { Calf Intestinal Phosphatase } \\ \text { CSL } & \text { Craniales Suspensorisches Ligament } \\ \text { d } & \text { Tag (day) } \\ \text { Da } & \text { Dalton } \\ \text { DAPI } & \text { 4,6-Diamidino-2-Phenylindol } \\ \text { dATP } & \text { desoxy-Adenosintriphosphat } \\ \text { dCTP } & \text { desoxy-Cytosintriphosphat } \\ \text { ddNTP } & \text { didesoxy-Nukleosidtriphosphat } \\ \text { dGTP } & \text { desoxy-Guanosintriphosphat } \\ \text { DMEM } & \text { Dulbecco`s Modified Eagle Medium } \\ \text { dNTP } & \text { desoxy-Nukleotidtriphosphat } \\ \text { dTTP } & \text { desoxy-Thymidintriphosphat } \\ \text { DEPC } & \text { Diethyl-Pyrocarbonat } \\ \text { DIG } & \text { Digoxigenin } \\ \text { DMSO } & \text { Dimethylsulfoxid } \\ \text { DNA } & \text { Desoxyribonukleinsäure } \\ \text { DNase } & \text { Desoxyribonuklease } \\ \text { dpc } & \text { Tage nach Befruchtung (days post coitum) } \\ \text { dsDNA } & \text { doppelsträngige DNA } \\ \text { DTT } & \text { 1,4-Dithiothreitol } \\ \text { E.coli } & \text { Escherichia coli } \\ \text { EDTA } & \text { Ethylendiamintetraacetat } \\ \text { EmFi } & \text { Embryonale Fibroblasten } \\ \text { EPIL } & \text { Early-Placenta Insulin-like Peptide } \\ \text { ES } & \text { Embryonale Stammzellen } \\ \text { EST } & \text { Expressed Sequence Tags } \\ \text { EtBr } & \text { Ethidiumbromid } \\ \text { EtOH } & \text { Ethanol } \\ & \end{array}$




\begin{tabular}{|c|c|}
\hline GPCR & G-Protein gekoppelter Hormonrezeptor \\
\hline hCG & humanes Choriongonadotropin \\
\hline $\mathrm{hEF}$ & humaner Elongationsfaktor \\
\hline et al. & et alteri (und andere) \\
\hline etc. & et cetera \\
\hline FISH & Fluoreszenz- in situ Hybridisierung \\
\hline FKS & Fötales Kälberserum \\
\hline FSH & Follikelstimulierendes Hormon \\
\hline $\mathrm{g}$ & Erdbeschleunigung $\left(9,80665 \mathrm{~m} / \mathrm{s}^{2}\right)$ \\
\hline GAPDH & Glycerinaldehyd-3-Phosphat-Dehydrogenase \\
\hline $\mathrm{H}_{2} \mathrm{O}$ & destilliertes Wasser \\
\hline IGF I, II & Insulin-like Growth Faktor I, II \\
\hline INS & Insulin \\
\hline Ins13,4,5,6 & Insulin-like Factor 3,4,5,6 \\
\hline IPTG & Isopropyl- $\beta$-D-Thiogalaktopyranosid \\
\hline IVF & In vitro-Fertilisation \\
\hline $\mathrm{K}$ & Kontrolle \\
\hline $\mathrm{kb}$ & Kilobasen-DNA-Leiter (Längenstandard) \\
\hline LB & Luria-Bertani \\
\hline Lgr & Leucine-rich repeat-containing G-protein coupled receptor \\
\hline $\mathrm{LH}$ & Luteinisierendes Hormon \\
\hline LIF & Recombinant Leukaemia Inhibitory Factor \\
\hline M & Molarität \\
\hline MAB & Maleinsäure-Puffer \\
\hline MOPS & 3-(N-Morpholino)-Propansulfonsäure \\
\hline mRNA & messenger RNA \\
\hline $\mathrm{NaAc}$ & Natriumacetat \\
\hline NBT-Lösung & $75 \mathrm{mg} / \mathrm{ml}$ Nitroblau Tetrazoliumsalz in Dimethylformamid \\
\hline NCBI & National Center for Biotechnology Information \\
\hline OD & Optische Dichte \\
\hline PCSK1, 2 & Prozessierende Enzyme des Substilisin/Kexin-Typs 1, 2 \\
\hline PBS & Phosphate Buffered Saline (Phosphatgepufferte Salzlösung) \\
\hline PCR & Polymerase Chain Reaction (Polymerasekettenreaktion) \\
\hline PFA & Paraformaldehyd \\
\hline PGK & Phosphoglycerinkinase \\
\hline $\mathrm{pH}$ & negativer dekadischer Logarithmus der Protonenkonzentration \\
\hline RNA & Ribonukleinsäure \\
\hline RNase & Ribonuklease \\
\hline rpm & rounds per minute \\
\hline RT & Raumtemperatur oder Reverse Transkriptase \\
\hline RZPD & $\begin{array}{l}\text { Resource Center/Primary Database (Deutsches Resourcenzentrum für } \\
\text { Genomfoschung in Berlin) }\end{array}$ \\
\hline s. & siehe \\
\hline $\mathrm{S}$. & Seite \\
\hline SDS & Sodium dodecylsulfate (Natriumdodecylsulfat) \\
\hline SSC & Standard Saline Citrate (-Puffer) \\
\hline STR & Straightness (Gradlinigkeit) \\
\hline STZ & Streptozotocin \\
\hline s.u. & siehe unten \\
\hline Tab. & Tabelle \\
\hline
\end{tabular}




$\begin{array}{ll}\text { Taq } & \text { Thermus aquaticus } \\ \text { TBE } & \text { Tris-Borat-EDTA (-Puffer) } \\ \text { TE } & \text { Tris-EDTA (-Puffer) } \\ \text { Tfm } & \text { Testikuläre Feminisierung } \\ \text { Tris } & \text { Tris(hydroxymethyl)aminomethan } \\ \text { tRNA } & \text { Transfer-RNA } \\ \text { TSH } & \text { Thyroidea-Stimulierendes Hormon } \\ \text { U } & \text { Unit (Einheit) } \\ \text { u.a. } & \text { unter anderem } \\ \text { üN } & \text { über Nacht } \\ \text { usw. } & \text { und so weiter } \\ \text { UTR } & \text { Untranslated Region } \\ \text { UV } & \text { Ultraviolett } \\ \text { VAP } & \text { Average Path Velocity (Weggeschwindigkeit) } \\ \text { VCL } & \text { Curvilinear Vlocity (Bahngeschwindigkeit) } \\ \text { Vol. } & \text { Volumen } \\ \text { VP } & \text { Vaginalpfropf } \\ \text { VSL } & \text { Straight Line Velocity (progessive Geschwindigkeit) } \\ \text { v/v } & \text { Volumen pro Volumen } \\ \text { Wt } & \text { Wildtyp } \\ \text { w/v } & \text { weight (Gewicht) pro Volumen } \\ \text { x-Gal } & \text { 5-Brom-4-Chloro-3-Indolyl- } \beta \text {-Galaktopyranosid } \\ \text { z. B. } & \text { zum Beispiel } \\ \text { z. T. } & \text { zum Teil }\end{array}$

\section{Symbole für Nukleotide (1-Buchstaben-Code):}

$\begin{array}{ll}\text { A } & \text { Adenosin } \\ \text { C } & \text { Cytosin } \\ \text { G } & \text { Guanin } \\ \text { T } & \text { Thymidin }\end{array}$

\section{Symbole für Aminosäuren:}

$\begin{array}{lll}\text { A } & \text { Ala } & \text { Alanin } \\ \text { C } & \text { Cys } & \text { Cystein } \\ \text { D } & \text { Asp } & \text { Asparaginsäure } \\ \text { E } & \text { Glu } & \text { Glutaminsäure } \\ \text { F } & \text { Phe } & \text { Phenylalanin } \\ \text { G } & \text { Gly } & \text { Glycin } \\ \text { H } & \text { His } & \text { Histidin } \\ \text { I } & \text { Ile } & \text { Isoleucin } \\ \text { K } & \text { Lys } & \text { Lysin } \\ \text { L } & \text { Leu } & \text { Leucin } \\ \text { M } & \text { Met } & \text { Methionin } \\ \text { N } & \text { Asn } & \text { Asparagin }\end{array}$




$\begin{array}{lll}\text { P } & \text { Pro } & \text { Prolin } \\ \text { Q } & \text { Gln } & \text { Glutamin } \\ \text { R } & \text { Arg } & \text { Arginin } \\ \text { S } & \text { Ser } & \text { Serin } \\ \text { T } & \text { Thr } & \text { Threonin } \\ \text { V } & \text { Val } & \text { Valin } \\ \text { W } & \text { Trp } & \text { Tryptophan } \\ \text { Y } & \text { Tyr } & \text { Tyrosin }\end{array}$

Dekadische Vorsilben

$\begin{array}{lllllll}\mathrm{X}= & 1 & 2 & 3 & 6 & 9 & 12 \\ 10^{-\mathrm{x}} & \text { dezi } & \text { centi } & \text { milli } & \text { mikro } & \text { nano } & \text { piko } \\ & (\mathrm{d}) & (\mathrm{c}) & (\mathrm{m}) & (\mu) & (\mathrm{n}) & (\mathrm{p})\end{array}$

\section{SI-Einheiten}

\begin{tabular}{|c|c|c|}
\hline A & Ampere & Stromstärke \\
\hline${ }^{\circ} \mathrm{C}$ & Grad Celsius & Temperatur \\
\hline $\mathrm{Ci}$ & Curie & $\begin{array}{l}\text { alte, noch gebräuchliche Einheit für Radioaktivität } \\
1 \mathrm{Ci}=3,7 \times 10^{10} \text { Becquerel }\end{array}$ \\
\hline $\mathrm{F}$ & Farad & Kapazität eines Kondensators \\
\hline $\mathrm{g}$ & Gramm & Masse \\
\hline $\mathrm{h}$ & Stunde & Zeit \\
\hline $\mathrm{Hz}$ & Hertz & Frequenz \\
\hline $\mathbf{J}$ & Joule & Energie \\
\hline 1 & Liter & Volumen \\
\hline $\mathrm{m}$ & Meter & Länge \\
\hline $\min$ & Minute & Zeit \\
\hline S & Sekunde & Zeit \\
\hline d & Tag & Zeit \\
\hline mol & Mol & Stoffmenge, $1 \mathrm{Mol} \hat{=} 6,022 \times 10^{23}$ Teilchen eines Stoffes \\
\hline M & molar & Konzentration, $\mathrm{M} \hat{=} \mathrm{Mol} /$ Liter \\
\hline V & Volt & Spannung \\
\hline
\end{tabular}




\section{EINLEITUNG}

\subsection{Die Insulinfamilie}

Die Insulin-like Peptid Familie umfasst derzeit 9 Mitglieder, nämlich Präpro-Insulin, Relaxin, -Insulin-like Growth Faktor I (IGF I) und -Insulin-like Growth Faktor II (IGF II), -INSL3, -INSL4, -INSL5, -INSL6 und Relaxin-3 (INSL7) (Blundell und Humbel, 1980; Adham et al., 1993; Laurent et al., 1998; Conklin et al., 1999; Hsu, 1999, Lok et al., 2000, Bathgate et al., 2002).

Diese Proteine werden als Präpro-proteine synthetisiert. Das Signalpeptid vermittelt die Sekretion des Prohormons durch das endoplasmatische Retikulum und wird anschließend abgespalten. Unter dem Einfluss des Verbindungspeptids (C-Peptid) werden B- und A-Kette zueinander gefaltet. Es werden dann Disulfidbrücken zwischen B- und A-Kette und innerhalb der A-Kette ausgebildet. Schließlich wird das C-Peptid proteolytisch abgespalten. Im Proinsulin und Prorelaxin sind B-und A-Ketten durch ein langes C-Peptid voneinander getrennt (Abb. 1.1). Pro-IGF I und Pro-IGF II beinhalten zwischen B- und A-Kette nur ein kurzes C-Peptid, welches auch im aktiven Wachstumsfaktor vorhanden ist. Am C-terminalen Ende schließen sich zwei zusätzliche Domänen D und E an, wovon nur die E-Domäne während des Reifungsprozesses abgespalten wird (Blundell und Humbel, 1980). Anhand der Aminosäuresequenzen für das aktive Insulin, Relaxin und IGF I und II und den Vergleichen mit der aus der cDNA abgeleiteten Aminosäuresequenz des Präpro-INSL3, -INSL4, -INSL5, -INSL6 und INSL7 ist es möglich, den Reifungsprozess dieser Hormone nachzuvollziehen. Die Lokalisierung von B- und A-Kette am C- bzw. N-Terminus und die Anwesenheit eines langen C-Peptids lassen vermuten, dass die posttranslationale Modifikation des ProINSL3, -INSL4, -INSL5 und -INSL6 der des Insulins bzw. Relaxins entspricht und die Struktur der aktiven Hormone ähnlich der von Insulin bzw. Relaxin ist (Adham et al., 1993; 1996). Zur Abklärung dieser Annahme müssten die aktiven INSL3-, INSL4-, INSL5- und INSL6-Faktoren isoliert und sequenziert werden. 


\section{A PräproInsl3 (131 As)}

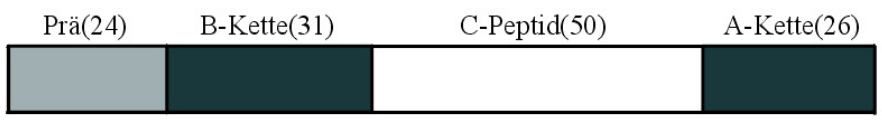

B PräproInsl2 (110 As)

\begin{tabular}{|l|l|l|l|}
\multicolumn{1}{l|}{ Prä(24) } & \multicolumn{1}{c}{ B-Kette(30) } & C-Peptid(35) & A-Kette(21) \\
& & & \\
\hline
\end{tabular}

\section{Präprorelaxin (185 As)}

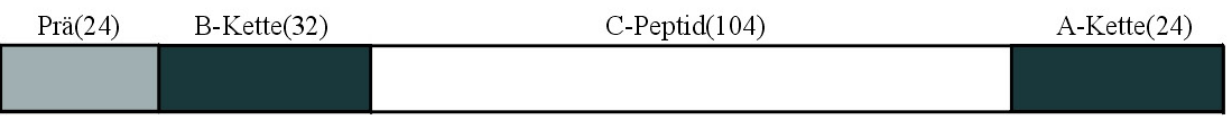

D PräproIGFI (130 As)

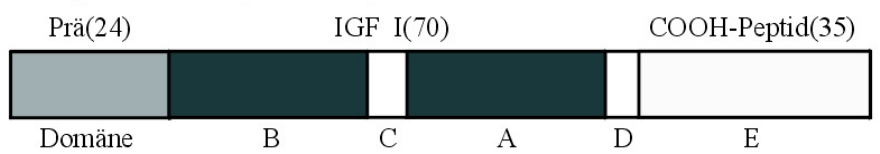

E PräproIGFII (180 As)

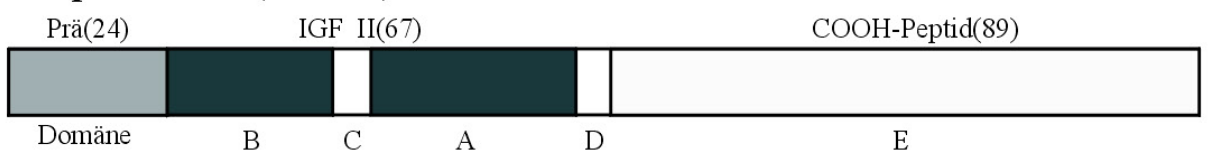

F PräproInsl4 (139 As)

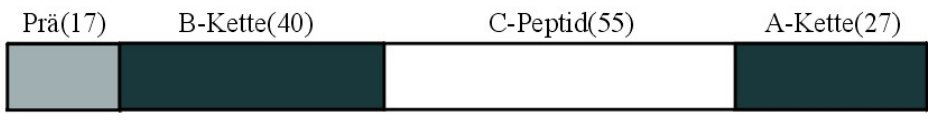

\section{G PräproInsl5 (135 As)}

\begin{tabular}{|l|l|l|l|}
\hline Prä(22) & \multicolumn{1}{c}{ B-Kette(26) } & C-Peptid(66) & A-Kette(21) \\
& & & \\
\hline
\end{tabular}

\section{H PräproInsl6 (213 As)}

\begin{tabular}{|l|l|l|l|}
\hline & & & \\
\hline
\end{tabular}

Abb. 1.1: Schematische Darstellung der Präprohormone einiger Mitglieder der Insulin-Superfamilie. Die Präprohormonformen von humanem Insulin (B) (Bell et al., 1979), Relaxin (C) (Hudson et al., 1983) IGF I (D) (Jansen et al., 1983) IGF II (E) (Bell et al., 1984), (F) Insl4 (Chassin et al., 1995), (G) Insl5 (Conklin et al., 1999) und (H) Insl6 (Lok et al., 2000) des Menschen im Vergleich zum PräproInsl3 (A) (Burkhardt et al., 1994a). Die verschiedenen Abschnitte der Polypeptidketten sind gekennzeichnet. Das Signalpeptid ist als hellgrauer Balken, A- und B-Kette sind als dunkelgraue Balken und das C-Peptid sowie die zusätzlichen Dömanen C/D/E von IGF I und IGF II sind als offene Balken dargestellt. Die Anzahl der Aminosäuren dieser Bereiche wird jeweils in Klammern angegeben. 
Beim Vergleich der Sequenzen der Prohormone findet man Sequenz-Ähnlichkeiten in dem Bereich von B- und A-Kette. Alle Mitglieder dieser Familie haben 6 konservierte Cysteine, welche die Bildung von zwei Disulfidbrücken zwischen B- und A-Kette und einer innerhalb der A-Kette ermöglichen. Das C-Peptid weist keine SequenzÄhnlichkeiten zwischen den Mitgliedern der Familie auf.

Anhand der Sequenzvergleiche zwischen den B- und A-Ketten aller Insulin-ähnlichen Peptide bei Mensch, Schimpanse, Rhesusaffe, Schwein, Maus, Ratte, Wallaby, FuguFisch, Zebrafisch, Regenbogenforelle, Wasserfrosch und zwei afrikanischen Krallenfroscharten wurde die phylogenetische Abstammung dieser Gene bestimmt (Abb. 1.2).

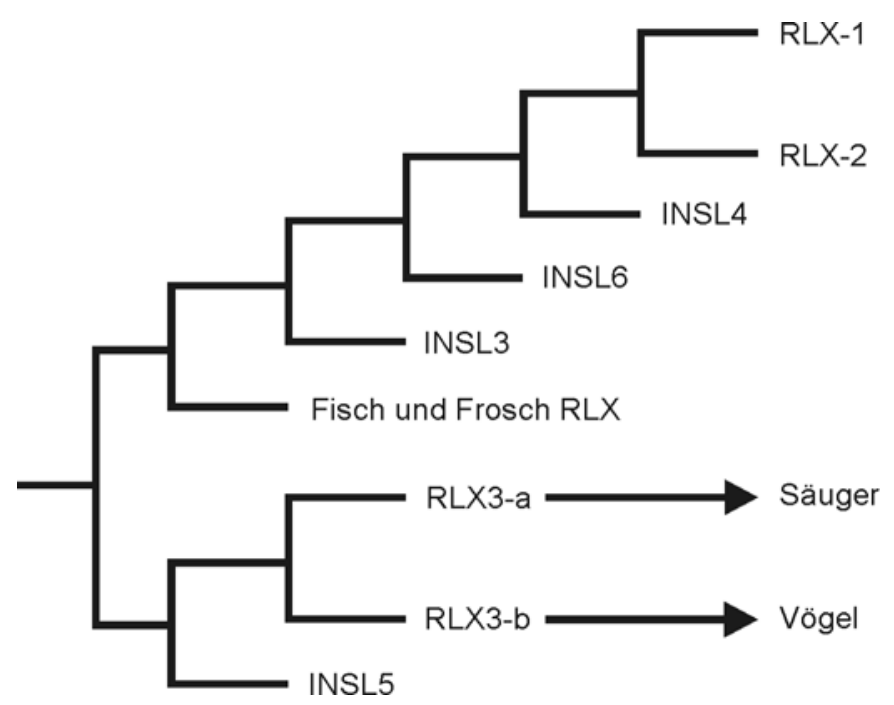

Abb. 1.2: Vereinfachtes Evolutionsschema der Relaxin ähnlichen Peptid Familie.

Die Expressionsanalyse für die verschiedenen Mitglieder der Insulin-ähnliche Familie zeigte, dass IGF I, IGF II und Relaxin ubiquitär exprimiert werden. Im Gegensatz dazu zeigen Insulin, INSL3 und INSL4 gewebespezifische Expression. Das Insulingen wird in prä- und postnatalen $\beta$-Zellen des Pankreas exprimiert. Die Untersuchung der räumlichen und zeitlichen Expressionsmuster des Insl3-Gens bei der Maus haben ergeben, dass das Insl3-Gen spezifisch in den prä- und postnatalen Leydigzellen des Testis und in wesentlich geringerem Ausmaß in den Thekazellen des postnatalen Ovars exprimiert wird (Zimmermann et al., 1997; Balvers et al., 1998). Die Expression von INSL4 wurde nur in der Plazenta detektiert (Koman et al., 1996). INSL5 wird 
insbesondere im Verdauungstrakt exprimiert (Conklin et al., 1999) und die Expression von INSL6 konnte speziell im Testis nachgewiesen werden (Lok et al., 2000).

Insulin ist in die Regulation des Glukose-Metabolismus involviert. Relaxin ist multifunktionell und u.a. bei der Regulation des Uterustonus, bei der Wachstumsstimulation von reproduktiven Geweben sowie bei Kollagenremodulierungsprozessen beteiligt (Sherwood et al., 1994; Sherwood, 2004). Ferner besitzt es nicht-reproduktive Funktionen. Es spielt bei der Heilung von Wunden, bei Antworten auf Allergene eine Rolle und bietet Schutz vor kardialen Erkrankungen. Die Funktion des Insl3-Gens konnte durch die Deletion des Insl3-Locus mittels homologer Rekombination und die Herstellung von homozygoten knock-out Mäusen ermittelt werden. Weibliche Tiere sind in ihrer reproduktiven Kapazität durch den Verlust des Insl3-Gens nicht betroffen. Bei männlichen Tieren besteht ein bilateraler Kryptorchismus (Zimmermann et al., 1999; Nef und Parada, 1999). Histologische Untersuchungen bei Insl $3^{-/}$Embryonen haben gezeigt, dass die Entwicklung des Gubernaculums ausbleibt. Das Gubernaculum ist das caudale Ligament, das die Gonaden mit dem Inguinalkanal verbindet. Die abdominale Lage der Testes bei Insl3defizienten Mäusen führt sekundär zur Schädigung des Keimepithels in den Tubuli seminiferi, wobei die Keimzellreifung auf der Stufe der primären Spermatozyten arretiert wird. Der Kryptorchismus ist mit 3 bis 5\% die häufigste Störung der Sexualentwicklung bei Jungen (Toppari und Kaleva, 1999). Bei den behandelten Männern ist das Risiko für Infertilität und Hodenkrebs erhöht (Pike et al., 1986; Strader et al., 1988; Whitaker, 1988; Møller et al., 1996).

Der Descensus testis findet während der Embryonalentwicklung statt. Während der frühen Embryonalentwicklung sind die Gonaden ventrolateral zu den Nieren lokalisiert und mit dem cranialen suspensorischen Ligament (CSL) und dem Gubernaculum verbunden. Die unterschiedliche Position der Testes und der Ovarien in adulten Tieren ist das Ergebnis der sexualdimorphen Entwicklung dieser Ligamente. Die Regression des CSL und das Wachstum des Gubernaculums verursachen den Descensus testis.

Das auch als Early-Placenta Insulin-like Peptide (EPIL) oder Placentin bezeichnete Insulin-Like Peptid 4 (INSL4) wird nur bei den Primaten exprimiert. Es gilt als wahrscheinlich, dass sich INSL4 vor dem Duplikationsereignis, welches zur Entstehung zweier Relaxin-Gene innerhalb der Familie der Hominidae führte, von dem VorläuferRelaxin-Gen abgespalten hat. Die Funktion dieses Peptids ist noch nicht bekannt, aber 
aufgrund der INSL4-Expression in den frühen Stadien der Plazentaentwicklung wird vermutet, dass dieses Peptid eine Rolle bei der Plazentaentwicklung spielt. Anhand von Analysen in den EST-Banken wurden die Insulin-Like Peptide 5 (INSL5) und 6 (INSL6) wegen ihrer konservierten Cystein-Motive als insulinähnliche Peptide identifiziert. Sowohl INSL5- als auch INSL6-Peptid zeigen höherer SequenzÄhnlichkeit zu Relaxin als zu Insulin. Ihre Funktionen konnten bisher noch nicht charakterisiert werden.

Die physiologische Wirkung der Insulin-ähnlichen Faktoren sollte über eine Signalkaskade vermittelt werden, bei der die Bindung der Liganden an einen Rezeptor zur Anschaltung der Signalübertragung führt. Bislang ist lediglich die Primärstruktur der Rezeptoren für Insulin, Insulin related, IGF I und IGF II bekannt (Ullrich et al. 1985; 1986; Morgan et al. 1987; Shier und Watt 1989). Da die ausbleibende Entwicklung des Gubernaculums als einzige Fehlbildung in Insl3-defizienten Mäusen und in Lgr8-trapped Mäusen identifiziert werden konnte, ist die Annahme gerechtfertigt, dass der Lgr-Rezeptor der Rezeptor für das Insl3-Hormon ist (Bogatcheva et al., 2003). Die normale Gubernaculumentwicklung bei weiblichen $\mathrm{Lgr}^{-/-}$ Mäuse, bei denen das Insl3 während der pränatalen Entwicklung überexprimiert ist, bestätigt die Wechselwirkung des Insl3-Hormons mit dem Lgr8-Rezeptor (Agoulnik et al., 2003). Die ausbleibende Entwicklung der Mamillen bei Relaxin- und Lgr7defizienten Weibchen deuten daraufhin, dass Lgr7 der Rezeptor für Relaxin ist (KrajncFranken et al., 2004). Lgr7 und Lgr8 gehören zur Subfamilie der G-Protein-gekoppelten Rezeptoren (LGR), die auch LH-, FSH- und TSH-Rezeptoren umfasst (Hsu et al., 2000).

\section{$1.2 \quad$ Insl2/Insl3 transgene Mäuse}

Aufgrund der strukturellen Ähnlichkeiten von Ins13 und Insulin sowie der Tatsache, dass Insulin in pankreatischen $\beta$-Zellen und Ins13 in testikulären Leydigzellen produziert werden, wurde der Versuch unternommen, transgene Mäuse zu generieren, welche aktives Insl3 in den $\beta$-Zellen produzieren und ins Blut ausschütten können (Adham et al., 2002). Dafür wurde das murine Insl3-Gen unter die regulatorische Kontrolle eines Insulin 2-Promotors der Ratte gestellt (Abb. 1.3). Das generierte Konstrukt wurde Ins12/Insl3 genannt. Mit diesem Experiment sollte die Effizienz der Insl3-Prozessierung im Pankreas und die Insl3-Sekretion in vivo überprüft werden. Es 
sollte auch untersucht werden, ob das pankreatische Insl3 bei weiblichen Mäusen bzw. männlichen Insl3-defizienten Mäusen das Auswachsen des Gubernaculums stimulieren kann (Adham et al., 2002).

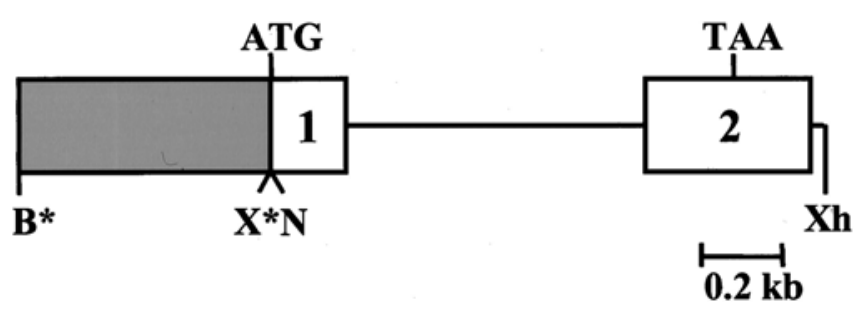

Abb. 1.3: Schematische Darstellung des Insl2/Insl3-Fusionsgens. Das Insl2/Insl3-Fusionsgen besteht aus einem 570 bp Promotorfragment des Insulin 2-Gens der Ratte (graue Box) und aus 22 bp der 5'nichttranslatierten Region. Daran ist das gesamte murine Insl3-Gen einschließlich 2 bp der 5'nichttranslatierten und 24 bp der 3'-flankierenden Region fusioniert. Die numerierten Boxen kennzeichnen die Lage der Exons, die dünnen Linien zeigen die intronischen Bereiche und die 3'flankierende Region. Dargestellt sind außerdem der Translationsstartpunkt (ATG), das Stopcodon (TAA) und die für die Herstellung des transgenen Konstruktes wichtigen Restriktionsschnittstellen (B, BamHI; $X$, XbaI; N, NotI; Xh, XhoI, die mit * markierten Restriktionsschnittstellen gehen nach dem Klonieren verloren).

In den Langerhans'schen Inseln der Bauchspeicheldrüse der Ins12/Insl3 transgenen Mäuse konnte Insl3 sowohl auf mRNA- als auch auf Proteinebene nachgewiesen werden. Northern-Blot-Analysen zeigten auf, dass die endogene Insl3-Expession im Testis durch die pankreatische Überproduktion nicht beeinflusst wird.

Bei transgenen Weibchen differenzierte im Gegensatz zum Wildtyp das Gubernaculum aus, was bei diesen Tieren deszendierte Ovarien zur Folge hatte. Die Fertilität weiblicher transgener Tiere ist reduziert. Transgene Männchen zeigten phänotypisch und bezüglich ihrer Fertilität keine Auffälligkeiten. Ein weiterer eindeutiger Beleg für die Funktionalität des pankreatischen Insl3 wurde mit dem nachfolgend beschriebenen Experiment erbracht. Insl2/Insl3 transgene Mäuse wurden mit Insl3-defizienten weiblichen Mäusen verpaart. Insl3-defiziente männliche Mäuse, die das transgene Allel trugen, durchliefen eine normale Embryonalentwicklung und die Ausdifferenzierung des Gubernaculums führte zum Descensus testis. Im Gegensatz dazu litten Insl3defiziente Männchen durchgehend an bilateralem Kryptorchismus.

Das bedeutet, dass pankreatisches Insl3 in seiner aktiven Form ins Blut ausgeschüttet 
wird und des Weiteren in der Lage ist, die Ausdifferenzierung des Gubernaculums zu stimulieren (Adham et al., 2002).

\subsection{Ziele der vorliegenden Arbeit}

In Rahmen der vorliegenden Arbeit sollten das murine Insl5- und Insl6-Gen isoliert und hinsichtlich der Expression in adulten Tieren charakterisiert werden. Durch die Methode der homologen Rekombination sollten für beide Gene knock-out Mäuse hergestellt werden, die das rekombinierte Allel im heterozygoten und homozygoten Zustand enthalten. Diese Mäuse sollten phänotypisch charakterisiert werden.

Es wurde oben dargestellt, dass die $\beta$-Zelle des Pankreas in der Lage ist, funktionsfähiges Insl3 zu produzieren und $\mathrm{zu}$ sezernieren. Daraus ergab sich die Hypothese, dass es möglich sein könnte, funktionelles Insulin in den testikulären Leydigzellen zu produzieren. Dies könnte einen Ansatz für eine Therapie des Diabetes mellitus Typ I liefern. Die Hypothese sollte mithilfe einer transgenen Maus überprüft werden können, bei der ein Insulin-Gen unter der Kontrolle des Ins13-Promotors in den Leydigzellen exprimiert wird.

Um transgenes Insulin von endogenem Insulin unterscheiden zu können, wurde für die Generierung des transgenen Konstrukts humanes Insulin (INS) gewählt, welches insbesondere in der Aminosäuresequenz des C-Peptids von den Prohormonen der murinen Insulingene abweicht. Im Gegensatz zum Menschen besitzt die Maus zwei nichtallelische Insulin-Gene. Das auf Chromosom 19 lokalisierte murine Insulin 1-Gen besitzt nur 2 Exons. Das auf Chromosom 7 gelegene murine Insulin 2-Gen setzt sich wie das humane Insulin (11p15.5) aus drei Exons zusammen, wobei jeweils das erste Exon nicht translatiert wird. Die Aminosäuresequenz des humanen Insulins ist mit 77\% der des murinen Insulin 1 und mit 81\% der des murinen Insulin 2 homolog. Die größten Differenzen finden sich jeweils in der Region des C-Peptids. Das humane Insulin ist mit den murinen Insulinhormonen bis auf 2 (Insulin 1) bzw. 4 (Insulin 2) Aminosäuren identisch.

Es wird davon ausgegangen, dass das Präprohormon des transgenen Ins12/Insl3 Allels (PräproIns13) innerhalb der $\beta$-Zellen auf gleichem Wege wie endogenes Präproinsulin prozessiert und sezerniert wird. Auf jeden Fall konnte aktives transgenes Insl3 die Differenzierung des Gubernaculums anregen und muss somit aus den $\beta$-Zellen ins Blut 
transportiert worden sein. Noch ist ungeklärt, ob auch ProInsl3 biologisch aktiv ist und somit kann auch die Prozessierung von transgenem ProInsl3 in den $\beta$-Zellen nicht als erwiesen angesehen werden. Wenn aber für die Aktivierung von Ins13 die Prozessierung des ProIns13 nötig ist, müssen die dafür erforderlichen Enzyme in den $\beta$-Zellen des Pankreas vorhanden sein. Aufgrund des Erfolgs dieses Experiments (Adham et al., 2002) schien es nicht unwahrscheinlich, dass wegen der strukturellen Ähnlichkeiten der beiden Präprohormone auch transgenes Präproinsulin in den Leydigzellen prozessiert und ins Blut ausgeschüttet werden kann.

Um Verwechslungen mit den von Adham et al. (2002) beschriebenen Insl3überexprimierenden Mauslinien zu vermeiden, wurden die für diese Arbeit verwendeten Konstrukte, bei denen das humane Insulin-Gen unter die Kontrolle des weiter oben beschriebenen murinen Ins13-Promotors gestellt wurde, mit $\mathrm{I}_{2} \mathrm{I}_{3}$ bezeichnet. 


\section{MATERIAL UND METHODEN}

\subsection{Material}

\subsubsection{Chemikalien}

Agar

Agarose

Ampicillin

Ampuwa

Aqua Poly/Mount

Borsäure

Bovine Serum Albumin (BSA)

5-Brom-4-Chlor-3-Indoylphosphat (BCIP)

Chloroform

Coomassie-Brilliant Blue R250

DAPI

Diethylpyrocarbonat (DEPC)

Dimethylformamid

Dimethylsulfoxid (DMSO)

Dithiothreitol (DTT)

DMEM

dNTPs

DPBS

DYEnamic ${ }^{\mathrm{TM}}$ ET terminator cycle

sequencing premix kit

Entwickler

Essigsäure

Ethanol

Ethidiumbromid
Roth, Karlsruhe

Invitrogen, Karlsruhe

AppliChem, Darmstadt

Fresenius AG, Bad Homburg

Polysciences, Inc., Warrington

ICN Biomedicals, Aurora, USA

Biomol, Hamburg

Invitrogen, Karlsruhe

Baker, Deventer, Niederlande

Sigma-Aldrich Chemie, Taufkirchen

Vector, Burfingame

Roth, Karlsruhe

Roth, Karlsruhe

Roth, Karlsruhe

Applichem, Darmstadt

PAN, Aidenbach

Finnzymes, Espoo, Finnland

Invitrogen, Karlsruhe

PAN, Aidenbach

Amersham, Freiburg

Agfa PMA Bode, Hamburg

Merck, Darmstsdt

Baker, Deventer, Niederland

Roth, Karlsruhe 
Ethylendiamintetraacetat (EDTA)

Fast red TR/Naphthol AS-Mx

Phosphat Plätzchen

Ficoll 400

Fixierer

FKS

Formaldehyd ( $\geq 37 \%)$

Formamid (deionisiert)

Glutaraldehyd

Glycerin

Glycin

Hefeextract

Hybridization Puffer

Isopropanol (2-Propanol)

Isopropyl- $\beta$-thiogalactopyranosid (IPTG)

IVF Medium

Kanamycin

Kompetente DH5a-Zellen

kb-Leiter

L.A.B. Demaskierungs-Solution

Lachsspermien-DNA

Lithiumacetat

Magnesiumchlorid

Membran Hybridisierungspuffer

$\beta$-Mercaptoethanol

Methanol

MikroSpin $^{\text {TM }}$ S200 Säulen

Milchpulver

Mineralöl

MOPS

Natriumacetat

Natriumchlorid

Natriumcitrat

Natriumdodecylsulfat (SDS)
ICN Biomedicals, Aurora, USA

Sigma-Aldrich Chemie, Taufkirchen

Fluka-Sigma-Aldrich Buchs, Schweiz

Agfa PMA Bode, Hamburg

PAN, Aidenbach

Merck, Darmstadt

Sigma-Aldrich Chemie, Taufkirchen

Sigma-Aldrich Chemie, Taufkirchen

Roth, Karlsruhe

Roth, Karlsruhe

Roth, Karlsruhe

KPL, Maryland, USA

Merck, Darmstadt

AppliChem, Darmstadt

Medicult, Dänemark

Roth, Karlsruhe

Invitrogen, Karlsruhe

Invitrogen, Karlsruhe

Polysciences, Inc., Warrington, USA

Sigma-Aldrich Chemie, Taufkirchen

Sigma-Aldrich Chemie, Taufkirchen

Roth, Karlsruhe

KPL medac, Wedel

Sigma-Aldrich Chemie, Taufkirchen

Baker, Deventer, Niederlande

Amersham, Freiburg

Roth, Karlsruhe

Sigma-Aldrich Chemie, Taufkirchen

Biomol, Hamburg

Merck, Darmstadt

Roth, Karlsruhe

Roth, Karlsruhe

Roth, Karlsruhe 
Natriumhydroxid

Neomycin

Nick Translationskit

Nitrotetrazoliumblau (NBT)

NuPage ${ }^{\circledR}$ LDS Sample Buffer (4x)

NuPage ${ }^{\circledR}$ Mops SDS Running Buffer

Orange-G

Paraformaldehyd

Parablast Embedding Media

Pepton

Pferdeserum

Phenol

Picogreen $\odot$ Quantification Kit

Pikrinsäure

Plasmid-Maxipräp Kit

Plasmid-Minipräp-Kit

PLATINUM® Taq DNA Polymerase

Proteinase K

Radioaktiv markierte Reagenzien: [ $\left.\alpha^{32} \mathrm{P}\right]-$ dCTP

Rapid-hybridization Puffer

Ready prime ${ }^{\mathrm{TM}}$ II (DNA Labelling Kit)

Restriktionsenzyme

Reverse Transkriptase Superscript ${ }^{\mathrm{TM}}$

System

RNA-Labelling-Kit

RNA-Ladder

RNase

RNase away

RNeasy Mini Kit

Roti-Quant

Salzsäure (rauchend)

SDS

SeeBlue ${ }^{\circledR}$ plus2 Pre-Stained Standard
Merck, Darmstadt

Gibco BRL, Karlsruhe

Gibco BRL, Karlsruhe

Fluka-Sigma-Aldrich Buchs, Schweiz

Invitrogen, Karlsruhe

Invitrogen, Karlsruhe

Fluka-Sigma-Aldrich Buchs, Schweiz

AppliChem, Darmstadt

Sigma-Aldrich Chemie, Taufkirchen

Roth, Karlsruhe

PAN, Aidenbach

Biomol, Hamburg

Invitrogen, Karlsruhe

Fluka-Sigma-Aldrich Buchs, Schweiz

Qiagen, Hilden

Qiagen, Hilden

Invitrogen, Karlsruhe

Roche Diagnostics, Mannheim

Amersham, Freiburg

Amersham, Freiburg

Amersham, Freiburg

Invitrogen, Karlsruhe

II- Invitrogen, Karlsruhe

Boehringer, Mannheim

Invitrogen, Karlsruhe

Invitrogen, Karlsruhe

Roth, Karlsruhe

Qiagen, Hilden

BioRad, München

Roth, Karlsruhe

Serva, Heidelberg

Invitrogen, Karlsruhe 
SOC-Medium

SP6-RNA-Polymerase

Streptozotocin

Taq-DNA-Polymerase

$\mathrm{T}_{4}$-DNA-Ligase

Tris

Triton-X-100

T7-RNA-Polymerase

Total RNA Isolation Reagent

Tween-20

Wasserstoffperoxid $\left(\mathrm{H}_{2} \mathrm{O}_{2}\right) 30 \%$

X-Gal

Xylol
Invitrogen, Karlsruhe

Boehringer, Mannheim

Sigma-Aldrich Chemie, Taufkirchen

Finnzymes, Espoo, Finnland

Promega, Mannheim

Roth, Karlsruhe

Serva, Heidelberg

Boehringer, Mannheim

Biomol, Hamburg

Roth, Karlsruhe

Roth, Karlsruhe

AppliChem, Darmstadt

Merck, Darmstadt

Alle Chemikalien, die nicht gesondert aufgeführt sind, wurden von der Firma Merck, Darmstadt, oder Roth, Karlsruhe, bezogen.

\subsubsection{Puffer und Stammlösungen}

Lösungen für den routinemäßigen Gebrauch wurden nach Sambrook et al. (1989) angesetzt. Die dazu benötigten Chemikalien wurden in bidestilliertem oder gegebenenfalls in DEPC behandeltem Wasser gelöst und nach Bedarf autoklaviert oder steril filtriert (2.1.4).

AP-Puffer

$100 \mathrm{mM}$ Tris/ $\mathrm{HCl}(\mathrm{pH} 9.5)$

$100 \mathrm{mM} \mathrm{NaCl}$

$50 \mathrm{mM} \mathrm{MgCl} 2$

BCIP- Stammlösung

$50 \mathrm{mg} / \mathrm{ml} \mathrm{BCIP}$

$70 \%(v / v)$ Dimethylformamid

Blockinglösung

$5 \%$ BSA in $4 x$ SSC

$0.2 \%$ Tween-20 
Bouin'sche Lösung

Coomassie-Lösung

Coomassie-Entfärber

Denaturierungslösung

DEPC- $\mathrm{H}_{2} \mathrm{O}$

Depurinierungslösung

dNTP-Mix

E-Puffer (10x)

Hybridisierungslösung

(für in situ-Hybridisierungen)
15 Vol. Pikrinsäure in $\mathrm{H}_{2} \mathrm{O}$

5 Vol. Formaldehyd

1 Vol. Essigsäure

$30 \%(\mathrm{v} / \mathrm{v})$ Methanol

$10 \%(\mathrm{v} / \mathrm{v})$ Essigsäure

0.05\% (w/v) Coomassie-Brilliant Blue R250

$30 \%(\mathrm{v} / \mathrm{v})$ Methanol

$10 \%(v / v)$ Essigsäure

$1.5 \mathrm{M} \mathrm{NaCl}$

$0.5 \mathrm{M} \mathrm{NaOH}$

$0.5 \%(v / v)$ DEPC in Aqua dest. üN auf Magnetrührer

$0.25 \mathrm{M} \mathrm{HCl}$

$2 \mathrm{mM}$ dATP

$2 \mathrm{mM}$ dGTP

$2 \mathrm{mM}$ dCTP

2 mM dTTP

$300 \mathrm{mM} \mathrm{NaH}{ }_{2} \mathrm{PO}_{4}$ (pH 7.0)

$50 \mathrm{mM}$ EDTA

$50 \%$ Formamid

5x SSC pH 4.5

$50 \mu \mathrm{g} / \mu \mathrm{l}$ Hefe tRNA

$100 \mu \mathrm{g} / \mu \mathrm{l}$ Heparin

$0.1 \%$ Tween 20 
IPTG

Lachs-Spermien-DNA

Lysispuffer (zur DNA-Isolierung)

Lysispuffer (für ES-Zellen)

MAB-Puffer (pH 7.5)

MAB/Block-Puffer

10x MOPS-Puffer (pH 7.0)

NBT-Stammlösung

Neutralisierungslösung
$100 \mathrm{mM}$ in $\mathrm{H}_{2} \mathrm{O}$

$100 \mu \mathrm{g} / \mathrm{ml}$

$100 \mathrm{mM} \mathrm{NaCl}$

$100 \mathrm{mM}$ Tris/HCl (pH 8.0)

100 mM EDTA (pH 8.0)

$0.5 \%(\mathrm{w} / \mathrm{v}) \mathrm{SDS}$

$100 \mathrm{mM}$ Tris/HCl (pH 8.5)

5 mM EDTA

$200 \mathrm{mM} \mathrm{NaCl}$

$0.2 \%(\mathrm{w} / \mathrm{v}) \mathrm{SDS}$

$100 \mu \mathrm{g} / \mathrm{ml}$ Proteinase K

0.1 M Maleinsäure

$0.15 \mathrm{M} \mathrm{NaCl}$

$0.1 \%$ Tween-20

$2 \%$ Blocking-Pulver in MAB

$0.2 \mathrm{M}$ MOPS

$50 \mathrm{mM} \mathrm{NaAc}$

0.5 M EDTA

in DEPC $\mathrm{H}_{2} \mathrm{O}$

$75 \mathrm{mg} / \mathrm{ml}$

$70 \%$ (v/v) Dimethylformamid

$1.5 \mathrm{M} \mathrm{NaCl}$

$1 \mathrm{M}$ Tris/HCl (pH 7.0) 
NTMT

P1 (Puffer für Minipräparation)

P2 (Puffer für Minipräparation)

P3 (für Minipräparation)

4\%ige Paraformaldehydlösung

PBS-Puffer (10x)

PBT-Puffer

Proteinase K

Proteinextraktionslösung
$100 \mathrm{mM}$ Tris/HCl (pH 9.5)

$50 \mathrm{mM} \mathrm{MgCl} 2$

$10 \mathrm{mM} \mathrm{NaCl}$

$0.1 \%$ Tween-20

$2 \mathrm{mM}$ Lavamisol

$50 \mathrm{mM}$ Tris- $\mathrm{HCl}(\mathrm{pH} 8.0)$

10 mM EDTA

$100 \mu \mathrm{g} / \mathrm{ml}$ RNase1

$200 \mathrm{mM} \mathrm{NaOH}$

$1 \%$ SDS

3 M K-Acetat-H-Acetat ( $\mathrm{pH}$ 5.5)

8 g PFA

$20 \mathrm{ml} \mathrm{10x}$ PBS

$180 \mathrm{ml}$ DEPC- $\mathrm{H}_{2} \mathrm{O}$

$200 \mu 1$ Tween-20

$1.37 \mathrm{mM} \mathrm{NaCl}$

$26.8 \mathrm{mM} \mathrm{KCl}$

$17.6 \mathrm{mM} \mathrm{KH}_{2} \mathrm{PO}_{4}$

$80.9 \mathrm{mM} \mathrm{Na} \mathrm{HPO}_{4} \times 2 \mathrm{H}_{2} \mathrm{O}$

$0.1 \%$ Tween-20 in PBS (1x)

$10 \mathrm{mg} / \mathrm{ml}$ in $\mathrm{H}_{2} \mathrm{O}$

$75 \%$ Ethanol

$1.5 \% \mathrm{HCl}$ 
$\operatorname{SSC}(20 x)$

Stop-Mix (5x)

5x TBE-Puffer

TE-Puffer

Waschlösung I

Waschlösung II

Waschlösung I für in situ-Hybridisierungen

Waschlösung II für in situ-Hybridisierungen

X-Gal-Stammlösung
$3 \mathrm{M} \mathrm{NaCl}$

$0.3 \mathrm{M}$ Trinatriumcitrat

$(\mathrm{pH} 7.0$ mit $\mathrm{NaOH})$

15\% Ficoll 400

$200 \mathrm{mM}$ EDTA

$0.1 \%$ Orange $\mathrm{G}$

10\% Glycerin

445 mM Tris/HCl (pH 8.0)

445 mM Borsäure

$10 \mathrm{mM}$ EDTA

$10 \mathrm{mM}$ Tris/HCl (pH 8.0)

$1 \mathrm{mM}$ EDTA

2x SSC

$0.1 \%$ SDS

$0.2 \times \mathrm{SSC}$

$50 \%$ Formamid

5x SSC (pH4.5)

$1 \%$ SDS

$\mathrm{H}_{2} \mathrm{O}$

$50 \%$ Formamid

2x SSC (pH4.5)

$0.2 \%$ SDS

$\mathrm{H}_{2} \mathrm{O}$

$20 \mathrm{mg}$ X-Gal/ml

in N,N-Dimethylformamid 


\subsubsection{Gebrauchswaren}

Gebrauchswaren, die nicht gesondert aufgeführt sind, wurden von den Firmen Schütt bzw. Krannich, Göttingen, bezogen.

Blottingpapier GB-003

Einmalfilter Minisart NML

(Porengröße 0.20 und $0.45 \mu \mathrm{m}$ )

Filterpapier 0858

Hybond C Membran

Hybond N Membran

Nitrocellulosefilter BA 85

Objektträger/Deckgläschen

Petrischalen

Pipettenspitzen

Plastikwaren

Polyallomer-Ultrazentrifugenröhrchen

Reaktionsgefäße

Röntgenfilme (Hyperfilm $\left.{ }^{\mathrm{TM}}-\mathrm{MP}\right)$

Superfrost Plus Objektträger

Thermo-Fast $@$ 96-well Platten

Ultrazentrifugengefäße

White-colored 384-well Platten

Zentrifugengefäße und -röhrchen
Schleicher \& Schüll, Dassel

Satorius, Göttingen

Schleicher \& Schüll, Dassel

Amersham, Freiburg

Amersham, Freiburg

Schleicher \& Schüll, Dassel

Menzelgläser, Braunschweig

Greiner Nunc., Nürtingen

Eppendorf, Hamburg

Greiner Nunc., Nürtingen

Beckmann, München

Eppendorf, Hamburg

Amersham, Freiburg

Schütt, Göttingen

ABgene, Hamburg

Beckmann, München

ABgene, Hamburg

Beckmann, München

\subsubsection{Sterilisation}

Die Sterilisation von Lösungen erfolgte für $20 \mathrm{~min}$ bei $120^{\circ} \mathrm{C}$ und $10^{5}$ Pascal im Dampfdruckautoklaven (Webeco, Bad Schwartau) oder bei hitzeempfindlichen Lösungen durch Sterilfiltration (Porengröße: $0.2 \mu \mathrm{m}$ ). Gebrauchswaren wurden entweder autoklaviert oder üN bei $220^{\circ} \mathrm{C}$ hitzesterilisiert. 


\subsubsection{Medien, Agarplatten und Antibiotika}

\subsubsection{Medien für Bakterien}

$\begin{array}{lll}\text { LB-Medium (pH 7.5): } & 1 \% & \text { Trypton } \\ & 0.5 \% & \text { Hefeextrakt } \\ & 1 \% & \mathrm{NaCl} \\ \text { LB-Agar enthielt zusätzlich } & 1.5 \% & \text { Agar }\end{array}$

Das LB-Medium wurde mit bidestilliertem Wasser angesetzt, autoklaviert und bei $4^{\circ} \mathrm{C}$ aufbewahrt.

\subsubsection{Medien für die Zellkultur}

Die zur Kultur von eukaryontischen Zellen verwendeten Medien wurden gekauft und vor Gebrauch je nach Kulturbedingungen der Zellen mit FKS, Antibiotika und Glutamin versetzt und sterilfiltriert. Für die Zelllinien wurden folgende Medien verwendet:

ES-Zellmedium:

DMEM (Dulbecco's Modified Eagle Medium)

$0.1 \mathrm{mM}$ nicht essentielle Aminosäuren

$1 \mathrm{mM}$ Natrium-Pyruvat

$10 \mu \mathrm{M} \beta$-Mercaptoethanol

2 mM L-Glutamin

$20 \%$ FKS

1000 U/ml LIF (Recombinant Leukaemia Inhibitory Factor)

EmFi- Zellmedium:

\section{DMEM}

2 mM L-Glutamin

$10 \%$ FKS 
Für die Langzeitlagerung der Zellen in flüssigem Stickstoff wurden folgende Einfriermedien verwendet:

ES-Zellen:

\author{
$30 \%$ ES-Zellmedium \\ $50 \%$ FKS \\ $20 \%$ DMSO
}

EmFi-Zellen:

$30 \%$ EmFi-Zellmedium
$50 \%$ FKS
$20 \%$ DMSO

Für die Präparation von befruchteten Oocyten und zur Kultivierung unter $5 \% \mathrm{CO}_{2}$ wurden folgende Medien verwendet:

M2-Medium:

$5 \mathrm{ml}$ 10x Hanks

$1.25 \mathrm{ml}$ 40x HEPES

$165 \mu 1300 x$ Na-Pyruvat

$0.25 \mathrm{ml} 1 \mathrm{M} \mathrm{NaOH}$

$0.5 \mathrm{ml}$ Penicillin $(6 \mathrm{mg} / \mathrm{ml})$

Streptomycin $(5 \mathrm{mg} / \mathrm{ml})$

$43 \mathrm{ml}$ Ampuwa

0.2 g BSA

M16-Medium:

$1 \mathrm{ml} \mathrm{10x}$ EARLE

$270 \mu 137.5 \times \mathrm{NaHCO}_{3}$

$3 \mu 1$ 300x Na-Pyruvat

$100 \mu 1$ Penicillin $(6 \mathrm{mg} / \mathrm{ml})$

Streptomycin $(5 \mathrm{mg} / \mathrm{ml})$

$8.6 \mathrm{ml}$ Ampuwa

40 mg BSA 


\subsubsection{Antibiotika}

Von den Antibiotika Ampicillin und Kanamycin wurden Stammlösungen angesetzt, die steril filtriert und bei $-20^{\circ} \mathrm{C}$ gelagert wurden. Das jeweils benötigte Antibiotikum wurde erst nach dem Autoklavieren und Abkühlen der Wachstumsmedien auf $55^{\circ} \mathrm{C}$ zugegeben.

\begin{tabular}{|c|c|c|c|}
\hline & $\underline{\text { Stammlösung }}$ & gelöst in & Endkonzentration \\
\hline Ampicillin & $50 \mathrm{mg} / \mathrm{ml}$ & $\mathrm{H}_{2} \mathrm{O}$ & $50 \mu \mathrm{g} / \mathrm{ml}$ \\
\hline Kanamycin & $25 \mathrm{mg} / \mathrm{ml}$ & $\mathrm{H}_{2} \mathrm{O}$ & $50 \mu \mathrm{g} / \mathrm{ml}$ \\
\hline G 418 & $40 \mathrm{mg} / \mathrm{ml}$ & PBS & $400 \mu \mathrm{g} / \mathrm{ml}$ \\
\hline Gancyclovir & $100 \mathrm{mM}$ & PBS & $2 \mu \mathrm{M}$ \\
\hline
\end{tabular}

\subsection{7}

IPTG/X-Gal-Platten

Zur Herstellung von IPTG/X-Gal-Platten (Blau-Weiß-Selektion) wurden dem LB-Agar $\left(55^{\circ} \mathrm{C}\right)$ Ampicillin, IPTG und X-Gal in entsprechenden Konzentrationen zugegeben und in Petrischalen gegossen. Die Platten wurden bei $4^{\circ} \mathrm{C}$ gelagert.

$\begin{array}{llll} & \text { Stammlösung } & \text { gelöst in } & \text { Endkonzentration } \\ \text { X-Gal } & 2 \% & \text { N,N-Dimethylformamid } & 0,0004 \% \\ \text { IPTG } & 100 \mathrm{mM} & \mathrm{H}_{2} \mathrm{O} & 1 \mathrm{mM}\end{array}$

\subsubsection{Bakterienstämme}

Zur Vermehrung der Vektoren bzw. der rekombinanten DNA wurde folgender Wirtsstamm eingesetzt:

E. coli DH5 $\alpha$

Invitrogen, Karlsruhe 


\subsubsection{Eukaryotische Zelllinien}

RI Embryonale Stammzellen

(Passage 11)

EmFi Embryonale Fibroblasten
Nagy et al., (1993)

Adham et al., (1997)

\section{Plasmide}

\author{
pBluescript II SK (+/-) \\ pGEM-T easy \\ pPNT \\ pUC 18 \\ pZErO-2
}

Lawrist 7

\author{
Stratagene, La Jolla, USA \\ Promega, Wisconsin, USA \\ Tybulewicz et al., (1991) \\ Norander et al., (1983) \\ Invitrogen, Karlsruhe \\ RZPD, Berlin
}

\subsubsection{Synthetische Oligonukleotide}

Alle für diese Arbeit verwendeten Oligonukleotide wurden von der Firma Qiagen (Hilden) synthetisiert und im lyophilisierten Zustand erworben, mit Ampuwa auf eine Konzentration von $100 \mu \mathrm{M}(100 \mathrm{pmol} / \mu \mathrm{l})$ eingestellt und als Stock bei $-20^{\circ} \mathrm{C}$ gelagert.

$\begin{array}{ll}\text { Hins21F } & \text { 5'- GCA TCT GCT CCC TCT ACC AG -3' } \\ \text { Hin 21R } & \text { 5'- CAA ACT GGG TTG TTG CAA TG -3' } \\ \text { Pelo F11 } & \text { 5'- TGA GCC CAG ACT GTA CG -3' } \\ \text { Pelo R12 } & \text { 5'- TCT GCA CCT TAG CGT GA -3' } \\ \text { Lyk2 } & \text { 5'- GCC GCA AGC TTC CGC ACC TGG GAG AGG -3' } \\ \text { HinsR3 } & \text { 5'- GGC AGA AGG ACA GTG ATC TGG -3' } \\ \text { HinsR5 } & \text { 5'- AAA AAA GTG CAC CTG ACC CCC TGC-3' } \\ \text { Pax 4 F } & \text { 5'- ATG GCT GTG TGA GCA AGA TCC -3' } \\ \text { Pax 4 R } & \text { 5'- TCC AGC TTC CCT TAA CTC CAG -3' }\end{array}$


MinsL1F 5'-GCC GCG CGG CCG CTG AAG GAG CAC AGG GCT CAG G -3'

MinsL1R 5'- GCC GCC CGC GGC GGT CTG GTC CGT GTG TGA CC-3'

Hins 11F 5'- GCC GCT CTA GAT CTG CCA TGG CCC TGT GGA TGC -3'

Hins 11R 5'- GCC GCG CGG CCG CCC TGC AGG CTG CGT CTA GTT -3'

Hins2F 5'- GCC GCT CTA GAC CTG AGC CCT CCA GGA CAG -3'

Hins2R 5'- GCC GCG CGG CCG CGG GAG GGG CTC ACA ACA GTG C -3'

T7

5'- TAA TAC GAC TCA CTA TAG GG -3'

T3 5'- ATT AAC CCT TCA CTA AAG -3'

SP6 5'- AGG TGA CAC TAT AGA ATA C -3'

H-insulinF1 5'- AGC CTT TGT GAA CCA ACA CC -3'

HinsulinR1 5'- GGT TCA AGG GCT TTA TTC CA -3'

M-I3F1 5'- TAC TGA TGC TCC TGG CTC TG -3'

M-I3R1 5'- AGG TCA TGA TGG GGC TTC TT -3'

GAPDH F 5'- CAC CAC CAA CTG CTT AGC C -3'

GAPDH R 5'- CGG ATA CAT TGG GGG TAG G -3'

Insl6-F2 5'- AGA GGA AGA GGA ATC CAG ACC-3'

Insl6-R1 5'- CGA GCA TAG TTC CTA CGA CAG -3'

Mins6-F40 5'- AAC AGG GCC AAG AAG ACT CA -3'

Mins6-R30 5'- GGC AAC ATG TGG GAA CTA GG -3'

PCSK-1F 5'- TCA ACC AGA GCA CAT GAA GC -3'

PCSK-1R 5'- GCA GCA GCC TGT CAT CTC TA -3'

PCSK-2F 5'- ATG GAG GGC GGT TGT GGA TC -3'

PCSK-2R 5'- CAG GTA CCA TTG CTT TGT AAA GAG A -3'

I5KO-F1 5'- CCA CTA GAG GTC TTA GGA TCC -3'

PGK3 5'- GGA TGT GGA ATG TGT GCG AGG -3'

C-Insl5-F 5'- GCT GAC CAC ATT GCT TCT CA -3'

C-Insl5-R 5'- TTT TGC ACA GCA CTC GAA AC -3'

C-Insl5-F8 5'- CGG ATC TCT CAG GAL AGG AG -3'

C-Insl5-R9 5'- ACC TCA GCA CAG GGA GAA GA -3'

LacZ-F 5'- TTG GCG TAA GTG AAG CGA C -3'

LacZ-R 5'- AGC GGC TGA TGT TGA ACT G -3' 


\subsubsection{2 cDNA-Proben}

Verwendete cDNA Sonden für Northern Blot-Rehybridisierungen:

Tab. 2.1: cDNA-Sonden für Northern Blot-Rehybridisierungen

\section{cDNA-Sonde Herkunft}

\begin{tabular}{l|l}
$\beta$-Actin & Clontech, Heidelberg
\end{tabular}

\subsubsection{Mausstämme}

Für die Herstellung von Chimären und die Rückkreuzung auf Wildtyp-Stämme wurden die Mausstämme C57BL und 129/SvJ verwendet. Sowohl die Mäuse des Stammes FVB als auch die transgenen Mäuse wurden in den institutseigenen Tierställen gezüchtet. Die Embryonen für die whole mount-in situ-Hybridisierung wurden vom Stamm CD1 präpariert. Die Haltungsbedingungen bestanden aus einem 12 h Hell-Dunkel-Rhythmus (Hellperiode: $6^{00}-18^{00} \mathrm{Uhr}$ ) bei $22^{\circ} \mathrm{C}$ und $55 \pm 5 \%$ relativer Luftfeuchtigkeit. Den Tieren standen eine pelletierte Zuchtdiät (Herilan, Eggersmann, Rinteln) und Wasser ad libitum zur Verfügung.

\subsubsection{Antikörper}

\section{$\underline{1 . \text { Antikörper }}$}

Monoklonaler Anti-Insulin Antikörper, (K36aC10), Sigma-Aldrich Chemie, Taufkirchen

Anti-Insl3-IgG, aufgereinigt aus Polyklonalem Serum, Kaninchen Anti-Insl5-IgG, aufgereinigt aus Polyklonalem Serum, Kaninchen Anti-Insl6-IgG, aufgereinigt aus Polyklonalem Serum, Kaninchen 
2. Antikörper (alle von Sigma-Aldrich Chemie, Taufkirchen)

Polyklonales Ziege-Anti-Maus-IgG-Alkalische Phosphatase-Konjugat,

Polyklonales Schaf-Anti-Kaninchen-IgG-Alkalische Phosphatase-Konjugat

Polyklonales Schaf-Anti-Kaninchen-IgG-Cy3-Konjugat

Polyklonales Ziege-Anti-Kaninchen-IgG-FITC-Konjugat

\subsubsection{Kits}

DIG Nucleic Acid Detection Kit

DIG-RNA Labelling Kit

DYEnamic ${ }^{\mathrm{TM}} \mathrm{ET}$ terminator cycle

sequencing premix Kit

Endo Free ${ }^{\circledR}$ Plasmid Maxi Kit

PCR Purification Kit

Picogreen ${ }^{\odot}$ Quantification Kit

pGEM $^{\circledR}$-T Easy Vector System I

QIAquick ${ }^{\circledR}$ Gel Extraction Kit

QIAshredderTM Mini Spin Säule

QuantiTect $^{\mathrm{TM}} \mathrm{SYBR}^{\circledR}$ Green PCR Kit

Ready prime ${ }^{\mathrm{TM}}$ II random labelling System

RNeasy Mini Kit
Roche Diagnostics, Mannheim

Roche Diagnostics, Mannheim

Amersham, Freiburg

Qiagen, Hilden

Qiagen, Hilden

Invitrogen, Karlsruhe

Promega, Mannheim

Qiagen, Hilden

Qiagen, Hilden

Qiagen, Hilden

Amersham Pharmacia Biotech, Freiburg

Qiagen, Hilden

\subsubsection{Geräte}

Beckman J2-21 Ultrazentrifuge

Branson Sonifier 250

CASA System

Dampfdruckautoklaven
Beckman Coulter, München

Heinemann, Schwäbisch Gmünd

Hamilton Thorne Research

Webeco, Bad Schwartau 
Elektroblotter Fastblot B44

Entwickler Curix 60

Eppendorf Zentrifuge 5415 D

Fotostereomikroskop SZX12

Gamma-Counter PC-RIA.Mas

GeneAmp PCR System 9600

Microtom Jung RM 2035

Mikroliterpipetten Pipetman ${ }^{\circledR}$ Gilson

Mikroskop BX 60

MWG Primus96 ${ }^{\text {plus }}$ Thermocycler

Paraffin-Einbettungsstation

Personal Molecular Imager FX

Phosphor-Imager

Sequenzierer Modell Megabace 1000

Spectrophotometer Ultraspec 3000

SpeedVac concentrator SVC 100H

Thermomixer 5436

Turbo-Blot-Apparatur

UV StratalinkerTM 1800

Video-Dokumentationssystem

Xell SureLock ${ }^{\mathrm{TM}}$ Elektrophoresekammer
Whatman Biometra, Göttingen

Agfa, München

Eppendorf, Hamburg

Olympus, München

Stratec Biomedical Systems, Birkenfeld

Perkin Elmer, Finnland

Leica, Nußloch

Abimed, Langenfeld

Olympus, München

MWG Biotech, Krannich, Göttingen

Shandon, Frankfurt a.M.

BIO-RAD Laboratories, München

BIO-RAD Laboratories, München

Amersham, Freiburg

Amersham Pharmacia Biotech, Freiburg

Schütt, Göttingen

Eppendorf, Hamburg

Schleicher \& Schüll, Dassel

Leica, Nußloch

Herolab, Heidelberg

Invitrogen, Karlsruhe 


\section{$2.2 \quad$ Methoden}

Die in dieser Arbeit durchgeführten Experimente wurden, wenn nicht anders beschrieben, im wesentlichen nach den Standardmethoden ausgeführt, die in „Molecular Cloning“ (Sambrook et al., 1989) und „Current Protocols in Molecular Biology“ (Ausubel et al., 1992) beschrieben werden.

\subsubsection{Methoden zur Isolierung von Nukleinsäuren}

\subsubsection{Isolierung von Plasmid DNA}

(Sambrook et al., 1989)

\subsection{Minipräparation von Plasmid-DNA}

Diese Methode dient der schnellen Isolierung kleiner Mengen Plasmid-DNA, wobei die Qualität der DNA für eine Restriktionsanalyse sowie für die Sequenzierung ausreichend ist. $5 \mathrm{ml} \mathrm{LB}$-Medium (mit $50 \mu \mathrm{g} / \mathrm{ml}$ Antibiotikum) wurden mit einer Einzelkolonie angeimpft und üN bei $37^{\circ} \mathrm{C}$ unter Schütteln inkubiert. Aus $600 \mu \mathrm{l}$ der Kultur wurde mit $200 \mu$ Glycerin ein Stock angelegt und dieser bei $-80^{\circ} \mathrm{C}$ aufbewahrt. Der Rest der Bakteriensuspension wurde bei 4000x g für 15 min auf $4^{\circ} \mathrm{C}$ abzentrifugiert. Das Pellet wurde in $100 \mu$ l Resuspension-Lösung (P1) wieder in Lösung gebraucht und in ein Eppendorfgefäß transferiert. Der Aufbruch der Zellen erfolgte durch Zugabe von $200 \mu \mathrm{l}$ Lysispuffer (P2). Nach einer Inkubationszeit von 5 min bei RT wurde die Suspension mit $150 \mu \mathrm{l}$ Neutralisierungspuffer (P3) gemischt. Die Zelltrümmer wurden mittels Zentrifugation bei $12000 \mathrm{x}$ g für 15 min pelletiert, der Überstand in ein neues Eppendorfgefäß überführt und die Zentrifugation wiederholt. Die obere Phase wurde abgenommen und in ein frisches Eppendorfgefäß überführt. Die Fällung der PlasmidDNA erfolgte durch Zugabe von 2.5 Vol. $100 \%$ Ethanol für 30 min bei $4^{\circ} \mathrm{C}$. Durch den anschließenden Zentrifugationsschritt mit 12000x g für 30 min bei RT wurde die DNA pelletiert, das Pellet mit 70\%-igem Ethanol gewaschen, luftgetrocknet und in $30 \mu \mathrm{H}_{2} \mathrm{O}$ aufgenommen. 


\subsection{Endotoxin-freie Maxipräparation von Plasmid-DNA}

Für die Transfektion von DNA in eukaryotische Zellen wurde das Plasmid mit dem EndoFree Plasmid Maxi-Kit (Qiagen, Hilden) Endotoxin-frei präpariert. Dazu wurden $100 \mathrm{ml}$ üN-Bakterienkultur abzentrifugiert und mittels alkalischer Lyse aufgeschlossen. Zelltrümmer, Proteine und Salzkomplexe wurden durch Filtration in der QIAfilter Maxi Cartridge abgetrennt, das Lysat über eine äquilibrierte Säule gegeben, die gebundene DNA gewaschen und in ein steriles, Endotoxin-freies Zentrifugenröhrchen aus Glas eluiert. Nach der Präzipitation mit 0.7 Vol. Isopropanol wurde das Pellet mit 70\%igem EtOH (hergestellt mit Endotoxin-freiem $\mathrm{H}_{2} \mathrm{O}$ aus dem Kit) gewaschen, luftgetrocknet und in 100-200 $\mu$ l ebenfalls Endotoxin-freiem TE-Puffer aufgenommen.

\subsubsection{Isolierung genomischer DNA aus Geweben}

(Laird et al., 1991)

Die Isolierung genomischer DNA aus Schwanzspitzen von Mäusen bzw. aus Gewebe für eine anschließende Genotypisierung wurde nach der Methode von Laird et al., (1991) durchgeführt. Hierbei bleibt die DNA durch eine Behandlung mit Proteinase K vor dem Verdau durch endogene Nukleasen geschützt.

$0.5 \mathrm{~cm}$ der Schwanzspitze von etwa 3 Wochen alten Mäusen bzw. 1 bis $2 \mathrm{~g}$ Gewebe wurden in $700 \mu \mathrm{l}$ Lysis-Puffer unter Zugabe von $35 \mu$ l Proteinase $\mathrm{K}(10 \mu \mathrm{g} / \mu \mathrm{l})$ bei $55^{\circ} \mathrm{C}$ üN unter Schütteln inkubiert. Nach einer Phenol/Chloroform-Extraktion wurde die DNA mit 0.7 Vol. Isopropanol bei RT präzipitiert und durch eine anschließende Zentrifugation mit 12000x g bei RT für 10 min pelletiert. Nach einem Waschschritt mit $500 \mu 170 \%$ igem Ethanol wurde das DNA-Pellet in $100-200 \mu 1 \mathrm{H}_{2} \mathrm{O}$ bei $60^{\circ} \mathrm{C}$ gelöst und bis zur Analyse bei $4^{\circ} \mathrm{C}$ gelagert.

\subsubsection{Isolierung genomischer DNA aus ES-Zellen}

Die 24 Well-Platten mit den ES-Zellen wurden mit PBS gewaschen und mit $500 \mu$ l ESLysispuffer pro ES-Zellklon üN bei $37^{\circ} \mathrm{C}$ inkubiert. Nach erfolgter Zelllyse wurde die DNA mit $500 \mu 1$ Isopropanol gefällt und 15 min bei RT inkubiert. Der Überstand wurde 
danach vorsichtig entfernt. Nach dem Waschen mit $1 \mathrm{ml}$ 70\%igem Ethanol wurde die DNA in $80 \mu 1$ TE-Puffer aufgenommen. Die DNA wurde bei offenem Deckel bei $60^{\circ} \mathrm{C}$ für 15 min gelöst und dabei noch vorhandene Ethanolrückstände verdampft. Die genomische DNA konnte nun restriktionsenzymatisch geschnitten, über ein analytisches Agarosegel aufgetrennt und einem Southern-Transfer unterworfen werden.

\subsubsection{Isolierung von Gesamt-RNA aus Geweben}

Alle für die Experimente mit RNA benutzen Glaswaren und Lösungen wurden mit 0.1\%igem DEPC für $12 \mathrm{~h}$ behandelt, um sie von RNasen $\mathrm{zu}$ befreien. Zur Zerstörung des DEPC wurde anschließend für 20 min autoklaviert. Alle Glaswaren wurden für mehrere Stunden bei ca. $200^{\circ} \mathrm{C}$ sterilisiert. Bei der Gewebepräparation wurde mit Handschuhen gearbeitet und das frisch präparierte Gewebe bis zur RNA-Isolierung bei $-80^{\circ} \mathrm{C}$ gelagert. Die Arbeitsschritte wurden nach Möglichkeit auf Eis oder im Kühlraum durchgeführt.

\subsection{Isolierung von RNA durch Fällung \\ (modifiziert nach Chomczynski und Sacchi, 1987)}

$100 \mathrm{mg}$ frisches Gewebe wurde in $1 \mathrm{ml}$ Total RNA Isolation Reagent (Biomol, Hamburg) gegeben, mit einem Glas-Teflon Werkzeug homogenisiert und die Suspension $5 \mathrm{~min}$ auf Eis inkubiert. Nach Zugabe von 0.2 Vol. vorgekühltem Chloroform wurde der Ansatz vorsichtig geschwenkt und für weitere 10 min auf Eis inkubiert. Die Probe wurde dann mit $12000 x$ g bei $4^{\circ} \mathrm{C}$ für 15 min zentrifugiert, der wässrige Überstand wurde zur Fällung der RNA mit 0.6 Vol. Isopropanol auf Eis für 10 min inkubiert und die RNA anschließend durch Zentrifugation $\left(20 \mathrm{~min}, 4^{\circ} \mathrm{C}, 10000 \mathrm{x} \mathrm{g}\right)$ pelletiert. Danach wurde das RNA-Pellet in $70 \%$ Ethanol resuspendiert, erneut sedimentiert und in DEPC- $\mathrm{H}_{2} \mathrm{O}$ gelöst. Die isolierte RNA konnte für reverse Transkriptase-Reaktionen und Northern Blot-Analysen eingesetzt werden. Nach der Konzentrationsbestimmung wurde die RNA in $20 \mu \mathrm{g}$-Aliquots aufgeteilt und bis zur weiteren Verwendung bei $-80^{\circ} \mathrm{C}$ aufbewahrt. 


\subsection{Isolierung von RNA über die Säule}

Um geringe Mengen RNA z. B. für eine RT-PCR aus wenig Gewebe zu erhalten, wurde eine Präparation mit dem RNeasy Mini Kit von Qiagen vorgenommen. Hierzu wurden $30 \mathrm{mg}$ Gewebe in $600 \mu \mathrm{l}$ RLT-Puffer (beinhaltet $\beta$-Mercaptoethanol) mit einem GlasTeflonwerkzeug homogenisiert, auf eine QIAShredder-Säule mit Sammelgefäß überführt und bei 12000x g bei RT für 2 min zentrifugiert. Zur Pelletierung der in das Filtrat gelangten Verunreinigungen wurde das Filtrat $3 \mathrm{~min}$ zentrifugiert. Zum Überstand wurde 1 Vol. 70\%iges Ethanol gegeben, die Lösung auf die RNeasy mini Spin-Säule überführt und $30 \mathrm{~s}$ mit 8000x g bei RT zentrifugiert. Die in dem Filter gebundene RNA wurde erst mit $700 \mu$ l RW1-Puffer und danach 2x mit $500 \mu 1$ RPEPuffer durch $30 \mathrm{~s}$ Zentrifugieren gewaschen. Die Trocknung der Membran erfolgte durch 2 min zentrifugieren mit 8000x g bei RT. Zum Schluss wurde die RNA mit $50 \mu 1$ RNase-freiem $\mathrm{H}_{2} \mathrm{O}$ aus dem Filter eluiert. Die Konzentration betrug 0.3-1.5 $\mu \mathrm{g} / \mu 1$.

\subsubsection{Konzentrationsbestimmung von DNA und RNA}

Die exakte Konzentrationsbestimmung von Nukleinsäuren ist für die Durchführung der meisten molekularbiologischen Analysen unabdingbar. Die Konzentrationen wurden mit einem Spektralphotometer gemessen. Nach Abgleichen der Nullwerte konnten das Absorptionsmaximum der gemessenen Nukleinsäuren (bei $260 \mathrm{~nm}$ ) bestimmt und gleichzeitig Verunreinigungen durch Proteine (bei $280 \mathrm{~nm}$ ) bzw. Salze (bei $230 \mathrm{~nm}$ ) festgelegt werden. Die Nukleinsäurekonzentration wurde nach folgender Formel berechnet:

$$
\begin{aligned}
& C[\mu \mathrm{g} / \mu \mathrm{l}]=\left(E_{260}-E_{320}\right) \times f \times c \\
& C=\text { Konzentration der gemessenen Probe } \\
& E=\text { Extinktion } \\
& f=\text { Verdünnungsfaktor } \text { Konzentration }_{\text {standard }} / \text { Extinktion }_{\text {standard }} \\
& \quad \text { für doppelsträngige DNA: } \quad \mathrm{c}=0,05 \mu \mathrm{g} / \mu \mathrm{l} \\
& \quad \text { für einzelsträngige DNA: } \quad \mathrm{c}=0,025 \mu \mathrm{g} / \mu \mathrm{l} \\
& \quad \text { für RNA: c }=0,04 \mu \mathrm{g} / \mu \mathrm{l} \\
& E_{230}=\text { Absorptionsmaximum von Salzen } \\
& E_{260}=\text { Absorptionsmaximum von DNA/RNA } \\
& E_{280}=\text { Absorbtionsmaximum vieler Proteine } \\
& E_{320}=\text { Nullwert }
\end{aligned}
$$


Der Quotient $E_{260} / E_{280}$ ist ein Maß für die Reinheit der DNA und sollte $2.0 \pm 0.2$ betragen.

\subsubsection{Enzymatische Modifikation von DNA}

\subsubsection{Restriktionsenzymatische Spaltung von DNA}

Restriktionsendonukleasen erkennen spezifische Nukleotid-Sequenzen (4-8 bp) und spalten endonukleolytisch. Die Spaltung von DNA durch die Restriktionsendonukleasen erfolgte in einem Volumen von mindestens $20 \mu \mathrm{l}$ bei der enzymspezifischen Temperatur $\left(37^{\circ} \mathrm{C}\right.$, normalerweise) für $1-3 \mathrm{~h}$, wobei pro $\mu \mathrm{g}$ DNA 2-10 $\mathrm{U}$ des jeweiligen Restriktionsenzyms eingesetzt wurden. Für Doppelspaltungen wurde entweder ein für beide Enzyme geeigneter Puffer genommen oder es wurde zunächst nach Verdauung des ersten Enzyms die DNA ausgefällt, in $\mathrm{H}_{2} \mathrm{O}$ gelöst und mit dem zweiten Restriktionsenzym geschnitten. Die so gespaltene DNA wurde anschließend für weiterführende Analysen, wie z.B. gelelektrophoretische Auftrennungen, Isolierungen von DNA-Fragmenten, etc. verwendet. Restriktionsreaktionen von genomischer DNA wurden üN bei $37^{\circ} \mathrm{C}$ inkubiert.

\subsubsection{Ligation eines DNA-Inserts in einen Plasmid-Vektor}

Die geschnittenen, isolierten und bei Bedarf aufgefüllten DNA-Fragmente können direkt in die komplementären Restriktionsschnittstellen der Plamid-Vektoren ligiert werden. Für den $10 \mu$ l Ligationsansatz wurde folgende Reaktion eingesetzt:

30 ng Vektor-Plasmid-DNA

50-100 ng DNA-Insert (1:3, Vektor: Insert Verhältnis)

$1 \mu 1$ 10x Ligationspuffer

$1 \mu \mathrm{l} \mathrm{T}{ }_{4}$ DNA-Ligase (5 U/ $\left.\mu \mathrm{l}\right)$

Der Ansatz wurde je nach Protokoll mit dem jeweiligen Vektor entweder üN bei $16^{\circ} \mathrm{C}$ oder bei $4^{\circ} \mathrm{C}$ inkubiert. 


\subsubsection{TA-Klonierung}

(Clark, 1988; Hu, 1993)

Zur Klonierung von PCR-Produkten wurde das pGEM-T easy Vektorsystem genutzt. Das System enthält linearisierten Vektor mit 3’-T-Überhängen, die kompatibel zu den 3'-A-Überhängen von PCR-Fragmenten sind, die von den meisten DNA-Polymerasen erzeugt werden. Zur Ligation in diese Vektoren wurde üN bei $4^{\circ} \mathrm{C}$ inkubiert.

\subsubsection{Dephosphorylierung von Plasmid-DNA mit alkalischer Phosphatase (CIAP)}

Bei diesem Verfahren werden Phosphat-Reste am 5'-Ende von DNA-Molekülen, die bei der restriktionsenzymatischen Spaltung (s. 2.2.3.1) entstehen, durch eine alkalische Phosphatase (AP) entfernt. Dadurch wird die Religation von Vektoren verhindert und somit die Rate der rekombinanten Klone erhöht. Zur Phoshatase-Behandlung wurde die „calf intestinal alkaline Phosphatase“ (1 U/ $\mu$ l) der Firma Invitrogen (CIAP) verwendet. Für 5'-überhängende Enden aus restriktionsenzymatischen Spaltungen von bis zu $20 \mu \mathrm{g}$ Vektor-DNA $(3.0 \mathrm{~kb})$ wurde standardmäßig $1 \mu$ l CIAP (1 U) in folgendem Ansatz eingesetzt und $30 \mathrm{~min}$ bei $37^{\circ} \mathrm{C}$ dephosphoryliert:

\begin{tabular}{|c|c|}
\hline $1 \mu \mathrm{l}$ & CIAP (Invitrogen, $1 \mathrm{U} / \mu \mathrm{l})$ \\
\hline $9 \mu 1$ & Verdünnungspuffer (Invitrogen, $+\mathrm{Zn}^{2+}$ ) \\
\hline $10 \mu 1$ & 10x CIAP-Puffer (Invitrogen) \\
\hline $\mathrm{x} \mu \mathrm{l}$ & DNA $(\leq 20 \mu \mathrm{g})$ \\
\hline ad $100 \mu 1$ & $\mathrm{H}_{2} \mathrm{O}$ \\
\hline
\end{tabular}

Für 3'-überhängende Enden oder „,blunt-ends“ aus restriktionsenzymatischen Spaltungen von bis zu $5 \mu \mathrm{g}$ Vektor-DNA wurden $5 \mu$ l CIAP ( $5 \mathrm{U}$ ) in folgendem Ansatz eingesetzt und für $1 \mathrm{~h}$ bei $50^{\circ} \mathrm{C}$ dephosphoryliert:

$\begin{array}{rl}5 \mu \mathrm{l} & \text { CIAP (Invitrogen, } 1 \mathrm{U} / \mu \mathrm{l}) \\ 5 \mu \mathrm{l} & \text { Verdünnungs-Puffer (Invitrogen, }+\mathrm{Zn}^{2+} \text { ) } \\ 10 \mu \mathrm{l} & 10 \mathrm{x} \text { CIAP-Puffer (Invitrogen) } \\ \mathrm{x} \mu \mathrm{l} & \text { DNA }(\leq 5 \mu \mathrm{g}) \\ \text { ad } 100 \mu \mathrm{l} & \mathrm{H}_{2} \mathrm{O}\end{array}$


Die alkalische Phosphatase wurde nach der Dephosphorylierung bei $75^{\circ} \mathrm{C}$ hitzeinaktiviert und die Vektor-DNA bei $-20^{\circ} \mathrm{C}$ gelagert.

\subsubsection{Auffüllreaktion}

(Costa und Weiner, 1994)

Wurden für Klonierungen DNA-Fragmente mit glatten Enden (blunt ends) benötigt, um so nicht kompatible DNA-Überhänge in blunt end-vorbereitete Vektoren zu ligieren, wurden diese durch eine Reaktion mit dem Klenowfragment aufgefüllt. 0.1-4 $\mu$ g von verdauter DNA wurden in $50 \mu$ l-Reaktionen mit $0.05 \mathrm{mM}$ dNTPs und 1-5 U Klenowfragment mit Reaktionspuffer gemischt und $15 \mathrm{~min}$ bei $37^{\circ} \mathrm{C}$ inkubiert. Anschließend wurde durch Hitze $\left(10 \mathrm{~min}, 75^{\circ} \mathrm{C}\right)$ inaktiviert.

\subsubsection{Plasmidtransformation in kompetente Bakterien}

(Ausubel et al., 1994)

$50 \mu 1$ kompetente E. coli DH5 $\alpha$ Zellen (Invitrogen) wurden auf Eis aufgetaut und nach Zugabe von maximal $5 \mu$ l (1-10 ng) des zu transformierenden Plasmids (2.2.1.1) oder 1$3 \mu 1$ des Ligationsansatzes (2.2.3.2) den Herstellerangaben folgend 30 min auf Eis inkubiert. Nach „Hitzeschock“ bei $37{ }^{\circ} \mathrm{C}$ für $45 \mathrm{~s}$ wurden die Zellen 2 min auf Eis inkubiert und nach Zugabe von $950 \mu \mathrm{l}$ SOC-Medium (Invitrogen) $1 \mathrm{~h}$ bei $37^{\circ} \mathrm{C}, 200$ rpm inkubiert. Je $50 \mu \mathrm{l}$ und $100 \mu \mathrm{l}$ der homogenen Zellsuspension wurden auf Selektionsplatten ausplattiert und üN bei $37^{\circ} \mathrm{C}$ im Brutschrank inkubiert. Zur PlasmidIsolierung wurden Einzelkolonien in $5 \mathrm{ml}$ LB-Medium mit dem entsprechenden plasmidkodierten Antibiotikum überführt, üN bei $37^{\circ} \mathrm{C}$ im Schüttler inkubiert und die Plasmid-DNA wie unter (2.2.1.1) beschrieben isoliert. 


\subsubsection{Gelelektrophorese von Nukleinsäuren}

Die durch Restriktionsendonukleasen gespaltene DNA wird im elektrischen Feld aufgetrennt. Die Wanderungsgeschwindigkeit der Fragmente hängt von deren Größe, der angelegten Spannung, der Agarosekonzentration sowie der Pufferzusammensetzung und der Pufferkonzentration ab.

\subsubsection{Horizontalgelelektrophorese}

Die horizontale Gelelektrophorese wurde hauptsächlich zur Auftrennung restringierter, rekombinanter DNA, zur Insertisolierung spezifischer DNA-Fragmente oder zur Kontrolle von PCR-Produkten verwandt. Dazu wurde die Agarose (0.8-2\%ige Gele je nach Größe der zu trennenden Fragmente) in 100 ml 0.5x TBE-Puffer durch Kochen gelöst, auf $60^{\circ} \mathrm{C}$ abgekühlt und nach Zusatz von $4 \mu$ Ethidiumbromid $(10 \mathrm{mg} / \mathrm{ml})$ in die vorgefertigten Gelträger überführt. Ethidiumbromid ist ein Fluoreszenzfarbstoff, dessen flaches mehrgliedriges Ringsystem zwischen benachbarten Basenpaaren interkaliert und so eine Sichtbarmachung unter UV-Licht ermöglicht. Nach vollständiger Verfestigung des Gels wurde die Elektrophorese in einer mit 0.5x Laufpuffer gefüllten Gelkammer bei konstanter Voltzahl $(6-8 \mathrm{~V} / \mathrm{cm})$ durchgeführt.

\subsubsection{Vertikalgelelektrophorese}

Die vertikale Gelelektrophorese wurde zur Auftrennung der enzymverdauten genomischen DNA verwendet. Die geringe Dicke des Gels gewährleistet eine bessere Übertragung der DNA beim Blotten. Zum Abdichten der Innenkammer wurde ein 2\%iges Sockelgel aus Agarose gegossen und nach der Erhärtung ein 0.8\%iges Gel darüber geschichtet. Als Elektrophoresepuffer wurde 1x E-Puffer benutzt. Die Elektrophorese wurde üN bei 15-20 V unter ständigem Umwälzen (Peristaltikpumpe Ismatec Sa, Zürich) des Laufpuffers durchgeführt. 


\subsubsection{Elektrophorese von RNA im Agarosegel}

(Hodge et al., 1994)

Um die Rückbildung der Sekundärstruktur der RNA während der Gelelektrophorese zu verhindern, wurde dem 1\%igen Agarosegel (gelöst in 1x MOPS-Puffer, angesetzt mit DEPC- $\mathrm{H}_{2} \mathrm{O}$ ) eine Formaldehyd-Lösung zugesetzt (Endkonzentration: 6.6\%). Die RNAProben mussten vor der Auftrennung folgendermaßen behandelt werden:

$\begin{array}{ll}\mathrm{x} \mu \mathrm{l} & \text { 10-20 } \mu \mathrm{g} \text { Gesamt-RNA } \\ 2 \mu \mathrm{l} & \text { 10x MOPS-Puffer } \\ 8 \mu \mathrm{l} & \text { deionisiertes Formamid } \\ 3 \mu \mathrm{l} & \text { Formaldehyd (37\%ige Lösung) } \\ 1.5 \mu \mathrm{l} & \text { Ethidiumbromid } \\ 20 \mu \mathrm{l} & \text { Gesamtansatz, aufgefüllt mit DEPC- } \mathrm{H}_{2} \mathrm{O}\end{array}$

Dieses Gemisch wurde dann bei $65^{\circ} \mathrm{C}$ für $10 \mathrm{~min}$ denaturiert und für 5 min auf Eis gestellt. Die RNA-Proben wurden mit 0.2 Vol. Stop-Mix versetzt und mit $60 \mathrm{~V}$ bei $4^{\circ} \mathrm{C}$ gelelektrophoretisch aufgetrennt.

\subsubsection{Isolierung von DNA-Fragmenten aus Agarosegelen}

Diese Methode wurde eingesetzt, um DNA-Fragmente zur Sequenzierung sowie für Hybridisierungs- und Klonierungsexperimente $\mathrm{zu}$ isolieren. Hierfür kam das Fertigsystem QIAquick ${ }^{\circledR}$ Gel Extraction Kit zum Einsatz. Die entsprechende DNABande wurde nach gelelektrophoretischer Auftrennung auf einem Transilluminator unter langwelligem UV-Licht (366 nm) mit einem sterilen Skalpell herausgeschnitten und nach Herstellerangaben isoliert. Die Agarose wurde anschließend nach Zugabe von 3 Vol. QG Puffer 10 min bei $50^{\circ} \mathrm{C}$ irreversibel aufgelöst und die DNA nach dem von Vogelstein und Gillespie (1979) beschriebenen Prinzip in QIAquick Säulen an Anionenaustauschersilikat gebunden, mit $0.75 \mathrm{ml}$ PE Puffer gewaschen und mit EBPuffer eluiert. Ein Aliquot der aufgereinigten DNA wurde zur Konzentrationsbestimmung auf ein Agarosegel aufgetragen. 


\subsubsection{Methoden der Polymerasekettenreaktion (PCR)}

(Saiki et al., 1985)

Mit der Methode der PCR (Polymerase-Kettenreaktion) werden DNA-Templates sequenzspezifisch amplifiziert. Dazu wird die DNA zuerst hitzedenaturiert (Denaturierung), darauf binden die Oligonukleotidprimer in einer Anlagerungsreaktion an den komplementären Strang (Anlagerung), und die Polymerase synthetisiert die DNA zwischen den Primern (Verlängerung). Die meist verwendete Taq DNA Polymerase (Chien et al., 1976) verfügt über einen hitzelabilen Inhibitor, der während der Denaturierung inaktiviert wird und damit die Durchführung einer hot start PCR möglich macht, wodurch die Entstehung unspezifischer Amplifikate während des ersten Zyklus vermieden wird. Es wurden zwei verschiedene Thermocycler verwendet, wobei entweder 0.2 oder $0.5 \mu$ l-Reaktionsgefäße verwendet und bei dem Thermocycler ohne Deckelheizung die Ansätze mit Mineralöl überschichtet wurden.

\subsubsection{PCR an Plasmid-DNA}

Eine PCR an Plasmid-DNA wurde durchgeführt, um Fragmente zu erhalten, die nicht über eine restriktionsenzymatische Spaltung isoliert werden konnten. Dazu wurde folgender Reaktionsansatz hergestellt:

$\begin{array}{rl}\mathrm{x} \mu \mathrm{l} & \text { Template-DNA }(10 \mathrm{ng}) \\ 1 \mu \mathrm{l} & \text { Primer } 1(10 \mathrm{pmol} / \mu \mathrm{l}) \\ 1 \mu \mathrm{l} & \text { Primer 2 }(10 \mathrm{pmol} / \mu \mathrm{l}) \\ 1 \mu \mathrm{l} & 10 \mathrm{mM} \text { dNTPs } \\ 5 \mu \mathrm{l} & \text { Taq-Polymerase Puffer }(10 \mathrm{x}) \\ 1.5 \mu \mathrm{l} & 50 \mathrm{mM} \mathrm{MgCl}_{2} \\ 0.5 \mu \mathrm{l} & \text { Taq-Polymerase }(5 \mathrm{U} / \mu \mathrm{l}) \\ \text { ad } 50 \mu \mathrm{l} & \mathrm{H}_{2} \mathrm{O}\end{array}$


Der Reaktionsansatz wurde folgendem Zyklus 15-35x im Thermocycler unterworfen:

\begin{tabular}{|l|l|l|}
\hline $30 \mathrm{~s}$ & $95^{\circ} \mathrm{C}$ & Denaturierung \\
\hline $30-90 \mathrm{~s}$ & $50-65^{\circ} \mathrm{C}$ & Annealing \\
\hline $30-90 \mathrm{~s}$ & $72^{\circ} \mathrm{C}$ & Elongation \\
\hline
\end{tabular}

Vor Beginn des ersten Zyklus wurde die DNA 5 min bei $95^{\circ} \mathrm{C}$ denaturiert. An den letzten Zyklus schloss sich ein weiterer Verlängerungsschritt von $10 \mathrm{~min}$ bei $72^{\circ} \mathrm{C}$ an. Nach Abschluss der PCR wurde zur Kontrolle 1/10 des Ansatzes mit Stopmix gemischt, je nach Größe des erwarteten PCR-Produkts auf ein 1-1.5\%iges Agarosegel aufgetragen und elektrophoretisch aufgetrennt.

\subsubsection{PCR an genomischer DNA}

Zur Amplifikation spezifischer Sequenzen genomischer DNA wurde diese wie unter 2.2.1.2 beschrieben extrahiert und mit folgenden Substanzen in einem Reaktionsansatz zusammengegeben:

$\begin{array}{rl}\mathrm{x} \mu \mathrm{l} & \text { DNA }(300-500 \mathrm{ng}) \\ 0.5 \mu \mathrm{l} & \text { Primer 1 }(10 \mathrm{pmol} / \mu \mathrm{l}) \\ 0.5 \mu \mathrm{l} & \text { Primer 2 }(10 \mathrm{pmol} / \mu \mathrm{l}) \\ 0.5 \mu \mathrm{l} & \mathrm{dNTPs}(10 \mathrm{mM}) \\ 2.5 \mu \mathrm{l} & \text { Taq-Polymerase Puffer }(10 \mathrm{x}) \\ 0.75 \mu \mathrm{l} & \mathrm{MgCl}_{2}(50 \mathrm{mM}) \\ 0.25 \mu \mathrm{l} & \mathrm{Taq} \text { Polymerase }(5 \mathrm{U} / \mu \mathrm{l}) \\ \operatorname{ad} 25 \mu \mathrm{l} & \mathrm{H}_{2} \mathrm{O}\end{array}$

Für jede Primerkombination wurden die $\mathrm{MgCl}_{2}$ - und dNTP-Mengen optimiert und optional DMSO zu der Reaktion zugegeben. Die Dauer des Verlängerungsschrittes wurde nach der Länge des zu amplifizierenden Fragmentes (1 kb 1 min) und die Anlagerungstemperatur nach dem Schmelzgrad der jeweiligen Primer gewählt. Die PCR begann mit einer initialen Denaturierung für 5 min bei $95^{\circ} \mathrm{C}$, der Zyklus wurde zumeist $35 \mathrm{x}$ wiederholt und nach dem letzten Zyklus ein weiterer Verlängerungsschritt für 10 
min bei $72^{\circ} \mathrm{C}$ durchgeführt. Nach der Amplifikation wurde der gesamte Reaktionsansatz in einem 1\%igen Agarose-Gel aufgetrennt.

\subsection{Analytische PCR an genomischer DNA von knock-out und transgenen Mäusen}

Für die Genotypisierung von transgenen Mäusen wurde folgende Reaktionen angesetzt:

$\mathbf{I}_{2} \mathbf{I}_{3}-\mathbf{0}$ und $\mathbf{I}_{2} \mathbf{I}_{3}-1$ Mäuse:

\begin{tabular}{ll}
$1 \mu \mathrm{l}$ & DNA $(300-500 \mathrm{ng})$ \\
$1 \mu \mathrm{l}$ & HinsR3 $(10 \mathrm{pmol} / \mu \mathrm{l})$ \\
$1 \mu \mathrm{l}$ & Lyk2 $(10 \mathrm{pmol} / \mu \mathrm{l})$ \\
$1 \mu \mathrm{l}$ & dNTPs $(10 \mathrm{mM})$ \\
$5 \mu \mathrm{l}$ & Taq Polymerase buffer $(10 \mathrm{x})$ \\
$5 \mu \mathrm{l}$ & DMSO \\
$1 \mu \mathrm{l}$ & $\mathrm{MgCl}_{2}$ \\
$0.5 \mu \mathrm{l}$ & Taq Polymerase $(5 \mathrm{U} / \mu \mathrm{l}, \text { Finnzym })_{35 \mathrm{l}}$ \\
\hline $\mathrm{H}_{2} \mathrm{O}$
\end{tabular}

$\mathbf{I}_{2} \mathbf{I}_{3}$-2 Mäuse:

$\begin{array}{ll}1 \mu \mathrm{l} & \text { DNA }(300-500 \mathrm{ng}) \\ 1 \mu \mathrm{l} & \text { HinsR5 }(10 \mathrm{pmol} / \mu \mathrm{l}) \\ 1 \mu \mathrm{l} & \text { Lyk2 }(10 \mathrm{pmol} / \mu \mathrm{l}) \\ 1 \mu \mathrm{l} & \text { dNTPs }(10 \mathrm{mM}) \\ 5 \mu \mathrm{l} & \text { Taq Polymerase buffer }(10 \mathrm{x}) \\ 5 \mu \mathrm{l} & \text { DMSO } \\ 1 \mu \mathrm{l} & \mathrm{MgCl}_{2} \\ 0.5 \mu \mathrm{l} & \text { Taq Polymerase }(5 \mathrm{U} / \mu \mathrm{l}, \text { Finnzym }) \\ 34.5 \mu \mathrm{l} & \mathrm{H}_{2} \mathrm{O}\end{array}$


Für die Genotypisierung von knock out-Mäusen wurde ein zusätzliches Primerpaar eingesetzt, so dass ein Wildtyp- und ein mutiertes Allel unterschiedlicher Länge amplifiziert werden konnten. Dazu wurde folgender Reaktionsansatz zusammen gegeben:

Pax4 Mäuse:

\begin{tabular}{|c|c|}
\hline $1 \mu l$ & DNA (300-500 ng) \\
\hline $0.5 \mu 1$ & Pax4 F (10 pmol/ $/ \mu \mathrm{l})$ \\
\hline $0.5 \mu 1$ & Pax4 R (10 pmol/ $/ \mu \mathrm{l})$ \\
\hline $0.5 \mu 1$ & LacZ F (10 pmol/ $/ \mu \mathrm{l})$ \\
\hline $0.5 \mu 1$ & LacZ R (10 pmol/ $\mu \mathrm{l})$ \\
\hline $0.2 \mu 1$ & dNTPs (10 mM) \\
\hline $2.5 \mu 1$ & Taq Polymerase buffer (10x) \\
\hline $0.5 \mu 1$ & Taq Polymerase (5 U/ $\mu 1$, Finnzym) \\
\hline ad $25 \mu 1$ & $\mathrm{H}_{2} \mathrm{O}$ \\
\hline
\end{tabular}

Insl5-Mäuse:

\begin{tabular}{|c|c|}
\hline $0.5 \mu 1$ & DNA (300-500 ng) \\
\hline $0.5 \mu 1$ & C-Insl5F8 (10 pmol/ $/ \mu \mathrm{l})$ \\
\hline $0.5 \mu 1$ & C-Insl5R9 (10 pmol/ $\mu \mathrm{l})$ \\
\hline $0.5 \mu 1$ & 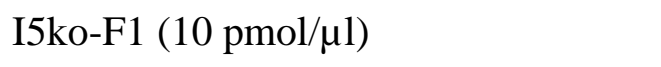 \\
\hline $0.5 \mu 1$ & Pgk3 (10 pmol/ $/ \mu \mathrm{l})$ \\
\hline $0.5 \mu 1$ & dNTPs $(10 \mathrm{mM})$ \\
\hline $2.5 \mu 1$ & Taq Polymerase buffer (10x) \\
\hline $0.75 \mu 1$ & $\mathrm{MgCl}_{2}(50 \mathrm{mM})$ \\
\hline $0.25 \mu 1$ & PLATINUM Taq Polymerase (5 U/ $\mu \mathrm{l})$ \\
\hline ad $25 \mu 1$ & $\mathrm{H}_{2} \mathrm{O}$ \\
\hline
\end{tabular}

Die DNA wurde über 35 Zyklen nach folgendem Programm in Thermocycler amplifiziert:

$\mathbf{I}_{2} \mathbf{I}_{3}-\mathbf{0}$ und $\mathbf{I}_{2} \mathbf{I}_{3}-1$ Mäuse:

\begin{tabular}{|l|l|l|}
\hline $30 \mathrm{~s}$ & $94^{\circ} \mathrm{C}$ & Denaturierung \\
\hline $30 \mathrm{~s}$ & $54^{\circ} \mathrm{C}$ & Annealing \\
\hline $45 \mathrm{~s}$ & $72^{\circ} \mathrm{C}$ & Elongation \\
\hline
\end{tabular}




\section{$\mathbf{I}_{2} \mathbf{I}_{3}-2$ Mäuse:}

\begin{tabular}{|l|l|l|}
\hline $30 \mathrm{~s}$ & $94^{\circ} \mathrm{C}$ & Denaturierung \\
\hline $45 \mathrm{~s}$ & $58^{\circ} \mathrm{C}$ & Annealing \\
\hline $1 \mathrm{~min}$ & $72^{\circ} \mathrm{C}$ & Elongation \\
\hline
\end{tabular}

Pax4 Mäuse:

\begin{tabular}{|l|l|l|}
\hline $1 \mathrm{~min}$ & $94^{\circ} \mathrm{C}$ & Denaturierung \\
\hline $1 \mathrm{~min}$ & $60^{\circ} \mathrm{C}$ & Annealing \\
\hline $2 \min$ & $72^{\circ} \mathrm{C}$ & Elongation \\
\hline
\end{tabular}

Insl5-Mäuse:

\begin{tabular}{|l|l|l|}
\hline $30 \mathrm{~s}$ & $94^{\circ} \mathrm{C}$ & Denaturierung \\
\hline $30 \mathrm{~s}$ & $58^{\circ} \mathrm{C}$ & Annealing \\
\hline $45 \mathrm{~s}$ & $72^{\circ} \mathrm{C}$ & Elongation \\
\hline
\end{tabular}

Vor Beginn des ersten Zyklus erfolgte eine initiale Denaturierung für 5 min bei $94^{\circ} \mathrm{C}$, an den letzten Zyklus schloss sich ein weiterer Verlängerungsschritt von 10 min bei $72^{\circ} \mathrm{C}$ an. Nach der Amplifikation wurde der gesamte Reaktionsansatz in einem 1.5\%igen Agarose-Gel aufgetrennt.

\subsubsection{Genotypisierung mittels quantitativer Real-Time-PCR}

Die Unterscheidung zwischen hemi- und homozygotem Zustand bei transgenen Mäusen wurde durch die Quantifizierung des Testamplikons relativ zu einem Referenzamplikon mittels quantitativer Real-Time-PCR ermöglicht. Die Vorgehensweise entsprach weitestgehend dem von Boehm et al. (2004) beschriebenen Verfahren zur Bestimmung subtelomerer Deletionen bzw. Duplikationen.

Real-Time quantitative PCR bezeichnet ein PCR-Verfahren, bei dem während der Reaktion die Menge der entstandenen Produkte in Echtzeit gemessen wird. Die Messung der Produktzunahme geschieht anhand von Fluoreszenzlicht, welches in 
Abhängigkeit von der Produktmenge emittiert wird. Eine Möglichkeit zur Generierung produktabhängiger Fluoreszenz bieten dsDNA-bindende Fluoreszenzfarbstoffe. In dieser Arbeit wurde der Cyaninfarbstoff SYBR-Green I (Jin et al., 1994; Singer et al., 1994), welcher als „QuantiTect ${ }^{\mathrm{TM}} \mathrm{SYBR}^{\circledR}$-Green PCR Master Mix“ von der Firma Qiagen vertrieben wird, verwendet. Der Farbstoff bindet weitgehend sequenzunspezifisch in der kleinen Furche doppelsträngiger DNA, mit einer etwa 100fach höheren Affinität als Ethidiumbromid. Das derart gebundene SYBR-Green fluoresziert nach Anregung etwa 1000fach stärker als der freie Farbstoff, weshalb SYBR-Green sehr gut geeignet ist, die Akkumulation doppelsträngiger PCR-Produkte sichtbar zu machen (Morrison et al., 1998). SYBR-Green lässt sich in Gegenwart von doppelsträngiger DNA mit Blaulicht $(480 \mathrm{~nm})$ anregen und zeigt ein Emissionsspektrum mit einem Maximum bei $520 \mathrm{~nm}$ (Abb. 2.1).
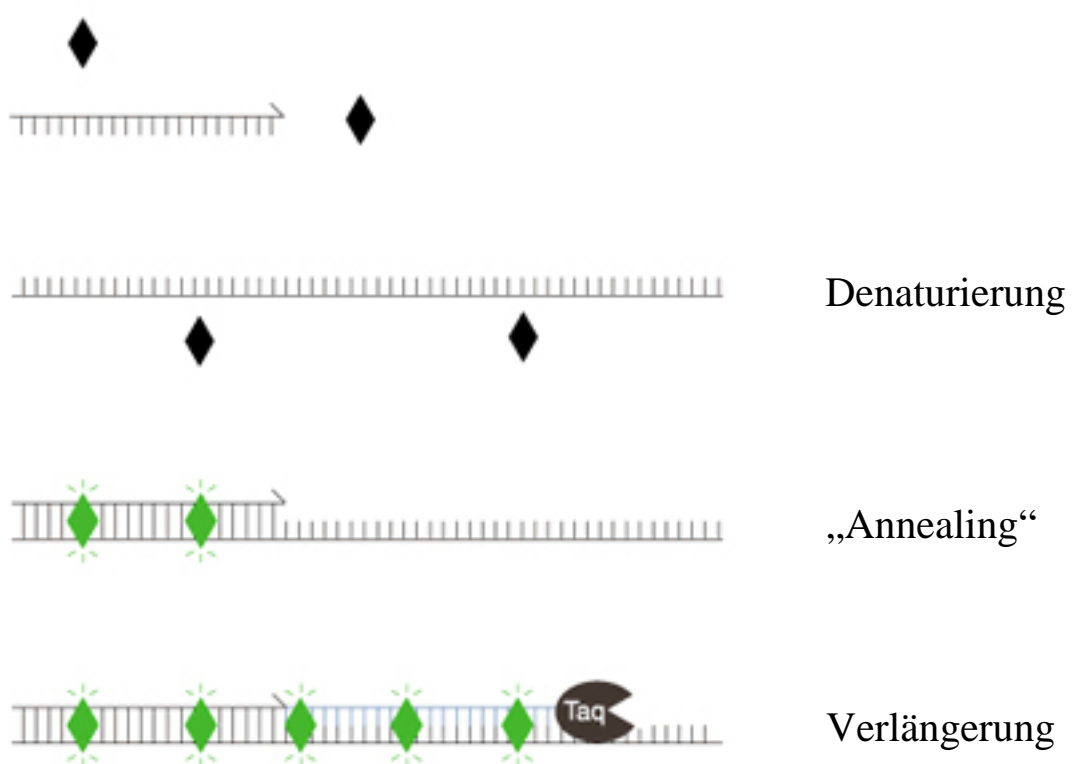

Abb. 2.1: Bindung von SYBR-Green an dsDNA. Der SYBR-Green-Fluoreszenzfarbstoff bindet interkalierend an doppelsträngige DNA und emittiert daraufhin ein Fluoreszenzsignal (Qiagen).

Die Analyse wurde in weißen 384-Well-Platten mit dem „ABI Prism 7900T Sequence Detection System“ durchgeführt. Dieses System arbeitet mit einem Temperatur-Cycler und einem Laser, der zu jedem der 384 Reaktionsansätze gelenkt wird und diese anregt. Über ein ladungsempfindliches Detektionssystem erfolgt die Messung der Fluoreszenz jeder Probe, die durch an die dsDNA gebundenes SYBR-Green emittiert wird. Die Daten wurden mit Hilfe der Sequenz-Detektionssystem-Software (SDS Version 2.1, PE 
Applied Biosystems) quantifiziert, exportiert und in Excel (Microsoft) grafisch ausgewertet.

Die Reaktionsansätze enthielten je 25 pmol der Oligonukleotide und $5 \mu \mathrm{l}$ 2x QuantiTect $^{\mathrm{TM}} \mathrm{SYBR}^{\circledR}$-Green PCR Master Mix. Letzterer enthält die $\operatorname{HotStarTaq}^{\mathrm{TM}}$ DNA-Polymerase in einem optimierten Puffer, dNTP-Mix (mit dUTP-Additiv), den SYBR $^{\circledR}$-Green I Fluoreszenz-Farbstoff und ROX Farbstoff als passive Referenz. Jedem Ansatz wurden schließlich entweder Verdünnungen der Kontroll-DNA eines hemizygoten transgenen $\mathrm{F}_{1}$-Tieres der jeweiligen Linie in einer Endkonzentration von $20.0 \mathrm{ng} / \mu \mathrm{l}, 10.0 \mathrm{ng} / \mu \mathrm{l}, 5.0 \mathrm{ng} / \mu \mathrm{l}, 2.5 \mathrm{ng} / \mu \mathrm{l}, 1.25 \mathrm{ng} / \mu \mathrm{l}$ und $0.625 \mathrm{ng} / \mu \mathrm{l}$, DNA eines definitiv hemizygoten Tieres und Proben-DNA von Mäusen der entsprechenden Linie in einer Endkonzentration $5 \mathrm{ng} / \mu \mathrm{l}$ zugegeben. Alle Primer wurden unter identischen Bedingungen amplifiziert.

Um das Auftreten von unspezifischen Produkten auszuschließen, wurde nach Abschluss der Amplifikation routinemäßig eine Schmelzkurvenanalyse durchgeführt. Dabei wurde kontinuierlich die Fluoreszenz $(\mathrm{F})$ bei steigender Temperatur $(\mathrm{T})$ gemessen und die Steigung dF/dT (1. Ableitung) errechnet. Diese wurde gegen die Temperatur aufgetragen und damit die Maxima bei den primerspezifischen Schmelztemperaturen aufgezeigt. Zusätzliche Maxima verrieten unspezifische Produkte wie z.B. PrimerDimere.

Folgendes Programm wurde für alle Primer verwendet:

\begin{tabular}{|c|c|c|c|}
\hline $50^{\circ} \mathrm{C}$ & $2 \min$ & & \\
\hline $95^{\circ} \mathrm{C}$ & $15 \mathrm{~min}$ & & Vordenaturierung \\
\hline $94^{\circ} \mathrm{C}$ & $15 \mathrm{~s}$ & & Denaturierung \\
\hline $60^{\circ} \mathrm{C}$ & $30 \mathrm{~s}$ & 40 Zyklen & Annealing \\
\hline $72^{\circ} \mathrm{C}$ & $1 \mathrm{~min}$ & & Elongation \\
\hline $94^{\circ} \mathrm{C}$ & $15 \mathrm{~s}$ & & \\
\hline $60^{\circ} \mathrm{C}$ & $15 \mathrm{~s}$ & & Schmelzkurve \\
\hline $95^{\circ} \mathrm{C}$ & $15 \mathrm{~s}$ & & \\
\hline
\end{tabular}

Die relative Quantifizierung der initialen Kopienzahl erfolgt bei der Real-Time-PCR anhand des Verhältnisses der Kopienzahl des zu untersuchenden Amplikons und zweier Referenzamplikons, die unter identischen Bedingungen amplifiziert werden. Bei der Auswertung wird ein Signal-Schwellenwert definiert, bei welchem sich jede Einzelreaktion in der exponentiellen Phase befindet. Der Zeitpunkt (in Zyklen), zu dem 
das Signal diesen Schwellenwert erreicht, wird als Schwellenwertzyklus oder $\mathrm{C}_{\mathrm{T}}$-Wert bezeichnet. Dieser $\mathrm{C}_{\mathrm{T}}$-Wert korreliert mit der Anzahl der Kopien, die für die Reaktion eingesetzt wurden. Wie in Abb. 2.2 gezeigt, resultiert eine höhere oder niedrigere Anfangskopienzahl in einem signifikant früheren oder späteren Anstieg der Fluoreszenz-Emission.

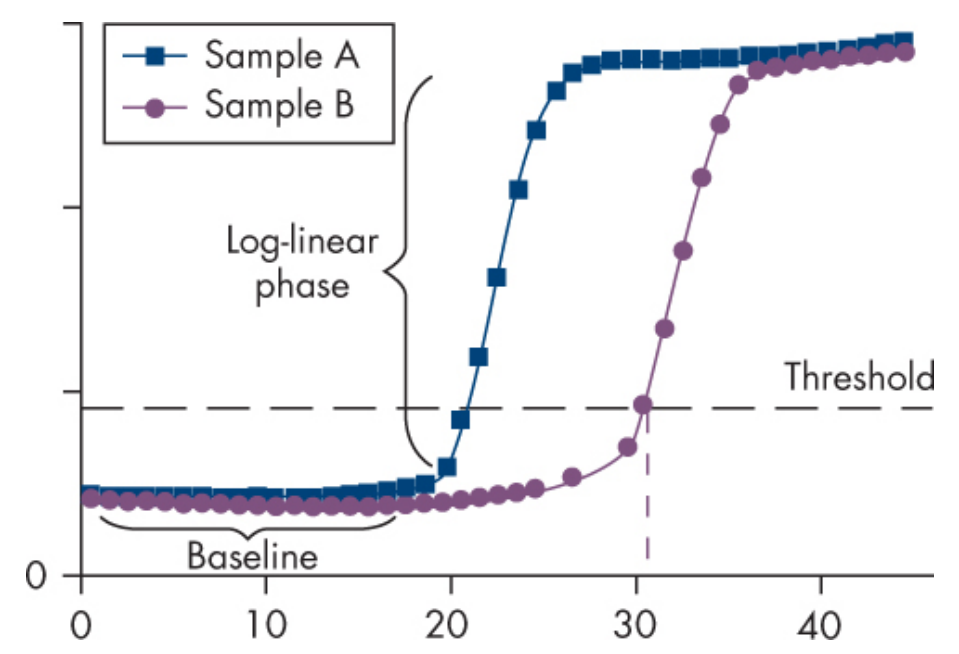

Abb. 2.2: Amplifikationsgraf: Anstieg der Fluoreszenz zweier Proben (A und B). Probe A enthält eine höhere Ausgangsmenge der Matrize als Probe B. Die Amplifikationskurve schneidet den Schwellenwert beim Schwellenwertzyklus (Qiagen).

Die gewonnen Daten wurden in Excel importiert und gegen das homozygote ReferenzAmplikon durch Berechnung des Verhältnisses $\mathrm{c}_{\mathrm{T}-\text { Testamplikon }} / \mathrm{c}_{\mathrm{T}-\text { Referenzamplikon }}$ normalisiert. Dadurch werden die Menge und die Qualität genomischer DNA für jede Probe normalisiert (Boehm et al., 2004).

Das Verhältnis $\mathrm{c}_{\text {Testamplikon }} / \mathrm{c}_{\text {Referenzamplikon }}$ der hemizygoten transgenen Kontrolltiere wurde einem Wert zugeordnet, welcher abhängig von der Anzahl der integrierten Kopien des $\mathrm{zu}$ untersuchenden Konstrukts $\left(\mathrm{I}_{2} \mathrm{I}_{3}\right)$ ist. Bei hemizygoten Tieren von transgenen Linien mit nur einer Integrationsstelle (2.2.7.4) für das $\mathrm{I}_{2} \mathrm{I}_{3}$-Konstrukt entspricht das Verhältnis $\mathrm{c}_{\text {Testamplikon }} / \mathrm{c}_{\text {Referenzamplikon }}$ diesem Wert, bei homozygoten Tieren ist er um das Doppelte erhöht. 


\subsubsection{Integrationszahlbestimmung des $\mathbf{I}_{2} \mathbf{I}_{3}$-Konstrukts mittels quantitativer Real-Time-PCR}

Die Taqman-Assays zur Bestimmung der Anzahl der Integrationen des $\mathrm{I}_{2} \mathrm{I}_{3}-1$ Konstrukts wurde ähnlich denen in 2.2.7.3 beschriebenen Genotypisierungsassays arrangiert.

Das Verhältnis $\mathrm{c}_{\text {Testamplikon }} / \mathrm{c}_{\text {Referenzamplikon }}$ entspricht bei transgenen $\mathrm{F}_{1}$-Tieren von Linien mit nur einer Integrationsstelle für das entsprechende Konstrukt einem bestimmten Wert $\mathrm{x}$, welcher bei korrekt eingestellten Standardkurven bei 1 liegen sollte. Wenn aber die $\mathrm{F}_{1}$-Tiere bezüglich dieses Wertes $\mathrm{x}$ signifikant differieren, deutet dies auf Segregation von mehreren Integrationen des Konstrukts im Genom des Founder-Tieres $\left(\mathrm{F}_{0}\right)$ hin.

\subsubsection{Kopienzahlbestimmung des $\quad \mathbf{I}_{2} \mathbf{I}_{3}$-Konstrukts mittels quantitativer Real-Time-PCR}

Als Standard-DNA für die Referenz-Amplifikation wurde wie in 2.2.7.3 beschrieben genomische DNA verwendet. Als Standard für die Testamplifikation wurde PlasmidDNA des $\mathrm{I}_{2} \mathrm{I}_{3}$-Konstrukts herangezogen. Ansonsten entsprach der Versuchsaufbau den in 2.2.7.3 beschriebenen Genotypisierungs-Assays.

\subsubsection{6 "Reverse Transkriptions PCR“ (RT-PCR)}

(Loh et al., 1989)

Die Methode der reversen PCR basiert auf der Umschreibung von mRNA in cDNA (Synthese der komplementären DNA) und einer sich anschließenden PCR. Mit Hilfe der RT-PCR können kleinste Transkriptmengen in Geweben detektiert werden. Man nutzt in diesem Verfahren die Eigenschaften der reversen Transkriptase, einer aus RNAViren stammenden DNA-Polymerase, die einzelsträngige mRNA als Matrize verwendet und von dieser eine DNA-Kopie herstellt. Diese cDNA dient als Matrize in der darauffolgenden PCR-Reaktion.

Die Intaktheit und die Integrität der verwendeten RNA wurden über eine Kontroll-RTPCR mit einem Primerpaar eines ubiquitär exprimierten Gens (GAPDH=Glycerinaldehyd-3-Phosphat-Dehydrogensase) amplifiziert und dokumentiert 
(Seipp und Buselmaier, 1994). Es wurden $5 \mu \mathrm{g}$ Gesamt-RNA mit 2 pmol genspezifischem Primer und 2 pmol des reversen GAPDH-Primers $\left(\mathrm{GAPDH}_{\mathrm{rev}}\right)$ in einem Ansatzvolumen von $12 \mu \mathrm{l}$ für $10 \mathrm{~min}$ bei $70{ }^{\circ} \mathrm{C}$ denaturiert und 5 min auf Eis gekühlt. Zu diesem Ansatz wurden folgende Komponenten aus dem SUPERSCRIPT ${ }^{\mathrm{TM}}$ II-System gegeben und anschließend 2 min bei $42^{\circ} \mathrm{C}$ vorinkubiert:

$\begin{array}{ll}12 \mu \mathrm{l} & \text { Ansatz (RNA und Primer) } \\ 4 \mu \mathrm{l} & \text { 5x Reverse Transkriptase-Puffer } \\ 2 \mu \mathrm{l} & \text { DTT }(0.1 \mathrm{M}) \\ 1 \mu \mathrm{l} & \text { dNTP-Mix (je } 10 \mathrm{mM}) \\ 1 \mu \mathrm{l} & \text { RNase Inhibitor }(10 \mathrm{U} / \mu \mathrm{l})\end{array}$

Nach der Vorinkubation wurde der Ansatz mit $1 \mu \mathrm{l}$ Reverse Transcriptase (Superscript ${ }^{\mathrm{TM}}$-II, $200 \mathrm{U}$ ) für $50 \mathrm{~min}$ bei $42^{\circ} \mathrm{C}$ für die Erststrangsynthese inkubiert, und anschließend wurde die Reaktion für 15 min bei $70^{\circ} \mathrm{C}$ Hitze inaktiviert. $1 \mu \mathrm{l}$ der cDNA konnte direkt als Template in die PCR-Reaktion eingesetzt werden oder wurde bei $20^{\circ} \mathrm{C}$ eingefroren.

\subsubsection{One Step RT-PCR}

Im Gegensatz zur "two-step" RT-PCR (2.2.7.6) beinhaltet der "one-step" RT-PCRAnsatz bereits alle Bestandteile für die reverse in vitro-Transkription der mRNA in cDNA sowie deren anschließender Amplifikation. Die "one-step" RT-PCR wurde mit dem QIAGEN ${ }^{\circledR}$ OneStep RT-PCR Kit durchgeführt:

$\begin{array}{ll}1 \mu \mathrm{g} & \text { Gesamt RNA } \\ 5 \mu \mathrm{l} & \text { 5x Qiagen OneStep RT-PCR Puffer } \\ 1 \mu \mathrm{l} & \text { Qiagen dNTP-Mix }(10 \mathrm{mM}) \\ 1 \mu \mathrm{l} & \text { Primer } 1(10 \mathrm{pmol} / \mu \mathrm{l}) \\ 1 \mu \mathrm{l} & \text { Primer } 2(10 \mathrm{pmol} / \mu \mathrm{l}) \\ 1 \mu \mathrm{l} & \text { Qiagen OneStep RT-PCR Enzym Mix } \\ \operatorname{ad} 25 \mu \mathrm{l} & \text { RNase freie } \mathrm{dH}_{2} \mathrm{O}\end{array}$


Die RT-PCR wurde mit der reversen Transkription bei $50^{\circ} \mathrm{C}$ für 30 min gestartet. Es folgte die Aktivierung der Polymerase bei $95^{\circ} \mathrm{C}$ für 15 min. Für den Ablauf der Polymerase-Kettenreaktion wurden 35 Zyklen nach folgendem Programm durchgeführt:

\begin{tabular}{|l|l|l|}
\hline $30-60 \mathrm{~s}$ & $95^{\circ} \mathrm{C}$ & Denaturierung \\
\hline $30-90 \mathrm{~s}$ & $50-65^{\circ} \mathrm{C}$ & Annealing \\
\hline $30-90 \mathrm{~s}$ & $72^{\circ} \mathrm{C}$ & Elongation \\
\hline
\end{tabular}

Um die Vervollständigung aller Fragmente zu gewährleisten, wurde der letzte Schritt auf 10 min bei $72^{\circ} \mathrm{C}$ verlängert.

Die Anzahl der Zyklen, die gewählten Temperaturen und die Dauer der einzelnen Zyklusschritte mussten für jedes cDNA-Fragment und die dafür eingesetzten Primer neu etabliert werden.

\subsubsection{Sequenzierung}

(Sanger et al., 1977)

Die nicht-radioaktive Sequenzierung wurde modifiziert nach dem Kettenabbruchverfahren nach Sanger et al. (1977) durchgeführt. Wie bei einer PCR binden sequenzspezifische Primer an die denaturierte DNA, so dass mit Hilfe einer hitzestabilen DNA-Polymerase ein komplementärer Strang generiert werden kann. Im Unterschied zur PCR werden jedoch nicht nur dNTPs verwendet, sondern auch vier unterschiedliche ddNTPs, die mit jeweils unterschiedlichen Fluoreszenzfarbstoffen markiert sind. Werden diese ddNTPs eingebaut, kommt es zu einem Abbruch der Strangsynthese. Dies führt per Zufall zu unterschiedlich großen DNA-Fragmenten. Nach einer elektrophoretischen Auftrennung können durch Fluorografie die Positionen des Kettenabbruchs sichtbar gemacht werden, woraus auf die Sequenz geschlossen werden kann.

Um eine Sequenzanalyse durchzuführen, wurden 200-500 ng eines aufgereinigten PCRProdukts, 10 pmol Primer und $4 \mu$ DYEnamic ${ }^{\mathrm{TM}}$ ET terminator cycle sequencing Ready 
Reaction Mix (ddNTPs, Didesoxy-Farbterminatoren und Taq-DNA-Polymerase) mit Ampuwa auf ein Reaktionsvolumen von $10 \mu$ verdünnt:

$\begin{array}{ll}\mathrm{x} \mu \mathrm{l} & \text { DNA (200-500 ng) } \\ 1 \mu \mathrm{l} & \text { Primer (10 pmol/ } \mu \mathrm{l}) \\ 4 \mu \mathrm{l} & \text { DYEnamic ET-Mix } \\ \text { ad } 10 \mu \mathrm{l} & \mathrm{H}_{2} \mathrm{O}\end{array}$

Nach 5-minütiger Aktivierung der Polymerase bei $95^{\circ} \mathrm{C}$ in einem Thermocycler folgte die Kettenabbruchreaktion mit 25 Zyklen nach folgendem Programm:

\begin{tabular}{|l|l|l|}
\hline $95^{\circ} \mathrm{C}$ & $30 \mathrm{~s}$ & Denaturierung \\
\hline $55^{\circ} \mathrm{C}$ & $20 \mathrm{~s}$ & Annealing \\
\hline $60^{\circ} \mathrm{C}$ & $1 \mathrm{~min}$ & Elongation \\
\hline
\end{tabular}

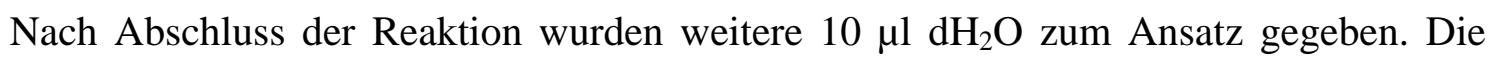
DNA-Fragmente wurden auf einer Sephadex-Säule aufgereinigt und über den automatischen Sequenzierer Modell MegaBace1000 ausgewertet. Die Analyse erfolgte über den Vergleich mit der Referenzsequenz (www.ncbi.nlm.nih.gov).

\subsubsection{Protein- und biochemische Methoden}

\subsubsection{Gesamtproteinisolierung aus Geweben}

Gesamtprotein aus Geweben wurde zum immunologischen Nachweis nach SDS-PAGEGelelektrophorese und Transfer der Proteine auf Nitrocellulose isoliert. Die Gewebe wurden in Proteinlysis Puffer (150 mM NaCl, 10 mM EDTA, 50 mM Tris/HCl, pH 7.6, $1 \%$ Triton X-100 und 1\% Natriumdeoxycholate) mit Protease-Inhibitoren $(1 \mu \mathrm{g} / \mu 1$ Leupeptin, $3 \mu \mathrm{g} / \mu \mathrm{l}$ Aprotinin) homogenisiert und sonifiziert. Nach 5 min Inkubation auf Eis wurden die Zellextrakte 20 min bei $4^{\circ} \mathrm{C}$ und 12000x g zentrifugiert. Der Überstand wurde aliquotiert und bei $-80^{\circ} \mathrm{C}$ gelagert. 


\subsubsection{Isolierung von Proteinen für Radio-Immunoassays (RIA)}

Frisch präparierte Organe $(0.1-0.3 \mathrm{~g})$ wurden auf Eis in PBS gewaschen, in $2 \mathrm{ml}$ Proteinextraktionslösung aufgenommen, in einem Falcon ${ }^{\circledR}$ Zentrifugationsröhrchen homogenisiert und anschließend bei $4^{\circ} \mathrm{C}$ auf einem Schüttler (Ika ${ }^{\odot}$ Vibrax VX2 basic) inkubiert. Nach der Inkubation wurden Zellbestandteile durch vorsichtige Zentrifugation $\left(30 \mathrm{~min}, 400 \mathrm{x} \mathrm{g}, 4^{\circ} \mathrm{C}\right.$ ) sedimentiert. Der Überstand wurde in neue Reaktionsgefäße überführt, mit $\mathrm{NaOH}$ neutralisiert (155 $\mu \mathrm{l} \mathrm{NaOH}$ pro $1 \mathrm{ml}$ Lösung) und bei $-80^{\circ} \mathrm{C}$ aufbewahrt.

\subsubsection{Bestimmung der Proteinkonzentration}

(Bradford, 1976)

Die Konzentrationsbestimmung von Proteinen in wässriger Lösung wurde nach Bradford (1976) durchgeführt. Das Absorptionsmaximum von Coomassie Brilliant Blau G-250 verschiebt sich durch Proteinbindung von $465 \mathrm{~nm} \mathrm{zu} 595 \mathrm{~nm}$, so dass die Absorption bei $595 \mathrm{~nm}$ mit der Proteinkonzentration steigt. Durch Mitführen einer BSA-Eichreihe als internen Standard kann die Proteinkonzentration aus der Eichgeraden extrapoliert werden $(0-6.7 \mu \mathrm{g}$ BSA/ml). Dazu wurden gemäß Protokoll 2 Vol. Bradfordreagenz Roti ${ }^{\circledR}$-Quant mit 5.5 Vol. $\mathrm{dH}_{2} \mathrm{O}$ verdünnt und je $200 \mu \mathrm{l}$ des Ansatzes mit je $50 \mu 1$ der zu messenden Probe 5 min inkubiert. Anschließend wurde die Absorption bei $595 \mathrm{~nm}$ im Mikrotiterplattenphotometer (Microplate Reader 450) gemessen und daraus die Proteinkonzentration ermittelt. 


\subsubsection{Transfertechniken}

\subsubsection{Transfer von DNA-Fragmenten: Southern-Blotting}

(Southern, 1975)

Mit Hilfe des Southern-Transfers werden DNA-Fragmente aus Agarosegelen auf Nitrocellulosemembranen übertragen. Um die DNA unter dem UV-Licht sichtbar zu machen, wurde das Gel nach der Elektrophorese zuerst für 10 min in $500 \mathrm{ml}$ Laufpuffer mit $50 \mu 1$ Ethidiumbromid gefärbt. Danach wurde es in $500 \mathrm{ml} 0.25 \mathrm{M} \mathrm{HCl}$ depuriniert, für $30 \mathrm{~min}$ in Denaturierungslösung überführt und dann für $45 \mathrm{~min}$ in Neutralisierungslösung behandelt. Die so behandelte einzelsträngige DNA wurde durch ein modifiziertes Kapillarblotting-Verfahren mit einem Turbo Blotter ${ }^{\mathrm{TM}}$ der Firma Schleicher \& Schüll auf eine Hybond C-Nitrozellulose Membran mit nukleinsäurebindenden Eigenschaften übertragen und durch zweistündige Inkubation bei $80^{\circ} \mathrm{C}$ oder durch „Crosslinken“ mit UV-Licht (UV Stratalinker ${ }^{\mathrm{TM}} 1800,254 \mathrm{~nm}, 120$ mJ) auf dem Filter fixiert. Der Southern-Blot wurde den Herstellerangaben folgend mit 20x SSC als Transferpuffer durchgeführt und erfolgte standardmäßig bei RT üN. Nach dem Transfer wurde der Filter kurz in 2x SSC-Puffer gespült, getrocknet und durch „Crosslinken“ oder Inkubation für $2 \mathrm{~h}$ bei $80^{\circ} \mathrm{C}$ kovalent auf dem Filter fixiert.

\subsubsection{Transfer von RNA aus Agarosegelen: Northern-Blotting}

Als "Northern-Blotting" wird die Übertragung von RNA auf nukleinsäurebindende Membranen bezeichnet. Die Technik ist der des „Southern-Blottings" äquivalent und wurde wie unter 2.2.10.1 beschrieben bei $4^{\circ} \mathrm{C}$ im Kühlraum durchgeführt. Zur Auflösung von Sekundärstrukturen wurde die Elektrophorese in einem denaturierenden Gel durchgeführt. Nach dem Lauf konnte das Gel daher direkt zum Transfer verwendet werden. Nach dem Transfer der RNA aus dem Gel auf den Nitrozellulosefilter wurde der Filter kurz in 2x SSC gewaschen, getrocknet und die RNA wie unter 2.2.10.1 beschrieben fixiert. Die Spur mit dem RNA-Längenstandard wurde vom Filter abgetrennt, die RNA 15 min mit 5\%iger Essigsäure fixiert, für 10 min mit 0.04\%iger 
Methylenblau-Lösung in $0.5 \mathrm{M} \mathrm{NaAc}, \mathrm{pH}$ 5.2, angefärbt und überschüssige Färbelösung unter fließendem Wasser abgespült.

\subsubsection{Radioaktive Markierung von DNA („random prime labelling“)}

(Feinberg und Vogelstein, 1983)

Für Hybridisierungsexperimente wurden DNA-Fragmente durch die ,random prime labelling"-Methode radioaktiv markiert (Feinberg und Vogelstein, 1983). Für die Markierungsreaktion wurde das „Ready prime ${ }^{\mathrm{TM}}$ II-random prime labelling“-System zum Einbau von $\left[\alpha^{-32} \mathrm{P}\right]$ dCTP verwendet. Pro Reaktion wurden 2.5-25 ng DNA in 46 $\mu 1$ TE-Puffer denaturiert, abgekühlt in das Reaktionsgefäß mit dem Ready prime-Pellet (dATP, dGTP, dTTP, Klenow Fragment 4-8 U) gegeben und nach Zugabe von $40 \mu \mathrm{Ci}$ $\left[\alpha-{ }^{32} \mathrm{P}\right] \mathrm{dCTP} 1 \mathrm{~h}$ bei $37^{\circ} \mathrm{C}$ inkubiert. Der Ansatz wurde nach der Inkubation auf eine MicroSpin-Säule (Amersham Pharmacia) aufgetragen und von nicht eingebauten Nukleotiden (dNTPs und $\left[\alpha^{32} \mathrm{P}\right] \mathrm{dCTP}$ ) aufgereinigt. Danach konnte die markierte Probe bei $4^{\circ} \mathrm{C}$ bis zur Verwendung gelagert oder sofort für $10 \mathrm{~min}$ bei $95^{\circ} \mathrm{C}$ denaturiert und verwendet werden.

\subsubsection{Hybridisierungsmethoden}

\subsubsection{Radioaktive Hybridisierungstechniken}

\subsection{Hybridisierung von Southern- und Northern-Blots}

(Denhardt, 1966)

Die Nitrozellulosefilter mit der gebundenen DNA bzw. RNA wurden für 10 min in $2 x$ SSC-Lösung eingeweicht. Nach Füllung der Hybridisierungstubes mit 2x SSC-Lösung und Entfernung entstandener Luftblasen legte sich die Membran beim Abgießen der 2x SSC-Lösung an die Tubewand an. Die Filter wurden mit $10 \mathrm{ml}$ Rapid-hyp Puffer (Amersham) bzw. Hybridisierungspuffer (KPL) und $200 \mu 1$ Lachsspermien-DNA (10 $\mathrm{mg} / \mathrm{ml}$, geschert durch Ultraschall) für mindestens $2 \mathrm{~h}$ bei $65^{\circ} \mathrm{C}$ im Rollerofen 
(Bachofer, Reutlingen) vorhybridisiert. Hiermit sollten unspezifische Bindungsstellen an den Filtern abgesättigt werden. Die radioaktiv markierte DNA-Probe wurde 10 min bei $95^{\circ} \mathrm{C}$ denaturiert, auf Eis abgekühlt und direkt zu der Vorhybridisierungslösung gegeben. Die Hybridisierung erfolgte üN bei den vorbezeichneten Temperaturen im Rollerofen. Nach Beendigung der Hybridisierung wurden die Filter 10 min mit 2x SSC bei RT und anschließend je nach gewünschter Stringenz bei $65^{\circ} \mathrm{C}$ gewaschen. Für eine geringe Stringenz wurde 2x mit Waschlösung I für 10 min und kurz mit Waschlösung II gewaschen, für eine höhere Stringenz wurde zusätzlich 2x 10 min mit Waschlösung II gewaschen. Die Filter wurden luftgetrocknet, in Folie eingeschweißt und in einer Röntgenfilmkassette befestigt. Darauf wurde ein Röntgenfilm (Hyperfilm ${ }^{\mathrm{TM}}-\mathrm{MP}$ ) gelegt, dieser für wenige Minuten bis zu mehreren Tagen bei $-80^{\circ} \mathrm{C}$ exponiert und dann im Entwicklungsgerät entwickelt. Alternativ wurde der Blot mit dem Phosphor-ImagerSystem nach 1-4 h ausgewertet.

\subsection{Hybridisierung der genomischen Cosmid-Bibliothek 129/Ola und PACs-Macroarrays}

Die Hybridisierung der Macroarrays erfolgte nach den von der RZPD empfohlenen Bedingungen. Die Filter wurden im Wasserbad bei $65^{\circ} \mathrm{C} 2 \mathrm{~h}$ in Hybridisierungslösung 2 mit $500 \mu \mathrm{l}$ Lachsspermien-DNA $(10 \mathrm{mg} / \mathrm{ml})$ vorhybridisiert. Nach Zugabe der denaturierten Sonde und Hybridisierung üN wurden die Filter 2x 20 min in $40 \mathrm{mM}$ Natriumphosphatpuffer, $0.1 \%$ SDS bei $65^{\circ} \mathrm{C}$ gewaschen, in PE-Folie eingeschweißt, autoradiografiert und die Signale nach Angaben der RZPD ausgewertet.

\subsubsection{3 „Strippen" von Filtern}

Zur Entfernung einer Hybridisierungsprobe von den Filtern wurden die Filter je nach gewünschter Stringenz in Waschlösung I oder Waschlösung II bei $65^{\circ} \mathrm{C}$ gewaschen und anschließend für nachfolgende Hybridisierungen feucht verwendet. 


\subsubsection{Quantitative Bestimmung des humanen Insulins in Serum und Testis durch Fluoroimmunoassay}

Der zwei-Seiten fluoroimmunometrische Auto DELFIA Insulin Assay basiert auf der „direkten Sandwitch Technik“. Hierbei kommen zwei verschiedene (aus Mäusen stammende) Antikörper zum Einsatz, welche jeweils spezifisch an 2 verschiedene Bereiche des zu detektierenden Biomoleküls (Insulin) binden. Standards mit bekannten Insulinkonzentrationen, Kontrollen sowie die einzelnen Proben (Serum) wurden separat mit an der Wand des Reaktionsgefäßes anhaftenden Anti-Insulin-Antikörpern und mobilen Europiummarkierten anti-Insulin-Antikörpern inkubiert.

Der Fest-Phasen-Antikörper und der Europiummarkierte Antikörper binden an die verschiedenen antigenen Determinanten des Insulins und das gesamte Agglomerat befindet sich nun in der stationären Phase. Die mobile Phase (Lösungsmittel, Serum) wird durch eine ,Verstärkungslösung' substituiert, in welcher die aus den markierten Antikörpern stammenden Europiumionen dissoziieren und in der Lösung stark fluoreszierende Chelate bilden. Anschließend wird mittels eines Fluoreszenzmessgerätes (Perkin Elmer, Finnland) die Fluoreszenz der Verstärkungslösung bestimmt, welche sich direkt proportional zur Anzahl der jeweils an die stationären und Europiummarkierten Antikörper gebundenen Insulinmoleküle verhält. Anhand einer erstellten Standardkurve können dann die Insulinkonzentrationen der einzelnen Proben bestimmt werden. Bei der Durchführung des Assays wurde den Herstellerangaben strikt Folge geleistet, sowie alle erforderlichen Chemikalien aus dem Kit entnommen.

\subsubsection{4 Überprüfung der testikulären Insulinprozessierung mittels Radio-Immunoassay für humanes C-Peptid}

Für die Quantifizierung von humanem C-Peptid im Serum von $\mathrm{I}_{2} \mathrm{I}_{3}$-transgenen Mäusen wurde der "Human C-Peptid RIA Kit" (LINCO Research, Inc.) verwendet. Hierbei wird eine festgelegte Konzentration eines markierten tracer-Antigens $\left({ }^{125}\right.$ I-Human C-Peptid) mit Antiserum einer konstanten Verdünnung in einer Weise inkubiert, dass die Anzahl der Antigenbindungsstellen limitierend ist und nur ein bestimmter Prozentsatz des angebotenen Tracers an die Antikörper bindet. Wenn unmarkierte Antigene dem System 
hinzugefügt werden, konkurrieren diese mit den markierten Antigenen um die limitierte und konstante Zahl der Bindungsstellen der Antikörper. Bei steigender Konzentration von unmarkierten Antigenen verringert sich die Anzahl von freien Bindungsstellen, und es kann weniger tracer-Antigen gebunden werden. Nach Entfernung von freien tracerAntigenen wird die Emission der gebundenen markierten Antigene per Gamma-Counter gemessen. In Ansätzen mit $100 \mu 1{ }^{125}$ I-markiertem humanen C-Peptid (Aktivität 658 $\mu \mathrm{Ci} / \mu \mathrm{g}$, Konzentration $27 \mu \mathrm{l} / \mathrm{ml}$ ) und unmarkiertem C-Peptid in Konzentrationen von $0.1 \mathrm{ng} / \mathrm{ml}, 0.2 \mathrm{ng} / \mathrm{ml}, 0.5 \mathrm{ng} / \mathrm{ml}, 1.0 \mathrm{ng} / \mathrm{ml}, 2.0 \mathrm{ng} / \mathrm{ml}$ und $5.0 \mathrm{ng} / \mathrm{ml}$ wurde eine Standardkurve erstellt, welche für die Konzentrationsberechnung der entsprechend behandelten Proben von Serum aus transgenen und Wildtyp-Kontroll-Mäusen sowie der Kontrolllösungen bekannter C-Peptid-Konzentrationen herangezogen wurde. Der Assay wurde exakt nach Herstellerangaben durchgeführt und die zum Kit gehörenden Chemikalien benutzt.

\subsubsection{Histologische Techniken}

\subsubsection{Herstellung von Paraffinschnitten}

Das frisch präparierte Material wurde in PBS gewaschen, für $24 \mathrm{~h}$ bei $4^{\circ} \mathrm{C}$ in $4 \%(\mathrm{w} / \mathrm{v})$ Paraformaldehyd oder Bouin'scher Lösung fixiert und erneut 2x 5 min in PBS bei RT gewaschen. Durch eine aufsteigende Ethanolreihe (1x 70\%, 3x 80\%, 4x 96\%, 5x 100\% für je $30 \mathrm{~min}$ ) wurde das Gewebe entwässert und üN in 2-Propanol inkubiert. Zur vollständigen Entfernung des Alkohols wurde das Gewebe in einer absteigenden 2Propanol:Xylol-Reihe (75:25, 50:50, 25:75) und anschließend üN in Xylol inkubiert. Danach folgten drei Paraffininkubationsschritte für jeweils 24 h. Für die folgende Einbettung wurde eine Paraffin-Einbettungsstation genutzt. Die Paraffinblöcke mit dem fixierten Material wurden zu Quadern optimaler Größe zurechtgeschnitten und in das Mikrotom (Jung RM 2035, Leica) eingespannt. Die Schnittdicke betrug 3-5 $\mu$ m. Mit Hilfe eines feinen Pinsels wurden die Schnitte zum Glätten in ein $40^{\circ} \mathrm{C}$ Wasserbad gegeben. Um eine bessere Haftung der Schnitte zu erreichen, wurden Superfrost Objektträger benutzt. Die Schnitte wurden auf die Objektträger übertragen und auf einer $40^{\circ} \mathrm{C}$ warmen Heizplatte getrocknet. Bis zur weiteren Verwendung wurden die Schnitte bei $4^{\circ} \mathrm{C}$ gelagert. 


\subsubsection{Färbung der histologischen Schnitte mit alkalischer Phosphatase}

Die Gewebeschnitte wurden zunächst 3x 3 min in Xylol bei RT deparaffiniert, 5 min in Ethanol gewaschen und durch eine absteigende Ethanolreihe in $\mathrm{H}_{2} \mathrm{O}(100 \%, 96 \%, 90 \%$, $\left.80 \%, 70 \%, 50 \%, \mathrm{dH}_{2} \mathrm{O}\right)$ jeweils für 2 min rehydriert. Nach einem Waschschritt in PBS für 5 min wurden die Gewebeschnitte für eine Stunde in 1\%igem Pferdeserum (gelöst in $0.05 \%$ Triton X-100/PBS) vorinkubiert und anschließend üN bei $4^{\circ} \mathrm{C}$ mit dem ersten Antikörper inkubiert. Anschließend wurden die histologischen Präparate mit alkalischer Phosphatase konjugiertem zweitem Antikörper (1:500) (Sigma-Aldrich Chemie, Taufkirchen) für 30 min bei RT in einer Feuchtkammer inkubiert. Nach dreimaligem Waschen mit PBS für jeweils 5 min wurde die Immunreaktion durch Inkubation in einer Lösung aus Fast red TR/Naphthol AS-Mx Phosphat Plätzchen nachgewiesen. Die Schnitte wurden 2x 5 min in PBS bei RT gewaschen und zur Lagerung bei $4^{\circ} \mathrm{C}$ mit Aqua Poly/Mount überschichtet.

\subsubsection{Färbung der histologischen Schnitte mit Fluoreszenzfarbstoffen}

Die Schnitte wurden wie unter 2.2.15.2 beschrieben entparaffiniert, rehydriert und mit anti-Insulin bzw. anti-Ins15 Antikörpern inkubiert. Anschließend wurden die histologischen Präparate mit Cy3-anti-Maus oder FITC-anti-Kaninchen Antikörpern (1:500) (Sigma-Aldrich Chemie, Taufkirchen) für $60 \mathrm{~min}$ in einer Feuchtkammer bei RT inkubiert. Nun wurden die Präparate mit DAPI-Einbettungsmedium (Vectashield Mounting Medium, Vector Laboratories, Wertheim) versetzt, mit einem sterilen Deckglas abgedeckt und mit Nagellack umrandet, um ein Verdunsten der Lösung zu vermeiden. Bis zur fotografischen Auswertung wurden die Präparate bei $4^{\circ} \mathrm{C}$ lichtgeschützt aufbewahrt.

\subsubsection{Fotografische Auswertungen}

Die in situ-gefärbten Embryonen und Schnittpräparate wurden mit einem Fotostereomikroskop und/oder Fotomikroskop mit Hilfe der AnalySIS ${ }^{\circledR}$-Software und einer digitalen Kamera fotografiert und die Bilder mit den Programmen Corel PhotoPaint und Microsoft PowerPoint bearbeitet. 


\subsubsection{Spermienanalyse}

\subsubsection{Spermienzahl und Motilitätsanalyse von Spermien}

Die Spermiengewinnung erfolgte aus Nebenhoden und Samenleiter. Das Gewebe wurde in ein Gewebekulturschälchen mit 1-2 ml IVF-Medium übertragen und $30 \mathrm{~min}$ bei $37^{\circ} \mathrm{C}$ inkubiert. Die Spermiensuspension wurde 1:40 mit PBS verdünnt und mit einer Neubauer-Zählkammer unter dem Mikroskop gezählt. Es wurden 8 Felder ausgezählt. Die Spermien aus dem Samenleiter wurden unverdünnt gezählt. Die Gesamtzahl der Spermien wurde nach folgender Formel bestimmt:

Zahl x 10 x Verd. x Vol gesamt $=$ Gesamtzahl Spermien

\subsubsection{Motilitätsanalyse von Spermien}

Die Spermienbeweglichkeit wurde mit dem Spermienanalyseprogramm CEROS (Version 10) von Hamilton Thorne Research quantifiziert. Es wurden je 200 Spermien analysiert. Dabei wurden die in der Tabelle angegebenen Parameter benutzt.

Tab. 2.2: Technische Informationen des Spermienanalyseprogramms CEROS

\begin{tabular}{l|l} 
Parameter & Wert \\
\hline Probeninformation & $0.5 \mathrm{ml}$, verdünnt 1:0.01 \\
\hline Analysesetup & Maus 3 (30 Bilder á 60 Hz) \\
\hline Kammer & 2 x Zelle $(80.0 \mu \mathrm{m})$ \\
\hline Vergrößerung & 2.04 \\
\hline Benötigte Felder & 20 \\
\hline Temperatur & $0.0^{\circ} \mathrm{C}\left(\right.$ eingestellt auf $\left.22.0^{\circ} \mathrm{C}\right)$ \\
\hline Video-Ursprung & $60 \mathrm{~Hz}$, Dunkelfeld \\
\hline Beleuchtungsintensität & 2300
\end{tabular}

Es wurden die Motilität und die progressive Motilität der Spermien analysiert. Außerdem wurden die Bahngeschwindigkeit (VCL), die Weggeschwindigkeit (VAP) und die progressive Geschwindigkeit (VSL) gemessen. Ferner wurden die Gradlinigkeit (STR), die Schlagfrequenz des Spermiumschwanzes (BCF) und die Breite des 
Kopfausschlages des Spermiums (ALH), 1.5 h, 3.5 h und 5.5 h nach der Präparation gemessen.

$\begin{array}{ll}\text { VCL } & \text { curvilinear velocity } \\ \text { VAP } & \text { average path velocity } \\ \text { VSL } & \text { straight line velocity } \\ \text { STR } & \text { straightness } \\ \text { BCF } & \text { beat frequency } \\ \text { ALH } & \text { lateral amplitude }\end{array}$

\subsubsection{Akrosomenreaktion}

(Kinloch et al., 1992)

Um die Akrosomenreaktion auszulösen, wurden Calcium-Ionophore eingesetzt. Die Spermiengewinnung erfolgte aus der Cauda epididymis geschlechtsreifer Männchen. Die Cauda epididymis wurde in eine Gewebekulturschale mit 1-2 ml IVF-Medium bei RT übertragen. Das grob zerkleinerte Gewebe führte zur Spermienverteilung im Medium und die Gewebsfragmente konnten entnommen werden. Die Spermiensuspension wurde für $1 \mathrm{~h}$ zur Kapazitation im Brutschrank bei $5 \% \mathrm{CO}_{2}$ und $37^{\circ} \mathrm{C}$ präinkubiert. Anschließend wurde die Suspension für 2 min bei 1000x $\mathrm{g}$ zentrifugiert und der Überstand bis auf $50 \mu$ l abgenommen. Nach Zugabe des CalciumIonophores A23187 (10 $\mu \mathrm{g}$, End.Konz; in DMSO gelöst) wurde die Suspension bei $37^{\circ} \mathrm{C} 1 \mathrm{~h}$ inkubiert. Die Negativkontrolle wurde mit $2.5 \mu$ l Phosphorsäure inkubiert. Die Spermien wurden in ca. $500 \mu \mathrm{l} 2 \%$ Formaldehyd/PBS für $30 \mathrm{~min}$ bei $4^{\circ} \mathrm{C}$ inkubiert. Danach wurde die Spermiensuspension in $500 \mu \mathrm{l} 0.15 \mathrm{M}$ Ammoniumacetat $(\mathrm{pH}$ 9.0) gewaschen und bei 10000x g 2 min zentrifugiert, auf Objektträgern ausgestrichen und anschließend mit $0.4 \%$ Coomassie blue $\mathrm{G}-250$ in $3.5 \% \mathrm{H}_{2} \mathrm{O}_{2}$ für 2.5 min gefärbt. Nach der Färbung wurde zweimal mit destillierten $\mathrm{H}_{2} \mathrm{O}$ gewaschen, eingedeckelt und ausgewertet. Spermien mit positiver Coomassie-Färbung zeigen den Akrosom-intakten Zustand. Die akrosomreagierten Spermien bleiben farblos. 


\subsubsection{Erzeugung eines Diabetes mellitus bei Mäusen}

2 Monate alten männlichen FVB- sowie transgenen Mäusen wurde Streptozotocin (STZ) injiziert. STZ ist ein aus Streptomyces achromogenes isoliertes BreitbandAntibiotikum. STZ zerstört u.a. im Pankreas die für die Insulinproduktion verantwortlichen $\beta$-Zellen sowie die $\delta$-Zellen und induziert somit bei diversen Tierspezies einen Diabetes mellitus. STZ wurde in einer Konzentration von $33.3 \mathrm{mg} / \mathrm{kg}$ Körpergewicht (gelöst in $50 \mathrm{mM}$ Citrat-Puffer, $\mathrm{pH}$ 4.5) den Tieren an fünf aufeinander folgenden Tagen zur gleichen Uhrzeit intraperitoneal injiziert. Vor der Behandlung wurden die Tiere gewogen und der Blutglukosewert mittels Teststreifen (HaemoglucoTest, Boehringer) an der Schwanzspitze gemessen. Im Folgenden wurden die so behandelten Tiere als auch die unbehandelten Kontrolltiere alle 2-3 Tage gewogen und der Blutglukosewert bestimmt. Zur histologischen Auswertung wurden die Pankreaspräparate immunologisch gegen Insulin gefärbt (2.2.15.2) und die gefärbten Inseln mittels des soft imaging Systems von AnalySIS (2.2.15.4) vermessen.

\subsubsection{Glukosetoleranztest}

Um zu überprüfen, ob die mit STZ behandelten $\mathrm{I}_{2} \mathrm{I}_{3}$-transgenen Mäuse humanes Insulin im Testis produzieren und in der Lage sind, wie unbehandelte Wildtypen, den durch intraperitoneal injizierte Glukoselösung erhöhten Blutglukosewert binnen einer Stunde zu senken, wurde ein Glukosetoleranztest durchgeführt. Den Mäusen wurde für $8 \mathrm{~h}$ die Nahrung entzogen und anschließend das Gewicht und der Blutglukosewert festgestellt. Danach wurde den Mäusen Glukose gespritzt (2 mg/g Körpergewicht) und dreimal in 20 min Abständen der Blutglukosewert bestimmt;

Glukose-Stammlösung: $300 \mathrm{mg} / \mathrm{ml}$. 


\subsubsection{Herstellung von mutanten Mäusen}

\subsubsection{Erzeugung von knock-out Mäusen}

\subsection{Routinekultur von ES-Zellen}

Die Isolierung und gezielte Manipulation pluripotenter embryonaler Stammzellen (ESZellen) ist ein entscheidender Fortschritt im Rahmen der entwicklungsbiologischen Forschung bei Säugetieren. Von Bradley et al. (1984) wurde gezeigt, dass diese Zellen sich an der Entwicklung sämtlicher Gewebe des resultierenden Embryos, einschließlich der Keimzellen beteiligen, wenn sie in Blastocysten injiziert werden. Die erste genetische Manipulation an ES-Zellen wurde von Robertson et al. (1986) durchgeführt. Er konnte zeigen, dass Mutationen im Genom von ES-Zellen von diesen durch die Keimbahn transmittiert werden. Die ersten erfolgreichen homologen Rekombinationen in ES-Zellen wurden fast gleichzeitig von Thomas und Capecchi (1987) sowie Doetschmann et al. (1987) publiziert. Heute liegen mindestens 2000 Berichte über gezielte genetische Manipulationen am Genom der Maus mit Hilfe der ES-ZellTechnologie vor.

In der vorliegenden Arbeit wurden „knock-out“-Mäuse über die Injektion von ESZellen in Blastocysten hergestellt. Embryonale Stammzellen wurden zusammen mit Mitomycin C-behandelten embryonalen Feederzellen (EmFi) auf 0.2\% Gelatinebeschichteten Kulturschalen ausplattiert. Das Kulturmedium wurde aufgrund der starken Ansäuerung durch die ES-Zellen täglich gewechselt. Eine erneute Passagierung wurde, je nach Dichte der Zellen, alle 2-3 Tage durchgeführt und ES-Zellen in Trypsin/EDTA-Puffer 1:3 bis 1:8 geteilt. Vor der erneuten Plattierung wurde die Trypsinlösung durch Zentrifugation bei 270x g für 5 min bei RT entfernt. Bei jeder Passage wurden Stocks der ES-Zellen in flüssigem Stickstoff kryokonserviert.

\subsection{Elektroporation und Selektion von ES-Zellen}

Die Elektroporation ist eine physikalische Methode zum Gentransfer. Sie basiert auf der Erkenntnis, dass biologische Membranen durch die Einwirkung kurzer elektrischer Impulse oberhalb der kritischen Feldstärke vorübergehend permeabilisiert werden, ohne dass die Membranstruktur zerstört wird. Während der Phase erhöhter Durchlässigkeit 
kann ein Eindringen linearisierter Plasmid-DNA durch die Membran erfolgen. Die Elektroporation der ES-Zellen wurde nach den Angaben von Joyner (1993) durchgeführt. Dazu wurden $7 \times 10^{6}$ bis $2 \times 10^{7}$ exponentiell wachsende Zellen nach der Trypsinisierung in $800 \mu \mathrm{l}$ Elektroporationspuffer und $40 \mu \mathrm{g}$ linearisierte DNA eingesetzt.

Die linearisierte Konstrukt-DNA wurde zunächst mit Phenol/Chloroform extrahiert, mit $100 \%$ igem Ethanol präzipitiert und zuletzt in $70 \%$ igem Ethanol gewaschen. Aus Sterilitätsgründen wurde das DNA-Pellet bei RT unter der Sterilbank luftgetrocknet und in $100 \mu$ l Elektroporationspuffer aufgenommen.

Die ES-Zellen wurden nach der Trypsinisierung in $9 \mathrm{ml}$ Elektroporationspuffer gewaschen, in einer Neubauer-Zählkammer ausgezählt und nach erneuter Zentrifugation in einem Vol. von $700 \mu$ l Elektroporationspuffer aufgenommen. Die Suspension wurde in einer Küvette (Gene Pulser Cuvette, $0.4 \mathrm{~cm}$, gap 50, BIO RAD) vereinigt und mit $240 \mathrm{~V}$ und $500 \mu \mathrm{F}$ bei RT elektroporiert (Gene Pulser, BIO RAD). Anschließend wurden die ES-Zellen für $20 \mathrm{~min}$ auf Eis inkubiert und dann in 2x $100 \mathrm{~mm}$ Kulturschalen auf embryonalen Fibroblasten ausplattiert. Die Selektion in G418 (Positiv-Selektion) und Gancyclovir (Negativ-Selektion) begann nach 12 bis $16 \mathrm{~h}$. Die Gancyclovir-Selektion wurde nach 3 Tagen beendet, während die G418-Selektion bis zur Isolierung resistenter Klone am Tag 8-9 aufrechterhalten wurde. Zur Kontrolle der Elektroporationseffizienz wurden die Zellen einer Kulturschale lediglich mit G418 selektioniert. Die Effizienz der Elektroporation lag bei einer von $10^{5}$ Zellen.

\subsection{Isolierung und Kryokonservierung von ES-Zellklonen}

Positive ES-Zellklone wurden lichtmikroskopisch identifiziert. Resistente Kolonien wurden nach einer G418-Selektion über 8 bis 9 Tage isoliert. Dazu wurden die Kulturen einmal in PBS-Puffer gewaschen und mit $10 \mathrm{ml}$ PBS-Puffer überschichtet. Die Klone wurden mechanisch mit Hilfe einer sterilen Pipettenspitze von den umgebenden embryonalen Fibroblasten getrennt und bei $37^{\circ} \mathrm{C}$ in $1 \mathrm{x}$ Trypsin/EDTA in 96-LochPlatten dissoziiert. Der enzymatische Verdau wurde nach 5 min durch Zugabe von $50 \mu 1$ ES-Zellmedium gestoppt. Die vereinzelten Klone wurden auf 24-Loch-Platten mit Fibroblasten und frischem ES-Zellmedium übertragen und bei $37^{\circ} \mathrm{C}$ kultiviert. Nach 2 bis 3 Tagen wuchsen die Einzelklone zur Konfluenz und wurden erneut trypsinisiert. Eine Hälfte der Zellen wurde erneut auf Fibroblasten ausplattiert (master plate), 
während die andere Hälfte der Zellen auf einer Gelatine-behandelten Platte (duplicate plate) inkubiert wurde. Die auf Fibroblasten wachsenden ES-Zellen wurden nach Erreichen der Konfluenz mit $100 \mu \mathrm{l}$ Trypsin/EDTA bei $37^{\circ} \mathrm{C}$ für 5 min dissoziiert, in 1 ml Kryogefäße (Nunc) überführt, nach Zugabe von $100 \mu 1$ 2x Gefriermedium gemischt und bei $-80^{\circ} \mathrm{C}$ eingefroren. Die für die DNA-Isolierung vorgesehenen Zellen wurden ebenfalls bis zur Konfluenz kultiviert und anschließend der DNA-Extraktion unterworfen. Homolog rekombinante Klone wurden nach dem Auftauen bei $37^{\circ} \mathrm{C}$ in 10 ml kaltes ES-Zellmedium gegeben, bei 270x g für $5 \mathrm{~min}$ abzentrifugiert und auf Fibroblasten in 24-Loch-Platten kultiviert. Nach Erreichen der Konfluenz wurden die Zellen trypsinisiert und in 3 bis 4 Aliquots eingefroren. Die für die Aggregation benötigten ES-Zellen wurden vier Tage vor der Aggregation aufgetaut und kultiviert.

\subsection{Herstellung und Identifizierung von Chimären}

Die Isolierung 3.5 Tage alter Mausembryonen/Blastocysten, die Injektion rekombinanter ES-Zellen in die Embryonen und die Reimplantation der injizierten Blastocysten in pseudoschwangere Mäuse wurde von MitarbeiterInnen des Max-PlanckInstituts für experimentelle Medizin, Göttingen, durchgeführt. Die ES-Zellen wurden aus Tieren des Mausstammes 129/SvJ isoliert, deren Fell eine braune Färbung aufweist (agouti-Fellmarker). Die für die Injektion eingesetzten Blastocysten wurden aus dem C57B1/6J-Stamm isoliert, dessen Mäuse eine schwarze Fellfärbung zeigen. Sind ESZellen an der Entwicklung der reimplantierten Embryonen beteiligt, können die chimären Tiere anhand einer gescheckten Fellfärbung identifiziert werden. Männliche Mäuse mit einem Chimärismus von mindestens $80 \%$ wurden mit Mäusen der Stämme C57Bl und 129/SvJ gekreuzt und die Tiere der F1-Generation im Alter von 5 Wochen mit Hilfe der PCR genotypisiert. Mit dieser PCR wurden auch die Tiere aller weiteren Generationen genotypisiert.

\subsubsection{Methoden zur Erzeugung transgener Mäuse}

Für die Erzeugung der $\mathrm{I}_{2} \mathrm{I}_{3}$ transgenen Mäuse wurde die Mikroinjektion, d.h. die Einführung der DNA mit Hilfe einer feinen Glaskapillare in den männlichen Vorkern, verwendet. Die weiblichen Tiere wurden superovuliert (7 PMS und 48 h später hCG) 
verpaart, am nächsten Tagen wurden die befruchteten Eizellen isoliert, und die DNA wurde in den männlichen Vorkern mikroinjiziert. Die überlebenden mikroinjizierten Oozyten wurden anschließend in die Eileiter eines scheinträchtigen Empfängertieres retransferiert. Die geborenen Mäuse wurden zum Nachweis der Integration der FremdDNA analysiert. Die Genotypisierung erfolgte mittels PCR (2.2.7.2) unter Verwendung sequenzspezifischer Primer. Die transgenen Mäuse wurden in Zusammenarbeit mit dem Max-Planck-Institut für experimentelle Medizin in Göttingen erstellt. Die Erzeugung transgener Mäuse wurde prinzipiell nach Hogan et al. (1986) durchgeführt.

\subsection{Vorbereiten der DNA zur Mikroinjektion}

Alle zur Mikroinjektion vorgesehenen Konstrukte wurden zur Kontrolle sequenziert (2.2.8). Laut Literatur (Brinster et al., 1985) integriert DNA bevorzugt in linearisierter Form, die Beschaffenheit der Enden spielt dagegen für die Integrationseffizienz keine Rolle. Das Konstrukt enthaltende DNA-Fragment wurde über einen Verdau des Vektorrückgrats mit entsprechenden Restriktionsenzymen aus dem Plasmid freigesetzt und über ein Agarosegel (ohne EtBr) vom Vektorrückgrat getrennt. Da DNA-Mengen von $25 \mu \mathrm{g}$ verdaut wurden, wurden mehrere Taschen eines Gels beladen. Die äußeren Taschen enthielten dabei nur etwa 1/10 der DNA/Dye-Lösung. Nach dem Gellauf wurden diese Taschen und der DNA-Längenstandard ausgeschnitten und die Gelstuicke im EtBr-Bad angefärbt. Nach dem Anfärben wurde das Gel zusammengesetzt und auf dem UV-Tisch die gesuchte Bande zwischen den angefärbten Bereichen ausgeschnitten. Die Elution der DNA erfolgte mit QIAquick-Säulen (siehe 2.2.6). Um nach der Gelelution jegliche verbliebenen Partikel zu entfernen, wurde das Eluat über kleine Mikrofilter (Fa. Millipore, Typ HY, $0.45 \mu \mathrm{m}$ ) filtriert. Die Konzentration der DNA wurde über eine Anfärbung mit EtBr nach der Agarosegelelektrophorese bestimmt. Dazu wurden verdünnte Aliquots der DNA-Lösung aufgetragen und die Anfärbung mit der auf gleicher Höhe laufenden Bande eines Markers verglichen, die definierte DNAMengen enthielt. Zur Mikroinjektion wurde die Konzentration auf etwa $5 \mathrm{ng} / \mu \mathrm{lmit} 1 \mathrm{x}$ Mikroinjektionspuffer verdünnt. 


\section{ERGEBNISSE}

\subsection{Insl5-Gen}

\subsubsection{Expression des Insl5-Gens bei der Maus}

\subsubsection{Amplifikation der Insl5-cDNA der Maus mittels RT-PCR}

Für die Herstellung einer Insl5 cDNA der Maus wurde die Methode der reversen PCR mit Insl5 spezifischen Oligonukleotiden gewählt.

Für die vorausgehende cDNA-Synthese wurden $1 \mu \mathrm{g}$ Gesamt-RNA aus Thymus der Wildtyp-Mäuse revers transkribiert und einer PCR mit den genspezifischen Primern CIns15/F und C-Ins15/R RT-PCR unterzogen (2.2.7.7). Nach gelelektrophoretischer Auftrennung wies das amplifizierte RT-PCR-Produkt eine Länge von etwa 650 bp auf. Nach der Klonierung in den Vektor pGEM-T Easy wurde das PCR-Produkte sequenziert. Durch Vergleich der Nukleotidsequenz des Klons mit der bereits bekannten Insl5-cDNA konnte eine Homologie von $100 \%$ zwischen den beiden Sequenzen festgestellt werden.

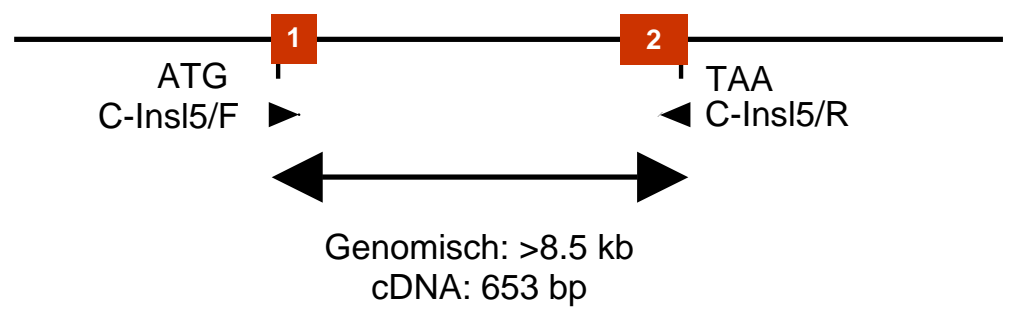

Abb. 3.1: Schema und Primerpositionen für die durchgeführte RT-PCR. Die PCR wurde so geplant, dass das PCR-Produkt eine Länge von 653 bp hat und die Sequenz beider Exons beinhaltet. PCRBedingungen: 35 Zyklen: $94^{\circ} \mathrm{C} 30 \mathrm{~s} ; 58^{\circ} \mathrm{C} 30 \mathrm{~s} ; 72^{\circ} \mathrm{C} 45 \mathrm{~s}$. 


\subsubsection{Untersuchung zur organspezifischen Expression des Insl5-Gens}

Durch Northern-Blot Hybridisierungsexperimente sollte sowohl die Größe der mRNA für das Insl5-Gen der Maus als auch dessen organspezifische Transkription überprüft werden. Für die Expressionsanalyse in adulten Geweben wurden von jedem untersuchten Gewebe $20 \mu \mathrm{g}$ Gesamt-RNA für einen Northern-Blot (2.2.5.3) eingesetzt. Die Hybridisierung erfolgte bei $65^{\circ} \mathrm{C}$ mit der radioaktiv markierten cDNA-Sonde (Abb. 3.1). Nach 16 stündiger Exposition des Autoradiogramms konnte ein Signal mit der Größe von $1 \mathrm{~kb}$ im distalen Kolon (Rektum) festgestellt werden (Abb. 3.2.A). Nach längerer Exposition (7 Tage) wurde ein schwaches Signal für ein kleineres Transkript im Thymus sichtbar (Abb. 3.2.B). Um die Integrität und Menge der untersuchten RNA zu überprüfen, wurde der Northern-Blot mit $\beta$-Aktin nachhybridisiert.

Um zu überprüfen, ob Insl5 auf niedrigem Level auch in anderen Geweben exprimiert wird, wurde die Expression des Insl5-Gens mittels RT-PCR analysiert. RNA wurde aus Gehirn, Thymus, Herz, Lunge, Niere, Milz, Magen, Leber, Kolon, Testis und Ovar adulter Mäuse extrahiert. $1 \mu \mathrm{g}$ der so hergestellten RNA wurde revers transkribiert und nachfolgend einer PCR mit den genspezifischen Primern (Abb. 3.2.C) unterzogen. Von den PCR-Ansätzen wurden $10 \mu \mathrm{l}$ in einem 1.5\%igem Agarosegel aufgetrennt. 
A

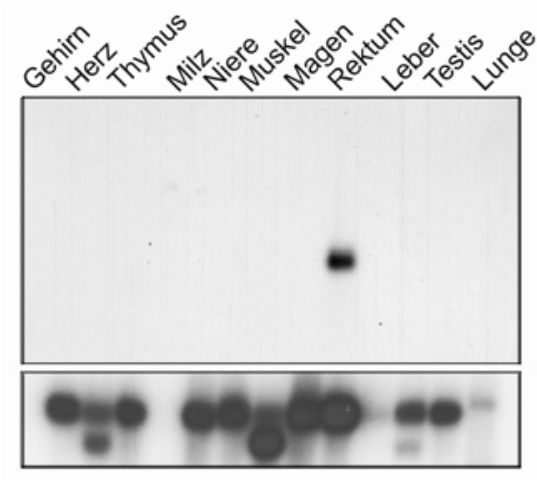

B

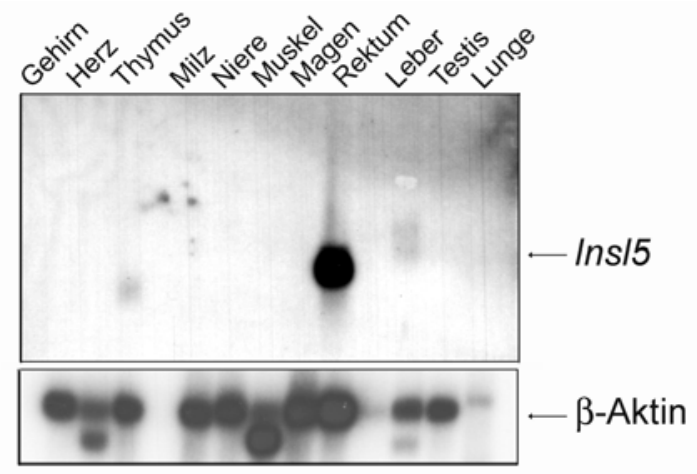

C

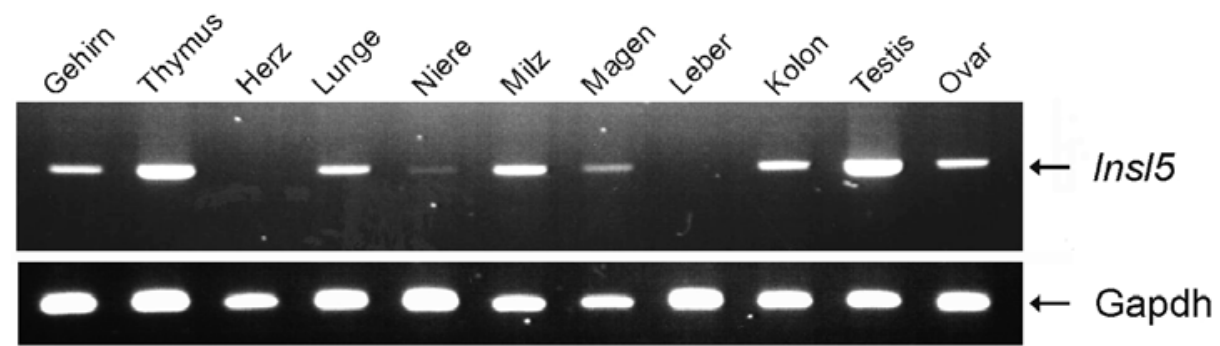

Abb. 3.2: Analyse der Expression des Insl5-Gens der Maus in verschiedenen Geweben. (A, B) GesamtRNA (je $20 \mu \mathrm{g}$ ) aus verschiedenen Geweben wurde nach denaturierender Gelelektrophorese auf eine Nitrocellulosemembran transferiert und mit der Insl5-cDNA-Sonde (Abb. 3.1) hybridisiert. Die Integrität und Menge der aufgetragenen RNA wurde durch eine Nachhybridisierung der Membran mit $\beta$-Aktin überprüft. (A) Die Expressionszeit des Autoradiogramms betrug 16 Stunden, (B) nach 7 Tagen. (C) Gelelektrophoretische Auftrennung der PCR-Produkte zur Analyse der Expression in den verschiedenen Organen der Maus. Die Gesamt-RNA aus verschiedenen Organen wurde einer RT-PCR mit Insl5spezifischen Primern unterworfen. Die Integrität der RNA wurde durch eine zweite PCR mit Gapdh spezifischen Primern überprüft.

Wie in Abb. 3.2.C zu sehen ist, konnten in einigen Organen Transkripte von Ins15 nachgewiesen werden. Die Integrität der verwendeten RNA wurde nachfolgend durch die Amplifikation der Gapdh-mRNA überprüft.

\subsubsection{Expressionsanalyse von Insl5 während der Embryonalentwicklung der Maus}

Um Aufschluss über den Zeitpunkt der Expression des Insl5-Gens während der pränatalen Entwicklung zu erhalten, wurden eine Northern-Blot und eine RT-PCR Analyse an embryonaler Gesamt-RNA durchgeführt. 
Für diese Analyse wurden Mäuseembryonen zwischen Tag 8.5 und 17.5 der Schwangerschaft präpariert. Die Bestimmung der jeweiligen Tage der Schwangerschaft erfolgte durch die Kontrolle des Vaginalpfropfes (VP) am Morgen nach natürlicher Verpaarung. Nach Extraktion der Gesamt-RNA wurden jeweils $20 \mu \mathrm{g}$ der RNA in einem denaturierenden Agarosegel aufgetrennt. Das Gel wurde geblottet und mit der radioaktiv markierten Insl5-cDNA-Sonde hybridisiert. Es konnten keine Insl5Transkripte während der Embryonalentwicklung nachgewiesen werden (Abb. 3.3.A). Die Integrität der eingesetzten RNA wurde durch Nachhybridisierung der Membran mit $\beta$-Aktin überprüft.

Mit Insl5-spezifischen Primern wurde ein RT-PCR-Ansatz mit RNA aus 9.5 bis 17.5 Tage alten Embryonen durchgeführt. Die PCR-Produkte wurden anschließend auf ein Agarosegel gegeben und elektrophoretisch aufgetrennt (Abb.3.3.B). Das erwartete PCRProdukt von 653 bp konnte erstmal bei 11.5 Tage alten Mäuseembryonen nachgewiesen werden. Daraus kann geschlossen werden, dass die Transkription von Insl5 bereits sehr früh in der Embryonalentwicklung beginnt. Die Integrität der eingesetzten RNA wurde durch eine Kontroll-PCR mit Gapdh-spezifischen Primern überprüft.

A

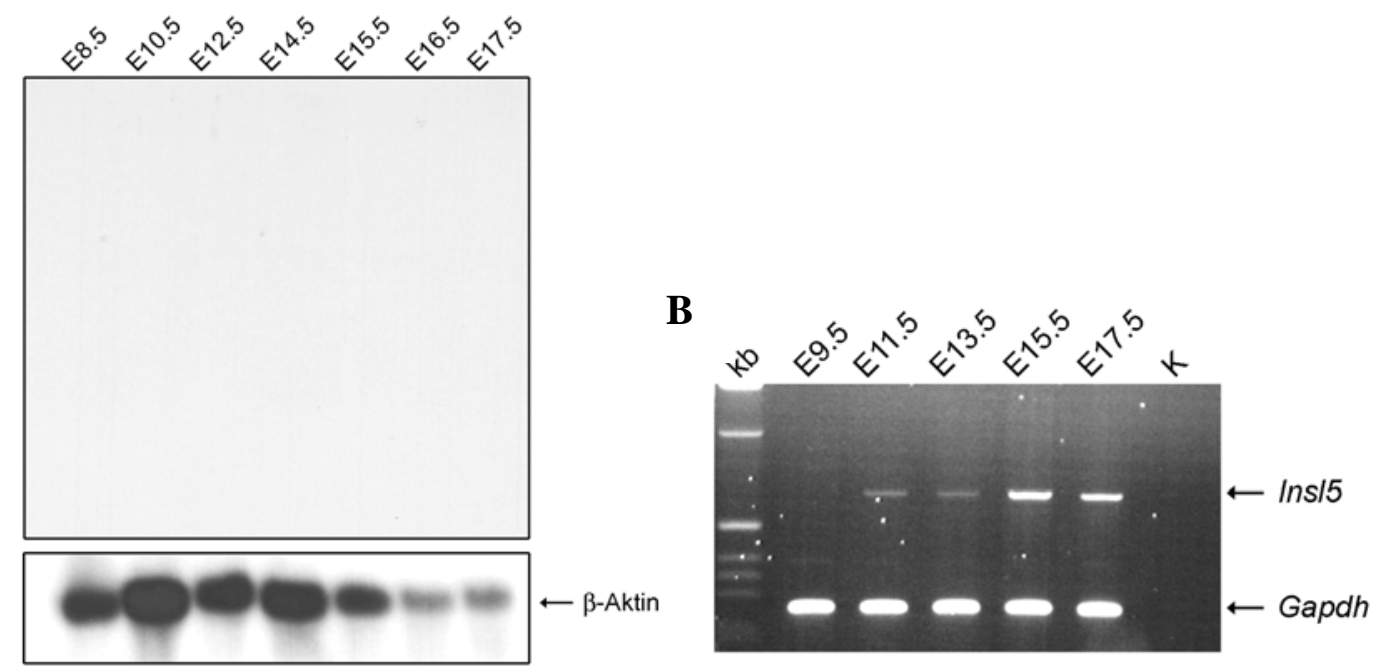

Abb. 3.3: Analyse der Expression des Insl5-Gens der Maus während der Embryonalentwicklung

(A) Gesamt-RNA (je $20 \mu \mathrm{g}$ ) aus ganzen Embryonen zwischen den Tagen 8.5 und 17.5 wurde nach denaturierender Gelelektrophorese auf eine Nitrocellulosemembran transferiert und mit der Insl5-cDNASonde hybridisiert. (B) Gelelektrophoretische Auftrennung der PCR-Produkte zur Analyse der Expression des Insl5-Gens in Mausembryonen. Die aufgereinigten Extrakte wurden für eine RT-PCR mit Insl5spezifischen Primern herangezogen. Die Integrität der RNA wurde durch eine zweite PCR mit Gapdhspezifischen Primern überprüft. $k b=1 \mathrm{~kb}$ Leiter, $K=$ Leerkontrolle. 


\subsubsection{Untersuchung zur Expression des Insl5-Gens der Maus in postnatalen Testes und bei verschiedenen Mausmutanten mit Keimzelldefekten}

Zur Untersuchung der Expression des Insl5-Gens während der postnatalen TestisEntwicklung wurden RT-PCR-Analysen an RNA aus Wildtyptestis sowie aus Testes der Mutanten $W / W^{\nu}, T f m / Y$, Insl3 ${ }^{-/}$, olt/olt und $q k / q k$ durchgeführt. Nach der Auftrennung der PCR-Produkte auf dem Agarosegel konnte das Insl5-Transkript in allen postnatalen Testis-Stadien nachgewiesen werden. Die Intensität des Insl5 steigt nach drei Wochen an (Abb. 3.4.A). Bei allen getesteten Mausmutanten ist das Insl5Transkript nachweisbar (Abb. 3.4.B).

Es wurde dann überprüft, ob die Insl5-Expression auf Keimzellen beschränkt ist. RTPCR-Analysen wurden mit RNA aus Testis, Ovar, einer Leydig-Zelllinie (MA10), einer Sertoli-Zelllinie (P15) und embryonalen Stammzellen (ES) durchgeführt. In der LeydigZelllinie (MA10), der Sertoli-Zelllinie (P15) und in den ES-Zellen waren keine Insl5Transkripte detektierbar (Abb. 3.4.C).

A

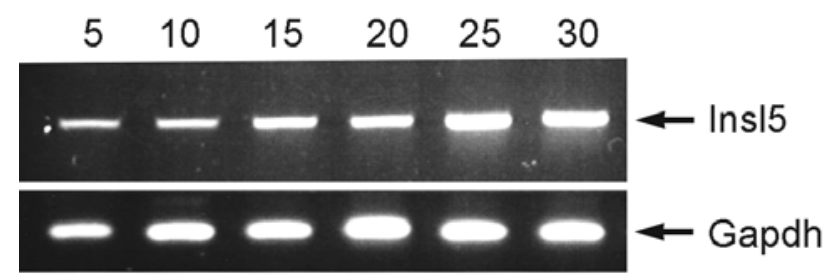

B

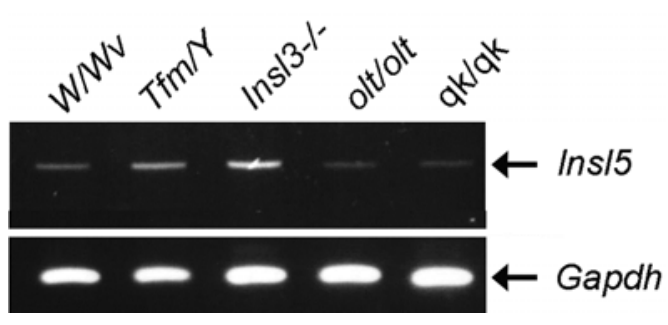

C

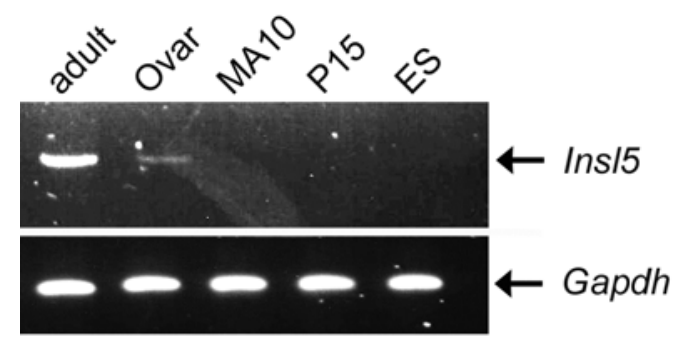

Abb. 3.4: Analyse der Expression des Insl5-Gens in der postnatalen Testisentwickliung, in verschiedenen Mausmutanten mit Keimzelldefekten und in verschiedenen Zellinien. RT-PCR mit Insl5-spezifischen Primern; die Integrität der RNA wurde durch eine zweite PCR mit Gapdh-spezifischen Primern überprüft. 


\subsubsection{Zur Funktion des Insl5-Gens}

\subsubsection{Die Strategie zur Inaktivierung des Insl5-Gens}

Um Informationen über die Funktion des Insl5-Gens zu erhalten, sollten knock-outMäuse hergestellt werden. Für die homologe Rekombination in den ES-Zellen der Maus benötigt man flankierende, genomische Fragmente einer Größe von 2-5 kb. Durch die Verwendung isogener, d.h. aus dem selben Mausstamm stammender DNA wird die Rekombinationsfrequenz erheblich gesteigert (Melton, 1994). Die homologe Rekombination wurde in R1-ES-Zellen (Nagy et al., 1993) durchgeführt, die ihrerseits aus Blastocysten des Mausstammes 129/SvJ isoliert worden waren. Die Inaktivierung eines Gens in embryonalen Stammzellen erfolgt dabei mit Hilfe eines TargetingVektors vom Replacement-Typ, durch den endogene Sequenzen im Allel gegen fremde DNA-Fragmente ausgetauscht werden. Zum Zwecke der Konstruktion des TargetingVektors und der Subklonierung geeigneter 5'- und 3'-flankierender Fragmente wurde im Vorfeld eine detaillierte Restriktionskarte der entsprechenden genomischen Insl5Sequenz hergestellt (Abb. 3.5).

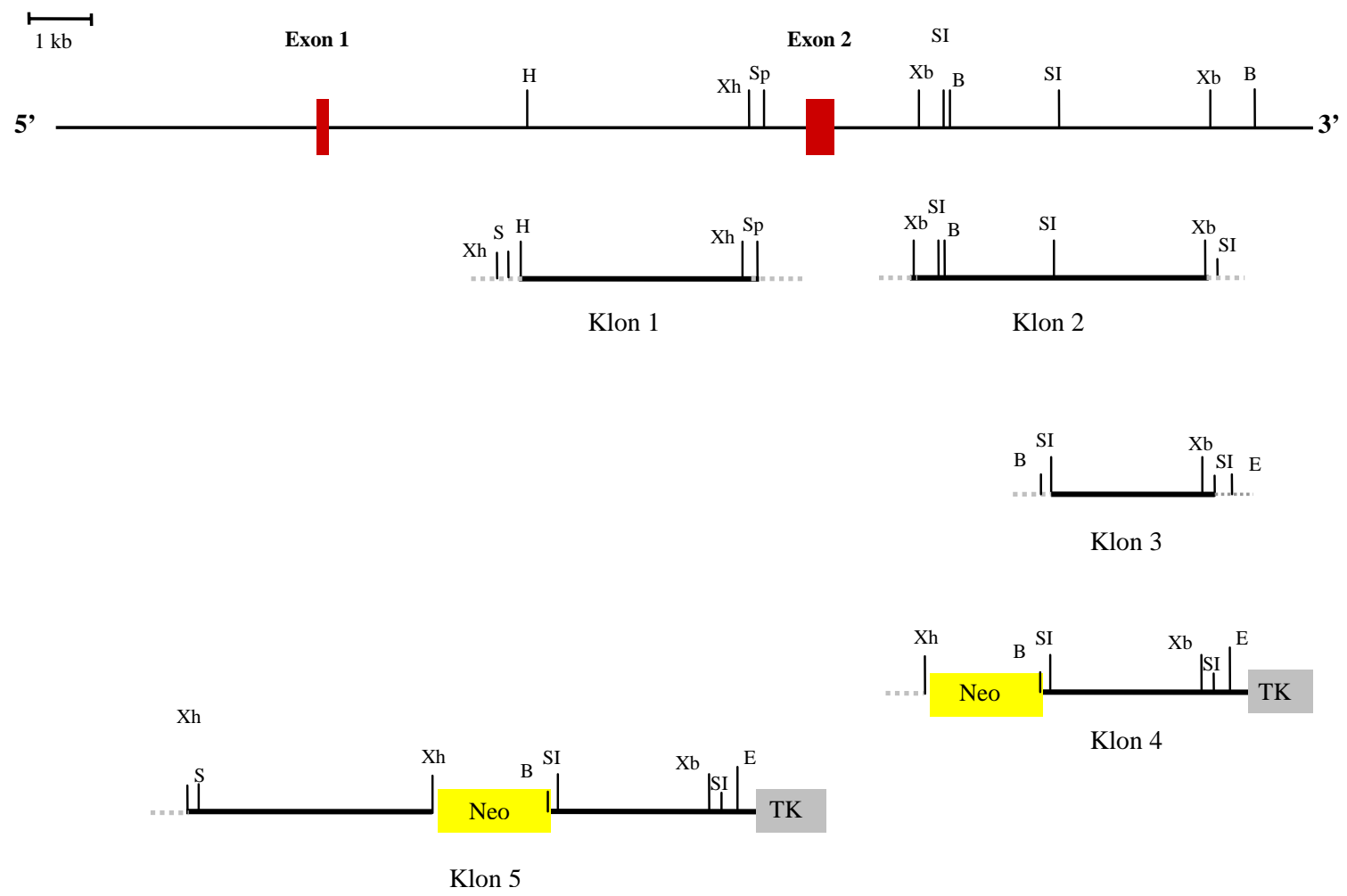


A Abb. 3.5: Strukturelle Organisation des Insl5-Gens der Maus und Restriktionskarte der Klone 1 ,2, 3, 4 und 5. Oben ist die strukturelle Organisation des Insl5-Gens der Maus dargestellt. Es enthält 2 Exons, die durch rote Rechtecken gekennzeichnet sind; das Intron ist 7.9 kb lang. Darunter sind die genomischen Subklone 1 bis 5 angegeben. Die Neomycin Kassette ist gelb; TK steht für die Herpes Simplex Virus Thymidinkinase Kassette und ist grau dargestellt. Die Großbuchstaben stehen für die Schnittstellen der Enzyme BamHI (B) EcoRI (E), HindIII (H), NotI (N), SalI (S), SpeI (Sp), SstI (SI), XbaI (Xb) und XhoI (Xh).

Die DNA-Fragmente wurden so gewählt, dass die PGK-Neomycin-Kassette das Exon 2 des Insl5-Gens ersetzt (Abb. 3.6). Dadurch sollte gewährleistet werden, dass das Transkript des Insl5-Gens ausgeschaltet wird. Bei den speziesfremden DNA-Segmenten handelt es sich um die $1.8 \mathrm{~kb}$ lange PGK-Neomycin-Kassette, die sich in dem Replacementvektor pPNT (Tybulewicz et al., 1991) befindet und für die positive Selektion benötigt wird. Die isolierten $5^{\prime}$ - und $3^{\prime}$-flankierenden Fragmente sollten in richtiger Anordnung in die entsprechenden Klonierungsstellen des pPNT-Vektors eingefügt und die richtige Orientierung durch nachfolgende Restriktionsanalysen überprüft werden. Zudem sollte eine außerhalb des Konstrukts gelegene 3'-Sonde isoliert werden, mit der die homologen Rekombinationsereignisse in ES-Zellen aufgezeigt werden können. Die hypothetische Strategie zur Inaktivierung des Insl5Gens ist in Abb. 3.6 dargestellt.
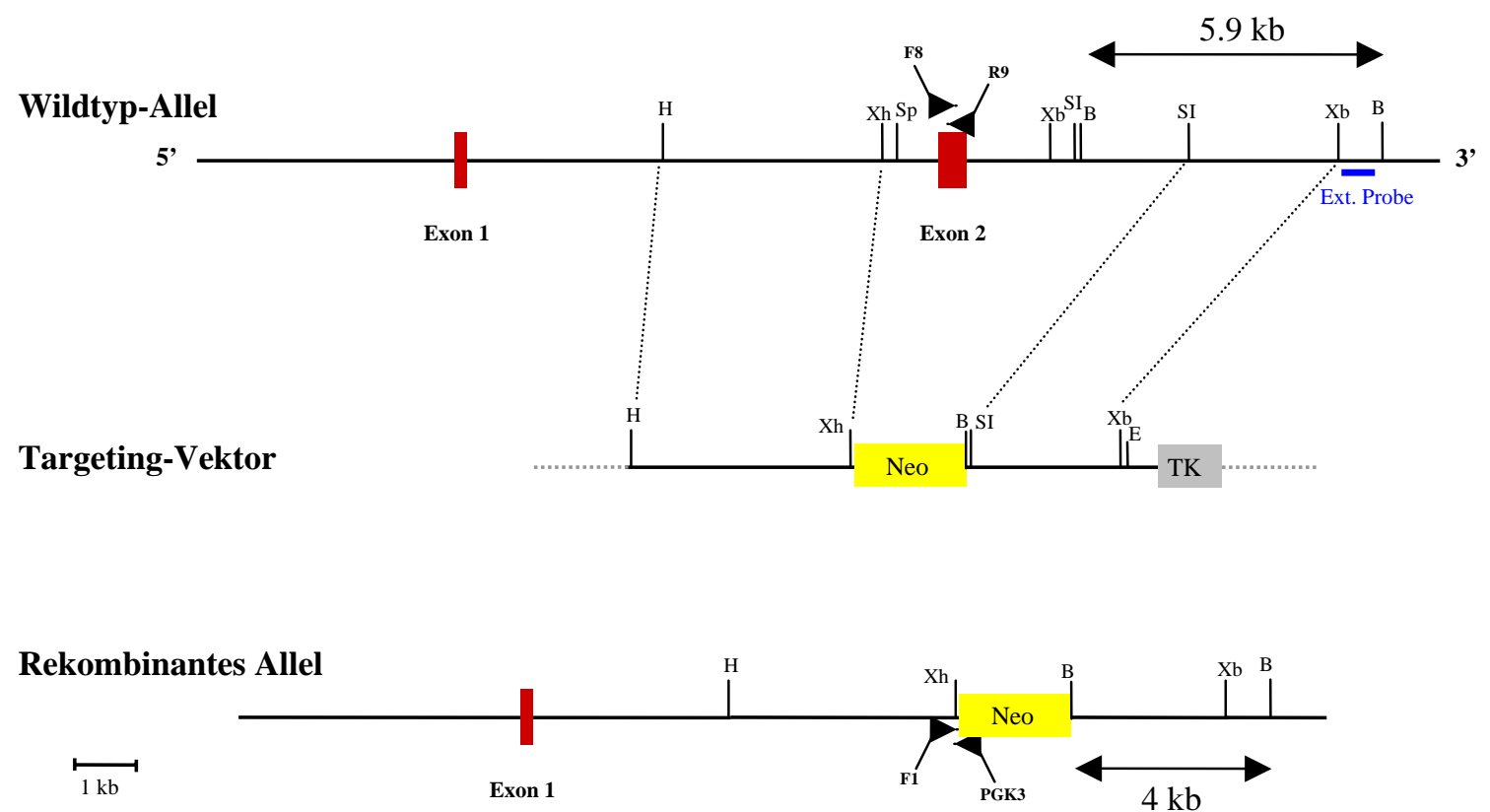
\ Abb. 3.6: Strategie zur Inaktivierung des Insl5-Gens der Maus. Die Darstellung zeigt schematisch den Vorgang der homologen Rekombination zur Deletion von Exon 2 des Insl5-Gens. Im oberen Teil findet sich das Wildtyp-Allel mit seinen 2 Exons. In der Mitte ist der Targeting Vektor dargestellt. Im unteren Teil ist das rekombinante Allel mit dem deletierten Bereich zwischen der XhoI- und der SstISchnittstelle abgebildet. Die Lokalisation der Neo- und der externen Sonde sind angegeben. Die Großbuchstaben stehen für die Schnittstellen der Enzyme BamHI (B), EcoRI (E), HindIII (H), SpeI (Sp), SstI (S), XbaI (Xb) und XhoI (Xh). TK steht für die Herpes Simplex Virus Thymidinkinase Kassette. Außerdem wurden die Primer für die Genotypisierungs-PCR eingezeichnet: das Primerpaar C-Insl5F8 (F8) und C-Insl5R9 (R9) dient zur Amplifizierung des Wildtyp-Allels, Insl5-F1 (F1) und pGK3 zur Amplifizierung des mutanten Allels.

\subsubsection{Isolierung und Klonierung der 3 '-flankierenden Region sowie der externen 3 '-Sonde}

Der PAC-Klon, der die Insl5-Sequenz beinhaltet, wurde im Institut für Humangenetik, Göttingen, isoliert. Aus dem PAC-Klon wurde ein 5.1 kb HindIII Fragment isoliert, das die 3'-flankierte Region des Insl5-Gens enthält. Das 5.1 kb HindIII Fragment wurde in den Bluescript Vektor subkloniert (Klon 2).

Aus dem genomischen Klon 2 (Abb. 3.5) wurde durch den Verdau mit dem Restriktionsenzym SstI ein $2.8 \mathrm{~kb}$ großes Fragment herausgeschnitten, über eine 0.8\%iges Agarosegel gelelektrophoretisch aufgetrennt und aus dem Gel isoliert. Dieses $2.8 \mathrm{~kb}$ SstI Fragment wurde erneut in den Vektor pUC 18 subkloniert und der entstandene Vektor als Klon 3 bezeichnet. Der Klon 3 wurde dann mit den Restriktionenzymen BamHI und EcoRI verdaut, das $2.8 \mathrm{~kb}$ große Fragment isoliert und in mit dem ebenfalls BamHI/EcoRI geschnittenen pPNT-Vektor subkloniert (Klon 4).

Für die Analyse korrekter Rekombinationsereignisse in den ES-Zellen war die Isolierung einer außerhalb des Konstrukts gelegenen Sonde notwendig. Wie in Abb. 3.6 erkennbar ist, gibt es in 3'-Richtung des Ins15 Gen eine BamHI-Schnittstelle, die 1.2 kb von der o.g. EcoRI-Schnittstelle entfernt liegt. Deshalb wurde durch PCR mit den Primern Mins5/F2 und Mins5/R2 ein 650 bp großes Fragment generiert, subkloniert und sequenziert. Diese 3'-Sonde zeigte nach Hybridisierung mit genomischer DNA der Maus keine repetitiven Sequenzen und wurde für die Southern-Blot Analyse transfizierter ES-Zellen eingesetzt. 


\subsubsection{Isolierung und Klonierung der 5'-flankierenden Region}

Aus dem PAC-Klon wurde ein $4.2 \mathrm{~kb}$ großes HindIII/SpeI Fragment isoliert, das die Intron Sequenz beinhaltet. Das $4.2 \mathrm{~kb}$ HindIII/SpeI Fragment wurde in den pBluescript Vektor subkloniert (Klon 1).

Für die Klonierung des 5'-flankierenden Bereichs des Targeting Vektors wurde die gesamte $4 \mathrm{~kb}$ große 5'-Region aus dem Subklon 1 mit dem Restriktionsenzym XhoI herausgeschnitten und aus dem Gel extrahiert. Für die Klonierung dieses 5'-Fragments wurde die DNA eines Klons 4, der bereits die 3'-flankierende Region in richtiger Orientierung enthielt, mit dem Enzym XhoI verdaut und mit dem 5'-flankierenden Fragment ligiert (Klon 5). Nach der Transformation des Ligationsansatzes wurden die Kolonien mit der cDNA-Sonde des Ins15-Gens gescreent. Die Plasmid-DNA positiver Klone wurde isoliert, mit dem Enzym XbaI verdaut und gelelektrophoretisch aufgetrennt. Die positiven und richtig orientierten Klone wiesen drei Fragmente der Größen $8.5 \mathrm{~kb}, 2.8 \mathrm{~kb}$ und $2.4 \mathrm{~kb}$ auf. Die Länge der Fragmente stimmt mit den Positionen der XbaI-Schnittstellen im Targeting Vektor überein.

Zudem musste überprüft werden, ob sich der Targeting Vektor mit dem Enzym SalI linearisieren lässt. Die SalI-Schnittstelle stammt dabei nicht aus der nativen Sequenz des Insl5-Gens, sondern wurde aus der Klonierungsstelle des Klons 1 nach Isolierung des $4 \mathrm{~kb}$ großen 5'-Fragments in das Konstrukt eingefügt.

\subsubsection{Elektroporation der ES-Zellen mit dem Targeting Vektor Insl5 und Selektion homolog rekombinanter InsI5 ${ }^{+/}$-ES-Zellen}

Die R1-ES-Zellen (Nagy et al., 1993) wurden auf einem konfluenten „Layer“ kultivierter, mit Mitomycin $\mathrm{C}$ behandelter, primärer embryonaler Fibroblasten (EmFi) ausplattiert. Exponentiell wachsende ES-Zellen wurden auf einer Kulturschale mit einem Durchmesser von $90 \mathrm{~mm}$ bis zu einer Zahl von 7 × $10^{6}$ Zellen kultiviert, durch Trypsinisierung geerntet und mit $50 \mu \mathrm{g}$ des durch SalI linearisierten Targeting-Vektors elektroporiert. Nach dem DNA-Transfer wurden die Zellen 20 min auf Eis inkubiert und anschließend in fünf $60 \mathrm{~mm} \varnothing$ Kulturschalen mit EmFi-Zellen ausplattiert. Die positive und negative Selektion (PNS) mit G418 (positive Selektion) und Gancyclovir (negative Selektion) begann nach 12 bis $16 \mathrm{~h}$. Die Gancyclovir-Selektion wurde nach fünf Tagen 
beendet, während die G418-Selektion bis zur Isolierung resistenter Klone am achten oder neunten Tag aufrechterhalten wurde. Nach der Identifizierung und Isolierung positiver Klone wurde die Hälfte der Zellen bei $-80^{\circ} \mathrm{C}$ kryokonserviert, während die andere Hälfte der Zellen bis zur Konfluenz kultiviert und für die Genotypisierung herangezogen wurde. Die isolierte DNA der ES-Zellklone wurde mit dem Restriktionsenzym BamHI geschnitten, nach der gelelektrophoretischen Auftrennung auf eine Nitrocellulosemembran transferiert und mit der externen $3^{\prime}$-Sonde (Abb. 3.6) hybridisiert. Das Wildtyp-Allel des Insl5-Gens sollte durch eine $5.9 \mathrm{~kb}$-Bande charakterisiert werden, während das mutierte Allel ein 4 kb langes Fragment anzeigt. Durch die Hybridisierung mit der externen 3'-Sonde wurde von 96 ES-Zellklonen ein positiver ES-Zellklon identifiziert (Abb. 3.7).

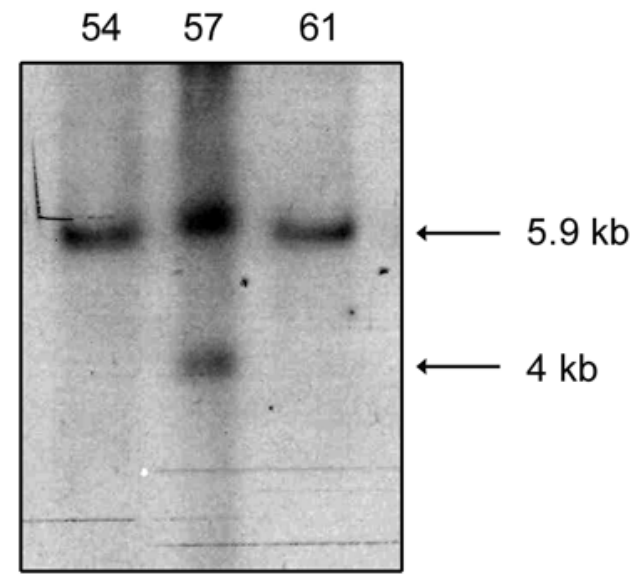

Abb. 3.7: Southern-Blot-Analyse von ES-Zell-DNA nach Elektroporation mit dem Targeting Vektor für Insl5. Genomische DNA aus isolierten ES-Zellkolonien wurde mit BamHI verdaut, gelelektrophoretisch aufgetrennt, auf eine Nitrocellulosemembran transferiert und mit der externen 3'Sonde hybridisiert. Das 5.9 kb große Fragment repräsentiert das Wildtypallel des Insl5-Locus, während die 4 kb Bande durch die Längendifferenz der Neomycinkassette im Vergleich zum deletierten Insl5Genabschnitt ca. 2 kb kürzer ist und das rekombinante Allel anzeigt. Die ES-Zellen 57 sind heterozygot für die Mutation. 


\subsubsection{5}

Herstellung von Chimären durch Injektion der Blastocysten mit den Insl5 ${ }^{+/-}$-ES-Zellen

Nach genomischer Charakterisierung der isolierten ES-Zelllinien wurden die Zellen in flüssigem Stickstoff kryokonserviert. Für die Mikroinjektion in 3.5 Tage alte Blastocysten des Mausstammes C57B1/6J wurden die Zellen der Linie \#57 vier Tage vor der Blastocysteninjektion aufgetaut und auf Feederzellen ausgesät. Die Zellen wurden nach zwei Tagen im subkonfluenten Zustand erneut trypsinisiert und auf zwei $30 \mathrm{~mm} \varnothing$ Kulturschalen verteilt. Nach der Injektion der Blastocysten mit den homolog rekombinanten ES-Zellen wurden die Blastocysten in Ammenmäuse transferiert und die geborenen Chimären anhand des Agouti-Fellmarkers identifiziert. Die Blastocysteninjektion wurde im Max-Planck-Institut für experimentelle Medizin Göttingen durchgeführt.

\subsubsection{Charakterisierung der Chimären}

Die Chimären wurden durch Kreuzung mit Mäusen des Stammes C57B1/6J auf Keimbahn-transmission getestet. Es wurden drei männliche Chimäre (30\%, 45\% und 70\% Chimärismus) aus den homolog rekombinierten ES-Klonen \#57 generiert. Im Alter von 7 Wochen wurden diese Chimären mit weiblichen Wildtyp-Mäusen des Stammes C57Bl/6J verpaart. Nachkommen der transmittierenden Chimäre mit dem dominanten agouti-Allel, erkennbar an der braunen Fellfarbe, wurden durch eine Southern-Blot Analyse genotypisiert. Männliche und weibliche heterozygote Mäuse wurden zum Zwecke der Generierung homozygoter Mutanten miteinander verpaart.

Konnten unter den Nachkommen keine heterozygoten Tiere gefunden werden, da sich die rekombinanten ES-Zellen nicht an der Keimbahn beteiligt hatten, wurde die Chimäre aus der Zucht entfernt. 


\subsubsection{Die Analyse Insl5-defizienter Mäuse}

\subsubsection{Genotypisierung der Nachkommen}

Für die Genotypisierung der Tiere der $\mathrm{F}_{1}$ - und der $\mathrm{F}_{2}$-Generation wurden bei den drei Wochen alten Mäusen Schwanzbiopsien durchgeführt und die genomische DNA isoliert. Die Genotypisierungs-PCR erfolgte mit 200 ng der genomischen DNA und mit Insl5-allelspezifischen und neomycinkassettenspezifischen Primern (Abb. 3.6; Sequenzen siehe Material und Methoden 2.1.11). Mit der Primerkombination C-Ins15F8 und C-Ins15R9 konnte ein genomisches Fragment von 300 bp für das Wildtyp-Allel amplifiziert werden. Für die Amplifikation des 220 bp langen Fragmentes für das mutierte Allel wurde das Primerpaar CIns15/F und pGK3 verwendet. Wurde die PCR gleichzeitig mit vier Primern durchgeführt, so konnten die heterozygoten Mäuse anhand der beiden im Gel sichtbaren Banden identifiziert werden, während sich bei homozygoten knock-out Mäusen-/- bzw. bei Wildtyp-Mäusen nur die Wildtyp bzw. die mutierten PCR-Fragmente amplifizieren ließen. In Abb. 3.8 ist exemplarisch das Gelfoto einer Genotypisierungs-PCR dargestellt.

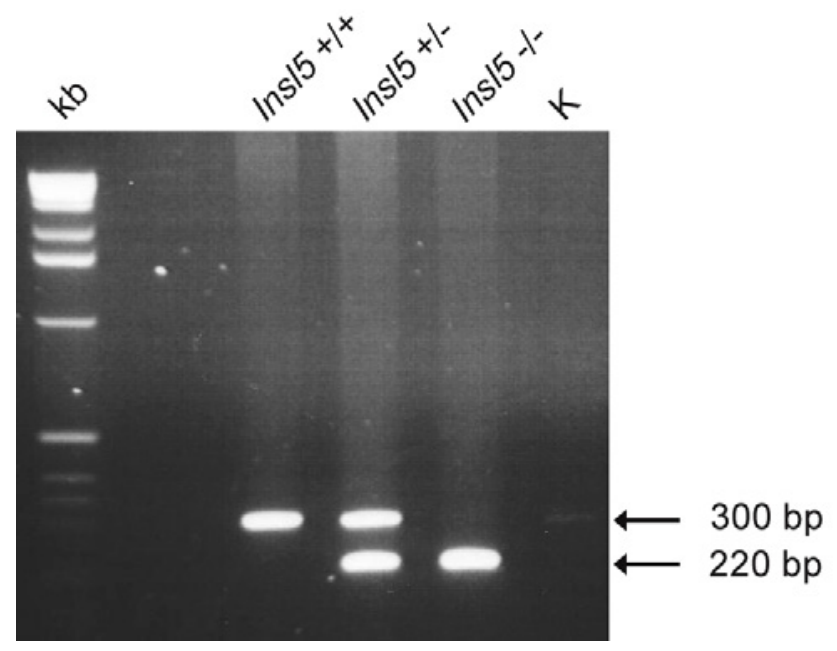

Abb. 3.8: Genotypisierung der Nachkommen in der $\boldsymbol{F}_{1^{-}}$und $\boldsymbol{F}_{2}$-Generation. Die Abbildung zeigt die gelelektrophoretische Auftrennung der PCR-Produkte zur Genotypisierung. Die PCR-Ansätze wurden für 35 Zyklen folgendem Programm unterzogen: $94^{\circ} \mathrm{C} 30 \mathrm{~s}, 58^{\circ} \mathrm{C} 30 \mathrm{~s}, 72^{\circ} \mathrm{C} 45 \mathrm{~s}$. Bei der PCR wurde beim Wildtyp ein 300 bp-Fragment, bei Insl5/--Mäusen ein 220 bp-Fragment und bei Insl5 ${ }^{+/-}$-Mäusen beide Banden amplifiziert. Kb ist Längestandard und K steht für Leerkontrolle. 


\subsubsection{Genotyp-Analyse der Nachkommen in der $F_{1}-$ und $F_{2}$-Generation}

Durch Verpaarung der männlichen Chimäre, die das mutierte Insl5-Allel durch die Keimbahn transmittierte, mit Weibchen des Stammes C57B1/6J wurden in der $\mathrm{F}_{1^{-}}$ Generation heterozygote und Wildtyp-Nachkommen generiert. Es konnte nur eine heterozygote Maus bei einer Gesamtzahl von 7 agouti-Tieren in vier Würfen identifiziert werden.

Nach der Verpaarung heterozygoter Eltern belief sich bei 26 Würfen mit insgesamt 193 Nachkommen der Anteil homozygoter -/- Tiere auf 22.3\% und der Anteil der WildtypNachkommen auf 24.3\%. 103 Tiere waren heterozygot (53.4\%). Diese Zahlen entsprechen den nach den Mendelschen Regeln zu erwartenden. Die durchschnittliche Wurfgröße ergab $7.4 \pm 2.9$ Tieren. Die homozygoten-/- Tiere unterschieden sich äußerlich nicht von ihren heterozygoten oder Wildtyp-Geschwistern.

In Tab. 3.1 ist die Verteilung der genotypisierten Nachkommen in der zweiten Generation dargestellt.

Tab. 3.1: Quantitative Verteilung von Wildtyp-, heterozygoten und homozygoten Mäusen in der $F_{2^{-}}$ Generation (+/- $x+/-)$ (Insl5)

\begin{tabular}{|c|c|c|c|c|c|c|}
\hline Generation & $\begin{array}{l}\text { Anzahl der } \\
\text { Würfe }\end{array}$ & $\begin{array}{l}\text { Gesamtzahl } \\
\text { (männlich) }\end{array}$ & $\begin{array}{c}\text { Homozygot } \\
-/- \\
\text { (männlich) }\end{array}$ & $\begin{array}{c}\text { Heterozygot } \\
+/-\end{array}$ & $\begin{array}{c}\text { Wildtyp } \\
+/+\end{array}$ & Wurfgröße \\
\hline $\mathrm{F}_{2}$ & 26 & 193(90) & $43(20)$ & 103 & 47 & $7.4 \pm 2.9$ \\
\hline
\end{tabular}

Die transmittierende Chimäre wurde auch mit Weibchen des Stammes 129/SvJ verpaart. Nach einer Verpaarung von insgesamt 8 Tieren konnten keine heterozygoten (+/-) Nachkommen erhalten werden.

Die durchschnittliche Wurfgröße nach Verpaarung homozygoter -/- Mäuse lag mit $5.5 \pm$ 2.1 Tieren bei einer Gesamtzahl von 71 in 13 Würfen niedriger als bei den heterozygoten Verpaarungen. 


\subsubsection{Kontrolle der Inaktivierung des Insl5-Gens durch Northern-Blot- Analyse}

Um die Inaktivierung des Insl5-Gens in den Insl5 ${ }^{-/}$-Mäusen nachzuweisen, wurde die Gesamt-RNA aus Rektum von Wildtyp-, heterozygoten und homozygoten Mäusen auf dem Hybridhintergrund C57Bl/6J x 129/SvJ isoliert und jeweils $20 \mu \mathrm{g}$ davon gelelektrophoretisch aufgetrennt. Die RNA wurde auf eine Membran transferiert und hybridisiert. Als Sonde für die Hybridisierung wurde das 650 bp lange Insl5-cDNAFragment benutzt (Abb. 3.1). Mit dieser Northern-Blot-Analyse sollte überprüft werden, ob in homozygoten -/- Mäusen ein Transkript auftritt. Die Integrität und die Menge der RNA wurde durch Nachhybridisierung mit der $\beta$-Aktin-Sonde überprüft.

Aus Abb. 3.9 geht hervor, dass im Rektum von Wildtyp-Mäusen ein starkes Signal für das Insl5-Transkript nachweisbar ist. Bei heterozygoten Tieren ist die Transkriptmenge eindeutig herabgesetzt, während bei Insl5 ${ }^{-/}$-Mäusen kein Transkript nachweisbar ist.

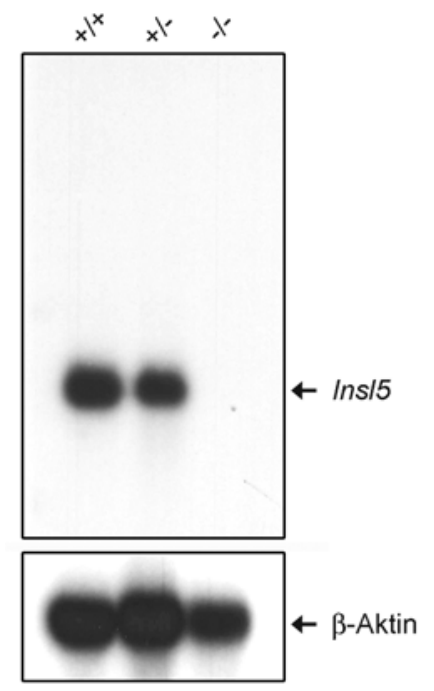

Abb. 3.9: Northern-Blot-Analyse mit Gesamt-RNA vom Rektum. Gesamt-RNA (je $20 \mu \mathrm{g}$ ) aus Rektum von Insl5 $5^{+/+}$-, Insl5 ${ }^{+/}$- und Insl5 ${ }^{/-}$-Mäusen wurde mit der Insl5-cDNA-Sonde hybridisiert. Die Integrität und Menge der aufgetragenen RNA wurde mit der $\beta$-Aktin-Sonde überprüft. 


\subsubsection{Histologische Darstellung und Alcian-Blau-Färbung von Kolon, Rektum und Thymus der Insl5-defizienten Mäuse}

Zur Analyse möglicher morphologischer Abweichungen von der Norm im Rektum (distales Kolon) und im Thymus der Ins15-defizienten Mäuse wurden von Prof. Dr. Klonisch (Department for Anatomy and Cell Science, Universität Manitoba, Kanada) Schnitte vom Rektum (distales Kolon) und Thymus von Insl5 ${ }^{-/}$-Mäusen sowie zur Kontrolle Schnitte einer Wildtyp-Maus angefertigt. HE-gefärbte Schnitte ergaben histomorphologische Veränderungen in den Insl5 ${ }^{--}$-Mäusen im Vergleich $\mathrm{zu}$ den Kontrollen. Insl5 ${ }^{-/}$-Mäuse zeigen Veränderungen im Kolonepithel; es erscheint weniger hoch und die beiden Hauptzelltypen, Kolonozyten und Becherzellen, scheinen in ihrer Anfärbbarkeit und in der Form der Zellkerne verändert. Außerdem ergab die histologische Schichtanalyse eine verminderte Vaskularisation im Bereich der Darmkrypten. (Abb. 3.10). Die unterschiedlichen Weiten der Drüsenschläuche und die unterschiedliche Höhe der Epithelien sind auf unterschiedliche Funktionszustände zurückzuführen. Im Thymus von Insl5 ${ }^{-/}$-Mäusen findet sich eine ,vermehrte“ Rinde (Cortex: enthält die Thymocyten) und ein kleineres Mark (Daten nicht gezeigt). Im Mark findet man vermehrt eosinophil-angefärbte (vermutlich) Thymus-Epithelzellen, welche Vorläufer der Hassall-Körper und typisch für den Thymus sind. Dies spräche für eine vermehrte Anhäufung und Differenzierung von Thymusepithelzellen und könnte Folge einer erhöhten Thymopoiese sein. 


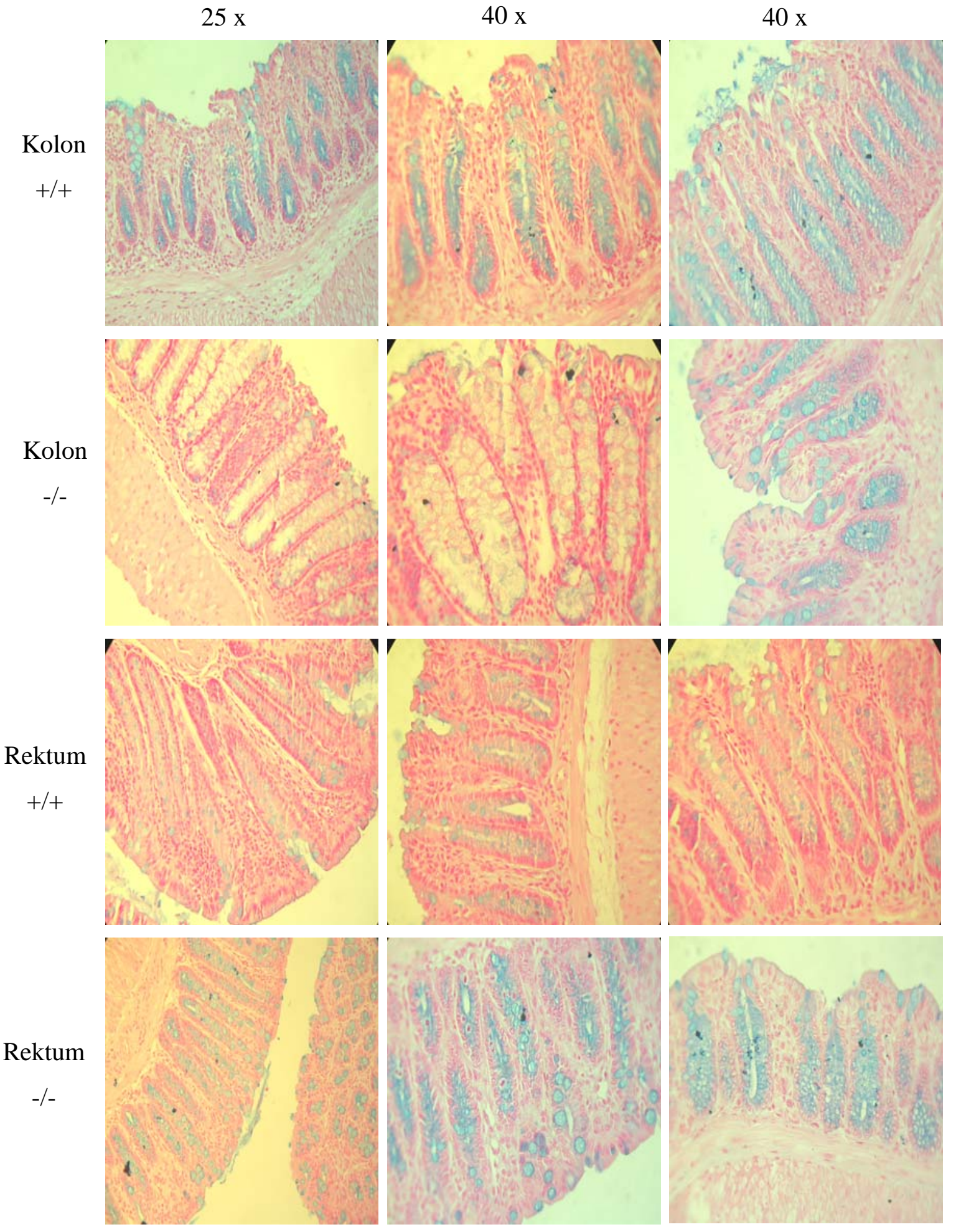

Abb. 3.10: Alcian-Blau-Färbung von Kolon und Rektum einer Insl5-defizienten Maus und einer Wildtyp-Maus (Prof. Dr. Klonisch). Die Abbildungen zeigen Schnitte durch das distale Kolon und Rektum einer Insl5 ${ }^{--}$-Maus und zum Vergleich Schnitte durch das distale Kolon und Rektum einer Wildtyp-Maus. 


\subsubsection{Analyse der Spermien der Insl5 $5^{-/-}$-Mäuse}

Die beobachtete Reduktion der Wurfgröße bei den Verpaarungen von Insl5 ${ }^{-/}$-Mäusen führten zu der Vermutung, dass Ins15 eine Rolle bei der Fertilität hat. Aus diesem Grund wurden verschiedene Spermienparameter analysiert.

\subsection{Analyse der Spermienanzahl}

Die Spermien zehn Wochen alter Insl5 ${ }^{-/}$- und Insl5 $5^{+/+}$-Mäuse wurden aus dem Nebenhoden in $2 \mathrm{ml}$ IVF-Medium resuspendiert und für $15 \mathrm{~min}$ bei $37^{\circ} \mathrm{C}$ inkubiert. Mit Hilfe der Neubauer-Zählkammer wurde die Zahl der Spermien bestimmt. Es wurden drei Mäuse pro Genotyp analysiert. Die Zahl der Spermien im Nebenhoden der Insl5 ${ }^{-{ }^{-}}$Mäuse war niedriger als die Spermienanzahl im Wildtyp (Tab. 3.2). Dieses Ergebnis könnte ein Hinweis auf eine leicht reduzierte Spermienanzahl bei Insl5-defizienten Mäusen sein.

Tab. 3.2: Spermienanalyse der Insl5 $5^{+/+}$- und Insl5 $5^{-/-}$-Mäuse

\begin{tabular}{|c|c|c|}
\hline \multicolumn{3}{|c|}{ Insl5 ${ }^{+/+}$-und Insl5 ${ }^{-/-}$-Mäuse auf dem genetischen Hintergrund C57Bl x 129/SvJ } \\
\hline Parameter: & \multicolumn{2}{|c|}{ Genotyp } \\
\hline & $+/+$ & $-/-$ \\
\hline Spermienanzahl im: & & \\
\hline Nebenhoden & $1.32 \times 10^{7} \pm 3.9 \times 10^{6}$ & $1.01 \times 10^{7} \pm 2 \times 10^{6}$ \\
\hline Akrosomenreaktion $(\%)$ & 84.5 & 71.7 \\
\hline
\end{tabular}

\subsection{Akrosomenreaktion}

Bevor ein Spermium eine Eizelle befruchten kann, muss es mehrere physikalische Barrieren durchdringen. Die aus Glykoproteinen bestehende Zona pellucida kann das Spermium durch Auslösen der Akrosomenreaktion durchdringen. Bei der Akrosomenreaktion wird der Inhalt des Akrosoms freigesetzt. Das dabei freigesetzte Akrosin baut die Zona pellucida lokal ab. Andere Proteine, die durch die Akrosomenreaktion freigesetzt werden, werden für die Bindung an die Eimembran und für die Fusion der Eizell- und Spermien-Membranen benötigt. Ohne die Akrosomenreaktion ist das Spermium nicht in der Lage, die Zona pellucida zu durchdringen. Um eine mögliche 
Funktion von Insl5 auf die Fähigkeit zur Akrosomenreaktion zu untersuchen, wurden Spermien von Insl5 ${ }^{-/}$- und Insl5 ${ }^{+/+}$-Mäusen aus der Cauda epididymis präpariert. Die Akrosomenreaktion wurde durch Inkubation der Spermien in modifiziertem TyrodeMedium mit Ionophor induziert, und dann mit Hilfe einer Coomassiefärbung untersucht. Spermien, die die Akrosomenreaktion durchgeführt haben, zeigen keine Färbung. Bei akrosomintakten Spermien wird eine spezifische Blaufärbung des Spermienkopfes nachgewiesen. Die quantitative Auswertung von 200 Spermien ergab keine signifikanten Unterschiede zwischen den Spermien aus den Wildtyp- und den Insl5 ${ }^{-/-}$-Mäusen (Abb. 3.11 und Tab. 3.2).

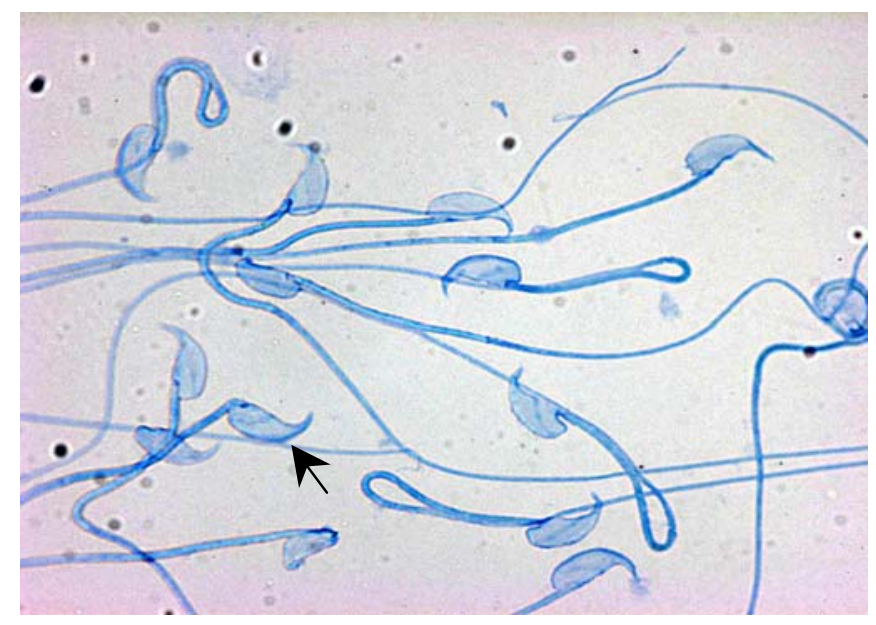

Abb. 3.11: Akrosomenreaktion an Insl5 ${ }^{-1}$-Spermien. Reagierende Spermien lassen sich nicht anfärben, während sich das Akrosom intakter Spermien blau anfärben lässt. In der Abbildung ist ein Spermium mit einer blauen Akrosomenkappe zu erkennen (Pfeil), das die Akrosomenreaktion nicht ausgeführt hat. Die Spermien ohne Blaufärbung sind akrosomreagiert.

\subsection{Analyse der Motilität von Spermien der Insl5-defizienten Mäuse}

Um eine mögliche Bedeutung des Insl5-Gens für die Motilität der Spermien zu analysieren, wurden aus dem Nebenhoden von zunächst drei männlichen Insl5defizienten und zwei Wildtypmäusen Spermien isoliert und mit einem computerunterstützten Spermienanalyseprogramm (CEROS) von Hamilton Thorne untersucht. Es wurde die Spermienmotilität nach 1.5, 3.5 und 5.5 h gemessen. Nach 1.5 h waren zwischen 40 bis $60 \%$ der Spermien der Insl $^{+/+}$- und $I n s l 5^{-/-}$-Mäuse beweglich und 25 bis $40 \%$ zeigten dabei progressive Bewegungen (Tab. 3.3). Die Messungen nach 3.5 h ergaben, dass sich der Anteil der motilen Spermien um ca. 10\% reduziert, die 
Progressivität dieser (motilen) Spermien aber nur geringfügig abnahmen. Einige Parameter wurden genauer untersucht, darunter die Geschwindigkeit, die Schlagfrequenz des Schwanzes und die Linearität des Schwimmens. Spermien zeigen ein spezifisches Bewegungsmuster, das in der Untersuchung durch die Messung der Weggeschwindigkeit (VAP), der progressiven Geschwindigkeit (VSL) und der Bahngeschwindigkeit (VCL) berücksichtigt wird (Tab. 3.4). Mit der Bahngeschwindigkeit wird die totale Distanz, die der Spermienkopf in einer Zeiteinheit zurückgelegt hat, gemessen. Die Weggeschwindigkeit zeigt den durchschnittlichen Weg, den das Spermium in einer Zeiteinheit zurückgelegt hat. Die progressive Geschwindigkeit wird als die gerade Distanz zwischen dem Anfang und dem Ende des Weges, geteilt durch die verstrichene Zeit, gewertet. Für Schlagfrequenz (BCF) und Gradlinigkeit (STR) waren die Unterschiede klein aber signifikant. Für VAP-, VCLund ALH-Parameter (Abb.3.12) konnte eine signifikante Reduktion bei Insl5 ${ }^{-{ }_{-}}$Spermien in Vergleich zu Wildtypspermien gefunden werden $(\mathrm{P}<0.001)$.

Tab. 3.3 : Analyse der Motilität der Spermien der Insl5 ${ }^{+/+}$- und Insl5 $5^{-/}$-Mäuse (jeweils 3 Tiere) In Klammern sind die prozentualen Werte angegeben.

\begin{tabular}{|c|c|c|c|c|c|c|}
\hline Genotyp der Maus & \multicolumn{3}{|c|}{$+/+$} & \multicolumn{3}{|c|}{$-/-$} \\
\hline Inkubationszeit (h) & 1.5 & 3.5 & 5.5 & 1.5 & 3.5 & 5.5 \\
\hline Gesamtzahl der gemessenen & 1271 & 1376 & 1414 & 1187 & 1201 & 1040 \\
\hline Spermien $(\%)$ & $(100)$ & $(100)$ & $(100)$ & $(100)$ & $(100)$ & $(100)$ \\
\hline $\begin{array}{l}\text { Anzahl der motilen } \\
\text { Spermien }(\%)\end{array}$ & $(52.5 \pm 11.5)$ & $(52 \pm 11)$ & $(45.5 \pm 8.5)$ & $(48 \pm 4.9)$ & $(39.3 \pm 12.6)$ & $(27.6 \pm 13)$ \\
\hline \begin{tabular}{|l|} 
Anzahl der Spermien mit \\
progressive Bewegungen $(\%)$
\end{tabular} & $34.5 \pm 9.5$ & $34.5 \pm 9.5$ & $31 \pm 6$ & $31.3 \pm 2.3$ & $25.6 \pm 8.9$ & $15.3 \pm 8.5$ \\
\hline
\end{tabular}

Tab. 3.4: Ergebnis der Spermienanalysen der Insl5 $5^{+/+}$- und Insl5 $5^{-/}-$Mäuse (jeweils drei Tiere)

\begin{tabular}{|l|c|c|c|c|c|c|} 
Genotyp & \multicolumn{5}{|c|}{$+/+$} & \multicolumn{3}{|c|}{$-/-$} \\
\hline Inkubationszeit $(\mathrm{h})$ & 1.5 & 3.5 & 5.5 & 1.5 & 3.5 & 5.5 \\
\hline Weggeschwindigkeit $(\mu \mathrm{m} / \mathrm{s})$ & 119.9 & 119.2 & 115.75 & 111.4 & 109.13 & 97.6 \\
\hline $\begin{array}{l}\text { Prog. Geschwindigkeit } \\
(\mu \mathrm{m} / \mathrm{s})\end{array}$ & 95.55 & 93.15 & 91.45 & 93.9 & 88.13 & 78.5 \\
\hline Bahngeschwindigkeit $(\mu \mathrm{m} / \mathrm{s})$ & 187.75 & 181.65 & 177.2 & 169.6 & 165.36 & 145.1 \\
\hline Seitliche Amplitude $(\%)$ & 8.1 & 8.1 & 8.05 & 7.7 & 7.5 & 6.7 \\
\hline Schlagfrequenz $(\%)$ & 17.65 & 15.1 & 14.05 & 17.26 & 16.1 & 13.13 \\
\hline Gradlinigkeit $(\%)$ & 78.5 & 77.5 & 78.5 & 83.3 & 79.6 & 80.3 \\
\hline Linearität $(\%)$ & 52.5 & 53.5 & 54 & 57.3 & 54.6 & 57 \\
\hline
\end{tabular}


Exemplarisch werden hier Schemata für die Spermienparameter für die Zeit nach $1.5 \mathrm{~h}$ dargestellt (Abb. 3.12).
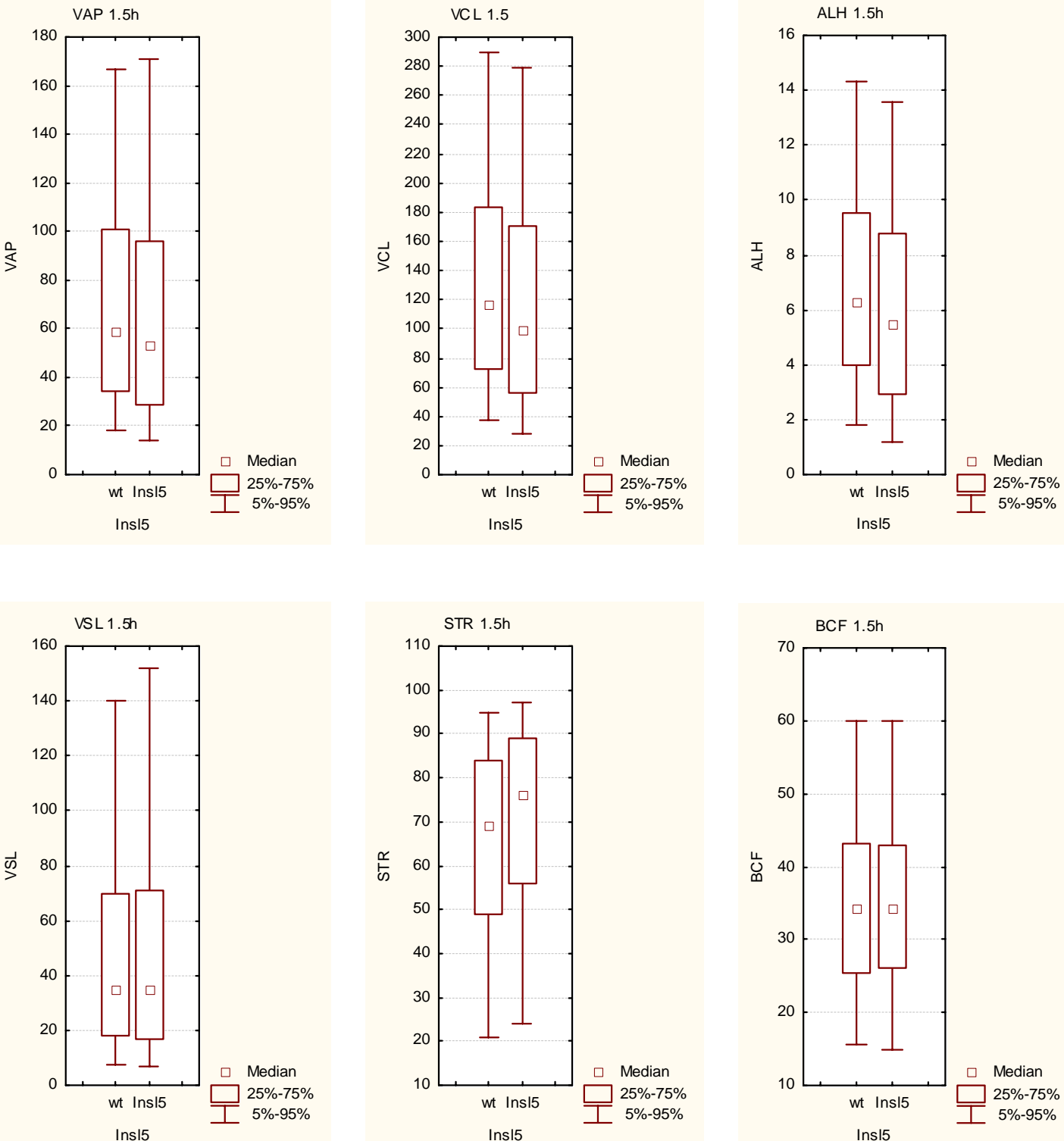

Abb. 3.12: Schematische Darstellung der Spermiengeschwindigkeitsparameter, aufgeschlüsselt nach

Mäusen. Es wurden je 3 Mäuse hinsichtlich der Spermienmotilität untersucht. Die Geschwindigkeiten sind zur besseren statistischen Vergleichbarkeit als Logarithmus naturalis (Ln) dargestellt. VAP= Weggeschwindigkeit, VSL= progressive Geschwindigkeit, VCL= Bahngeschwindigkeit, $A L H=$ seitliche Amplitude. Zusammenfassend kann festgestellt werden, dass sich die Spermienmotilität der Insl5defizienten Mäuse von der der Wildtyp-Mäuse unterscheidet. 


\subsection{Insl6-Gen}

\subsubsection{Expression des Insl6-Gens bei der Maus}

Das Insl6-Gen wird bei der adulten Maus ausschließlich im Testis exprimiert (Lok et al., 2000). Im Rahmen dieser Arbeit wurden weitere Experimente zur Analyse der Expression des Insl6-Gens durchgeführt.

\subsubsection{Herstellung der Insl6-cDNA der Maus mittels RT-PCR}

Die Expression des Insl6-Gens in verschiedenen Geweben wurde mittels Northern-Blot und RT-PCR untersucht.

Für die Expressionsexperimente mussten zunächst die entsprechenden Sonden für die Hybridisierungen hergestellt werden. Die Insl6-cDNA wurde durch RT-PCR mit Insl6 spezifischen Primern amplifiziert. Für die cDNA-Synthese wurde $1 \mu \mathrm{g}$ Gesamt-RNA aus Testis einer adulten Maus mit dem One-Step RT-PCR-Kit umgeschrieben. Nach der Klonierung in den Vektor pGEM-T ${ }^{\circledR}$ Easy wurde das PCR-Produkte sequenziert. Durch Vergleich der Nukleotidsequenz des cDNA-Klons mit Insl6-cDNA in der Datenbank konnte eine Homologie von 100\% innerhalb der entsprechenden Bereiche der cDNA festgestellt werden (Abb. 3.13).

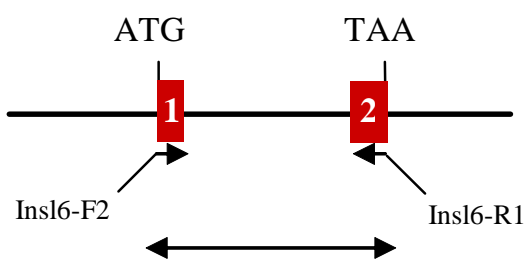

Genomisch: $>3.8 \mathrm{~kb}$ cDNA: $580 \mathrm{bp}$

Abb. 3.13: Schema und Primerpositionen für die durchgeführte RT-PCR. . Die PCR wurde so geplant, dass das PCR-Produkt eine Länge von 580 bp hat und die Sequenz beider Exons von Insl6 beinhaltet. PCR-Bedingungen: 35 Zyklen: $94^{\circ} \mathrm{C} 30 \mathrm{~s} ; 60^{\circ} \mathrm{C} 30 \mathrm{~s} ; 72^{\circ} \mathrm{C} 45 \mathrm{~s}$. 


\subsubsection{Analyse der Expression von Insl6 an RNA aus verschiedenen Geweben der Maus}

Für die Northern-Blot-Analyse wurde Gesamt-RNA aus verschiedenen Organen der adulten Maus präpariert und $20 \mu \mathrm{g}$ der jeweiligen RNA in einem denaturierenden Agarosegel aufgetrennt. Das Gel wurde geblottet und mit der radioaktiv markierten Insl6-cDNA-Sonde (Abb. 3.13) hybridisiert.

Die Expression des Insl6-Gens konnte durch Hybridisierungssignale in einigen adulten Geweben nachgewiesen werden (Abb. 3.14.A). Das stärkste Signal konnte im Testis detektiert werden. In Niere, Ovar, Kolon und Milz konnten schwache Signale nachgewiesen werden. Eine anschließende Rehybridisierung des Northern-Blots mit einer cDNA-Sonde für $\beta$-Aktin diente zur Überprüfung der Integrität der RNA sowie zur Prüfung, ob gleiche Mengen an RNA eingesetzt wurden.

Zur Untersuchung des Insl6-Gens in verschiedenen Geweben wurde auch eine RT-PCR Analyse wie unter 3.2.1.1 durchgeführt. Wie aus der Abbildung 3.14.B entnommen werden kann, ist die Intensität der amplifizierten RT-PCR-Produkte im Testis höher als in anderen Geweben. Wie beim Northern-Blot konnte auch bei der RT-PCR Analyse keine Insl6-Expression in Gehirn, Herz, Lunge, Magen und Leber nachgewiesen werden. 
A

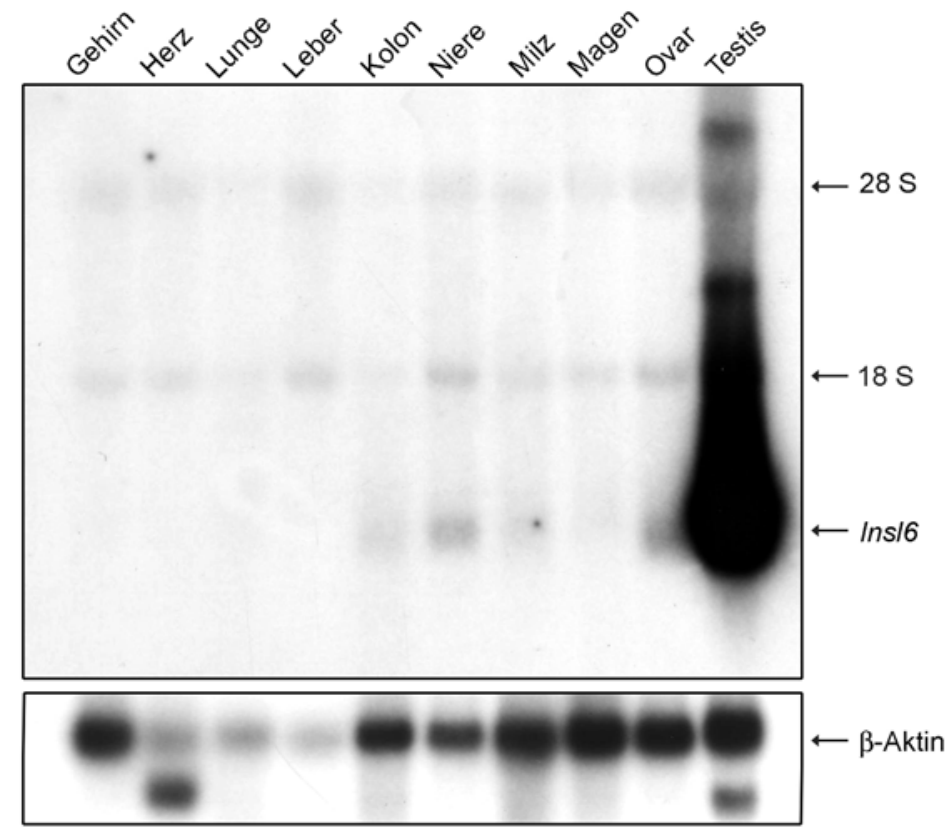

B

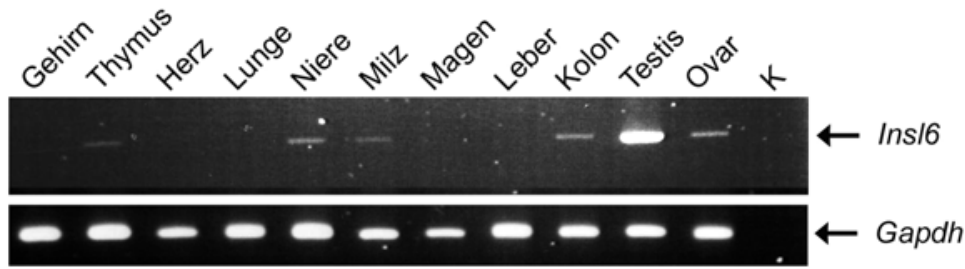

Abb. 3.14: Analyse der Expression des Insl6-Gens der Maus in verschiedenen Geweben. (A) GesamtRNA aus verschiedenen Geweben wurde mit der Insl6-cDNA-Sonde hybridisiert. Die Integrität und Menge der aufgetragenen RNA wurde durch eine Nachhybridisierung der Membran mit $\beta$-Aktin überprüft. (B) Gelelektrophoretische Auftrennung der PCR-Produkte zur Analyse der Expression in den verschiedenen Organen der Maus. Die Gesamt-RNA aus verschiedenen Organen wurde einer RT-PCR mit Insl6-spezifischen Primern unterworfen. Die Integrität der RNA wurde durch eine zweite PCR mit Gapdh spezifischen Primern überprüft.

\subsubsection{Expressionsanalyse von Insl6 durch RT-PCR an Gesamt-RNA der embryonalen Maus}

Um Aufschluss über den Zeitpunkt der Expression des Insl6-Gens während der pränatalen Entwicklung zu erhalten, wurde eine RT-PCR an embryonaler Gesamt-RNA durchgeführt. Mit Insl6-spezifischen Primern wurde ein RT-PCR-Ansatz mit RNA aus 9.5 bis 15.5 Tage alten Embryonen durchgeführt. Die PCR-Produkte wurden anschließend auf ein Agarosegel gegeben und elektrophoretisch aufgetrennt (Abb. 
3.15). Das erwartete PCR-Produkt von 650 bp konnte in jedem Ansatz nachgewiesen werden. Daraus kann geschlossen werden, dass die Transkription des Insl6-Gens bereits sehr früh in der Embryonalentwicklung beginnt. Die Integrität der eingesetzten RNA wurde durch eine Kontroll-PCR mit Gapdh-spezifischen Primern überprüft.

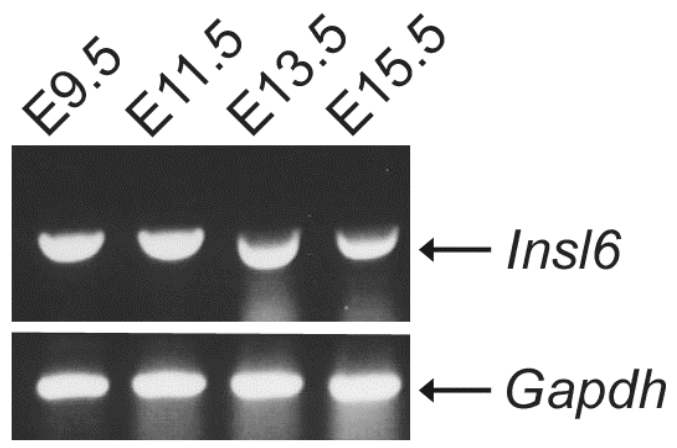

Abb. 3.15: Expression von Insl6 während der Embryonalentwicklung der Maus. Für die ReverseTranskriptase-Reaktion wurden RNA-Proben aus Embryonen der Entwicklungstage 9.5 bis 15.5 dpc (nach Befruchtung) verwendet. Die PCR-Produkte konnten durch die genspezifischen Primer Insl6-F2 und Insl6-R1 nach der Reversen-Transkriptase-Reaktion amplifiziert werden und wurden anschließend in einem 1.5\%igen Agarosegel aufgetrennt. Das 650 bp große Fragment konnte in allen Ansätzen nachgewiesen werden. Eine Gapdh-Kontrolle diente zur Überprüfung der Integrität der RNA.

\subsubsection{Untersuchungen zur Expression des Insl6-Gens während der Testisentwicklung}

Zur Untersuchung der Expression des Insl6-Gens während der postnatalen Testisentwicklung wurde Gesamt-RNA aus Testes von 5, 10, 15, 20, 25 und 30 Tage alten Mäusen und auch aus adulten Mäusen präpariert. Die RNA wurde anschließend denaturierend gelelektrophoretisch aufgetrennt und auf eine Nitrocellulosemembran transferiert (Northern-Blot). Die Northern-Blot-Membran wurde anschließend mit dem radioaktiv markierten $0.65 \mathrm{~kb}$ langen Insl6-cDNA-Fragment üN bei $65^{\circ} \mathrm{C}$ hybridisiert.

Wie Abb. 3.16 zeigt, ist das 0.8 kb lange Insl6-Transkript erst ab Tag 15 der postnatalen Entwicklung detektierbar. An diesem Tag hat die Spermatogenese das Stadium der Pachytän-Spermatozyten erreicht. Zur Prüfung der Integrität der verwendeten RNA wurde die Membran mit der $\beta$-Aktin Sonde nachhybridisiert. 


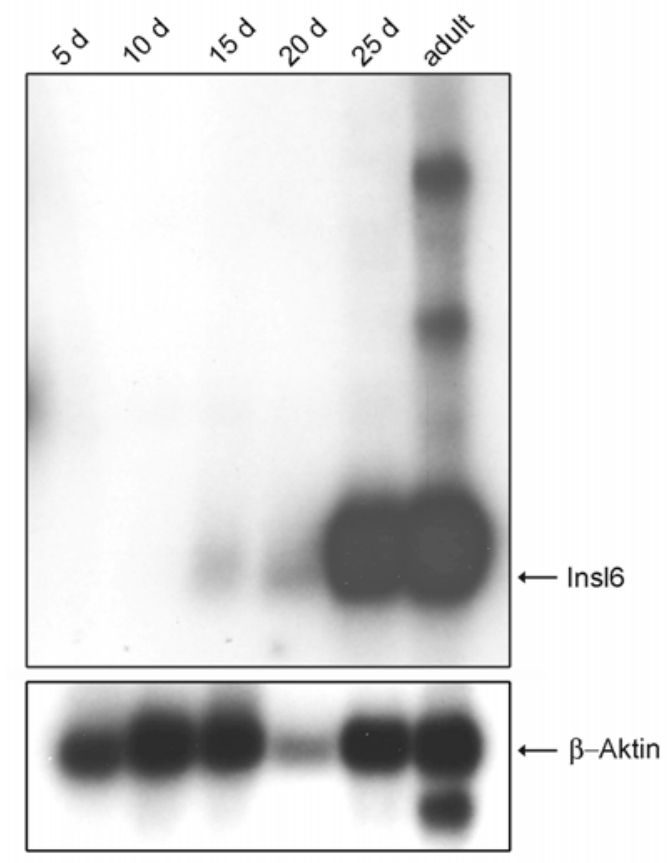

Abb. 3.16: Northern-Blot-Analyse zur Expression des Insl6-Gens der Maus in der postnatalen Testisentwicklung. Gesamt-RNA (je $20 \mu \mathrm{g}$ ) aus Testes 5, 10, 15, 20 und 25 Tage alter und adulter Mäuse wurde nach denaturierender Gelelektrophorese auf eine Nitrocellulosemembran transferiert und mit der Insl6-cDNA-Sonde hybridisiert. Die Integrität und Menge der aufgetragenen RNA wurde durch eine Nachhybridisierung der Membran mit $\beta$-Aktin überprüft.

\subsubsection{Analyse der Expression des Insl6-Gens in Testes verschiedener Mausmutanten mit Keimzelldefekten}

Für die Untersuchung der Expression von Insl6 im Testis verschiedener Mutanten der Maus wurden jeweils $20 \mu \mathrm{g}$ Gesamt-RNA aus Testes der Mutanten $W / W^{\nu}, T f m / Y$ (Lyon und Hawkes, 1970), Insl3 ${ }^{--}$(Zimmermann et al., 1997), olt/olt (Moutier, 1976) und $q k / q k$ (Bennett et al., 1971) gelelektrophoretisch aufgetrennt, auf eine Nitrocellulosemembran transferiert und mit der radioaktiv markierten 600 bp langen Insl6-cDNA hybridisiert (Abb. 3.17). 


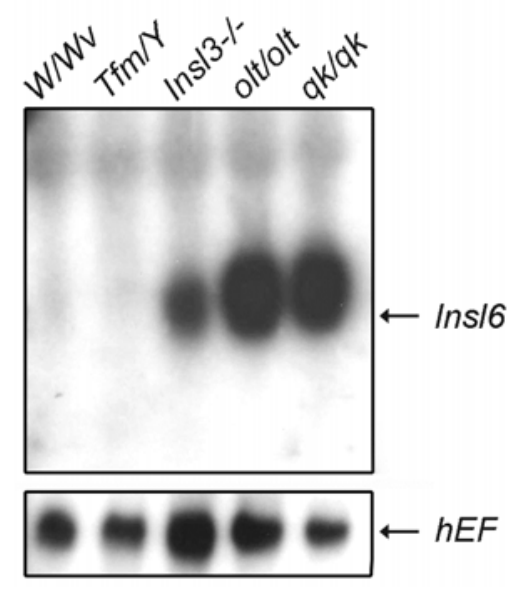

Abb. 3.17: Analyse der Expression des Insl6-Gens in Testes verschiedener Mausmutanten mit Keimzelldefekten. Gesamt-RNA (je $20 \mu \mathrm{g}$ ) aus Testes adulter Mäuse der Linien W/W ${ }^{\nu}$, Tfm/Y, Insl3 ${ }^{-/}$, olt/olt und $q k / q k$ wurde nach denaturierender Gelelektrophorese auf eine Nitrocellulosemembran transferiert und mit der Insl6-cDNA-Sonde hybridisiert. Die Integrität und Menge der aufgetragenen RNA wurde durch eine Nachhybridisierung der Membran mit hEF-cDNA überprüft. Die starke Expression bei den Mutanten olt/olt sowie $q k / q k$, sowie die deutlich schwächere Expression in der Mauslinie Insl3 ${ }^{-/}$ist gut zu erkennen.

Nach etwa einwöchiger Exposition konnten positive Hybridisierungssignale bei den Mäusen der Linien olt/olt und $q k / q k$ nachgewiesen werden, bei der Insl3 ${ }^{-/}$-Mutante wurden geringe Insl6-Transkriptmengen detektiert. Bei der $W / W^{\nu}$ - und $T f m / Y$-Mutante konnte kein Insl6-Transkript gefunden werden (Abb. 3.17). Diese Ergebnisse haben gezeigt, dass Insl6 erst in Pachytän-Spermatozyten exprimiert wird.

Im Testis der $W / W^{\nu}$-Mutante fehlen die Keimzellen. Bei der $T f m / Y$-Maus differenzieren sich die Spermatogonien bis zu den Primärspermatozyten, während bei olt/olt- und $q k / q k$-Mutanten die Spermatogenese bis zu den haploiden Spermatiden erfolgt. Im Testis der kryptorchiden Mausmutante $I n s 3^{-/-}$entwickeln sich die Spermatogonien aufgrund der abdominalen Temperatur um $37^{\circ} \mathrm{C}$ nur bis zu den diploiden PachytänSpermatozyten, jedoch können sich einige wenige Spermatogonien auch weiter ausdifferenzieren und die haploide Phase erreichen. 


\subsection{2 Zur Funktion des Insl6-Gens}

Bislang liegen weder Erkenntnisse über die Funktion des murinen Insl6-Gens noch des humanen INSL6-Gens vor. Daher sollten Insl6-knock out Mäuse erzeugt werden, durch deren Analyse Erkenntnisse über die Funktion des Gens gewonnen werden sollen.

\subsubsection{Isolierung eines genomischen Klons für das Insl6-Gen der Maus}

\subsection{Screen einer Cosmid-Maus-Bibliothek}

Zur Isolierung genomischer Klone wurde eine Cosmid-Bibliothek der Maus des RZPD (Berlin) eingesetzt. Als Sonde für das Screenen der genomischen Bank diente das radioaktiv markierte cDNA-Fragment (Abb.3.13) des Insl6-Gens. Mit dieser radioaktiv markierten Sonde konnte kein positiver Klon detektiert werden.

\subsection{Screenen einer PAC-Bibliothek}

Zur Isolierung genomischer Klone für das Insl6-Gen der Maus wurde eine genomische PAC-Bibliothek (RZPD, Berlin) gescreent, die aus dem Mausstamm 129/SvJ etabliert wurde. Es wurden zwei PAC-Klone identifiziert. Diese Klone wurden bei RZPD (Berlin) bestellt.

Die Plasmid-DNA der zwei positiven PAC-Klone (Klon RPCIP711I09135Q2 und RPCIP711I0987Q2) wurde präpariert. Die DNA dieser Klone wurde mit den Restriktionsenzymen BamHI und SstI gespalten, auf einem Agarosegel aufgetrennt und auf Nitrozellulosefilter transferiert. Der Southern-Blot wurde mit der radioaktiv markierten Insl6-cDNA-Sonde hybridisiert. Durch den Vergleich mit dem Bandenmuster auf dem Agarosegel und dem Hybridisierungsmuster zeigte sich der Klon RPCIP711I09135Q2 als positiv und wurde deshalb für eine weitergehende Untersuchung berücksichtigt. 


\subsubsection{Die Strategie zur Inaktivierung des Insl6-Gens}

Zum Zwecke der Konstruktion des Targeting Vektors und der Subklonierung geeigneter 5'- und 3'-flankierender Fragmente wurde im Vorfeld eine detaillierte Restriktionskarte der entsprechenden genomischen Insl6-Phagenklone hergestellt.

Die DNA-Fragmente wurden so gewählt, dass die PGK-Neomycin-Kassette das Exon 1 des Insl6-Gens, in dem das Startkodon (ATG) enthalten ist, ersetzt (Abb. 3.18). Die hypothetische Strategie zur Inaktivierung des Insl6-Gens ist in Abb. 3.18 dargestellt.

$14 \mathrm{~kb}$
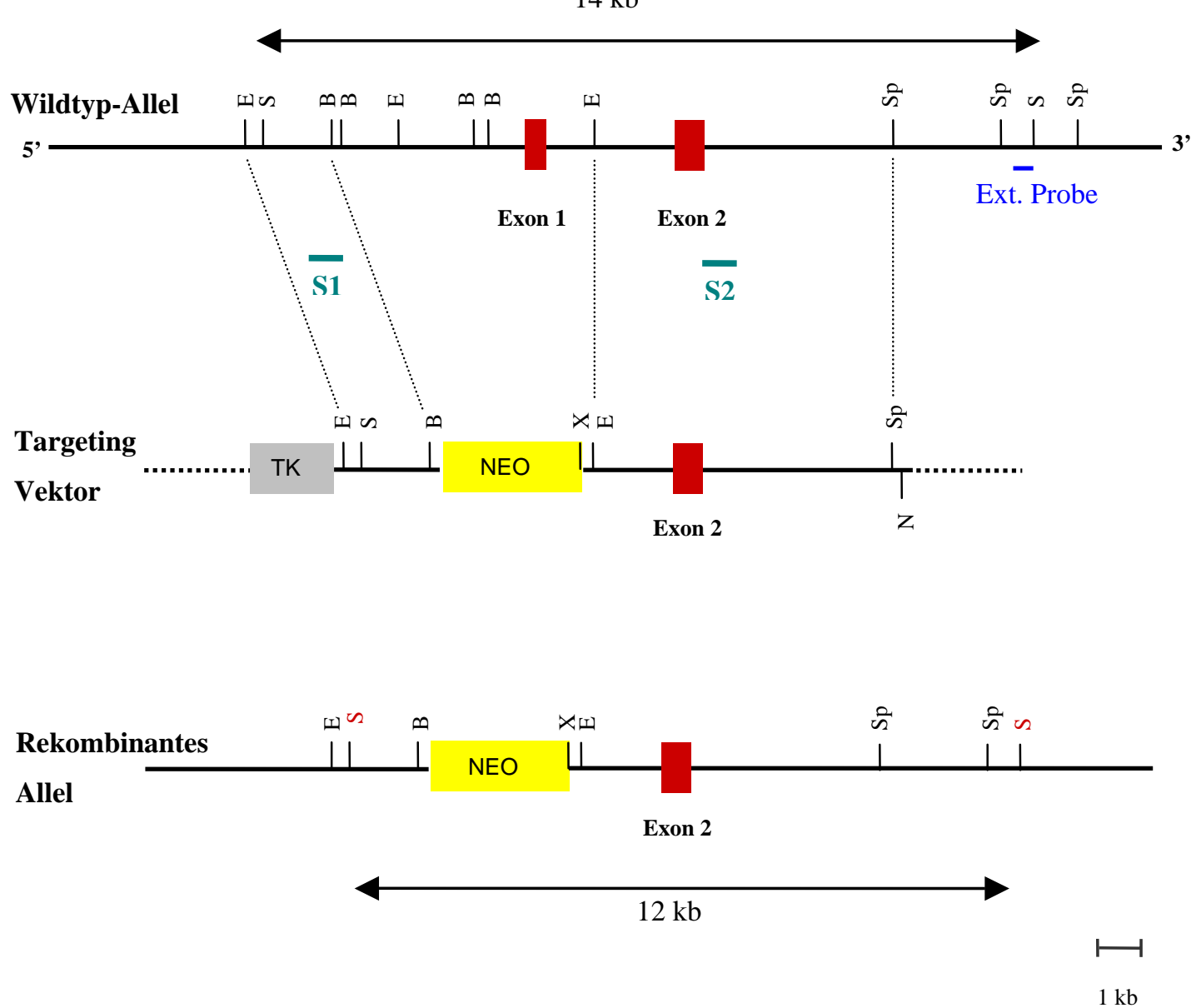

Abb. 3.18: Zur Inaktivierung des Insl6-Gens der Maus. Die Darstellung zeigt schematisch den Vorgang der homologen Rekombination zur Deletion von Exon 1 des Insl6-Gens. Im oberen Teil findet sich das Wildtyp-Allel mit seinen 2 Exons. In der Mitte ist der Targeting Vektor dargestellt. Im unteren Teil ist das rekombinante Allel mit dem deletierten Bereich zwischen der BamHI- und der EcoRI-Schnittstelle abgebildet. Die Lokalisation von Neomycin (Neo), der externen Probe (Ext.), der Sonde 1 (S1) und Sonde 2 (S2) ist angegeben. Die Großbuchstaben stehen für die Schnittstellen der Enzyme BamHI (B) EcoRI (E), $\operatorname{NotI}(N)$, SpeI (Sp), SstI (S), XhoI (X). 
Der PAC-Klon RPCIP711I09135Q2 wurde mit EcoRI geschnitten und in die EcoRISchnittstelle des pZErO-2.1 Vektors subkloniert. Das in pZErO subklonierte EcoRI genomische Fragment wurde dann mit zwei Sonden (Sonde 1 und 2 in Abb. 3.18) hybridisiert. Die Sonde 1 liegt in der 5'-flankierenden Region des Ins6-Gens, während die Sonde 2 in der 3'-flankierenden Region des Insl6-Gens liegt.

Die Sonde 1 identifizierte einen Klon (E6), der das 6 kb EcoRI-Fragment enthält. Dieses 6 kb EcoRI Fragment beinhaltet die 5' flankierende Region und Exon 1 des Insl6-Gens. Die Sonde 2 identifizierte einen Klon (E18), der das 18 kb EcoRI Fragment enthält. Das 18 kb EcoRI Fragment beinhaltet das Intron 1, Exon 2 und die 3'flankierende Region (Abb. 3.19).
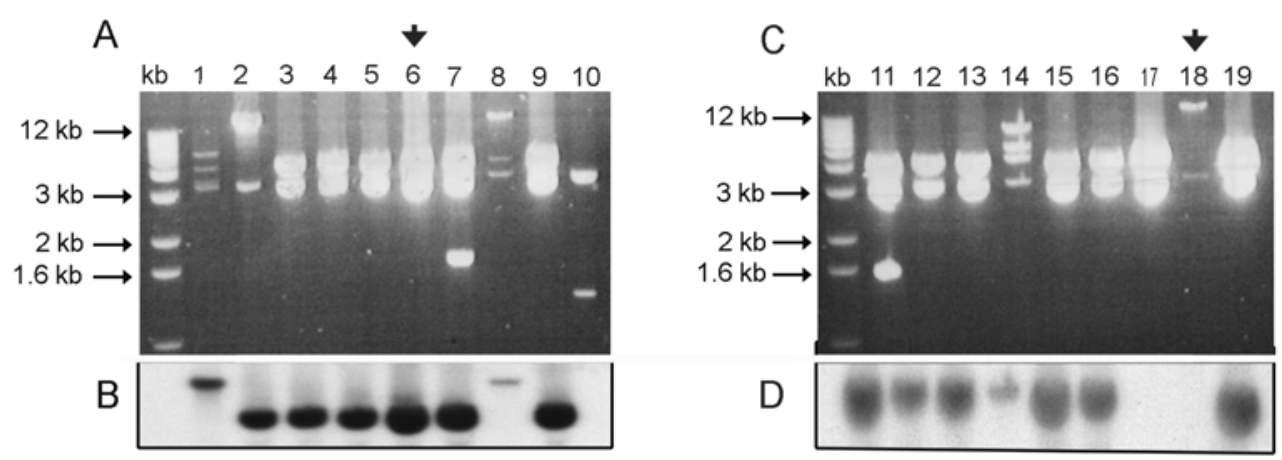

Abb. 3.19: Isolierung der 5'- und 3'-flankierenden Bereiche des Insl6-Gens. DNA der positiven Klone, die die 5'Region (A) und die 3'Region (B) des Insl6-Gens enthalten, wurden mit EcoRI verdaut und auf dem Gel aufgetrennt. Die Southern-Blots für die Agarosegele A bzw. B wurden mit Sonde 1 (C) bzw. Sonde 2 (D) hybridisiert. Ein aufgetragener Längenstandard (kb) diente der Bestimmung der Fragmentgröße.

Mit Hilfe der genomischen Sequenz konnte bestimmt werden, wie die Anordnung der Fragmente im isolierten Klon ist. Es wurden Restriktionskarten für die Klone E6, E18 und das gesamte Insl6-Gen erstellt (Abb. 3.20). 


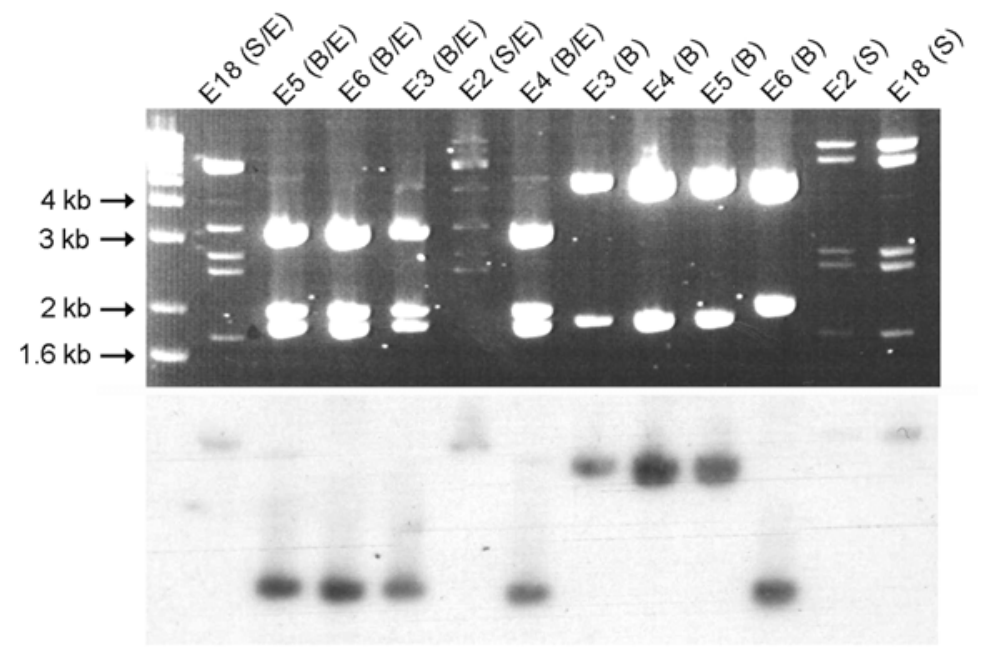

Abb. 3.20: Restriktionsanalyse für die positiven Klone. Die positiven Klone wurden für die verschiedenen Schnittstellen und die Länge der Fragmente überprüft und mit der Insl6-cDNA hybridisiert. Die Großbuchstaben stehen für die Schnittstellen der Enzyme BamHI (B), EcoRI (E) und SpeI (S).

\subsubsection{Isolierung und Klonierung der 5'-flankierenden Region}

Für die Klonierung des 5'-flankierenden Bereichs des Targeting Vektors wurde das 6 kb EcoRI genomische Fragment des Klons E6 mit den Restriktionsenzymen EcoRI und BamHI verdaut. Das $1.8 \mathrm{~kb}$ große EcoRI/BamHI-Fragment wurde aus dem Klon E6 isoliert und als 5'-flankierendes Fragment in den Targeting Vektor pPNT subkloniert. Dieser Klon wurde als Klon I/4 bezeichnet und für die weitere Klonierung benutzt.

\subsubsection{Isolierung und Klonierung der 3 '-flankierenden Region sowie der externen 3 '-Sonde}

Der genomische Klon E18 (Abb. 3.19), der ein insgesamt 18 kb großes Fragment der 3'-flankierenden Region des Insl6-Gens enthält, wurde nacheinander mit den Restriktionsenzymen EcoRI und SpeI verdaut. Aus dem 18 kb genomischen Fragment wurde ein $6.5 \mathrm{~kb}$ EcoRI/SpeI großes Fragment herausgeschnitten (Abb. 3.20) und mit dem EcoRI/SpeI-verdauten pBluescript-Vektor ligiert (Abb. 3.21). Die positiven Klone wiesen zwei Fragmente der Größen 6.5 kb und 3 kb auf. Dieser Klon wurde als Klon II/3 bezeichnet und sequenziert. 


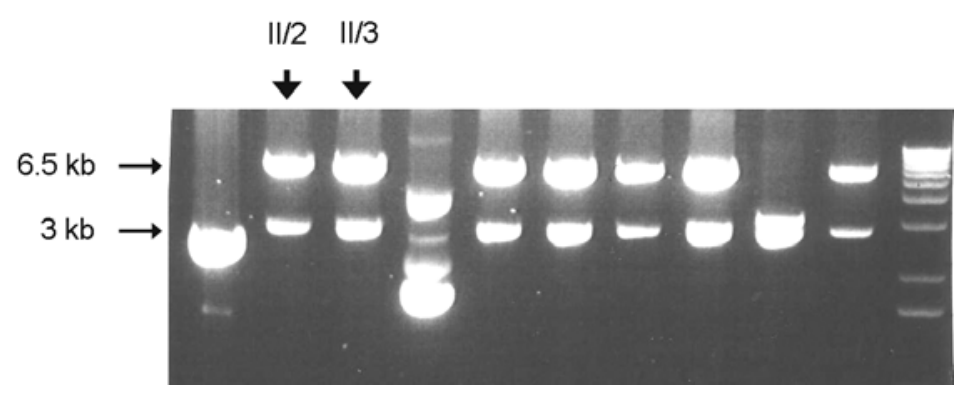

Abb. 3.21: Isolierung des 6.5 kb Fragments für die 3'- flankierende Region des Insl6-Gens.

Der Klon II/3 (Abb. 3.21), der ein insgesamt 6.5 kb großes Fragment der 3'flankierenden Region des Insl6-Gens enthält, wurde nacheinander mit den Restriktionsenzymen XhoI und NotI verdaut und ein $6.5 \mathrm{~kb}$ großes Fragment herausgeschnitten. Das NotI/XhoI-Fragment wurde aus dem Gel extrahiert und mit dem NotI/XhoI-verdauten pPNT5'-Klon (Klon I/4) ligiert. Nach der Transformation des Ligationsansatzes wurden 8 Kolonien gepickt, Plasmid-DNA isoliert und mit den Enzymen XhoI/NotI verdaut. Zwei der acht gepickten Klone enthielten das erwartete 6.5 kb große 3'-Fragment (Abb. 3.22).

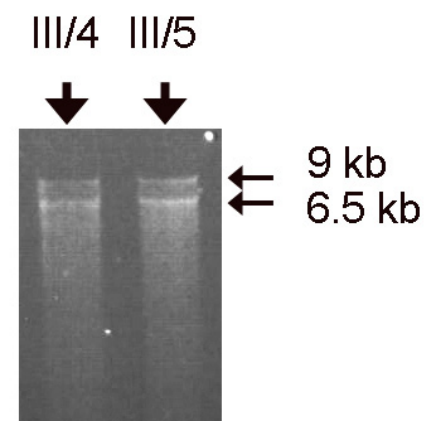

Abb. 3.22: Insl6-Konstrukt. Pfeile zeigen die positiven Klone, die das vollständige Konstrukt für Insl6 enhalten. Nach dem Verdau der DNA des Targeting-Konstrukts (III/5) mit NotI und XhoI konnten die erwarteten 9 und $6.5 \mathrm{~kb}$ großen Fragmente detektiert werden.

Für die Analyse korrekter Rekombinationsereignisse in den ES-Zellen war die Isolierung einer außerhalb des Konstrukts gelegenen Sonde notwendig. Wie in Abb. 3.18 erkennbar, wurde in 3'-Richtung des Insl6 Gens zwischen der SpeI- und BamHISchnittstelle mit den Primern Mins6/F40, Mins6/R30 ein 650 bp großes Fragment 
generiert, subkloniert und sequenziert. Diese 3'-Sonde zeigte nach Hybridisierung mit genomischer DNA der Maus keine repetitiven Sequenzen (Daten nicht gezeigt) und wurde für die Southern-Blot Analyse transfizierter ES-Zellen eingesetzt.

\subsubsection{Linearisierung des Targeting-Vektors}

Nach Insertion der 5'- und 3'-flankierenden Regionen des Ins6-Gens der Maus in den Transfer-Vektor pPNT musste überprüft werden, ob sich der Targeting Vektor (Klon III/5) mit dem Enzym NotI linearisieren lässt. Die NotI-Schnittstelle stammt dabei nicht aus der nativen Sequenz des Insl6-Gens, sondern wurde aus der Klonierungsstelle des Klons II/3 nach Isolierung des 6.5 kb großen 3'-Fragments in das Konstrukt eingefügt.

\subsubsection{6}

Elektroporation der ES-Zellen mit dem Targeting Vektor III/5 und Selektion homolog rekombinanter Insl6 ${ }^{+/}$-ES-Zellen

Die R1-ES-Zellen (Nagy et al., 1993) wurden wie in 3.1.2.4 beschrieben kultiviert und elektroporiert. Nach der Selektion wurden resistente Klone identifiziert und isoliert. Die isolierte DNA der ES-Zellklone wurde mit dem Restriktionsenzym SstI geschnitten, nach der gelelektrophoretischen Auftrennung auf eine Nitrocellulosemembran transferiert und mit der externen 3'-Sonde hybridisiert. Das Wildtyp-Allel des Insl6Gens sollte durch eine 14 kb-Bande charakterisiert werden, während das mutierte Allel durch ein $12 \mathrm{~kb}$ langes Fragment angezeigt wird. Durch die Hybridisierung mit der externen 3'-Sonde wurde von ca. 600 ES-Zellklonen 1 positiver ES-Zellklon identifiziert (Abb. 3.23). 


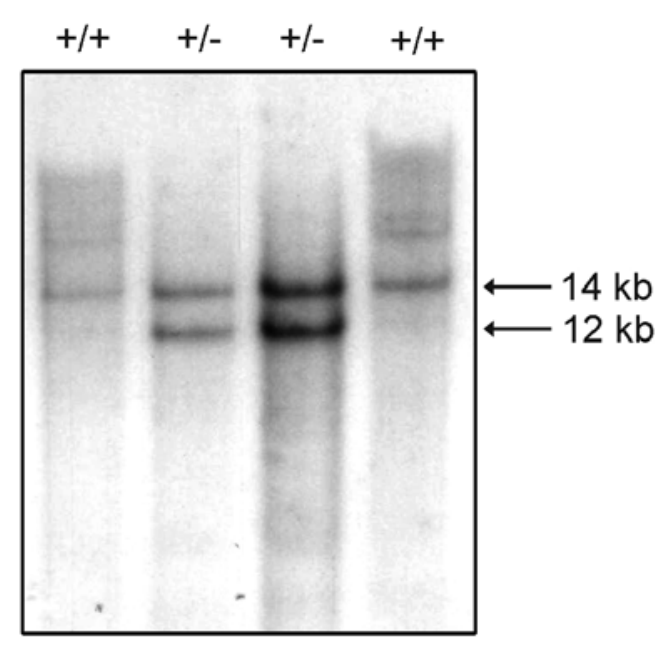

Abb. 3.23: Southern-Blot-Analyse von DNA aus ES-Zellkolonien nach Elektroporation mit dem Targeting Vektor für Insl6. Genomische DNA aus ES-Zellkolonien wurde mit SstI verdaut, gelelektrophoretisch aufgetrennt, auf eine Nitrocellulosemembran transferiert und mit der externen 3'Sonde hybridisiert. Das 14 kb große Fragment repräsentiert das Wildtypallel des Insl6-Locus, während die $12 \mathrm{~kb}$ Bande durch die Längendifferenz der Neomycinkassette im Vergleich zum deletierten Insl6Genabschnitt ca. 2 kb kürzer ist und das rekombinante Allel anzeigt. Der +/- ES-Zell Klon ist heterozygot für die Mutation. Hier wurde zweimal aufgetragen.

\subsubsection{7}

Herstellung von Chimären durch Injektion der Blastocysten mit den InsI6 $^{+/-}$-ES-Zellen

Die Chimären wurden wie unter 3.1.2.5 beschrieben durch eine Injektion der homolog rekombinanten ES-Zellen in Blastocysten hergestellt. Drei männliche Mäuse mit 5-30\% Chimärismus wurden im hauseigenen Tierstall mit Weibchen der Mauslinien C57BL und 129/SvJ verpaart. Die Genotypisierung der Nachkommen konnte im Rahmen der vorliegenden Arbeit nicht mehr durchgeführt werden. 


\subsection{Untersuchung zur Funktion des testikulären Insulins in $\mathbf{I}_{2} \mathbf{I}_{3}$-transgenen Mauslinien}

\subsubsection{Generierung der transgenen Konstrukte $\mathbf{I}_{2} \mathbf{I}_{3}$}

Um die Expression des humanen Insulin-Gens (INS) in den Leydigzellen zu induzieren, wurden im Rahmen dieses Projekts drei transgene Konstrukte hergestellt, in denen das humane INS-Gen unter die Kontrolle der 5'-flankierenden 700 bp Promotorregion des murinen Insl3-Gens gestellt wurde, welches insbesondere in den Leydigzellen exprimiert wird.

Das humane Insulin-Gen besitzt drei Exons. Das Exon 1 umspannt die 170 bp lange 5'nicht translatierte Region (5'-UTR), während die Exons 2 und 3 die translatierten Sequenzen beinhalten. Exon 3 schließt mit dem 96 bp langen 3'-nicht translatierten Bereich (3'-UTR) ab. Die drei transgenen Vektoren unterscheiden sich bezüglich ihrer 3'- und 5'-nichttranslatierten Regionen voneinander (Abb. 3.24). In dem ersten mit $\mathrm{I}_{2} \mathrm{I}_{3}-0$ benannten Konstrukt wurde das gesamte humane Insulin-Gen mit der 3'-UTR unter die Kontrolle des murinen Insl3-Promotors gestellt. Da die Stabilität der transkribierten mRNA von der Bindung der an die 3'-UTR bindenden gewebespezifischen RNABindungsproteine abhängig ist (Bernstein et al., 1989), wurde dieser Bereich bei den beiden weiteren als $\mathrm{I}_{2} \mathrm{I}_{3}-1$ und $\mathrm{I}_{2} \mathrm{I}_{3}-2$ bezeichneten Konstrukten durch die 3'nichttanslatierte Region des murinen Insl3-Gens substituiert. Da in einigen Publikationen gezeigt wurde, dass die Distanz von Transkriptionsstartpunkt und Translationsstartcodon für die Effizienz der Translation bedeutsam ist (Hecht, 1988; Nayernia et al., 1992) und diese Distanz bei dem murinen Insl3-Gen 3 bp, bei dem humanen Insulin-Gen aber 170 bp beträgt, wurde für das dritte Fusions-Konstrukt $\mathrm{I}_{2} \mathrm{I}_{3}-2$ der 5'-nicht translatierte Bereich durch die Deletion des nicht translatierten Exon 1 angeglichen. Die drei Fusionskonstrukte sind in Abbildung 3.24 dargestellt. 

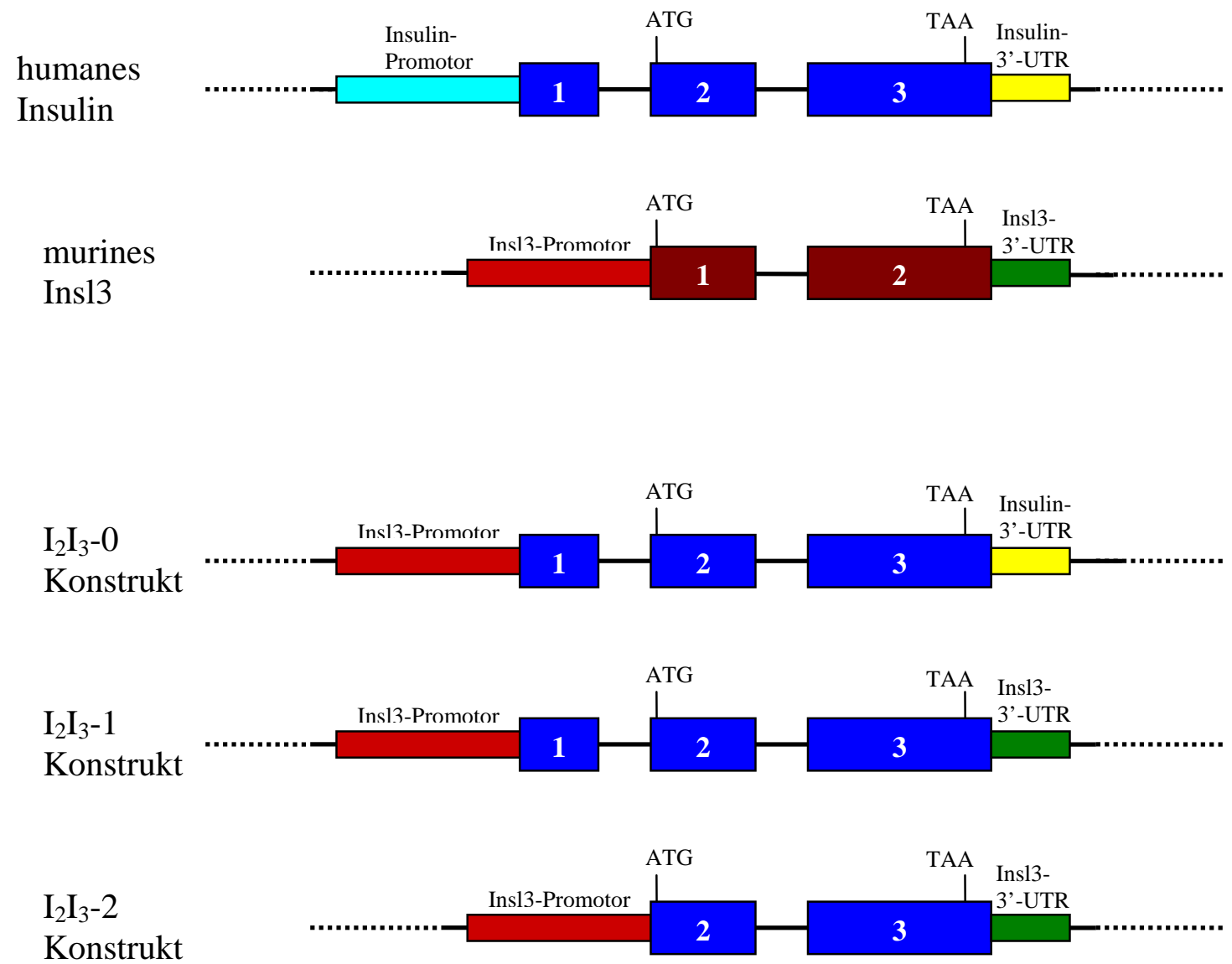

Abb. 3.24: Schematische Darstellung des humanen Insulin-Gens und des murinen Insl3-Gens sowie der Fusionskonstrukte $\boldsymbol{I}_{2} \boldsymbol{I}_{3}-\mathbf{0}, \boldsymbol{I}_{2} \boldsymbol{I}_{3}-1$ und $\boldsymbol{I}_{2} \boldsymbol{I}_{3}-2$. Die Konstrukte $I_{2} I_{3}-0$ und $I_{2} I_{3}-1$ beinhalten die Exons 1,2 und 3 und das Konstrukt $I_{2} I_{3}-2$ die Exons 2 und 3 des humanen INS-Gens (blaue Boxen) Die Konstrukte $I_{2} I_{3}-1$ und $I_{2} I_{3}-2$ enthalten die 3'-nichttranslatierte Region des Insl3-Gens. Dargestellt sind außerdem die Positionen der Translationsstartpunkte und der Stopkodons.

\subsubsection{Generierung des transgenen Konstrukts $\mathbf{I}_{2} \mathbf{I}_{3}-\mathbf{0}$}

Zur Generierung des $\mathrm{I}_{2} \mathrm{I}_{3}-0$ Fusionskonstrukts wurde zunächst ein $0.7 \mathrm{~kb}$ langes HindIII/XbaI-Fragment, welches die 5'-flankierende Region des murinen Insl3-Gens umspannt, aus einem Insl3-CAT-Vektor (Zimmermann et al., 1998) isoliert und in ein mit HindIII/XbaI verdauten pBluescript II SK +/- Vektor subkloniert. Der resultierende Vektor wurde sequenziert und als Klon 1 bezeichnet (Abb. 3.25).

Mittels der Primer Hins2F und Hins2R wurde an humaner genomischer DNA ein $1.3 \mathrm{~kb}$ langes Fragment amplifiziert und in den pGEM $^{\circledR}-\mathrm{T}$ easy Vector subkloniert. Der resultierende Vektor wurde Klon 2/0 genannt (Abb. 3.25). Der Primer Hins2F besitzt die komplementäre Sequenz der ersten 21 bp des Exons 1 des humanen Insulin-Gens. 
Der Primer Hins2R ist in der 5'-nichttranslatierten Region des humanen Insulin-Gens lokalisiert und beinhaltet 55 bp nach dem Stop-Kodon des humanen Insulin-Gens. Das amplifizierte Fragment besitzt innerhalb der Primersequenzen an seinem 5'-Ende eine XbaI- und an seinem 3'-Ende eine NotI-Schnittstelle. Das aus Klon 2/0 isolierte $1.3 \mathrm{~kb}$

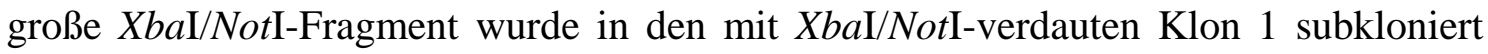
(Abb. 3.25). Das resultierende Konstrukt wurde als Klon $3 / 0$ bezeichnet und sequenziert.

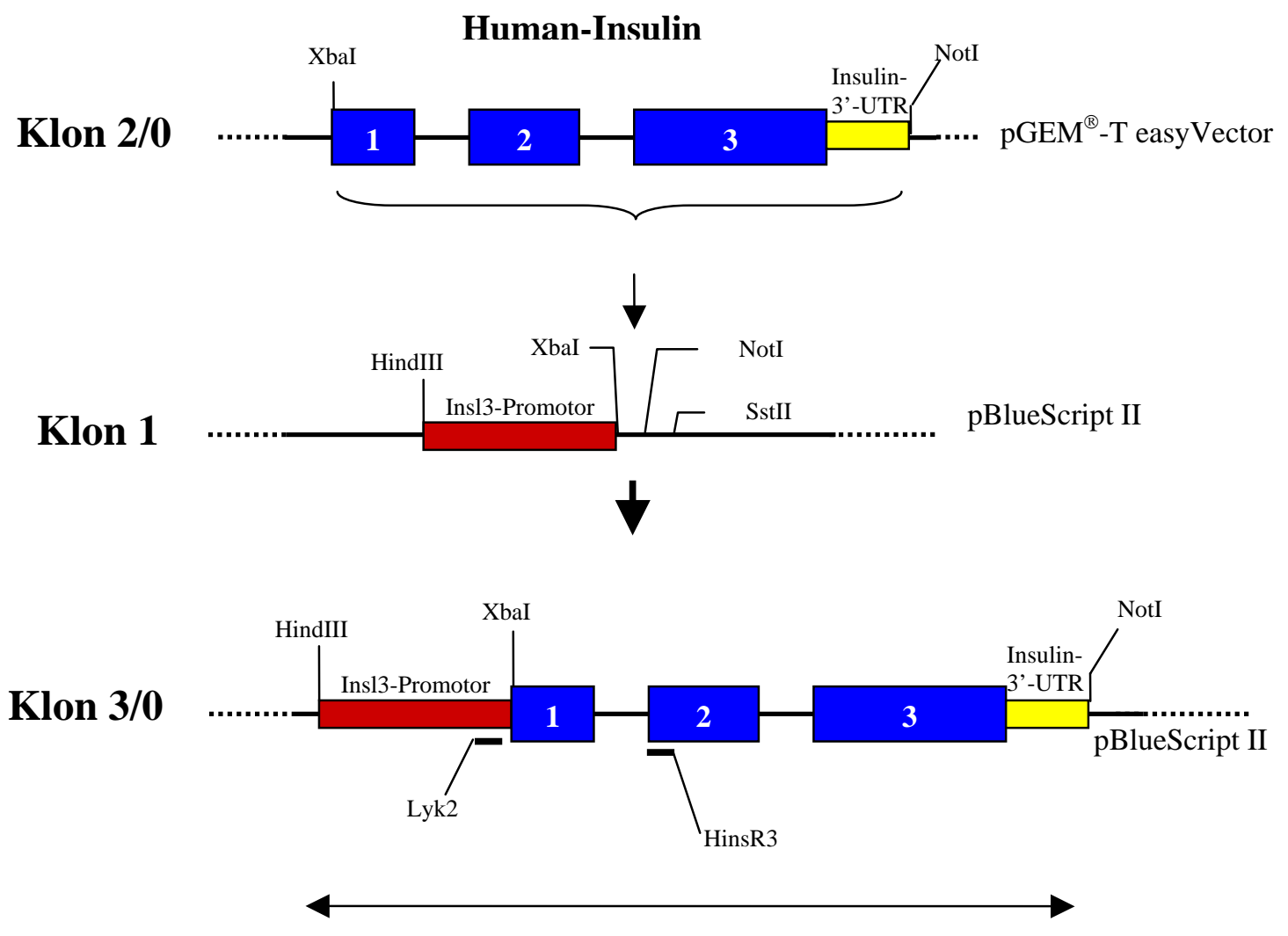

$\mathbf{I}_{2} \mathbf{I}_{3}-\mathbf{0}$ Konstrukt

$A b b$. 3.25: Schematische Darstellung der für die Generierung des $I_{2} I_{3}-0$ Konstrukts benötigten Klone 1, 2/0 und 5/1. Die Klone 1 und 3/0 enthalten den gesamten 0.7 kb Insl3-Promotor (rote Box). Die Klone 2/0 und 3/0 besitzen alle drei Exons des humanen Insulin-Gens (blaue Boxen), sowie die 3'-UTR des humanen Insulin-Gens (gelbe Boxen). Die für die Klonierungsstrategie erforderlichen Restriktionsschnittstellen und die verwendeten Vektor-Systeme sind ebenfalls dargestellt. Die Position der Primer (Lyk2 und HinsR3) für die Genotypisierung sind abgebildet. 


\subsubsection{Generierung des transgenen Konstrukts $\mathbf{I}_{2} \mathbf{I}_{3}-1$}

Mittels der Primer Hins2F und Hins11R wurde an humaner genomischer DNA ein 1.3 kb langes Fragment amplifiziert und in den $\mathrm{pGEM}^{\circledR}-\mathrm{T}$ easy Vector subkloniert. Der resultierende Vektor wurde Klon 2/1 genannt (Abb. 3.26). Der Primer Hins2F besitzt die komplementäre Sequenz der ersten 21 bp des Exons 1 des humanen Insulin-Gens, wohingegen der Primer Hins11R die letzten 6 translatierten Kodons sowie das StopKodon des humanen Insulin-Gens beinhaltet. Das amplifizierte Fragment besitzt innerhalb der Primersequenzen an seinem 5'-Ende eine XbaI- und an seinem 3'-Ende eine NotI-Schnittstelle. Das aus Klon $2 / 1$ isolierte $1.3 \mathrm{~kb}$ große XbaI/NotI-Fragment wurde in den mit XbaI/NotI-verdauten Klon 1 subkloniert (Abb. 3.26). Das resultierende Konstrukt wurde als Klon 3/1 bezeichnet und sequenziert.

Die 250 bp lange 3'-nicht translatierte Region des murinen Insl3-Gens wurde mit Hilfe der Primer Mins11F und Minsl1R amplifiziert und in einen als Klon 4 bezeichneten pGEM $^{\circledR}-$ T easy Vektor subkloniert und sequenziert. Der Klon 4 enthält an seinem 5'Ende eine NotI- und an seinem 3'-Ende eine SstII-Schnittstelle (Abb. 3.26).

Aus Klon 4 wurde nun das 300 bp NotI/SstII-Fragment isoliert und für die Generierung des mit Klon 5/1 bezeichneten Vektors in den mit NotI/SstII verdauten Klon 3/1 subkloniert (Abb. 3.26) und anschließend sequenziert. In Klon 5/1 ist zwischen den Restriktionsschnittstellen HindIII und SstII das $\mathrm{I}_{2} \mathrm{I}_{3}-1$ Fusionskonstrukt enthalten. 


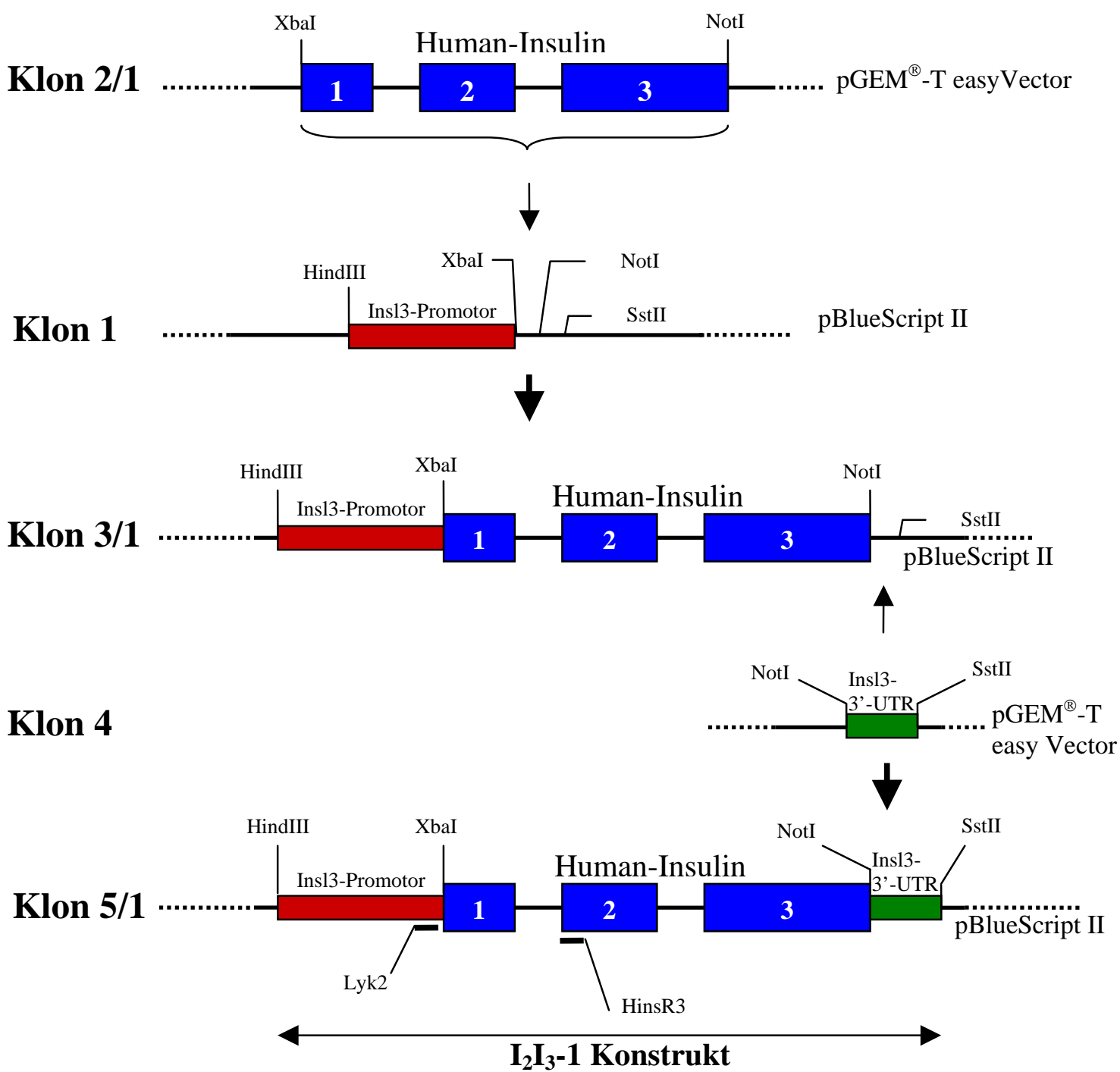

Abb. 3.26: Schematische Darstellung der für die Generierung des $I_{2} I_{3}-1$ Konstrukts benötigten Klone 1, 2/1, 3/1, 4 und 5/1. Die Klone 1, 3/1 und 5/1 enthalten den gesamten 0.7 kb Insl3-Promotor (rote Box). Die Klone 2/1, 3/1 und 5/1 besitzen alle drei Exons des humanen Insulin-Gens (blaue Boxen). Der Klon 5/1 enthält zusätzlich die aus Klon 4 stammende 250 bp 3'-UTR des Insl3-Gens (grüne Box). Die für die Klonierungsstrategie erforderlichen Restriktionsschnittstellen und die verwendeten Vektor-Systeme sind ebenfalls dargestellt. 


\subsubsection{Generierung des transgenen Konstrukts $\mathbf{I}_{2} \mathbf{I}_{3}-2$}

Die Herstellung des Konstruktes $\mathrm{I}_{2} \mathrm{I}_{3}-2$ erfolgte entsprechend der Generierung des $\mathrm{I}_{2} \mathrm{I}_{3}-1$ Fusionskonstrukts. Mittels der Primer Hins11F und Hins11R wurde an humaner genomischer DNA ein 1.1 kb langes Fragment, welches die Exons 2 und 3 des humanen Insulin-Gens umfasst, amplifiziert und in den pGEM $^{\circledR}-\mathrm{T}$ easy Vector subkloniert. Der als Klon 2/2 bezeichnete resultierende Vektor wurde sequenziert und besitzt wie Klon 2/1 an seinem 5'-Ende eine XbaI- und am 3'-Ende eine NotI-Schnittstelle (Abb. 3.27).

Das aus dem Klon 2/1 isolierte $1.1 \mathrm{~kb}$ XbaI/NotI-Fragment wurde in den mit XbaI/NotI verdauten Klon 1 subkloniert. Der resultierende Vektor wurde als Klon 3/2 bezeichnet. Für die Generierung des Klons 5/1 wurde dann aus Klon 4 das 250 bp NotI/SstIIFragment isoliert und in den NotI/SstII verdauten Klon 3/2 subkloniert und anschließend sequenziert (Abb. 3.27). Der so entstandene Klon $5 / 2$ enthält die Sequenz des $\mathrm{I}_{2} \mathrm{I}_{3}-2$ Fusionskonstrukts. 

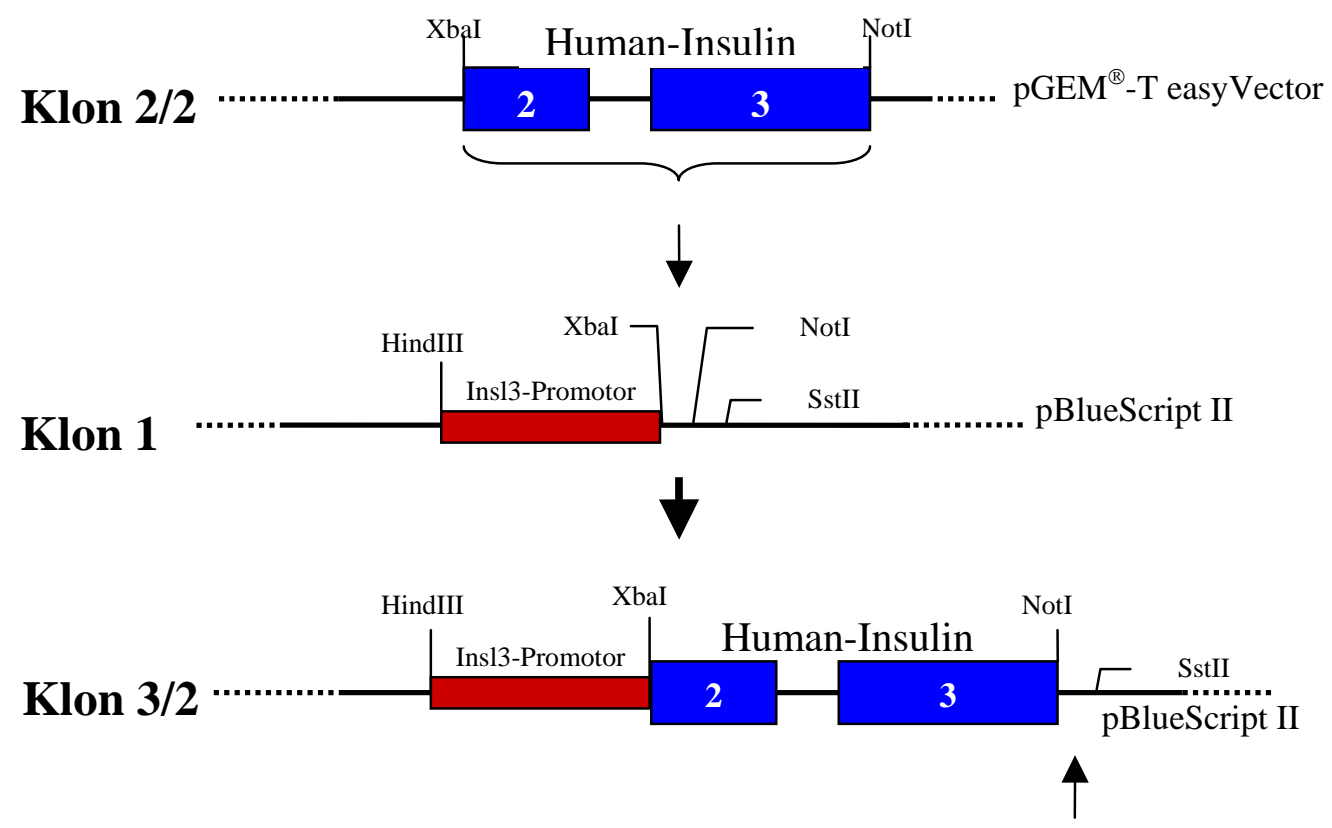

Klon 4
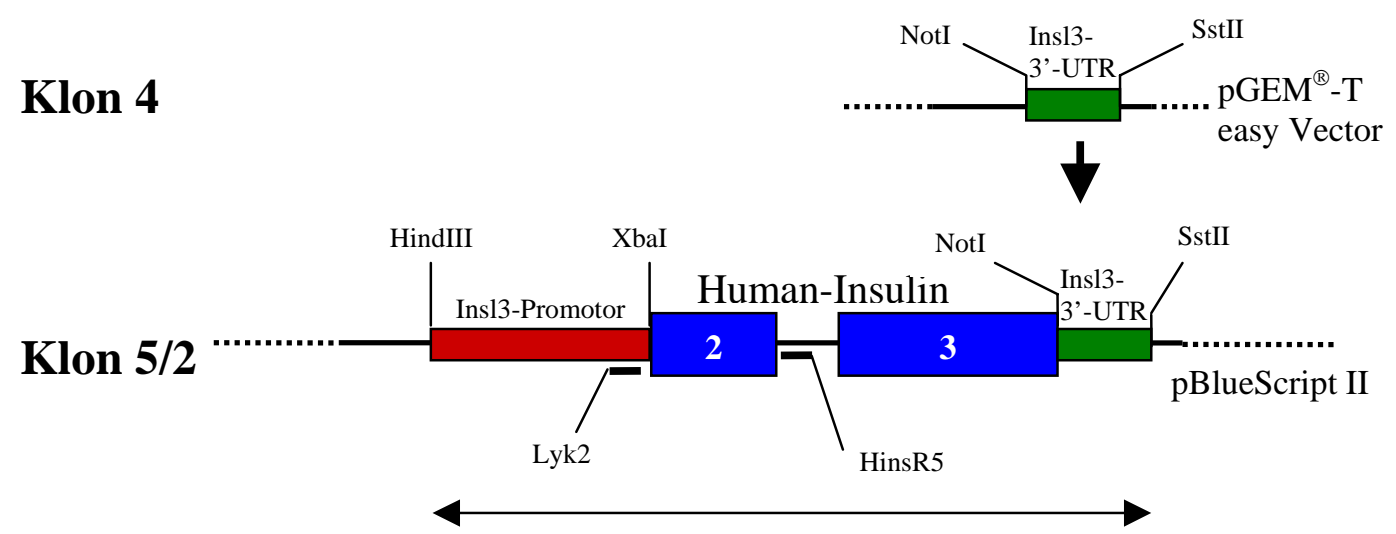

$\mathbf{I}_{2} \mathbf{I}_{3}-2$ Konstrukt

Abb. 3.27: Schematische Darstellung der für die Generierung des $I_{2} I_{3}-2$ Konstrukts benötigten Klone 1, 2/2, 3/2, 4 und 5/2. Die Klone 1, 3/2 und 5/2 enthalten den gesamten 0.7 kb Insl3-Promotor (rote Box). Die Klone 2/2, 3/2 und 5/2 besitzen die Exons 2 und 3 des humanen Insulin-Gens (blaue Boxen). Der Klon 5/2 enthält zusätzlich die aus Klon 4 stammende 250 bp 3'-UTR des Insl3-Gens (grüne Box). Die für die die Klonierungsstrategie erforderlichen Restriktionsschnittstellen und die verwendeten VektorSysteme sind ebenfalls dargestellt. 


\subsubsection{Herstellung und Genotypisierung $\mathbf{I}_{2} \mathbf{I}_{3}$-transgener Mäuse}

Aus den Klonen 3/0, 5/1 und 5/2 wurde jeweils das HindIII/NotI $\mathrm{I}_{2} \mathrm{I}_{3}$-Fragment aus den entsprechenden Vektoren herausgeschnitten, durch Agarosegelelektrophorese gereinigt und anschließend isoliert. Die so gewonnenen $\mathrm{I}_{2} \mathrm{I}_{3}$ Fusiongene wurden danach für die Mikroinjektion in die zur Verfügung stehenden Oozyten herangezogen.

Die Generierung transgener Founder-Tiere erfolgte im Max-Planck-Institut für experimentelle Medizin in Göttingen. Für die Erzeugung der $\mathrm{I}_{2} \mathrm{I}_{3}$ transgenen Mäuse wurde die Methode der Mikroinjektion, d.h. die Einführung der DNA mit Hilfe einer feinen Glaskapillare in den männlichen Vorkern verwendet. Nach der Superovulation wurden die befruchteten Eizellen isoliert und die DNA in den männlichen Vorkern mikroinjiziert. Die überlebenden mikroinjizierten Oozyten wurden anschließend in die Eileiter eines scheinträchtigen Empfängertieres retransferiert. Um die Integration der Fremd-DNA nachzuweisen, wurden die geborenen Mäuse per PCR genotypisiert. Für den Nachweis der transgenen Allele $\mathrm{I}_{2} \mathrm{I}_{3}-0$ und $\mathrm{I}_{2} \mathrm{I}_{3}-1$ wurde das Primerpaar Lyk2 und HinsR3 gewählt, so dass ein Fragment von der 5'-flankierenden Region des murinen Insl3-Gens bis zum Exon 2 des humanen Insulin-Gens entsteht (Abb. 3.25 und 3.26). Bei beiden Konstrukten wurde ein 400 bp großes DNA-Fragment amplifiziert (Abb.3.28A), weil die Sequenzen der beiden Konstrukte in diesem Bereich identisch sind. Für die Genotypisierung der $\mathrm{I}_{2} \mathrm{I}_{3}-2$ transgenen Mäuse wurden die Lyk2 und HinsR5 Primer gewählt, dabei entsteht ein 520 bp großes Fragment (Abb.3.28B), welches von der 5'-flankierenden Region des murinen Insl3-Gens bis zum Intron 2 des humanen Insulin-Gens reicht (Abb. 3.27).

A

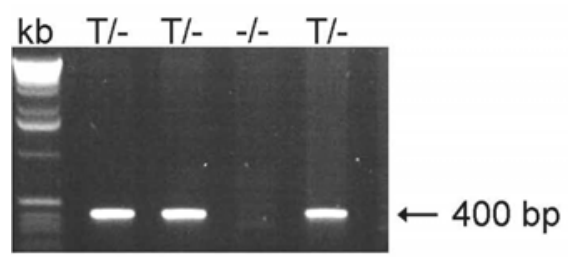

B

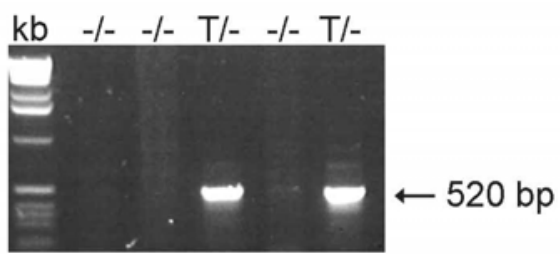

Abb. 3.28: Genotypisierung der $\boldsymbol{I}_{2} \boldsymbol{I}_{3}$ transgenen Mäuse. Die Abbildung zeigt die gelelektrophoretische Auftrennung der PCR-Produkte zur Genotypisierung; (A) Genotypisierung der $\mathrm{I}_{2} I_{3}-\mathrm{O}$ und $\mathrm{I}_{2} I_{3}-1$ transgenen Mäuse. (B) Genotypisierung der $I_{2} I_{3}-2$ transgenen Mäuse. (T) steht für transgenes Allel und (-) ist für Wildtyp-Allel. 


\subsubsection{Analyse der Expression und Fertilität der $\mathbf{I}_{2} I_{3}-0$ transgenen Mäuse}

Es konnten insgesamt vier $\mathrm{I}_{2} \mathrm{I}_{3}-0$ transgene Founder identifiziert werden. Mithilfe diese Tiere konnten anschließend vier transgene Mauslinien etabliert werden, welche mit 1.12, 35, 1.39 und 2.7 bezeichnet wurden. Dafür wurden die 4 Founder Tiere mit Wildtyp-Mäusen verpaart und die Nachkommen genotypisiert. Alle 4 Founder transmitierten das transgene Allel $\mathrm{I}_{2} \mathrm{I}_{3}-0$. Um die Expression des $\mathrm{I}_{2} \mathrm{I}_{3}-0$ Transgens im Testis zu prüfen, wurde eine Northern-Blot Analyse mit RNA aus Testes heterozygoter Nachkommen der Founder durchgeführt. Die Analyse zeigte, dass das $\mathrm{I}_{2} \mathrm{I}_{3}-0$ Allel nur im Testis der Linie 1.12 exprimiert wird (Abb. 3.29). Deshalb wurde nur mit der Linie 1.12 weitergearbeitet. Mit der in (2.2.7) beschriebenen PCR-Genotypisierung war es nicht möglich, zwischen Homozygotie und Hemizygotie für das transgene Allel $\mathrm{I}_{2} \mathrm{I}_{3}-0$ $\mathrm{zu}$ unterscheiden. Um homozygote Tiere des $\mathrm{F}_{2}$-Generation (Nachkommen aus den Verpaarungen definitiv hemizygot transgener $F_{1}$-Tiere) identifizieren und somit charakterisieren zu können, wurde wie folgt vorgegangen:

Es wurden einige transgene $F_{2}$-Tiere (von denen gemäß den Mendelschen Regeln 1/3 homozygot sein sollten) mit Wildtypen rückgekreuzt und die Nachkommen anschließend genotypisiert. Waren 100\% dieser Nachkommen (hemizygot) transgen, bedeutet dies, dass das für diese Verpaarung herangezogene $\mathrm{F}_{2}$-Tier homozygot bezüglich des Allels $\mathrm{I}_{2} \mathrm{I}_{3}-0$ gewesen sein muss.

Die homozygoten $\mathrm{I}_{2} \mathrm{I}_{3}-0$ Tiere zeigten keine phänotypischen Auffälligkeiten. Und die durchschnittliche Wurfgröße der $\mathrm{F}_{2}$-Verpaarungen war mit 7.6 normal.

Analyse der Expression des transgenen Allels $\mathbf{I}_{2} \mathbf{I}_{3}-1$ und der Fertilität der $\mathbf{I}_{2} \mathbf{I}_{3}-1$ transgenen Mäuse

Es konnten insgesammt fünf $\mathrm{I}_{2} \mathrm{I}_{3}-1$ transgene Founder-Tiere identifiziert werden. Mit Hilfe von Northern-Blot Analysen wurde die Expression des Allels $\mathrm{I}_{2} \mathrm{I}_{3}-1$ im Testis der transgenen $F_{1}$-Nachkommen untersucht. Wie die Abb. $3.29 \mathrm{zu}$ sehen, wird das $\mathrm{I}_{2} \mathrm{I}_{3}-1$ Allel im Testis der Linien 2, 5, 9 und 12 exprimiert. Im Testis der $\mathrm{I}_{2} \mathrm{I}_{3}-1$ hemizygoten transgenen Tiere der Linie 10 konnten keine Insulin-Transkripte detektiert werden. 


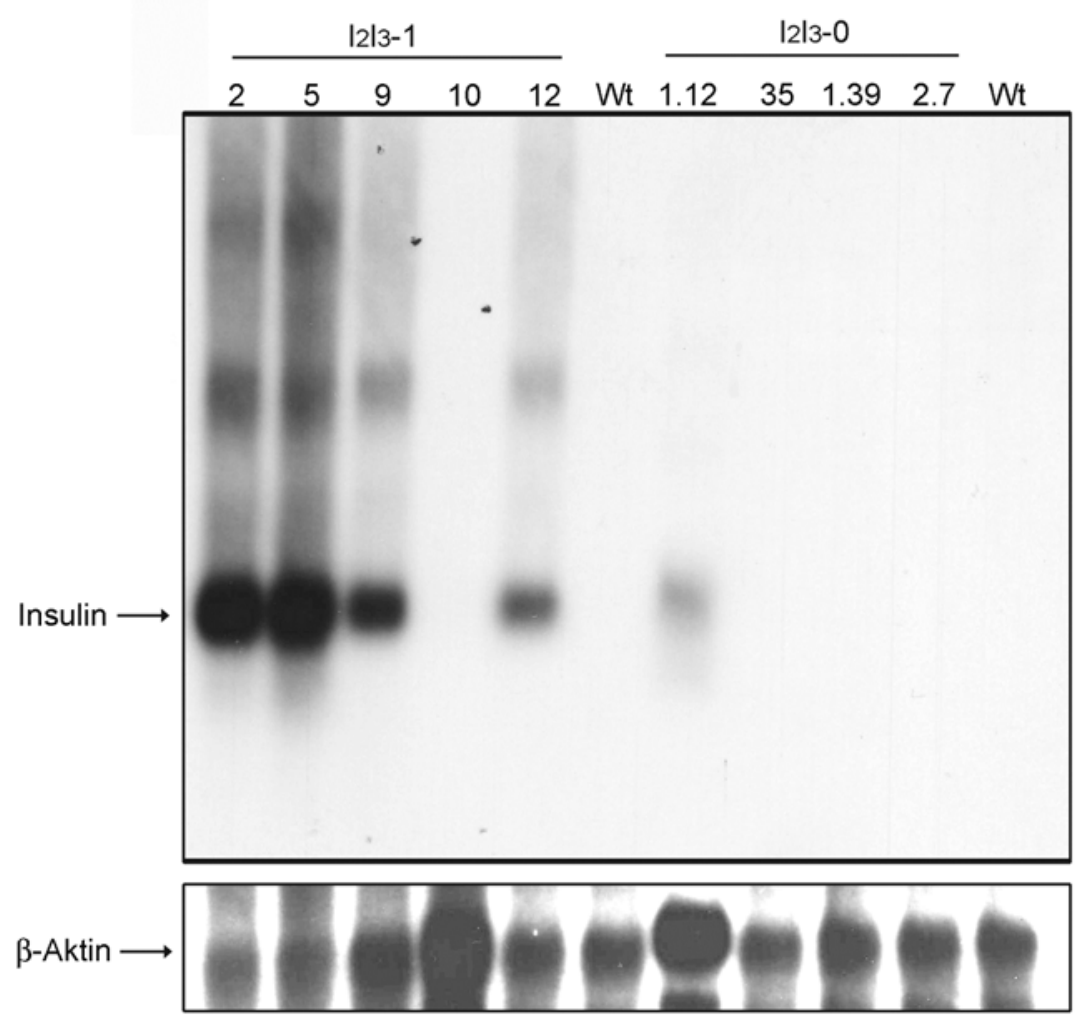

Abb. 3.29: Northern-Hybridisierung an testikulärer RNA von Wildtyp-(WT) und $I_{2} I_{3}$-transgenen

Mäusen. Die aus den Testes isolierte Gesamt-RNA von adulten $F_{1}$-Mäusen der $I_{2} I_{3}-1$ transgenen Linien 2, 5, 9, 10 und 12 sowie der $I_{2} I_{3}-0$ transgenen Linien 1.12, 35, 1.39 und 2.7 wurde mit einer $0.8 \mathrm{~kb}$ Insulin-cDNA Sonde hybridisiert. Um die Integrität und Quantität der RNA zu belegen, wurde mit einer $\beta$-Aktin-cDNA-Sonde rehybridisiert.

Um die Zahl der Integrationsstellen und die Kopienzahlen des $\mathrm{I}_{2} \mathrm{I}_{3}-1$ Allels im Genom der Tiere der Linien 2, 5, 9 und 12 zu bestimmen, wurden quantitative Real-Time-PCRAnalysen durchgeführt. Diese Analyse hat gezeigt, dass das transgene Allel bei den Linien 2 und 12 an einer Stelle des Genoms des jeweiligen Founder-Tieres inseriert worden sein muss, wohingegen bei den Foundern der Linien 5 und 9 das transgene $\mathrm{I}_{2} \mathrm{I}_{3^{-}}$ 1 Allele an mehreren Stellen des Genoms integriert war. Diese Ergebnisse wurden durch FISH-Analysen an Metaphasechromosomen bestätigt (Prof. Schmidt, Würzburg). In Abb. 3.30 werden exemplarisch die Ergebnisse von Linie 2 und Linie 9 dargestellt. 

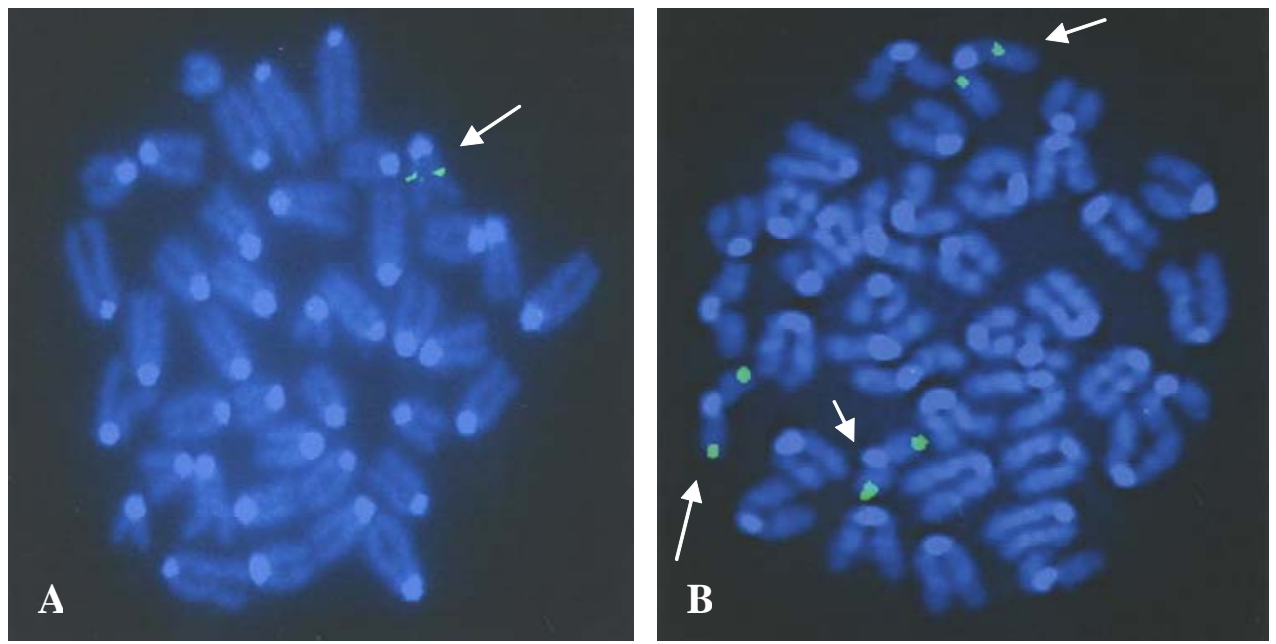

Abb. 3.30: FISH an Metaphasechromosomen der $\boldsymbol{I}_{2} \boldsymbol{I}_{3}-1$ transgenen Mäuse. (A) FISH mit Hilfe der fluoreszenzmarkierten Sonde $I_{2} I_{3}-1$ an Metaphasechromosomen der transgenen Mauslinie 2. Wie aus der Abb. hervorgeht, konnte eine Integrationsstelle des transgenen Konstrukts in dieser Mauslinie nachgewiesen werden (s. Pfeil). (B) Im Gegensatz dazu konnte mittels FISH-Analysen gezeigt werden, dass das transgene Konstrukt Integrationsstellen auf verschiedenen Chromosomen der Mauslinie 9 zeigt (s. Pfeile).

Mit Linien, bei denen das transgene Konstrukt an mehreren Stellen in das Genom des Foundertieres inseriert war, wurde nicht weitergearbeitet. Die Kopienzahl des in das Genom der untersuchten $F_{1}$-Tiere der Linie 2 bzw. 12 integrierten transgenen $\mathrm{I}_{2} \mathrm{I}_{3}-1$ Allels wurde mit 16 für die Linie 2 bzw. 3 für Linie 12 berechnet. Da nur diese Linien eine Expression zeigten, wurden auch nur diese Linien für weiteren Untersuchungen herangezogen.

Die $\mathrm{F}_{1}$-Tiere der beiden Linien wurden jeweils untereinander verpaart und die Tiere in der $\mathrm{F}_{2}$-Generation mittels Real-Time-PCR genotypisiert. Die durchschnittliche Wurfgröße bei der Linie 12 war $9 \pm 0.5$. Das Verhältnis von nicht transgenen zu transgenen Tieren in der $\mathrm{F}_{2}$-Generation wich nicht signifikant von den nach den Mendelschen Regeln zu erwartenden Zahlenverhältnissen ab. In Gegensatz dazu war die Wurfgröße bei den Verpaarungen der Linie 2 (2.7 \pm 0.87) deutlich reduziert. Bei den mittels quantitativer Real-Time-PCR genotypisierten Tieren der $\mathrm{F}_{2}$-Generation konnten keine homozygoten Mäuse für die Linie 2 identifiziert werden (Tab. 3.5). 
Tab. 3.5: Verhältnisse von Wildtyp (-/-) und $I_{2} I_{3}$ transgenen hemizygoten (T/-) und homozygoten (T/T) Nachkommen der $F_{2}$-Generation, sowie die durchschnittlichen Wurfgrößen der Verpaarungen hemizygoter $F_{1}$-Tiere.

\begin{tabular}{|c|c|c|c|c|c|c|}
$\begin{array}{c}\text { Trans- } \\
\text { genes } \\
\text { Allel }\end{array}$ & Linie & $\begin{array}{c}\text { Anzahl der } \\
\text { Würfe }\end{array}$ & $\begin{array}{c}\text { Durch- } \\
\text { schnittliche } \\
\text { Wurfgröße }\end{array}$ & $\begin{array}{c}\text { T/T } \\
\text { Anzahl } \\
\mathbf{( \% )}\end{array}$ & $\begin{array}{c}\text { T/- } \\
\text { Anzahl } \\
\mathbf{( \% )}\end{array}$ & $\begin{array}{c}-/- \\
\text { Anzahl } \\
\mathbf{( \% )}\end{array}$ \\
\hline $\mathrm{I}_{2} \mathrm{I}_{3}-0$ & 1.12 & 7 & $7.6 \pm 2.26$ & $\begin{array}{c}13 \\
(24.5)\end{array}$ & $\begin{array}{c}40 \\
(75.5)\end{array}$ & 0 \\
\hline $\mathrm{I}_{2} \mathrm{I}_{3}-1$ & 2 & 22 & $2.7 \pm 0.87$ & 0 & 48 & 11 \\
\hline $\mathrm{I}_{2} \mathrm{I}_{3}-1$ & 12 & 7 & $9 \pm 0.5$ & 10 & 29 & 14 \\
& & & & $(19)$ & $(55)$ & $(26)$ \\
\hline
\end{tabular}

Für die Reduktion der Wurfgröße in der $\mathrm{F}_{2}$-Generation der Linie 2 gibt es mehrere mögliche Erklärungen:

1- Die Überexpression von Insulin in den $\mathrm{I}_{2} \mathrm{I}_{3}-1$ transgenen Weibchen führt zu einer Reduktion der ovulierten Eizellen.

2- Die Überexpression von Insulin in männlichen Tieren führt zur Störung der Spermatogenese.

3- Das transgene $I_{2} I_{3}-1$ Allel wurde innerhalb eines Gens inseriert (und dieses somit ausgeschaltet), dessen Proteinprodukt für die embryonale Entwicklung essentiell ist.

Um die verschiedenen Ursachen für die Reduktion der Wurfgröße zu analysieren, wurden weibliche Wildtyp-Mäuse mit hemizygot-transgenen Männchen und hemizygottransgene Weibchen mit Wildtyp-Männchen verpaart.

Diese Analysen haben gezeigt, dass die Wurfgröße bei diesen beiden reziproken Verpaarungen deutlich reduziert ist und somit keine signifikanten Abweichungen von den Verpaarungen hemizygot-transgener Tiere untereinander aufzeigten (Tab. 3.6). Die Ergebnisse sind daher nicht sehr aussagekräftig. 
Tab. 3.6: Ergebnisse der Verpaarung von Wildtyp (-/-) und $I_{2} I_{3}-1$ transgenen hemizygoten (T/-) Nachkommen der $F_{2}$-Generation, sowie die durchschnittlichen Wurfgrößen der Verpaarungen hemizygoter $F_{1}$-Tiere mit Wildtyp.

\begin{tabular}{|c|c|c|c|c|c|c|}
\hline $\begin{array}{l}\text { Trans- } \\
\text { genes } \\
\text { Allel }\end{array}$ & Linie & $\begin{array}{c}\text { Ver- } \\
\text { paarungen }\end{array}$ & $\begin{array}{c}\text { Nach- } \\
\text { kommen } \\
\text { insgesamt }\end{array}$ & $\begin{array}{c}\text { Durch- } \\
\text { schnittliche } \\
\text { Wurfgröße }\end{array}$ & $\begin{array}{c}\text { T/-Anzahl } \\
\text { (\%) }\end{array}$ & $\begin{array}{c}-/- \\
\text { Anzahl } \\
(\%)\end{array}$ \\
\hline $\mathrm{I}_{2} \mathrm{I}_{3}-1$ & 2 & $\mathrm{~T} /-\mathrm{x} \mathrm{T} / \mathrm{-}$ & 59 & $2.7 \pm 0.87$ & $\begin{array}{c}48 \\
(81)\end{array}$ & $\begin{array}{l}11 \\
(19)\end{array}$ \\
\hline $\mathrm{I}_{2} \mathrm{I}_{3}-1$ & 2 & $\mathrm{O}^{1} \mathrm{~T} /-\mathrm{x}-/-$ & 74 & $3 \pm 1.51$ & $\begin{array}{c}31 \\
(42)\end{array}$ & $\begin{array}{c}43 \\
(58)\end{array}$ \\
\hline $\mathrm{I}_{2} \mathrm{I}_{3}-1$ & 2 & q $\mathrm{T} /-\mathrm{x}-/-$ & 109 & $3.4 \pm 1.69$ & $\begin{array}{c}53 \\
(49)\end{array}$ & $\begin{array}{c}56 \\
(51)\end{array}$ \\
\hline
\end{tabular}

Um zu bestimmen wann die Embryonen bei den Verpaarungen der hemizygoten Männchen mit Wildtyp-Weibchen sterben, wurde die Zahl der Embryonen am Embryonaltag 15.5, 11.5 und 7.5 bestimmt. Am E15 und E11.5 war die Zahl der implantierten Embryonen deutlich reduziert. Im Gegensatz dazu war die Zahl der implantierten E7.5 Embryonen normal. Die Ergebnisse deuten daraufhin, dass die embryonale Entwicklung der trangenen Mäuse nach der Implantation gestört sein muss. Um den Effekt der Überexpression von Insulin auf die Spermatogenese bei $\mathrm{I}_{2} \mathrm{I}_{3}-1$ transgenen Mäusen zu klären, wurden verschiedene Spermparameter untersucht. Bei dieser Untersuchung wurden 3, 6 und 9 Monate alte männliche transgene hemizygote Mäuse herangezogen. Bei 3 Monate alten $\mathrm{I}_{2} \mathrm{I}_{3}-1$ transgenen Mäusen zeigten sich nur signifikante Unterschiede bezüglich der Spermienzahl im Vergleich zu den Werten der Wildtyp-Mäuse. Im Gegensatz dazu waren Spermienzahl, Spermienmotilität und Progressivität bei den älteren transgenen Mäusen der Linie 2 deutlich reduziert (Tab. 3.7 und Abb. 3.31.A-C). Diese Ergebnisse lassen die Vermutung gerechtfertigt erscheinen, dass die Überexpression des Insulins zu einer Störung der Spermatogenese führt, und dabei auch die Spermienmotilität bei älteren $\mathrm{I}_{2} \mathrm{I}_{3}-1$ transgenen Männchen betroffen ist. 
Tab. 3.7: Ergebnisse der Spermienanalysen der $I_{2} I_{3}-1$ transgenen Männchen der Linien 2 und 12 sowie der Wildtypkontrollmäuse

\begin{tabular}{|c|c|c|c|}
\hline Linie & Spermienzahl & Spermienmotilität (\%) & Progressivität (\%) \\
\hline $\begin{array}{c}\text { Linie } 2 \\
\text { (3 Monate) }\end{array}$ & $5.16 \times 10^{6} \pm 4.5 \times 10^{5}$ & $48 \pm 8.1$ & $29.6 \pm 6.6$ \\
\hline Wt (3 Monate) & $1.3 \times 10^{7}$ & 61 & 42 \\
\hline $\begin{array}{c}\text { Linie } 2 \\
\text { (6 Monate) }\end{array}$ & $4.5 \times 10^{6} \pm 3.1 \times 10^{5}$ & $30.3 \pm 7.9$ & $19.3 \pm 5.8$ \\
\hline Wt (6 Monate) & $8.6 \times 10^{6}$ & 45 & 27 \\
\hline $\begin{array}{c}\text { Linie } 2 \\
\text { (9-12 Monate) }\end{array}$ & $4.4 \times 10^{5} \pm 2.5 \times 10^{5}$ & $13.6 \pm 7.7$ & $7.4 \pm 5.8$ \\
\hline $\begin{array}{c}\text { Linie } 12 \\
\text { (8 Monate) }\end{array}$ & $1.3 \times 10^{5} \pm 1.5 \times 10^{5}$ & 2 & 0 \\
\hline Wt (8 Monate) & $1.6 \times 10^{6} \pm 0.6 \times 10^{5}$ & 33 & 21 \\
\hline
\end{tabular}



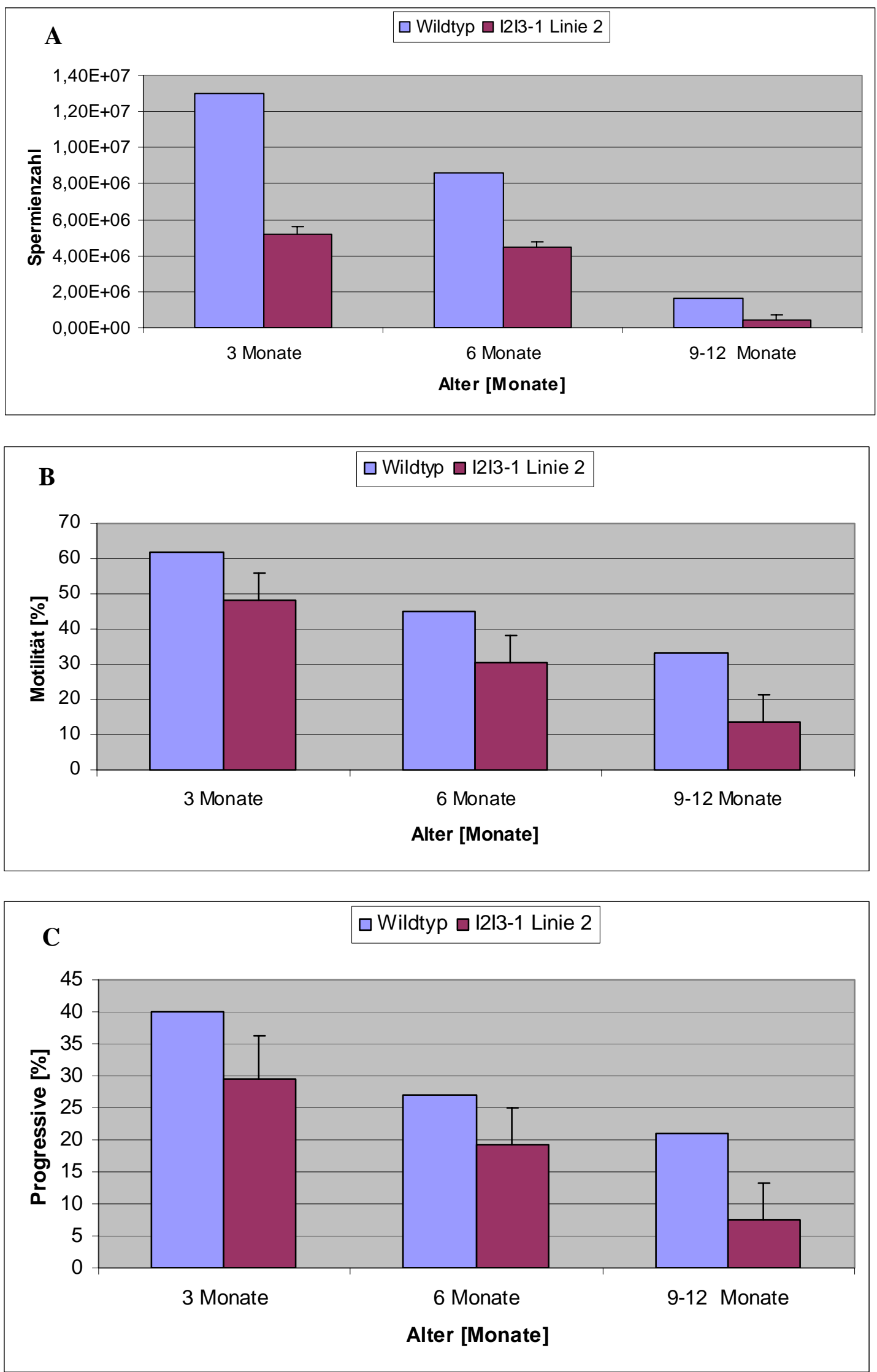
$\triangle$ Abb. 3.31: Darstellung der Analyse der Spermienparameter bei Tieren der $I_{2} I_{3}-1$ transgene Linie 2. Es wurden Spermienanalysen bei unterschiedlich alten Mäusen: 3, 6 und 9-12 Monate durchgeführt. (A) Spermienzahl, (B) Motilität der Spermien, (C). Progressivität der Spermien.

Es wurden auch weitere Parameter untersucht. Exemplarisch werden hier Ergebnisse für die Weggeschwindigkeit (VAP), progressive Geschwindigkeit (VSL), Bahngeschwindigkeit (VCL), die seitliche Amplitude (ALH), Schlagfrequenz (BCF) und Gradlinigkeit (STR) für die Zeit 1.5 h nach Präparation dargestellt (Abb. 3.32).
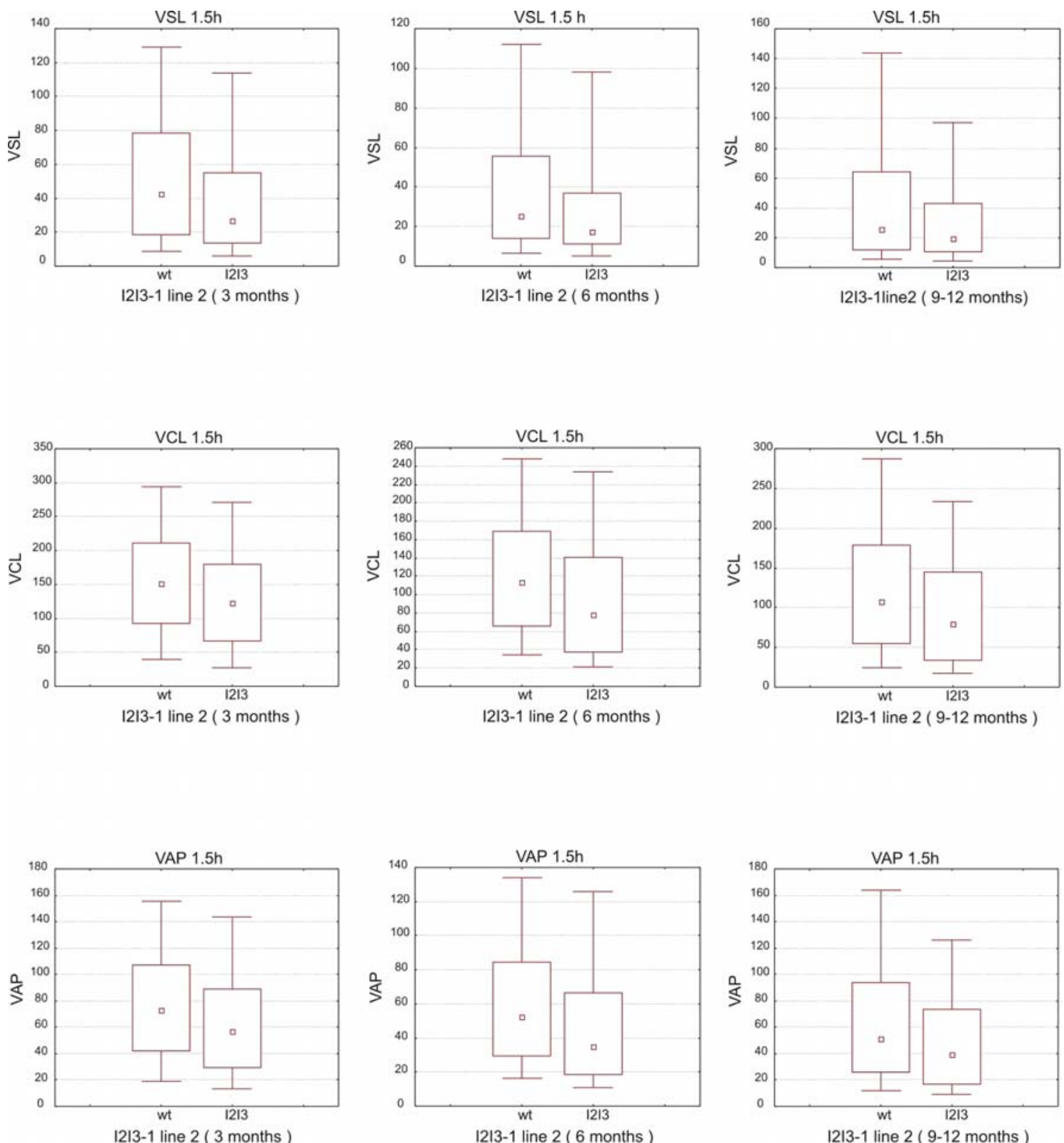

12/3-1 line 2 ( 9-12 months ) 

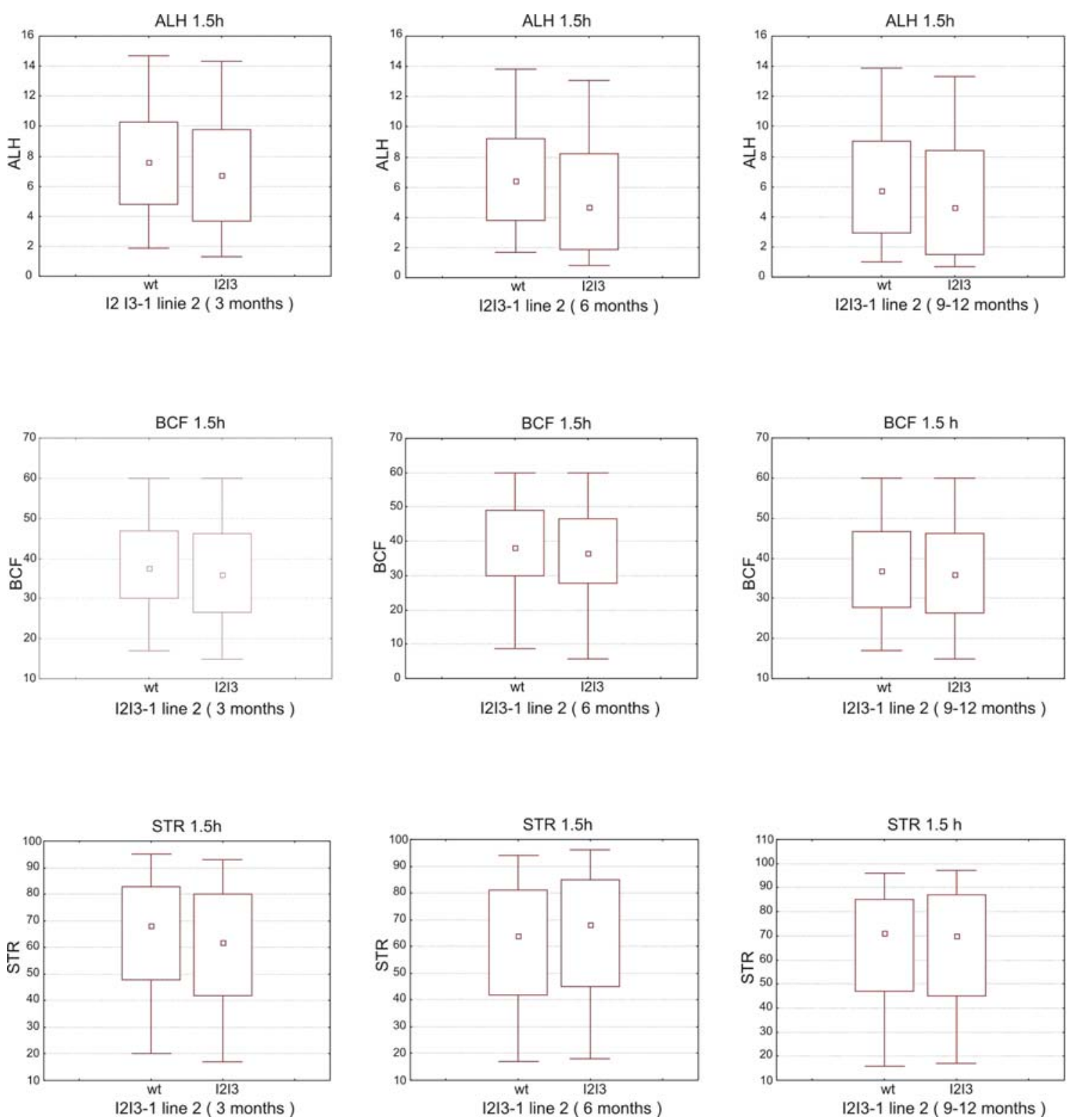

口 Median

$\square 25 \% .75 \%$

Abb. 3.32: Schematische Darstellung der Spermiengeschwindigkeitsparameter bei der $I_{2} I_{3}-1$ transgenen Linie 2 nach 1.5 h. Es wurden Spermienanalysen bei unterschiedlich alten Mäuse durchgeführt: 3, 6 und 9 Monate. Exemplarisch dargestellt sind die Werte nach 1.5 h; VSL= progressive Geschwindigkeit, $V C L=$ Bahngeschwindigkeit, $V A P=$ Weggeschwindigkeit, $A L H=$ Seitliche Amplitude $B C F=$ Schlagfrequenz, $S T R=$ Gradlinigkeit .

Die Spermienparameter Bahngeschwindigkeit (VCL), progressive Geschwindigkeit (VSL), Weggeschwindigkeit (VAP) und die seitliche Amplitude (ALH) sind bei den transgenen Mäusen deutlich reduziert. Allerdings für Schlagfrequenz (BCF) und Gradlinigkeit (STR) waren die Differenzen geringer. 
Diese Ergebnisse zeigen, dass sich bei den transgenen Mäusen die Spermienparameter mit dem Alter stark verändern und sich von Wildtyp Mäusen unterscheiden.

Die Wurfgröße bei den Verpaarungen der hemizygoten Tiere der Linie 12 zeigten keine Auffälligkeiten. Um die Linie 12 in einen homozygoten Zustand zu bringen, wurden die mittels quantitativer Real-Time-PCR-Analyse determinierten homozygoten $\mathrm{F}_{2}$ Tiere untereinander verpaart. Allerdings traten bei diesen Verpaarungen keine Nachkommen auf. Durch die Verpaarungen der homozygoten transgenen Weibchen mit WildtypMännchen und der homozygoten transgenen Männchen mit Wildtyp-Weibchen wurde nachgewiesen, dass die homozygoten männlichen Tiere der Linie 12 infertil sind, wohingegen die homozygoten Weibchen fertil waren.

Um die Ursache der Infertilität der homozygoten Männchen herauszufinden, wurden verschiedene Spermienparameter bei 3 männlichen Tieren sowie die Histologie der Testes diese Tiere untersucht. Es zeigte sich, dass die Spermienzahl und die Spermienmotilität bei diesen Tieren eindeutig reduziert sind. (Abb. 3.33).
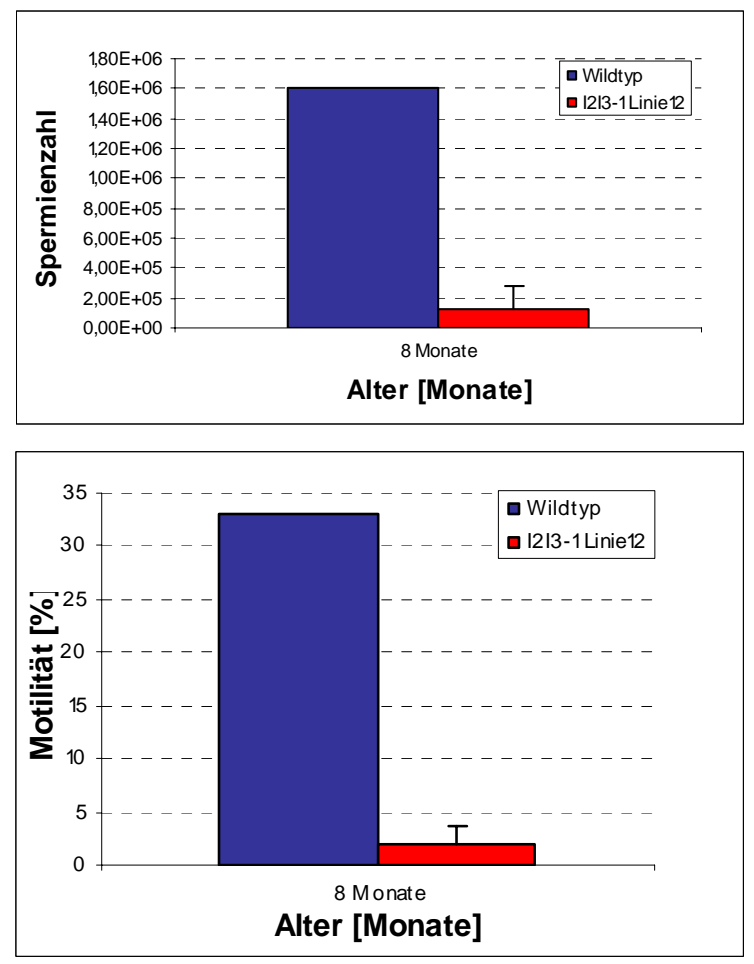

Abb. 3.33: Analyse der Spermienparameter bei der $I_{2} I_{3}-1$ transgenen Linie 12. Es wurden Spermienanalysen bei homozygot transgenen Tieren im Alter von 8 Monaten durchgeführt. (A) Spermienzahl (B) Motilität der Spermien. Aufgrund der Nullwerte bei der Progessivität konnten diese Daten nicht dargestellt werden. 


\subsection{Analyse der Spermatogenese bei $\mathbf{I}_{2} \mathbf{I}_{3}-1$ transgenen Mäusen der Linien 2 und 12}

Aufgrund der Infertilität und auffälligen Spermienparameter bei den Linien 2 und 12 wurden Testes dieser Mäuse von Prof. Dr. Meinhardt (Gießen) histologisch untersucht. Die Spermatogenese der Linie 12 wurde in Testisschnitten von zwei Tieren untersucht. Die Analyse zeigt, dass bei der Maus 12/C (7.5 Monate) in etwa 70-80\% der Tubuli die Keimzellen zurückgebildet sind und das Tubuluslumen vakuolisiert ist, während in einer anderen Maus 12/B (7.5 Monate) die Keimzellen in nur 10\% der Tubuli betroffen sind. Bei der Linie 2 wurden Testisschnitte von vier Tieren untersucht: bei der Maus 2/68A (15 Monate) waren die Keimzellen in 100\% der Tubuli, bei der Maus 2/93B (13 Monate) in 20-30\% der Tubuli zurückgebildet. Die Spermatogenese der zwei anderen Mäuse 2/80A und 2/82A (4 Monate) war hingegen normal (Abb. 3.34).

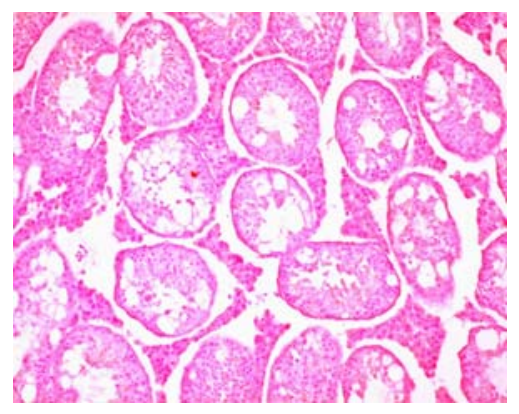

$\mathrm{I}_{2} \mathrm{I}_{3}-12 / 68 \mathrm{~A}$

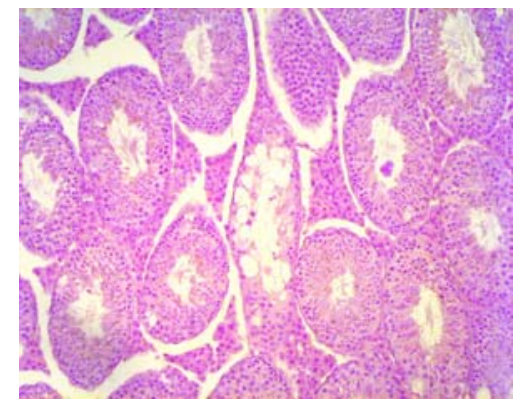

$\mathrm{I}_{2} \mathrm{I}_{3}-112 / \mathrm{B}$

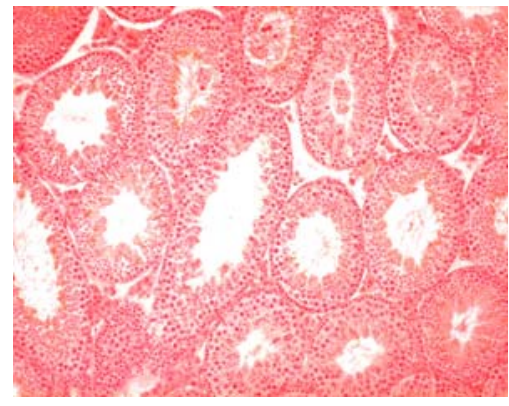

$\mathrm{I}_{2} \mathrm{I}_{3}-12 / 82 \mathrm{~A}$

Abb. 3.34: Testishistologie von $\mathbf{I}_{2} \mathbf{I}_{3}-1$ transgenen Mäusen Es wurden Testes von (A) Linie 2 Nr.68A mit 15 Monaten, (B) Linie 12 Nr.B mit 8 Monaten und (C) Line 2 Nr. 82A mit 4 Monaten untersucht.

\subsection{Untersuchung des Expressionsmusters des transgenen Allels $I_{2} I_{3}-1$ in verschiedenen Geweben mittels Northern-Blot-Analyse}

Um zu analysieren, in welchem Gewebe das $\mathrm{I}_{2} \mathrm{I}_{3}$ Transgen transkribiert wird, wurde eine Northern-Blot-Analyse mit jeweils $10 \mu \mathrm{g}$ Gesamt-RNA aus verschiedenen Geweben von einer adulten männlichen homozygoten $\mathrm{I}_{2} \mathrm{I}_{3}-1$ transgenen Maus der Linie 12 mit einer humanen Insulin-cDNA-Sonde hybridisiert. 


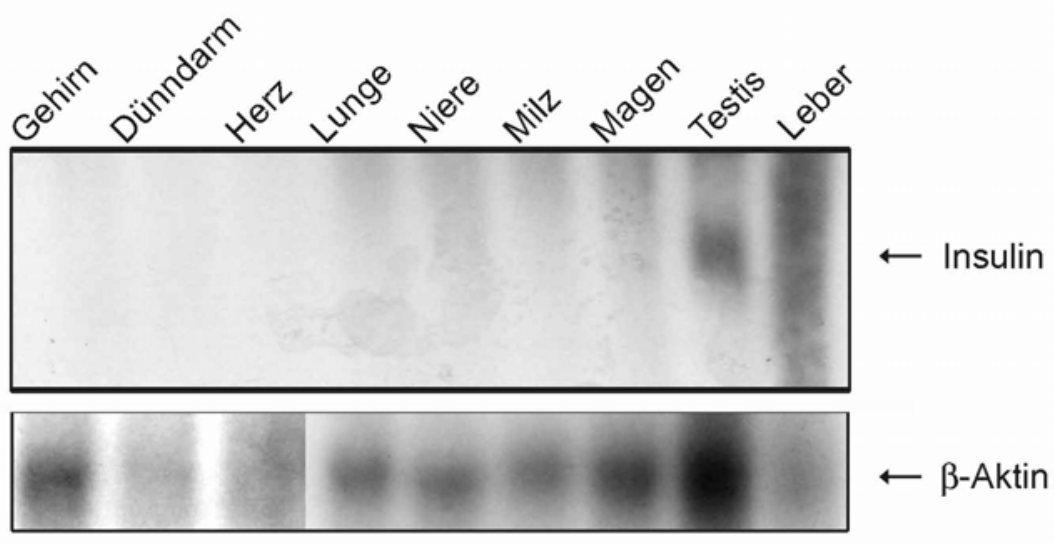

Abb. 3.35: Northern-Hybridisierung an aus verschiedenen Geweben stammender RNA von adulten $\mathbf{I}_{2} \boldsymbol{I}_{3}-1$ transgenen Mäusen. Es wurde Gesamt-RNA aus Gehirn, Dünndarm, Herz, Lunge, Niere, Milz, Magen, Testis und Leber isoliert und mit einer Insulin-cDNA-Sonde hybridisiert. Zum Nachweis der Integrität der RNA wurde der Northern-Blot mit einer cDNA-Sonde für das ubiquitär-exprimierte $\beta$-Aktin rehybridisiert.

Eine Expression des transgenen Allels konnte lediglich im Testis, nicht aber in den übrigen Geweben der $\mathrm{I}_{2} \mathrm{I}_{3}-1$ Maus nachgewiesen werden. Wie an der $\beta$-AktinRehybridisierung zu erkennen, wurde bis auf Dünndarm und Leber genügend GesamtRNA pro Spur aufgetragen (Abb. 3.35).

\subsection{Expression des transgenen Allels $\mathbf{I}_{2} \mathbf{I}_{3}-1$ in prä- und postnatalen Entwicklungsstadien des Testis}

Die Expression des Insl3-Gens ist bereits ab Tag E13.5 in den testikulären Leydigzellen von Maus-Embryonen nachzuweisen (Adham et al., 2000). Während der postnatalen Entwicklung bleibt die Insl3-Expression zunächst auf einem niedrigen Level. Nach 15 bis 20 Tagen ist dann eine deutliche Erhöhung des Expressionslevels zu verzeichnen (Zimmermann et al., 1999). Um zu untersuchen, welchem temporären Expressionsmuster das den Insl3-Promoter beinhaltende transgene Allel $\mathrm{I}_{2} \mathrm{I}_{3}-1$ folgt, wurde testikuläre RNA aus 1, 3, 5, 6, 8, 10, 15, 20 und 25 Tage alten homozygoten postnatalen und adulten $\mathrm{I}_{2} \mathrm{I}_{3}-1$ transgenen Mäusen der Linie 12 und von Wildtypmäusen isoliert. Diese RNA wurde dann für eine Northern-Blot-Analyse herangezogen, wobei mit einer Insulin-cDNA-Sonde hybridisiert wurde. Da das Transkript des transgenen Allels und das Insl3-Transkript annähernd gleiche Größen besitzen, wurde der Filter 
gestrippt und mit einer Insl3-cDNA-Sonde rehybridisiert. Damit war es möglich die Insl3-Expression mit der des transgenen Allels vergleichen zu können. Außerdem wurde zum Nachweis der Qualität und Integrität der RNA mit einer cDNA-Sonde für das "housekeeping"- Gen $\beta$-Aktin rehybridisiert. Die Ergebnisse dieser Expressionsanalysen sind in den Abbildungen 3.36, 3.37 und 3.38 dargestellt.

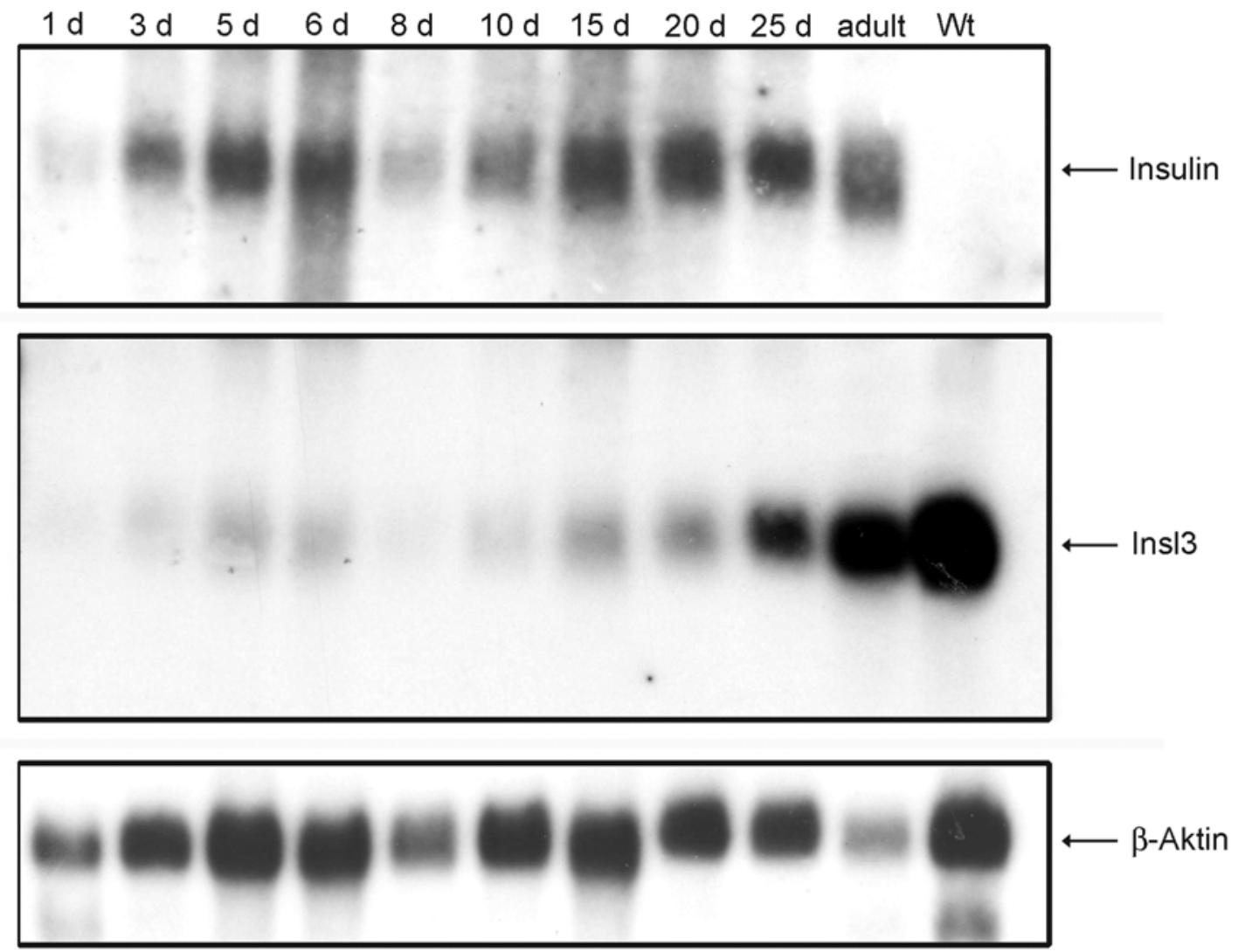

Abb. 3.36: Northern-Hybridisierung mit testikulärer RNA von postnatalen und adulten $I_{2} I_{3}-1$ transgenen Mäusen der Linie 12. Es wurde aus den Testes gewonnene Gesamt-RNA von 1, 3, 5, 6, 8, 10, 15, 20 und 25 Tage alten und adulten transgenen sowie Wildtyp (WT)-Mäusen isoliert. In jeder Spur wurden $10 \mu \mathrm{g}$ Gesamt-RNA aufgetragen. Dargestellt sind die Hybridisierungen für das Transkript des transgenen Allels (Insulin) und für das Insl3-Transkript. Um die Qualität und Integrität der RNA zu belegen, enthält die Abbildung ebenfalls das Ergebnis der ß-Aktin-Rehybridisierung.

Wie Abbildung 3.36 zeigt, konnte eine Expression des transgenen Allels $\mathrm{I}_{2} \mathrm{I}_{3}-1$ in testikulärem Gewebe transgener Mäuse während der gesamten postnatalen Entwicklung nachgewiesen werden. Bei aus Testes von einer Wildtyp-Maus gewonnener KontrollRNA blieb die Hybridisierung für Insulin aus. Die Expression des Ins13-Transkripts konnte ebenfalls während der ganzen neonatalen Entwicklungsperiode transgener 
Mäuse belegt werden, wobei ein Anstieg der Expression in spätjuvenilen (25 Tage) sowie in adulten Tieren zu erkennen ist. Auch in RNA aus Testes der Kontroll-WildtypMaus wurde das Insl3-Transkript detektiert.

Wie die $\beta$-Aktin-Kontrollhybridisierung belegt, differieren die applizierten RNAQuantitäten dieser Northern-Blot-Analyse etwas. Deshalb wurden die Expressionsstärken für das Insl3-Gen sowie für das transgene Transkript der jeweiligen Proben mit den zugehörigen $\beta$-Aktin-Expressionen densidometrisch ausgewrtet. Hierfür wurde nach der jeweiligen Hybridisierung die für 4-18 h exponierte Phosphor-Membran mit einem Phosphor-Imager eingelesen (Personal Molecular Imager FC, BIO-RAD) und mittels der Software Quantity One ${ }^{\odot}$, Version 4.4 bearbeitet. Die Ergebnisse für die einzelnen Entwicklungsstadien der transgenen und der Wildtyp-Maus sind bezogen auf die Expression des transgenen Allels in Abbildung 3.37 und für die Insl3-Expression in Abbildung 3.38 dargestellt.

Wie aus Abbildung 3.37 hervorgeht, wird das transgene Allel bis zum zwanzigsten Tag nach der Geburt auf einem gleichmäßigen Level exprimiert. Danach steigt der Expressionslevel an (Tag 25) und erreicht in den Testes transgener adulter Mäuse ein Maximum.

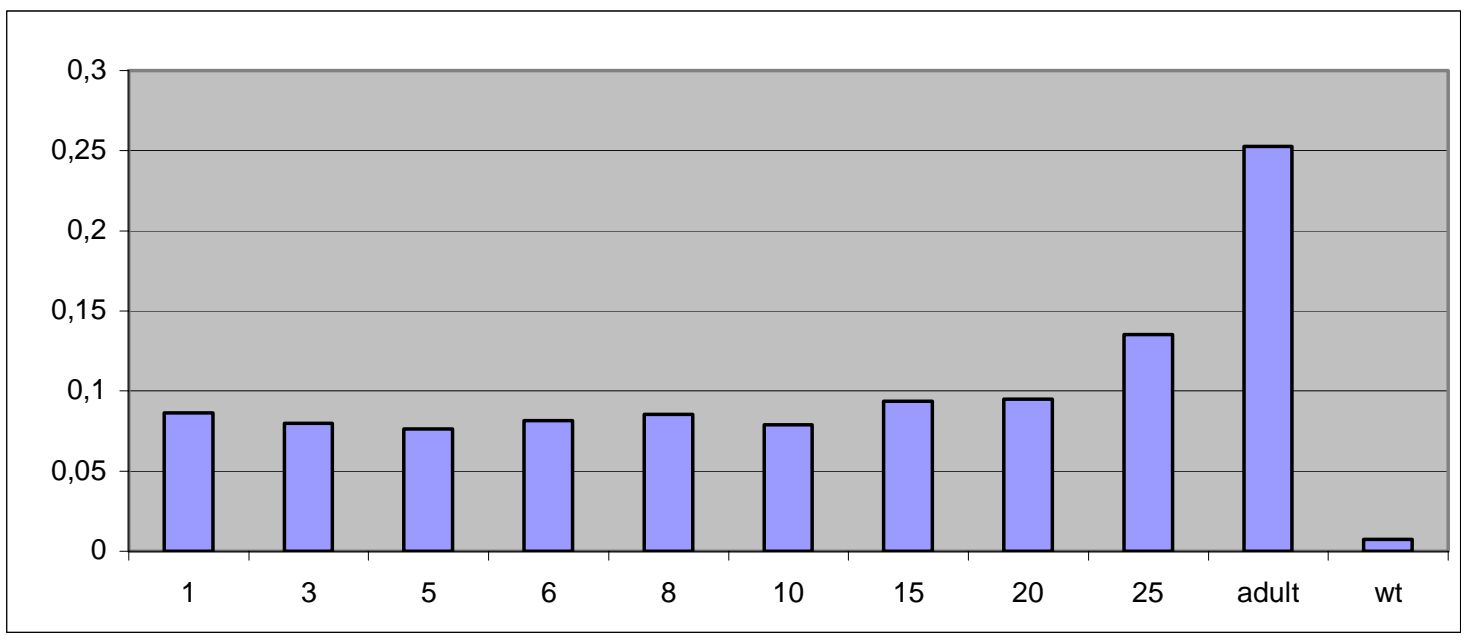

Abb. 3.37: Expressionsmuster des $I_{2} I_{3}-1$ Allels in Testes verschieden alter neonataler und adulter transgener Mäuse. Dargestellt sind die auf der in Abb. 3.36 dargestellten Northern-Blot-Analyse basierenden, densidometrierten und mit der $\beta$-Aktin-Kontrollhybridisierung normalisierten Expressionsstärken des Allels $I_{2} I_{3}-1$ in Testes von 1, 3, 5, 6, 8, 10, 15, 20 und 25 Tage alten postnatalen und adulten homozygot transgenen Mäusen sowie die der WT-Kontrolle. Da es sich bei den dargestellten Werten um die Quotienten aus Insulin-Expression (counts $/ \mathrm{mm}^{2}$ ) durch die zugehörige $\beta$-Aktin-Expression (counts $/ \mathrm{mm}^{2}$ ) handelt, besitzt die Ordinate keine Einheit. 


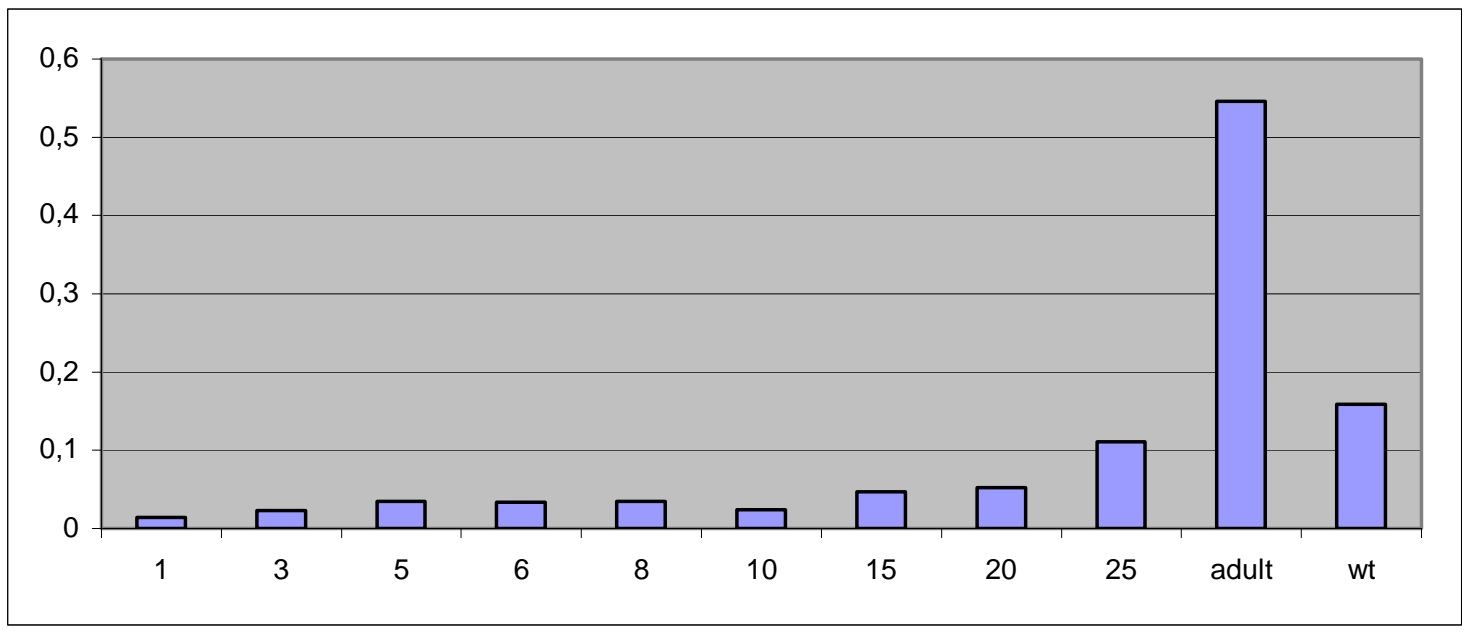

Abb. 3.38: Expressionsmuster des Insl3-Gens in Testes verschieden alter postnataler und adulter transgener Mäuse. Dargestellt sind die auf der in Abb. 3.36 dargestellten Northern-Blot-Analyse basierenden, densidometrierten und mit der $\beta$-Aktin-Kontrollhybridisierung normalisierten Expressionsstärken des Insl3-Gens in Testes von 1, 3, 5, 6, 8, 10, 15, 20 und 25 Tage alten postnatalen und adulten homozygot transgenen Mäuse sowie die der WT-Kontrolle. Da es sich bei den dargestellten Werten um die Quotienten aus der Insulin-Expression (counts $/ \mathrm{mm}^{2}$ ) durch die zugehörige $\beta$-AktinExpression (counts $/ \mathrm{mm}^{2}$ ) handelt, besitzt die Ordinate keine Einheit.

Wie in Abbildung $3.38 \mathrm{zu}$ sehen ist, wird auch das Insl3-Gen während der frühen postnatalen Entwicklungsstadien auf einem konstant niedrigen Level exprimiert, wobei dieser ab dem 25. Tag nach der Geburt ansteigt und in adulten transgenen Mäusen seinen maximalen Wert erreicht. Es ist klar zu erkennen, dass das Expressionsmuster des transgenen Allels $\mathrm{I}_{2} \mathrm{I}_{3}-1$ dem des Insl3 folgt (Abb. 3.37 und 3.38), womit die entscheidende Rolle des Insl3-Promotors im transgenen Konstukt für dessen Expressionsmuster nachgewiesen worden ist. Auch in der Wildtyp-Maus wird das Insl3Gen transkribiert (Abb. 3.38).

Wie die Northern-Blot-Analysen belegen, konnte das Transkript des $\mathrm{I}_{2} \mathrm{I}_{3}-1$ Allels während der gesamten postnatalen Entwicklung detektiert werden. So stellte sich die Frage, ob sich eine Expression des $\mathrm{I}_{2} \mathrm{I}_{3}$-Allels bereits während der pränatalen Entwicklung in den Testes transgener Mäuseembryonen nachweisen lässt. Da die Northern-Blot-Methode ein weniger sensitives Verfahren darstellt und die Quantität der für dieses Experiment aus den Testes gewonnenen RNA einer embryonalen (E17.5) homozygot $\mathrm{I}_{2} \mathrm{I}_{3}-1$ transgenen $\mathrm{F}_{3}$-Maus sehr gering war, wurde eine RT-PCR durchgeführt. Hierfür wurde jeweils $1 \mu$ der embryonalen Testis-RNA sowie testikuläre 
RNA von einer adulten $\mathrm{I}_{2} \mathrm{I}_{3}-2$ transgenen $\mathrm{F}_{2}$-Maus der Linie 15 als Kontrolle verwendet. Amplifiziert wurde mittels eines Primerpaares (Hins21F/Hins21R) ein von Exon 3 des humanen Insulin-Gens bis zur 3'-UTR des murinen Insl3-Gens reichendes Fragment. Somit konnte gewährleistet werden, dass die Amplifikation der $\mathrm{I}_{2} \mathrm{I}_{3-}$ Konstrukte, welche sich in der durch die Primer begrenzten Region nicht unterscheiden, nicht durch Amplifikationen des murinen Insulin- oder Insl3-Gens beinträchtigt wird. Um die Qualität der verwendeten RNA zu kontrollieren, wurde außerdem ein $\beta$-AktinPrimerpaar verwendet. Sowohl der Transkriptionsschritt, für den die reversen Primer herangezogen wurden, als auch der Amplifikationsschritt wurden in getrennten Reaktionsgefäßen durchgeführt, die Ansätze aber ansonsten gleich behandelt.

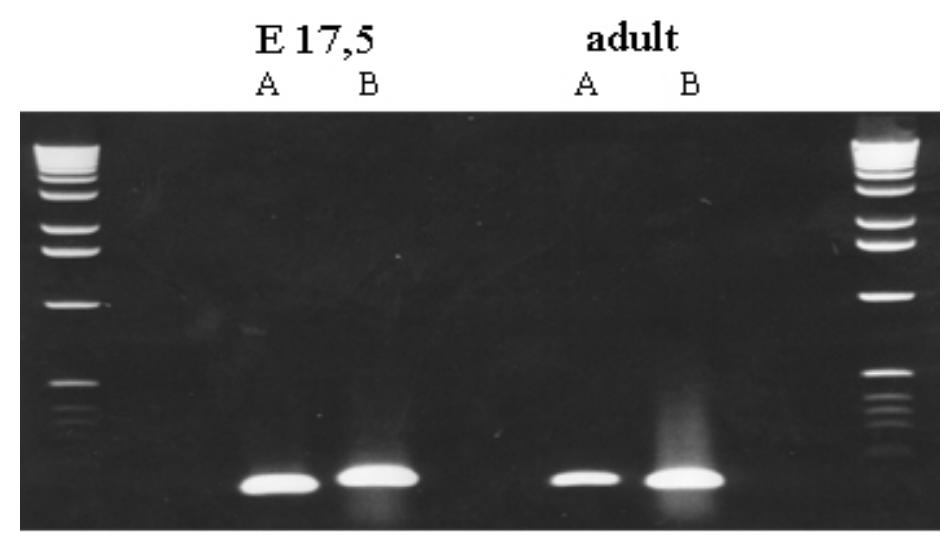

Abb. 3.39: RT-PCR-Analyse für die $I_{2} I_{3}$-Allele mit testikulärer RNA einer adulten transgenen Maus sowie eines 17,5 Tage alten Embryos (E17.5). Dargestellt sind die mit den Primern Hins21F/Hins21R amplifizierten 155 bp langen Fragmente für die transgenen Allele $I_{2} I_{3}-1$ und $I_{2} I_{3}-2(A)$, sowie die mit den Primern ß-AktinF/ß-AktinR amplifizierten 150 bp Fragmente der Kontrollamplifikation (B), die die Integrität der verwendeten RNA belegen sollen.

Wie aus Abbildung 3.39 hervorgeht, wird das transgene Allel bereits in den Testes des 17.5 Tage alten Embryos transkribiert. 


\subsubsection{Analyse der Expression und Fertilität der transgenen Allele $\mathbf{I}_{2} \mathbf{I}_{3}-2$}

\subsection{Expressionsanalyse der Allele $\mathbf{I}_{2} \mathbf{I}_{3}-2$ in Testes der transgenen Mauslinien}

Für die Determination, in welchen transgenen Linien die Allele $\mathrm{I}_{2} \mathrm{I}_{3}-2$ exprimiert werden, wurde eine Northern-Blot-Analyse durchgeführt. Dafür wurden jeweils $10 \mu \mathrm{g}$ testikuläre RNA von adulten hemizygoten $\mathrm{F}_{1}$-Tieren mit einer humanen Insulin-cDNASonde hybridisiert.

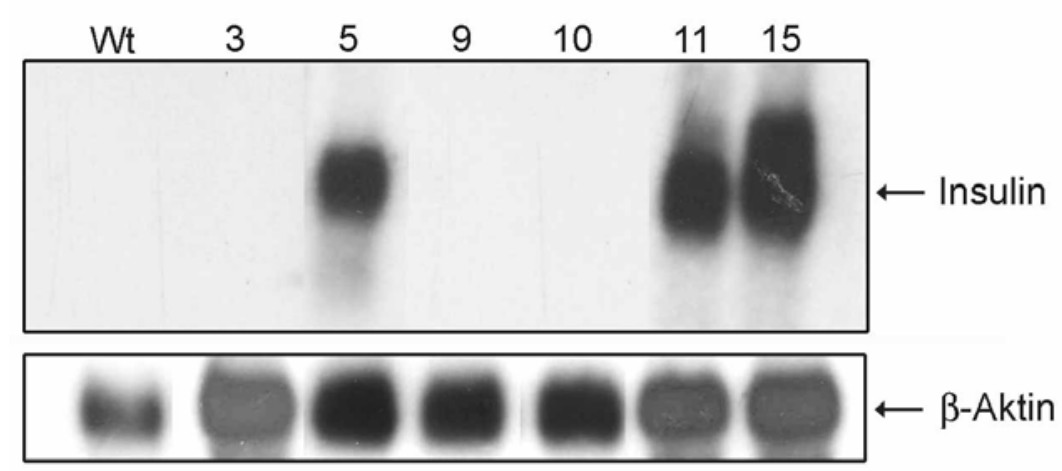

Abb. 3.40: Northern-Hybridisierung mit testikulärer RNA von Wildtyp-(WT) sowie $I_{2} I_{3}-2$ transgenen Mäusen. Die aus den Testes isolierte Gesamt-RNA von adulten $\mathrm{I}_{2} I_{3}-2$ transgenen Mäusen der Linien 3, 5, 9, 10, 11 und 15 wurde mit einer $0.8 \mathrm{~kb}$ Insulin-cDNA Sonde hybridisiert. Um die Integrität und Quantität der RNA zu belegen, wurde mit einer $\beta$-Aktin-cDNA-Sonde rehybridisiert.

Die Mäuse der $\mathrm{I}_{2} \mathrm{I}_{3}-2$ Linien 5, 11 und 15 exprimierten das transgene Allel in den Testes, während bei den Linien 3, 9 und 10 keine testikuläre Expression des transgenen Allels nachgewiesen werden konnte (Abb.3.40), weshalb von einer weiteren Charakterisierung dieser Linien abgesehen wurde. 


\subsection{Analyse der Motilität von Spermien von Wildtyp- und $I_{2} I_{3}-2$ transgenen Mäusen der Linie 15}

Um einen möglichen Einfluss des $\mathrm{I}_{2} \mathrm{I}_{3}-2$ Transgens auf die Motilität der Spermien zu analysieren, wurden von jeweils 3 transgenen männlichen Mäuse und Wildtypmäusen Spermien isoliert. Es wurde die Spermienmotilität nach $1.5 \mathrm{~h}$ gemessen.

Tab. 3.8: Analyse der Motilität der Spermien in $I_{2} I_{3}-2$ transgenen Mäusen der Linie 15 und in WildtypMäusen. In Klammern sind die prozentualen Werte angegeben.

\begin{tabular}{|c|c|c|c|c|}
\hline Genotyp & $\begin{array}{c}\text { Zeit nach } \\
\text { Isolation } \\
\text { (h) }\end{array}$ & $\begin{array}{c}\text { Gesamtzahl der ge- } \\
\text { messenen Spermien }\end{array}$ & $\begin{array}{c}\text { Anzahl der } \\
\text { motilen } \\
\mathbf{( \% )}\end{array}$ & $\begin{array}{c}\text { Anzahl der Spermien } \\
\text { mit progressiven } \\
\text { Sermien (\%) }\end{array}$ \\
\hline $\mathrm{FVB} / \mathrm{N}$ & 1 & $1570(100)$ & $1032(66)$ & $691(44)$ \\
\hline $\mathrm{FVB} / \mathrm{N}$ & 2 & $1478(100)$ & $560(38)$ & $353(24)$ \\
\hline $\mathrm{FVB} / \mathrm{N}$ & 4,5 & $1578(100)$ & $456(29)$ & $266(17)$ \\
\hline $\mathrm{I}_{2} \mathrm{I}_{3}-2$ & 1 & $1824(100)$ & $1151(63)$ & $718(39)$ \\
\hline $\mathrm{I}_{2} \mathrm{I}_{3}-2$ & 2 & $2340(100)$ & $1094(47)$ & $590(25)$ \\
\hline $\mathrm{I}_{2} \mathrm{I}_{3}-2$ & 4,5 & $2297(100)$ & $1065(46)$ & $577(25)$ \\
\hline
\end{tabular}

Die Ergebnisse dieser Messungen sind in Tabelle 3.8 dargestellt. Nach einer Stunde lag der Anteil der motilen Spermien bei den Wildtyp-(FVB/N) als auch bei den transgenen Mäusen zwischen 60-70\% und der Anteil der progressiv motilen Spermien jeweils zwischen 35-45\%. Die in Tabelle 3.7 zusammengefassten Daten lassen auch erkennen, dass sich nach 2 und $4.5 \mathrm{~h}$ der Anteil der motilen und progressiv motilen Spermien der transgenen und der Wildtyp-Maus in ähnlicher Weise reduzierte.

Einige Parameter wurden genauer untersucht. Die Ergebnisse zeigen, dass sich die Motilität der Spermien von transgenen Mäusen nicht wesentlich von der Motilität der Spermien des Wildtyps unterscheidet (Daten nicht gezeigt). 


\subsubsection{Analysen der Translation, Prozessierung und der Sekretion für das transgene Allel $\mathbf{I}_{2} \mathbf{I}_{3}$}

Da Northern-Blot- und RT-PCR-Analysen gezeigt haben, dass die transgenen Allele $\mathrm{I}_{2} \mathrm{I}_{3}-1$ und $\mathrm{I}_{2} \mathrm{I}_{3}-2$ in testikulärem Gewebe exprimiert werden, sollte auch der Nachweis auf Protein-Ebene erfolgen. Außerdem sollte untersucht werden, ob das transgene Proinsulin im Testis korrekt prozessiert und sezerniert wird.

\subsubsection{Immunhistochemische Analysen für das transgene Allel $\mathbf{I}_{2} \mathbf{I}_{3}$}

Gewebeschnitte von Pankreas und Testis von transgenen und Wildtyp-Mäusen wurden mit einem monoklonalen Maus-Anti-Insulin-IgG Antikörper inkubiert, welcher sowohl an murines als auch an humanes Insulin und Proinsulin bindet. Dieser wurde dann mit einem 2. Fluoreszenz-Antikörper (Anti-Maus-IgG-F(ab') $)_{2}$ Fragment-Cy3) sichtbar gemacht. Die Zellkerne wurden mit DAPI gefärbt. Die Präparate wurden mit einem Fluoreszenz-Mikroskop mit einer digitalen Kamera fotografiert und mittels der AnalySISS-Software ausgewertet.
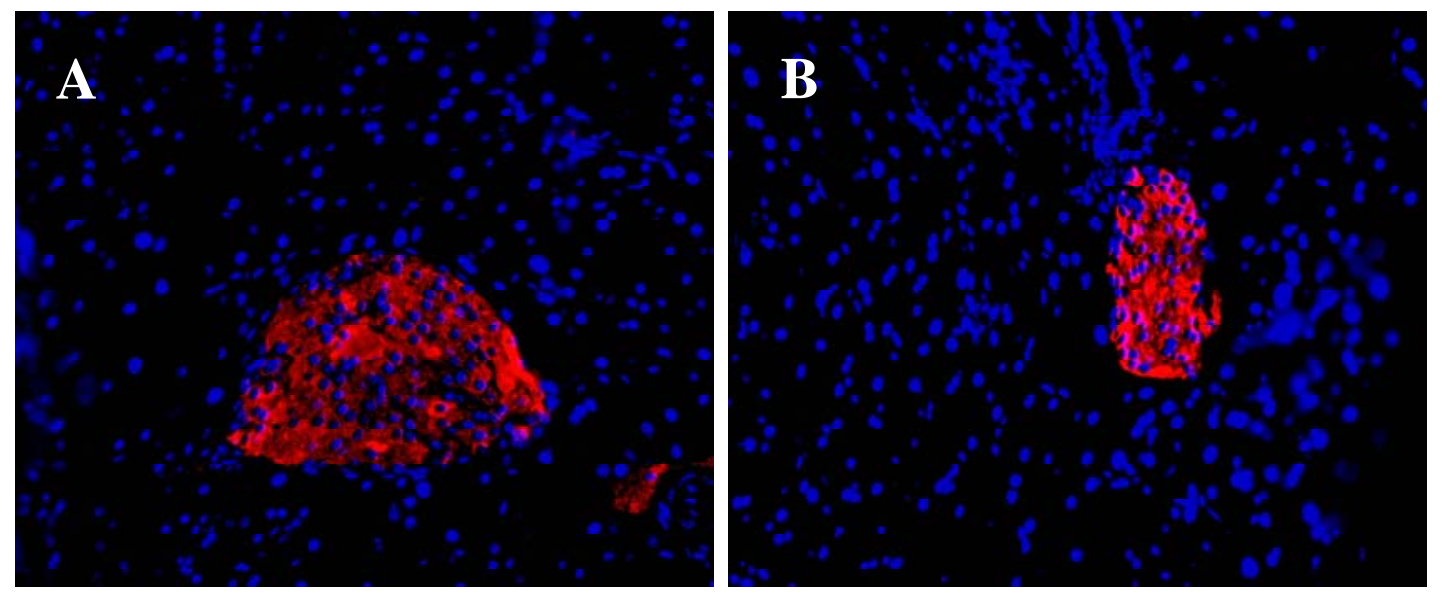

Abb. 3.41: Immunhistochemische Detektion von Insulin in pankreatischem Gewebe. Dargestellt sind Überlagerungsbilder von der mit 200 ms belichteten DAPI-Färbung (blau) der Kerne und der mit 600 ms belichteten Cy3-Färbung (rot) gegen Insulin. Die Gewebe stammen von einer Wildtyp (A) und einer $I_{2} I_{3}$ transgenen Maus(B). 
Wie in Abbildung 3.41 zu erkennen, sind jeweils die gesamten Langerhans'schen Inseln mit dem Cy3-Fluoreszenz-Antikörper gefärbt. Unabhängig vom genetischen Hintergrund konnte Insulin in den Langerhans'schen Inseln detektiert werden.
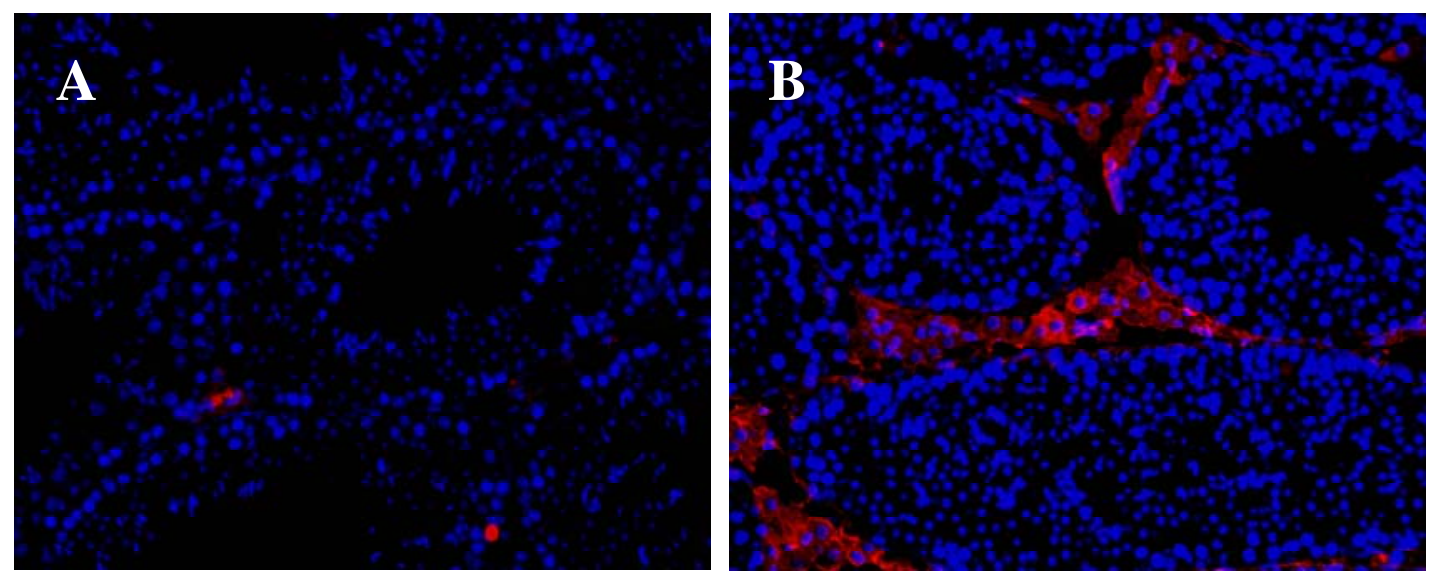

Abb. 3.42: Immunhistochemische Detektion von Insulin in testikulärem Gewebe $I_{2} I_{3}$ transgener Mäuse. Dargestellt sind Überlagerungsbilder von der mit 200 ms belichteten DAPI-Färbung (blau) der Kerne und der mit 600 ms belichteten Insulin-Cy3-Färbung (rot). Die Gewebe stammen von einer Wildtyp (A) und einer $I_{2} I_{3}$ transgenen Maus (B).

In Abbildung 3.42 kann man anhand der durch DAPI gefärbten Zellkern-Formation die Strukturen der Tubuli seminiferi deutlich erkennen. In den Testis-Präparaten der $\mathrm{I}_{2} \mathrm{I}_{3}$ transgenen Mäuse (B) ist die Insulin-Färbung der Regionen des interstitiellen Gewebes, welches unter anderem die Leydigzellen enthält, deutlich zu erkennen. Die interstitielle Region des Wildtyp-Testis (A) verbleibt weitestgehend ungefärbt. Es ist wahrscheinlich, dass die sehr kleinen gefärbten Areale auf nicht abgewaschene ungebundene Antikörper zurückzuführen sind. Im Vergleich hierzu sind die mit gleich langer Belichtungszeit aufgenommenen Fluoreszenz-Färbungen der Testes transgener Mäuse flächig. Eine Kreuz-Hybridisierung mit dem Insl3-Protein ist ebenfalls vorstellbar. Demnach muss davon ausgegangen werden, dass die wesentlich stärkeren Färbungen der Präparate der transgenen Tiere auf transgenes Human-Insulin hinweisen. Das bedeutet, dass das transgene Allel in den Leydigzellen exprimiert wird und die mRNA translatiert wird. 


\subsubsection{Untersuchung über die Translation des transgenen Allels $I_{2} I_{3}-1$ mittels Fluoroimmunoassay}

Für einen weiteren Nachweis des transgenen Allels $\mathrm{I}_{2} \mathrm{I}_{3}-1$ auf Proteinebene wurden Proteinextrakte aus Testis und Pankreas von Wildtyp- und $\mathrm{I}_{2} \mathrm{I}_{3}-1$ transgenen Mäusen der Linie 2 mittels eines Fluoroimmunoassays analysiert. Hierbei kamen für humanes und murines Insulin und Proinsulin spezifische Antikörper zum Einsatz (2.2.13). Dieser Assay enthält zwei verschiedene monoklonale Antikörper, welche an 2 unterschiedliche antigene Bereiche des Insulinmoleküls binden. Es wurden jeweils die Proteinextrakte aus Testis und Pankreas von 6 Wildtypen und 6 transgenen Mäusen untersucht.

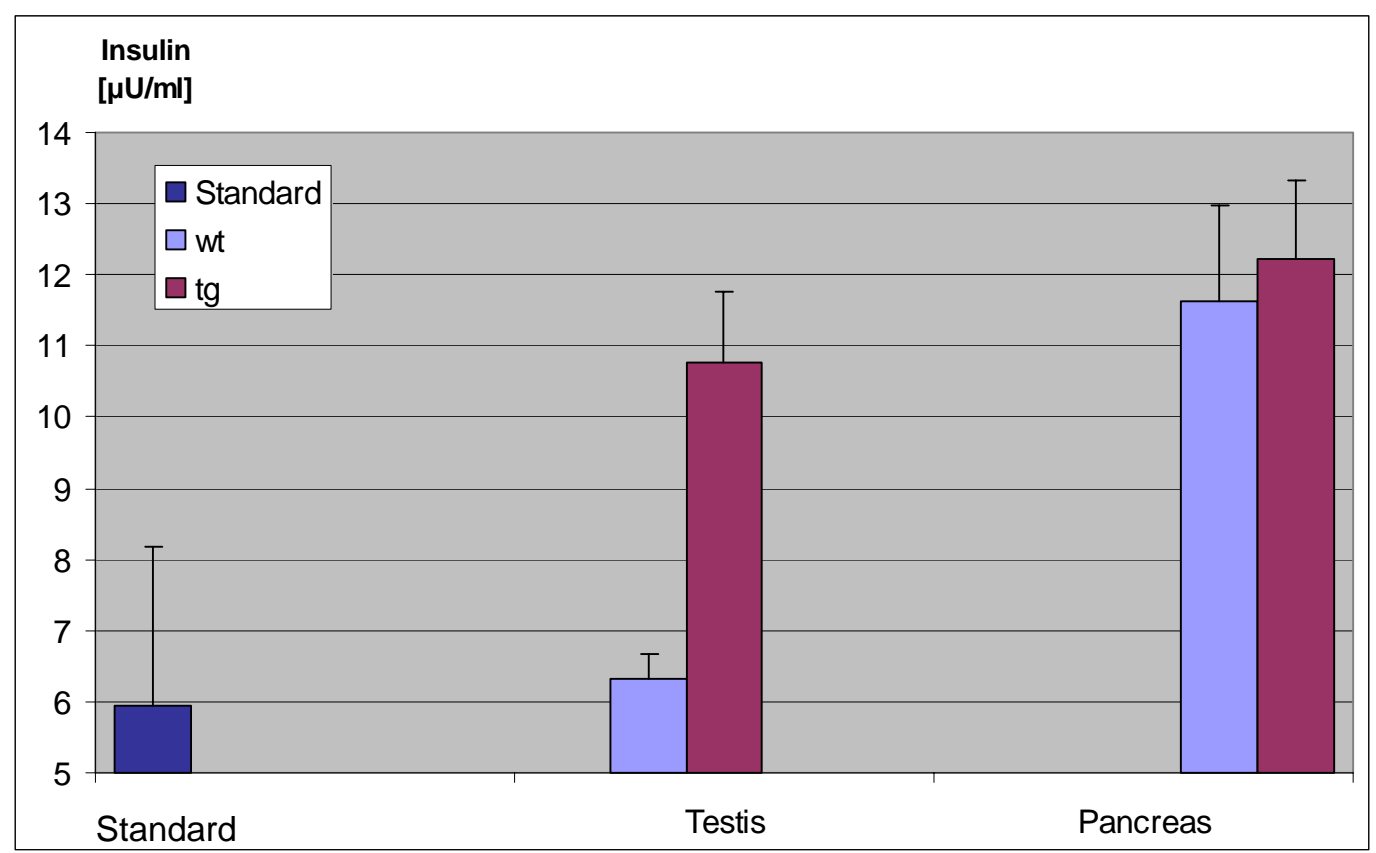

Abb. 3.43: Insulinkonzentrationen in den Proteinextrakten von Wildtypen (Wt) und $I_{2} I_{3}-1$ transgenen

(tg) Mäusen der Linie 2. Es wurden Proteinextrakte aus Testes und Pankreas der Wildtyp- bzw. transgenen Mäuse isoliert und jeweils die Insulinkonzentration bestimmt.

Wie aus Abbildung $3.43 \mathrm{zu}$ entnehmen ist, ist die Insulinkonzentration des aus den Wildtyptestes stammenden Proteinextrakte sehr gering $(6.33 \pm 0.35 \mu \mathrm{U} / \mathrm{ml})$ und vergleichbar mit der Standard $(5.94 \pm 2.24 \mu \mathrm{U} / \mathrm{ml})$. Im Gegensatz dazu war der InsulinLevel in den Testesproteinextrakten der transgenen Tiere mit $10.75 \pm 0.99 \mu \mathrm{U} / \mathrm{ml}$ erheblich höher und entspricht weitestgehend den Werten der Pankreasextrakte von Wildtyp-(11.6 $\pm .1 .34)$ bzw. transgenen Mäusen $(12.23 \pm 1.08 \mu \mathrm{U} / \mathrm{ml})$. 
Diese Befunde belegen, dass das transgene Allel $\mathrm{I}_{2} \mathrm{I}_{3}-1$ im Testis der transgenen Tiere transkribiert und translatiert wird. Zum Prozessierungsgrad des testikulären Insulins bzw. Proinsulins können hier aber keine Angaben gemacht werden.

Analyse der Sekretion prozessierten Insulins mittels Radio-ImmunoAssay

Northern-Blot-Analysen und immunhistochemische Analysen haben gezeigt, dass das transgene Allel $\mathrm{I}_{2} \mathrm{I}_{3}$ in den Leydigzellen transaktiviert und Proinsulin produziert wird. Die Unfähigkeit (fehlende Wirkung) des transgenen Insulins zur Rettung der diabetischen $\mathrm{Pax}^{-/-}$Mäuse (s. 3.3.4.1) führte $\mathrm{zu}$ der Überprüfung der Frage, ob das transgene Proinsulin zu Insulin prozessiert und in die Blutbahn ausgeschüttet wird.

Nach der Prozessierung von Proinsulin in aktives Insulin durch die enzymatische Entfernung des die A- und B-Peptidkette verbindenden C-Peptids, wird in den pankreatischen $\beta$-Zellen Insulin und freies C-Peptid ins Blut ausgeschüttet. Ließe sich humanes C-Peptid im Serum von $\mathrm{I}_{2} \mathrm{I}_{3}$ transgenen Tieren nachweisen, würde dies für eine korrekte Prozessierung innerhalb der das transgene Allel transkribierenden und tanslatierenden Leydigzellen sowie anschließender Sekretion sprechen. Um dies zu überprüfen, wurde ein Radio-Immunoassay für humanes C-Peptid durchgeführt (LINCO Research, Inc.). Hierfür wurden Lösungen aufgereinigten humanen C-Peptids determinierter unterschiedlicher Konzentrationen zusammen mit ${ }^{125} \mathrm{I}$-markiertem humanen C-Peptid (Tracer) und Meerschwein-Anti-humanen C-Peptid-Antikörpern inkubiert. Mittels Zugabe eines zweiten Antikörpers (Ziege-Anti-Maus-IgG) und anschließender Zentrifugation wurden die Agglomerate aus humanem C-Peptid und der beiden Antikörper präzipitiert, wobei ungebundene Tracer in Lösung verblieben. Danach wurde der Anteil der Tracer innerhalb der gebundenen Fraktion humanen CPeptids per Gamma-Counter bestimmt. Da das Tracer-Antigen mit unmarkiertem humanem C-Peptid um die Antigen-Bindungsstellen konkurriert, verringert sich bei Applikation von unmarkiertem C-Peptid der Anteil der an die Antikörper gebundenen Tracer-Antigene. Mittels einer mit bekannten Konzentrationen von unmarkierten Antigenen erstellten Standardkurve kann dann die Konzentration von humanem CPeptid der einzelnen Proben bestimmt werden. Es wurden die Konzentrationen von humanem C-Peptid in Serum von 9 männlichen und 2 weiblichen $\mathrm{I}_{2} \mathrm{I}_{3}-1$ Mäusen der 
Linie 2, $6 \mathrm{I}_{2} \mathrm{I}_{3}-1$ männlichen Mäusen der Linie 12 und 4 männlichen und 5 weiblichen $\mathrm{I}_{2} \mathrm{I}_{3}-2$ Mäuse der Linie 15 gemessen. Als Kontrolle wurden 9 männliche Wildtyp Tiere verwendet.

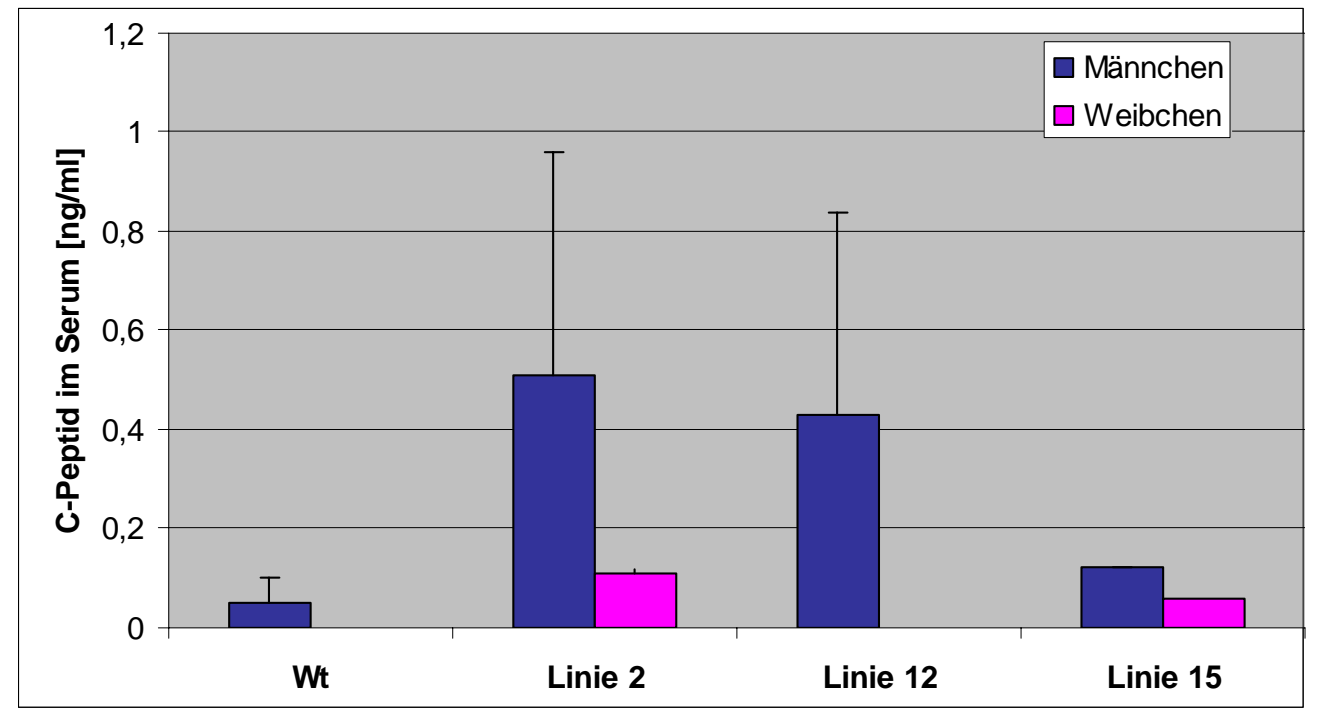

Abb. 3.44: Darstellung der Konzentration von humanem C-Peptid im Serum $I_{2} I_{3}$ transgener Mäuse sowie von Wildtyp-Kontrollen. Es wurde die Konzentration von humanem C-Peptid im Serum weiblicher und männlicher Mäuse der Linie 2, von männlichen Tieren der Linie 12 und von männlichen und weiblichen Mäusen der Linie 15 gemessen. Als Kontrollen wurden männliche Wildtyp FVB Mäuse analysiert.

In Abbildung 3.44 sind die Konzentrationen des humanen C-Peptids im Serum der männlichen und weiblichen $\mathrm{I}_{2} \mathrm{I}_{3}-1$ Tiere der Linien 2 und 12 und $\mathrm{I}_{2} \mathrm{I}_{3}-2$ der Linie 15 dargestellt. Die Konzentration des C-Peptids im Serum der männlichen transgenen Tiere der Linien 2 und 12 bzw. 15 ist $0.51 \pm 0.45 \mathrm{ng} / \mathrm{ml}$ und $0.43 \pm 0.41 \mathrm{ng} / \mathrm{ml}$ und lag damit über der vom Hersteller angegebenen Sensitivitätgrenze $(0.1 \mathrm{ng} / \mathrm{ml})$, während die Konzentration des humanen C-Peptids im Serum der männlichen Wildtyp Mäuse bzw. der weiblichen $\mathrm{I}_{2} \mathrm{I}_{3}-2$ Tiere bei $0.1 \pm 0.02$ bzw. $0.00 \mathrm{ng} / \mathrm{ml}$ unter der Sensitivitätgrenze $0.1 \mathrm{ng} / \mathrm{ml}$ lag.

Die Ergebnisse deuten daraufhin, dass das testikuläre (Pro)Insulin zu Insulin prozessiert und aus den Leydigzellen in Blut ausgeschüttet wird.

Da Insl3 in geringem Ausmaß auch in den Ovarien transkribiert wird (Zimmermann et al., 1997; Balvers et al., 1998) und das transgene Allel soweit untersucht dem 
Expressionsmuster des Insl3-Gens folgt, ist es nicht unwahrscheinlich, dass auf niedrigem Level humanes (Pro)Insulin aus den Theka-Zellen ins Blut ausgeschüttet wird.

\subsubsection{4}

\section{Expressionsanalyse der Proinsulin-prozessierenden Enzyme PCSK1 und PCSK2}

An der Prozessierung von Proinsulin in aktives Insulin sind die Prohormon prozessierenden Enzyme des Substilisin/Kexin-Typs 1 und 2 (PCSK1 und PCSK2) beteiligt (Steiner et al., 1998; Steiner et al., 2000). Außerdem ist bekannt, dass zumindest im Pankreas die besagten Prohormon Konvertasen transkribiert werden und in den $\beta$-Zellen des Pankreas Proinsulin korrekt prozessiert wird. Um zu überprüfen, ob die genannten Enzyme im Testis von Mäusen exprimiert werden, wurde eine "one-step" RT-PCR durchgeführt. Dafür wurde jeweils $1 \mu$ von aus Testis und Pankreas adulter Wildtyp-Mäuse (FVB/N) gewonnene Gesamt-RNA verwendet. Jeder Ansatz wurde in einem separaten Reaktionsgefäß synchron transkribiert bzw. amplifiziert. Es wurden spezifische Primer für PCSK1, PCSK2 (2.1.11) verwendet.

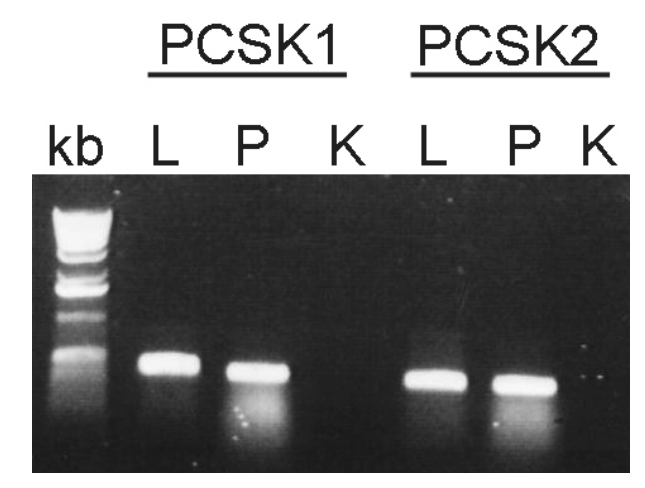

Abb. 3.45: RT-PCR-Analyse für die Proinsulin-prozessierenden Enzyme PCSK1 und PCSK2 mit testikulärer und pankreatischer RNA von Wildtyp-Mäusen. Dargestellt sind die mit den PCSK1 und PCSK2 spezifischen Primern amplifizierten PCSK1-und PCSK2-Fragmente an aus Leydigzellen $(L)$ und Pankreas (P) gewonnener Gesamt-RNA von FVB/N-Wildtyp-Mäusen. K ist für Leerkontrolle.

Wie Abbildung 3.45 zeigt, konnte die Expression der Gene PCSK1 und PCSK2 in den Testes von Mäusen gezeigt werden. Dieses Ergebnis legt nahe, dass die Proinsulinprozessierenden Enzyme PCSK1 und PCSK2 auch in den das transgene Allel translatierenden Leydigzellen transkribiert werden. 


\subsubsection{Rettungsexperimente und Glukose-Toleranz-Test diabetisierter männlicher transgener Mäuse}

\subsubsection{Untersuchung zur Funktion des testikulären Insulins in vivo}

Da gezeigt werden konnte, dass das $\mathrm{I}_{2} \mathrm{I}_{3}$ transgene Allel in den Leydigzellen sowohl transkribiert als auch translatiert wird, stellte sich nun die Frage, ob das testikuläre Insulin in der Lage ist, die Funktion des normalerweise von den $\beta$-Zellen produzierten Insulins in einem $\beta$-Zell-Defizienz Tiermodell zu übernehmen. Um dies zu überprufen, wurde zum einen das $I_{2} I_{3}-1$-und in einem anderen Experiment $I_{2} I_{3}-2$ transgene Allel in das Genom von Pax4-defizienten Mäusen eingebracht. Der Transkriptionsfaktor Pax4 gehört zu der „Paired box-Gen“-Familie und wird in fetalen $\beta$ - und $\delta$-Zellen der Pankreas exprimiert. Die Analyse von Pax4-defizienten Mäuse hat gezeigt, dass die Proliferation von $\beta$ - und $\delta$-Zellen während der embryonalen Entwicklung stark beeinträchtigt ist. $P a x 4^{-/}$Mäuse besitzen keine ausgereiften $\beta$ - und $\delta$-Inseln. Aufgrund der fehlenden $\beta$-Zellen kann kein Insulin in den Pax4-defizienten Embryonen gebildet werden und die neugeborenen Mäuse sterben ca. 1-4 Tage nach der Geburt an einem Diabetes mellitus (Sosa-Pineda et al., 1997).

$\mathrm{Um} \mathrm{Pax} 4^{-/} / \mathrm{I}_{2} \mathrm{I}_{3}$ Mäuse zu generieren, wurden die $\mathrm{I}_{2} \mathrm{I}_{3}-1$ transgenen Tiere der Linie 12 und die $\mathrm{I}_{2} \mathrm{I}_{3}-2$ transgenen Tiere der Linie 15 mit Pax $4^{+/-}$Mäusen verpaart.

Mit Hilfe von PCR-Analysen wurden die $\mathrm{Pax} 4^{+/-} / \mathrm{I}_{2} \mathrm{I}_{3}$ trangenen Mäuse in der $\mathrm{F}_{1^{-}}$ Generation identifiziert. Die selektierten Tiere der $F_{1}$-Generation wurden dann untereinander verpaart. Die Verhältnisse der verschiedenen Genotypen in der zweiten Generation wurden wiederum mittels PCR-Analyse untersucht. Außer Pax $4^{-/-}$- und $\mathrm{Pax}^{-/-} / \mathrm{I}_{2} \mathrm{I}_{3}$ transgenen Mäusen konnten alle weiteren möglichen Genotypen in 3 Wochen alten Mäusen identifiziert werden.

Die Genotypen fast aller Neugeborener, welche innerhalb der ersten 3 Tage nach Geburt gestorben sind, waren entweder $\operatorname{Pax} 4^{-/-}$oder $\operatorname{Pax} 4^{-/} / \mathrm{I}_{2} \mathrm{I}_{3}-1$. Ähnliche Ergebnisse waren auch bei der Analyse der $\mathrm{F}_{2}$-Generation aus den Verpaarungen der $\mathrm{Pax}^{+/-}$mit Tieren +/-Mäuse der $\mathrm{I}_{2} \mathrm{I}_{3}-2$ transgenen Linie $15 \mathrm{zu}$ beobachten. Diese Ergebnisse lassen vermuten, dass das testikuläre Insulin nicht (ausreichend) die Funktion des pankreatischen Insulins übernehmen kann.

Die Unfähigkeit des testikulär produzierten Insulins, einen ausgeprägten Diabetes mellitus bei Pax $4^{-/-}$Mäusen zu verhindern, könnte auf eine zu niedrige Expression des 
transgenen Allels während der ersten drei Wochen zurückzuführen sein. Um dies zu überprüfen, wurden die $\mathrm{F}_{2}$-Tiere von Geburt an täglich mit Insulin (durch intraperitonäle Injektion: $0.02 \mathrm{U} / \mathrm{g}$ Körpergewicht) supplementiert. Diese Behandlung hat die Lebensdauer der $\mathrm{Pax}^{-/-}$und $\mathrm{Pax}^{-/-} / \mathrm{I}_{2} \mathrm{I}_{3}-1$ und $\mathrm{I}_{2} \mathrm{I}_{3}$-2-Tiere um etwa 8-12 Tage verlängert. Allerdings überlebte keines dieser so behandelten $P a x 4^{-1-} / I_{2} I_{3}$ Tiere den 12 . Tag.

\subsubsection{Generierung transgener diabetischer Mäuse}

Es sollte in vivo untersucht werden, ob die Produktion von transgenem Insulin in diabetischen Mäusen den Blutzuckerspiegel nachhaltig bzw. kurzfristig nach einer Glukose-Injektion senken kann. Diabetes mellitus wurde bei den zu untersuchenden 2 Monate alten Mäusen durch intraperitoneale Injektion von Streptozotocin (STZ) (33.3 $\mathrm{mg} / \mathrm{kg}$ Körpergewicht; gelöst in $50 \mathrm{mM}$ Citrat-Puffer; $\mathrm{pH} 4.5$ ) an fünf aufeinander folgenden Tagen zur gleichen Uhrzeit induziert. Streptozotocin ist ein aus Streptomyces achromogenes isoliertes Breitband-Antibiotikum und zerstört u.a. die für die Insulinproduktion verantwortlichen $\beta$-Zellen in Pankreas und induziert somit Diabetes. Es wurden 5 Wildtyp-Tiere, $5 \mathrm{I}_{2} \mathrm{I}_{3}-1$ transgene Tiere der Linie2, 7 Tiere der Linie 12, 4 Wildtyp-Tiere, $7 \quad \mathrm{I}_{2} \mathrm{I}_{3}-2$ transgene Tiere der Linie 11 und 8 Tiere der Linie 15 mit Streptozotocin behandelt.

\subsection{Analyse der Blutglukosekonzentration in mit Streptozotocin behandelten $\mathbf{I}_{2} \mathbf{I}_{3}$-Mäusen}

Beginnend am Tag der ersten Streptozotocin-Injektion wurde von den behandelten transgenen und Kontroll-Wildtyp-Mäusen und unbehandelten Vergleichstieren im Abstand von 2-3 Tagen das Gewicht und der Glukosespiegel im Blut gemessen. Die obere Grenze des Messbereichs des den Blut-Glukosespiegel bestimmenden Messgeräts (Haemogluco-Test, Boehringer) lag bei $600 \mathrm{mg} / \mathrm{dl}$, so dass höhere Glukose-Werte auf $600 \mathrm{mg} / \mathrm{dl}$ gesetzt werden mussten. 
Wie die Abbildungen 3.46 und 3.47 zeigen, steigt der Blut-Glukose Spiegel 5 Tage nach der Behandlung an. Sowohl bei den transgenen $\mathrm{I}_{2} \mathrm{I}_{3}-1$ Tieren der Linien 2 und 12 als auch bei den Wildtyp-Mäusen erreicht der Glukosewert nach 15 Tagen der Behandlung etwa $500 \mathrm{mg} / \mathrm{dl}$.

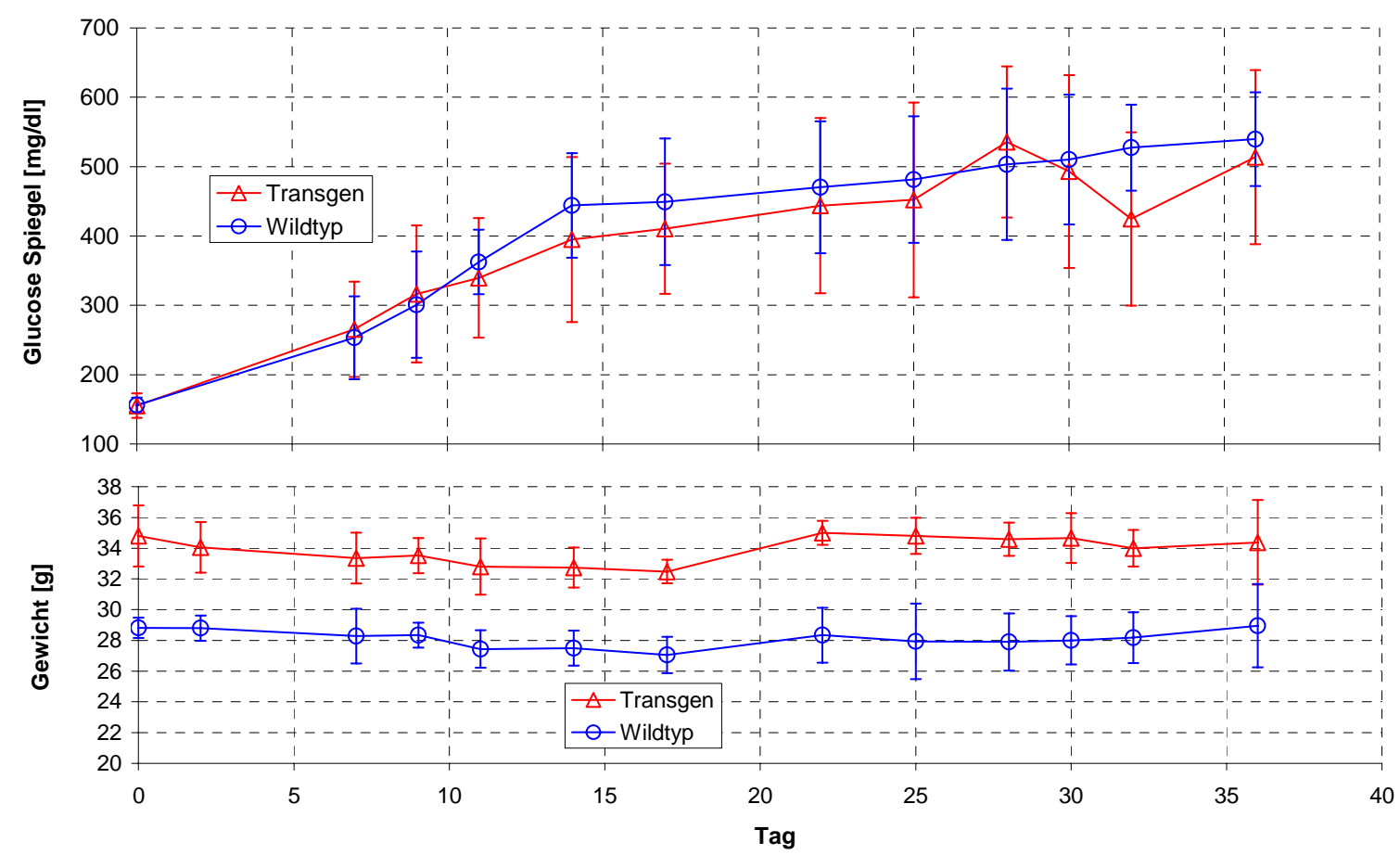

Abb. 3.46: Darstellung der Blutglukosewerte und der Gewichte von Streptozotocin-behandelten $I_{2} I_{3}-1$ transgenen Mäusen der Linie 2 und von Wildtyp-Kontroll-Mäusen. Die Blutglukosewerte steigen sowohl bei den transgenen als auch bei Wildtyp-Mäusen. 


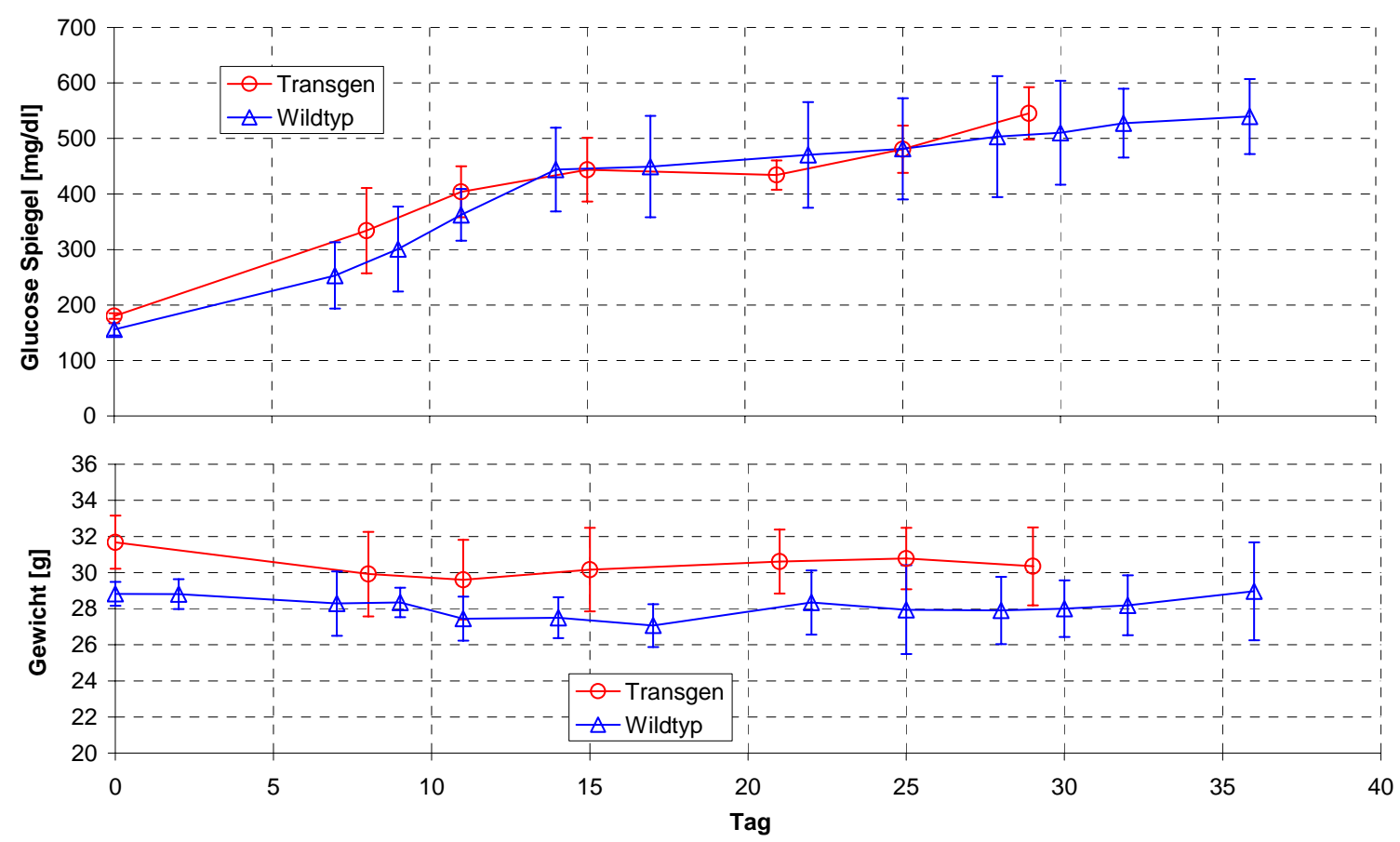

Abb. 3.47: Darstellung der Blutglukosewerte und der Gewichte von Streptozotocin-behandelten $I_{2} I_{3}-1$ transgenen Mäusen der Linie 12 und von Wildtyp-Kontroll-Mäusen. Auch hier steigen die Blutglukosewerte sowohl bei den transgenen als auch bei den Wildtyp-Mäusen.

Diese Experimente zeigen, dass die Wildtyp Tiere als auch die transgenen Tiere einen Diabetes entwickelten. Es ist davon auszugehen, dass das aus dem Testis der transgenen Tiere ausgeschüttete Insulin nicht ausreicht, um die Funktion des fehlenden pankreatischen Insulins zu übernehmen.

Interessanterweise lag das Körpergewicht bei den $\mathrm{I}_{2} \mathrm{I}_{3}-1$ transgenen Tieren der Linien 2 und 12 höher als bei den Wildtyp Tieren. (Abb. 3.46, 3.47)

\subsection{Glukosetoleranz}

Um zu überprüfen, ob die mit Streptozotocin behandelten transgenen Mäuse in der Lage sind, den durch intraperitoneal injizierte Glukoselösung erhöhten Blutglukosewert innerhalb kurzer Zeit wieder zu senken, wurde ein Glukosetoleranztest durchgeführt. So sollte untersucht werden, ob in transgenen Mäusen der induzierte erhöhte Glukosespiegel im Serum eine Antwort in Form der Sekretion aktiven humanen Insulins 
aus den Leydigzellen in das Blut hervorrufen kann. Den Mäusen wurde Glukose gespritzt (2 mg/g Körpergewicht) und in 20 Minuten Abständen dreimal der Blutglukosewert bestimmt. Die Ergebnisse sind in Abbildung 3.48 grafisch dargestellt.

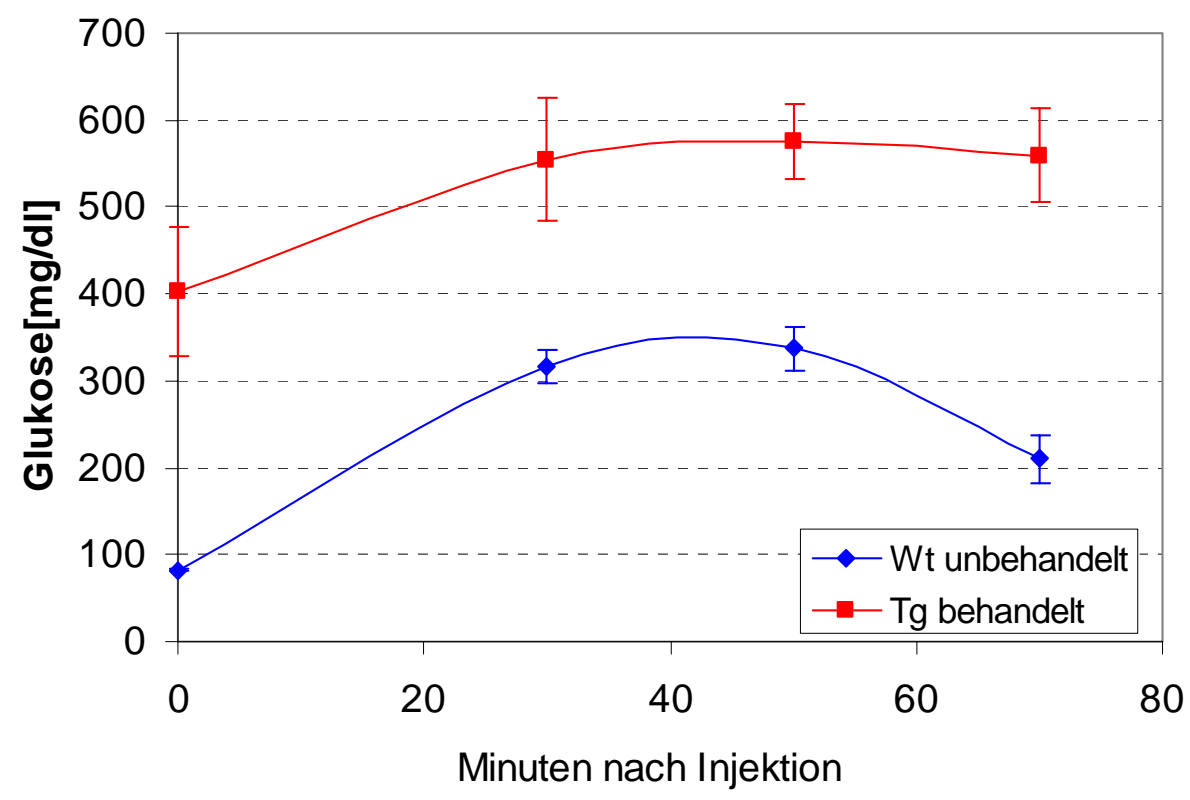

Abb. 3.48: Darstellung der zeitabhängigen Blutglukosewerte von Streptozotocin (STZ)-behandelten $I_{2} I_{3}$ transgenen Mäusen und unbehandelten Wildtyp-Kontroll-Mäusen (Wt). $I_{2} I_{3}$ Trangene Mäuse werden hier mit Tg bezeichnet.

Die in Abbildung 3.48 dargestellten Blutglukosekurven der unbehandelten Wildtyp Tiere zeigen einen normalen Verlauf. Streptozotocin-behandelte transgene Tiere zeigten bereits zu Beginn des Experiments erhöhte Blutzuckerwerte, die während der untersuchten Zeitspanne auch nicht zurückgingen. Aus diesen Ergebnisse kann man entnehmen, dass ein erhöhter Glukosespiegel die Sekretion von testikulärem Insulin in transgenen diabetisierten Tieren nicht stimuliert, was für die fehlende Präsenz eines glukoseabhängigen Sekretionsmechanismus in den Leydigzellen spricht. 


\section{$4 \quad$ DISKUSSION}

Nach dem Abschluss des Humanen Genomprojekts und der Sequenzierung der ESTs (Expressed Sequence Tags) sind mittlerweile die Nukleotidsequenzen von über der Hälfte aller humanen Gene zugänglich. So ist die EST Genbank zu einer wertvollen Quelle bzw. einem hilfreichen Werkzeug avanciert, um bisher unbekannte paraloge Formen bekannter Gene derselben Spezies oder orthologe Gene anderer Arten zu identifizieren.

Aufgrund der Sequenz-Ähnlichkeiten der B- und A-Kette aller Mitglieder der Insulinähnliche Familie wurde in der Datenbank mittels eines Blast-Programms nach EST-Sequenzen gesucht, die für weitere Mitglieder diese Familie codieren. Dabei konnte Hsu (1999) zwei neue Mitglieder der Insulin/Relaxin homologen Familie identifizieren. Die ursprünglich als Relaxin-Insulin-Faktor (RIF) 1 und 2 benannten Proteine wurden später mit breitem Konsens als INSL5 und INSL6 bezeichnet.

\subsection{Das Insl5-Gen}

Die Gesamtlänge der Ins15-cDNA der Maus beträgt 713 bp und die des Menschen 726 bp. Die 5'- bzw. 3'-untranslatierte Region besteht bei der humanen cDNA aus 48 bzw. 373 bp. Das aus der codierenden Sequenz abgeleitete Präpropeptid beider Spezies hat eine Länge von 135 Aminosäuren und ein Molekulargewicht von 15.5 kDa. Die primäre Struktur der abgeleiteten Präproproteine setzt sich wie bei den anderen Mitgliedern der Insulinähnliche Familie ebenfalls aus Signalpeptid, B- und A-Kette und einem C-Peptid zusammen.

Die Aminosäuresequenz der B- und A-Kette vom humanen INSL5 hat eine Homologie von $71 \%$ zur entsprechenden Sequenz der Maus. Bei dem Vergleich der Sequenzen von B- und A-Kette findet man beim Menschen eine Homologie von $40 \%$ zu Relaxin, von $34 \%$ zu INSL3, von $30 \%$ zu Insulin, von $29 \%$ zu INSL6 und IGF2, von $28 \%$ zu IGF1 und von 22\% zu INSL4 (Abb. 4.1). Die Homologie des humanen INSL5 C-Peptids ist mit $48 \%$ zur entsprechenden Sequenz von murinen Ins15 relativ hoch. Es konnten 
jedoch keine Sequenzähnlichkeiten der C-Kette zu entsprechenden Sequenzen von anderen Mitgliedern der Insulinfamilie gefunden werden (Conklin et al., 1999).

\section{B-Kette}

\begin{tabular}{|c|c|}
\hline hINSL5 & - - - - - -KESVRLCGLEYIRTVIYICASSRWRR \\
\hline mIns15 & - - - - - -RQTVKLCGLDYVRTVIYICASSRWRR \\
\hline hINSL6 & -RELSDISSARKLCGRYLVKEIEKLCGHANWSQFR \\
\hline rIns16 & - - - QEEVTSPTKLCGRDLLVEVIKLCGQNDWSR \\
\hline IGF1 & - - - GPETLCGAELVDALQFVCGDRGFYFN \\
\hline IGF2 & - - - - - AYRPSETLCGGELVDTLQFVCGDRGFYFSRPA \\
\hline Insulin & - - FVNQHLCGSHLVEALYLVCGERGFFYTPKTRR \\
\hline Relaxin2 & - - - -SWMEEVIKLCGRELVRAQIAICGMSTWSKR \\
\hline Relaxin3 & - - - -RAAPYGVRLCGREFIRAVIFTCGGSRW \\
\hline INSL3 & LGPAPTPEMREKLCGHHFVRALVRVCGGPRWSTEARR \\
\hline INSL4 & - - AELRGCGPRFGKHLLSYCPMPEKTFTTTPGG \\
\hline Motiv & hCG hh hC \\
\hline
\end{tabular}

\section{A-Kette}

$66--$ - QDLQTLCCTDGCSMTDLSALC

67 - - DLQALCCREGCSMKELSTLC

118 - -GYSEKCCLTGCTKEELSIACLPYIDF

110 - -GFADKCCAIGCSKEELAVACLPFVDF

15 - - -GIVDECCFRSCDLRRLEMYCA

8 - - - GIVEECCFRSCDLALLETYCA

- - - GIVEQCCTSICSLYQLENYCN

QLYSALANKCCHVGCTKRSLARFC

DVLAGLSSSCCKWGCSKSEISSLC

AAATNPARYCCLSGCTQQDLLTLCPY

SGRHRFDPFCCEVICDDGTSVKLCT

CC $\quad \mathrm{c}$ h hC

Abb. 4.1: Vergleich der abgeleiteten Aminosäuresequenzen von B- und A-Kette der Mitglieder der Insulinfamilie. Für INSL5 ist sowohl die humane (h) als auch die murine (m) AS-Sequenz dargstellt. Für INSL6 wurden die Aminosäuresequenzen des Menschen (h) und der Ratte (r) dargestellt. Darunter sind die konservierten Sequenzen als „, $h$ “ angedeutet.

Die für die biologische Aktivität notwendigen Aminosäuren der insulinähnlichen Hormone sind nach Blundell und Humbel (1980) innerhalb der B- und A-Kette zu finden. Von besonderer Wichtigkeit sind dabei die sechs Cysteinreste, die für die Ausbildung der drei Disulfidbrücken innerhalb des reifen Hormons essentiell sind (Abb. 4.2).
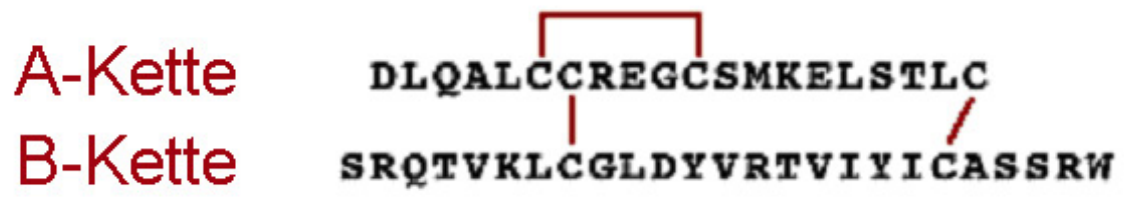

Abb. 4.2: Aminosäuresequenz des humanen INSL5-Peptids (Insulin-like Peptide 5) Die Abbildung zeigt das reife Hormon nach der Abspaltung der C-Kette. Die Disulfidbrücken wurden durch Linien innerhalb der A-Kette und zwischen der A- und B-Kette gekennzeichnet. 
Der Vergleich der Aminosäuresequenzen der B-Ketten von verschiedenen Mitgliedern der Insulin/Relaxin Familie zeigte auf, dass zwei positiv geladene Aminosäuren, die bei INSL5 an den Positionen $\mathrm{B}^{5}$ und $\mathrm{B}^{13}$ der B-Kette liegen, auch in Relaxin-2 (RLN2), INSL3, INSL4 und INSL6 konserviert sind. Es konnte gezeigt werden, dass bei Relaxin und Ins13 diese beiden Aminosäuren eine Schlüsselrolle bei der Bindung an ihre jeweiligen Rezeptoren LGR7 und LGR8 spielen (Bullesbach \& Schwabe, 2000; Claasz et al., 2002; Tan et al., 2003). Im Gegensatz dazu besitzen Insulin und die insulinartigen Wachstumsfaktoren an den entsprechenden Positionen keine der beiden erwähnten positiv geladenen Aminosäuren. Die Signalübertragung von Insulin und IGF1 wird durch die Bindung an einen anderen Typ von Rezeptoren vermittelt. Der Insulinrezeptor und der IGF-Rezeptor gehören zu den Tyrosinkinaserezeptoren (Ulrich et al., 1985; Ulrich et al., 1986).

Aufgrund der Konservierung der beide positiven Aminosäuren wurde angenommen, dass Relaxin, Ins13, Ins14, Ins15 und Ins16 Liganden für LGR7, LGR8 oder eng verwandte G-Protein gekoppelte Hormonrezeptoren (GPCRs) sein müssten (Hsu, 2003). Es wurde in vitro und in vivo gezeigt, dass Relaxin bzw. INSL3 an LGR7 bzw. LGR8Rezeptoren binden und diese aktivieren (Liu et al., 2005). Weiterhin stellte sich bei in vitro Experimenten heraus, dass Relaxin-3 der Ligand für 2 typische peptidartige GPCRs (GPCR135 und GPCR142) ist (Liu et al., 2005). Obwohl GPCR135 und GPCR142 nicht in dieselbe Subfamilie wie LGR7 und LGR8 gestellt werden, gehören aber alle genannten Rezeptoren der Typ 1 GPCR Familie an. Die Identifikation von INSL5 als weiteren Liganden für GPCR142 unterstützt ebenfalls die von Hsu aufgestellte Hypothese. Obwohl die Rezeptoren für INSL4 und INSL6 bisher noch nicht identifiziert werden konnten, wird angenommen (Liu et al., 2004), dass sie ebenfalls der GPCR Familie angehören.

Da Relaxin-3 als Ligand für GPCR135, GPCR142 und LGR7 fungiert, scheint die Annahme gerechtfertigt, dies würde auch für das innerhalb der Insulin/Relaxin Familie am engsten mit Relaxin-3 verwandte Ins15 gelten. Es stellte sich aber heraus, dass Ins15 zwar GPCR142, nicht aber GPCR135, LGR7 oder LGR8 aktiviert. Es wurde aber ebenfalls demonstriert, dass INSL5 unter bestimmten Vorraussetzungen auch an GPCR135 binden kann. Da aber GPCR135 zusammen mit Relaxin-3 vorzugsweise im Gehirn, GPCR142 aber genauso wie INSL5 im Gehirn und in peripheren Geweben 
(insbesondere im Dickdarm) exprimiert wird, ist anzunehmen, dass Relaxin-3 (RLN3) der endogene Ligand für GPCR135 und INSL5 der endogene Ligand für GPCR142 ist. Im Genom der Ratte konnte GPCR142 als Pseudogen identifiziert werden (Liu et al., 2003; Hosaka et al., 1991). Bei der Fahndung nach Insl5 im Rattengenom konnte eine genomische Sequenz identifiziert werden, die homolog zum murinen Insl5 ist. Diese genomische Region enthält die codierende Sequenz für Signalpeptid und A-Kette, wohingegen die für die B-Kette codierende Region fehlt. Daher ist anzunehmen, dass das Insl5-Gen der Ratte nicht für ein funktionelles Peptid codiert und ebenfalls ein Pseudogen ist.

\subsubsection{Genomische Struktur des Insl5-Gens}

Die Charakterisierung der genomischen Sequenz des Ins15 Gens ergab, dass das Gen aus zwei Exons (Exon $1=210$ bp, Exon $2=480$ bp) besteht, welche durch ein $7.9 \mathrm{~kb}$ langes Intron getrennt werden. Das Exon 1 codiert für das Signalpeptid, die B-Kette sowie für die ersten neun Aminosäuren des C-Peptids, während das Exon 2 für die restlichen 57 Aminosäuren des C-Peptids und die A-Kette codiert.

Mit Hilfe von Fluoreszenz in situ-Hybridisierung (FISH) konnte das Insl5-Gen der Maus auf Chromosom 4C5-7 lokalisiert werden (Hsu, 1999). Der Locus des INSL5Gens des Menschen konnte über Kopplungsanalyse in die Region 1p 31.1-1p.22.3 kartiert werden.

\subsubsection{Expression von INSL5}

Mittels Nothern-Blot Analyse konnte beim Menschen das INSL5-Transkript im Uterus und in den Organen des Verdauungstraktes nachgewiesen werden (Conklin et al., 1999). Besonders stark fiel die Expression des 0.8 - 1.2 kb Transkriptes im Rektum aus. Mit Ausnahme des Uterus und des aszendierenden und deszendierenden Kolons konnte in keinem anderen Gewebe eine Expression von INSL5 nachgewiesen werden (Conklin et al., 1999).

Für murines Insl5 konnte mithilfe von Nothern-Blot Analysen eine Expression lediglich im Thymus gezeigt werden (Conklin et al., 1999). Für die Bestimmung des relativen Expressionslevels von Ins15 der Maus wurde eine quantitative Real-Time-RT-PCR- 
Analyse durchgeführt. Dabei wurde der relative Expressionslevel im Thymus mit 1000 Kopien/ng Gesamt-RNA berechnet. Überraschenderweise war die Expression besonders im distalen Kolon mit ca. 10000 Kopien/ng Gesamt-RNA sogar noch stärker. Eine Expression auf sehr niedrigem Level (50 Kopien/ng Gesamt-RNA) konnte im Testis detektiert werden (Conklin et al., 1999).

In der vorliegenden Arbeit konnte mittels Northern-Blot Analyse mit aus verschiedenen Geweben adulter Mäuse stammender Gesamt-RNA weder im Kolon noch im Thymus eine Insl5-Expression nachgewiesen werden. Interessanterweise war aber eine Expression von Ins15 im Rektum (bzw. im distalen Kolon) deutlich zu verzeichnen. Weiterhin wurde die Ins15-Expression mithilfe einer RT-PCR Analyse mit RNA aus verschiedenen Geweben der Maus untersucht. Die stärkte Expression war im Thymus $\mathrm{zu}$ verzeichnen. Etwas geringere Insl5-Expressionslevel zeigten Testis und Kolon, aber auch in Gehirn, Lunge, Milz, Magen und Ovar konnte eine schwache Expression nachgewiesen werden.

Um den zeitlichen Verlauf bzw. den Zeitpunkt des Einsetzens der Insl5-Expression während der pränatalen Entwicklung zu bestimmen, wurde sowohl eine Northern-Blotals auch eine RT-PCR-Analyse an embryonaler Gesamt-RNA durchgeführt. Bei der Northern-Blot-Analyse konnten während der gesamten Embryonalentwicklung keine Ins15-Transkripte nachgewiesen werden. Im Gegensatz dazu konnte bei der RT-PCR Analyse eine Ins15-Expression erstmals ab Embryonaltag 11.5 belegt werden.

Die Expression des Ins15 wurde auch in Testis-RNA verschiedener Stadien von Wildtyp-Mäusen sowie in testikulärer RNA von adulten Tieren diverser Mutantenlinien $\left(W / W^{\nu}, T f m / Y\right.$, Insl3 $^{--}$, olt/olt und $\left.q k / q k\right)$ durchgeführt, es erfolgte und eine RT-PCRAnalyse. In allen postnatalen Testis-Stadien konnte das Ins15-Transkript nachgewiesen werden, wobei die Intensität der Expression nach ca. 3 Wochen ansteigt. Bei allen verschiedenen Mausmutanten konnte ebenfalls eine Insl5-Expression dokumentiert werden. Die Expression des Ins15 im $W / W^{\nu}$-Testis, welcher keine Keimzellen besitzt, deutet daraufhin, dass die Expression von Ins15 nicht nur auf die Keimzellen beschränkt ist. Allerdings führt die Zunahme des Ins15-Transkribtes nach Tag $21 \mathrm{zu}$ der Annahme, dass Ins15 in haploiden Spermatiden stärker exprimiert wird.

Um die zelluläre Expression von Ins15 lokalisieren zu können, wurde auch eine immunhistochemische Analyse mit Anti-Ins15 Antikörpern, die von Prof. Schwabe 
(USA) zur Verfügung gestellt wurden, durchgeführt. Diese Analyse erbrachte jedoch keine zufriedenstellenden Ergebnisse.

\subsubsection{Funktionsanalyse des Insl5-Gens}

Die Erzeugung von Funktionsverlustmutationen durch das ,gene targeting“ bietet die Möglichkeit, anhand des Phänotyps der gendefizienten Mäuse genauere Kenntnisse über Wirkungsort und -weise des entsprechenden Gens zu gewinnen (Strachan und Read, 1996). Mittels Deletion des Insl5-Gens in einem knock-out Mausmodell sollten Erkenntnisse über die Funktion des Ins15 bzw. des humanen Homologs INSL5 gewonnen werden.

Für die Erzeugung einer Insl5-defizienten Maus wurden das gesamte Exon 2 mit Hilfe eines knock-out Konstrukts durch homologe Rekombination in embryonalen Stammzellen deletiert (s. Abb. 3.6). Exon 2 codiert für das C- und A-Peptid, und es wird davon ausgegangen, dass Insl5 ohne die A-Domäne nicht funktionsfähig ist.

Die Ins15 $5^{+-}$rekombinanten ES-Zellen wurden zur Generierung von Chimären in 3.5 Tage alte Mausembryonen injiziert und die erhaltenen Chimären mit Mäusen des Stamms C57BL verpaart. Heterozygote $\mathrm{Insl5}^{+/-}$Mäuse der $\mathrm{F}_{1}$-Generation wurden untereinander verpaart und brachten homozygote Ins15 ${ }^{-/-}$Mäuse $\left(\mathrm{F}_{2}\right.$-Generation) hervor. Mittels Northern-Blot wurde die Inaktivierung des Insl5-Gens im Rektum bestätigt. Phänotypisch waren weder die heterozygoten noch die homozygoten Tiere von den Wildtypmäusen zu unterscheiden. Der Anteil der homozygoten Nachkommen war 22.3\%, der heterozygoten $53.4 \%$ und der Wildtyp-Nachkommen $24.3 \%$ und entspricht somit den Mendelschen Regeln. Daher scheint Ins15 nicht für die embryonale oder postnatale Entwicklung benötigt zu werden. Die durchschnittliche Wurfgröße ergab bei der heterozygoten $(+/-\mathrm{x}+/-)$ Verpaarung $7.6 \pm 2.9$ und bei der homozygoten $(-/-\mathrm{x}-/-)$ Verpaarung $5 \pm 2.1$. Aufgrund der verminderten Wurfgröße bei den homozygoten Verpaarungen wurde angenommen, dass die homozygoten Ins15 $5^{-/-}$-Mäuse subfertil sind. Diese Subfertilität könnte auf eine Störung bei der Spermatogenese, der Spermienfunktion oder der Follikelentwicklung zurückzuführen sein. Aus diesem Grunde wurden verschiedene Parameter der Spermien untersucht. So wurde die Spermienzahl im Nebenhoden von Insl5-defizienten Mäusen bestimmt und mit der von 
Wildtyptieren verglichen. Bei Ins15 ${ }^{-/}$-Mäusen konnte eine leichte Reduktion der Spermienzahl belegt werden. Ein signifikanter Unterschied zum Wildtyp konnte aber nicht festgestellt werden (s. Tab. 3.2). Außerdem wurden Spermien aus dem Nebenhoden der Ins15 $5^{-/-}$, Ins15 $5^{+/-}$und Wildtyp-Mäuse isoliert und ihre Motilität nach $1.5 \mathrm{~h}, 3.5 \mathrm{~h}$ und nach $5.5 \mathrm{~h}$ gemessen. Nach $1.5 \mathrm{~h}$ waren $52.5 \%$ der Wildtyp-Spermien motil, davon zeigten $34.5 \%$ progressive Bewegung. Die untersuchten Parameter der Spermien der homozygoten Tiere unterschieden sich nicht signifikant von denen des Wildtyps. Von den Spermien der Ins15 ${ }^{-/}$-Mäusen waren $48 \%$ beweglich und $31.3 \%$ zeigten eine progressive Bewegung. Die Messungen nach $3.5 \mathrm{~h}$ ergaben, dass sich der Anteil der motilen Spermien um ca. 10\% reduzierte, die Progressivität dieser (motilen) Spermien aber nur geringfügig abnahm. Um die Spermienmotilität detaillierter zu untersuchen, wurden die Bahn- und Weggeschwindigkeiten der Spermien, die Schlagfrequenz des Spermienschwanzes und andere Parameter analysiert. Alle untersuchten Parameter der Ins15 ${ }^{+/-}$-Spermien waren signifikant geringer als die der Wildtypen ( $\mathrm{P}<0.001)$ (s. Tab. 3.3, 3.4 und Abb. 3.12).

Es wäre möglich, dass die Reduktion in Geschwindigkeit und Schlagfrequenz der Spermien dazu führt, dass weniger Spermien den Ovidukt erreichen können. Um diese Annahme zu überprüfen, sollte die Spermienzahl im Ovidukt von Wildtyp-Weibchen nach der Verpaarung mit Ins15 ${ }^{-/-}$-Männchen bestimmt werden.

Aufgrund der Ins15-Expression im Rektum der Wildtypmaus (s. Abb. 3.2) und der von Conklin et al. (1999). beschriebenen Insl5-Expression in Thymus wurden Gewebe von männlichen und weiblichen Insl5-defizienten und Wildtypkontroll-Mäusen von Prof. Klonisch (Kanada) histologisch untersucht. Es sollten mögliche morphologische Veränderungen identifiziert werden.

In Thymus erkennt man eine scheinbar in Läppchen gegliederte Bauweise. Jedes „Läppchen“ besteht aus der lymphozytenreichen Rinde (Cortex) und dem zellärmeren Mark (Medulla). Zwischen den Läppchen breitet sich gefäßführendes Bindegewebe aus, das auch in Form von Septen bis zur Rinden-Mark-Grenze vordringt. Unter den Zellen der Rinde dominieren kleine Lymphozyten (T-Lymphozyten), im Mark herrschen Lymphoblasten, Lymphozyten und epitheliale Retikulumzellen vor. Im Mark sind auch Hassall-Körperchen zu finden. Verschiedene epitheliale Zellen des Thymus produzieren Stoffe, die vermutlich Hormoncharakter besitzen. Bekannte und gut definierte Stoffe sind u.a. Thymosin, Thymopoetin und Thymulin. 
Der Thymus von Insl5 $5^{-/-}$-Mäusen besitzt eine vermehrte dickere Rinde und ein kleineres Mark. Im Mark wurden vermehrt eosinophil-angefärbte Thymus-Epithelzellen beobachtet. Diese Zellen sind die Vorläufer der Hassall-Körper, welche für den Thymus typisch sind. Die vermehrte Anhäufung und Differenzierung von Thymusepithelzellen der Ins15 $5^{--}$-Mäusen könnte durch eine erhöhte Thymopoiese hervorgerufen worden sein. Bei den Untersuchungen des Kolons haben sich im Epithel der Ins15 ${ }^{-/}$-Mäuse Veränderungen gezeigt. Die Epithelzellen sind weniger hoch und die beiden Hauptzelltypen, Kolonozyten und Becherzellen, zeigen Veränderungen in ihrer Anfärbbarkeit und in der Form der Zellkerne. Außerdem ergab die histologische Schichtanalyse eine verminderte Vaskularisation im Bereich der Darmkrypten. Diese Veränderungen im distalen Kolon und Rektum der Ins15-defizienten Mäuse weisen daraufhin, dass das Insl5-Hormon in den Kolonepithelzellen und in den Becherzellen produziert wird. Aufgrund der Veränderungen im distalen Kolon und im Rektum der Ins15-defizienten Mäuse wäre es denkbar, dass das Ins15-Hormon in den Kolonepithelzellen (Becherzellen) produziert wird.

Bisher ist die Funktion des Insl5- Gens noch unklar. Es gibt zwei Erklärungen dafür:

1. Unsere bisherigen Experimente konnten nicht das betroffene Gewebe oder die gestörte Wechselwirkung bei Ins15-defizienten Mäusen nachweisen.

2. Das Insl5 hat keine Funktion bei der Maus. Diese Aussage kann durch die Beobachtung bei der Ratte unterstützt werden. Im Genom der Ratte fehlt die codierende Region für die B-Kette, so dass das Insl5-Gen kein funktionsfähiges Peptid codieren kann.

\subsection{Das Insl6-Gen}

Die primäre Struktur des Insl6-Proteins besteht wie bei anderen Mitgliedern diese Familie aus einem Signalpeptid, einer B- und einer A-Cystein Domäne sowie der dazwischen liegenden C-Domäne (Lok et al., 2000). Die Gesamtlänge der Ins6-cDNA der Maus beträgt 700 bp, von denen 15 bp die 5' nicht codierenden Sequenz und 112 bp die 3' nicht codierende Region ausmachen. 
Die Gesamtlänge der cDNA der Ratte beträgt 790 bp und die des Menschen 717 bp (Lok et al., 2000). Das aus der codierenden Sequenz abgeleitete Präpropeptid der Maus hat eine Länge von 191 Aminosäuren mit einem Molekulargewicht von 22 kDa (Kasik et al., 2000). Das menschliche INSL6-Gen codiert für ein Polypeptid mit 213 Aminosäuren mit einem Molekulargewicht von 24.9 kDa. Das Insl6 der Ratte codiert für ein Peptid mit 188 Aminosäuren.

So wie alle anderen Mitglieder der Insulinfamilie besitzt auch Insl6-Peptid die 6 konservierten Cysteine. Die B- und A-Kette des INSL6-Peptids des Menschen ist mit 55\% denen des Ratten Insl6 und mit 43\% mit der A- und B-Kette des humanen Relaxin H2 homolog. Schwächere Homologien zeigen sich mit 38\% zum humanen INSL3, mit $36 \%$ zum humanen Insulin, mit 36\% zu IGF2, mit 33\% zu IGF1 und mit 24\% zu INSL5 und INSL4 (s. Abb. 4.1).

Die Homologie des 78 Aminosäuren langen humanen INSL6 C-Peptids ist mit 43\% zur 110 AS langen Ratten Insl6-C-Kette verhältnismäßig hoch. Es konnten jedoch keine signifikanten Sequenzähnlichkeiten der C-Kette zu den anderen Mitgliedern der Insulinfamilie gefunden werden (Lok et al., 2000), wobei alle untersuchten Rodentiern eine hochkonservierte Sequenz innerhalb der C-Kette besitzen (Kasik et al., 2000).

\subsubsection{Genomische Struktur des Insl6-Gens}

Die Charakterisierung der genomischen Sequenz von Insl6 der Maus ergab, dass das Gen aus zwei Exons (Exon $1=286$ bp, Exon $2=389$ bp) besteht, welche durch ein 3.3 kb langes Intron getrennt werden. Das Exon 1 codiert für das Signalpeptid, die B-Kette sowie für die ersten 27 Aminosäuren des C-Peptids, während das Exon 2 für die restlichen 63 Aminosäuren des C-Peptids und die A-Kette codiert.

Mit Hilfe von Fluoreszenz in situ-Hybridisierung (FISH) konnte das Insl6-Gen der Maus auf Chromosom 19C3 lokalisiert werden (Hsu, 1999). Das INSL6-Gen des Menschen konnte zusammen mit den anderen Mitgliedern der Insulin/Relaxin Familie (INSL4, Relaxin 1 und Relaxin 2) und dem JAK2-Gen auf Chromosom 9 lokalisiert werden und der Lokus in die Region 9p24 eingegrenzt werden (Lok et al., 2000; Ivell und Bathgate, 2002). 


\subsection{2}

Expression von INSL6

Mittels Nothern-Blot Analyse konnte beim Menschen ein starkes 1.2 kb großes Ins16Transkript nur im Testis nachgewiesen werden (Lok et al., 2000; Hsu 1999). In der Ratte konnte die Ins16-Expression mithilfe von Nothern-Blot-Analysen im Testis und in der Prostata gezeigt werden (Lok et al., 2000). Für murines Insl6 konnte durch NothernBlot Analysen das Transkript in der Niere und besonders stark im Testis dokumentiert werden (Kasik et al., 2000).

In der vorliegenden Arbeit konnte mittels Northern-Blot Analyse mit aus verschiedenen Geweben adulter Mäuse stammender Gesamt-RNA eine Insl6-Expression besonders stark im Testis und relativ schwach auch in Ovar, Niere und Milz nachgewiesen werden. Weiterhin wurde die Ins16-Expression mithilfe einer RT-PCR Analyse mit RNA aus verschiedenen Geweben der Maus untersucht. Die stärkste Expression war im Testis zu verzeichnen. Etwas geringere Insl6-Expressionslevel zeigten Ovar und Niere, aber auch in Thymus und Kolon konnte eine schwache Expression nachgewiesen werden (s. Abb.3.14).

Um den zeitlichen Verlauf bzw. den Zeitpunkt des Einsetzens der Insl6-Expression während der pränatalen Entwicklung zu bestimmen, wurde eine RT-PCR-Analyse an embryonaler Gesamt-RNA durchgeführt. Es konnte eine Insl6-Expression ab Embryonaltag 9.5 gezeigt werden. Um zu klären, $\mathrm{zu}$ welchem Zeitpunkt der postanatalen Testisentwicklung die Insl6-Expression einsetzt, wurde die Gesamt-RNA aus Testes von 5 bis 25 Tage alten und adulten Mäusen mittels Northern-Blot Analyse untersucht (s. Abb. 3.16). Das Insl6-Transkript konnte erstmals in der Testis-RNA 15 Tage alter Mäuse detektiert werden. $\mathrm{Zu}$ diesem Zeitpunkt befindet sich die Spermatogenese im Stadium der Pachytän-Spermatozyten. Weiterhin wurde ein Northern-Blot mit Testes-RNA von $W / W^{\nu}, T f m / Y$, Insl3 $3^{-/}$, olt/olt und $q k / q k$ Mausmutanten, bei denen die Spermatogenese in unterschiedlichen Stadien arretiert ist, mit Insl6-cDNA hybridisiert (s. Abb. 3.17). Bei der $W / W^{\nu}$ - und $T f m / Y$-Mausmutanten wurden kein Ins16-Transkripte gefunden. Im Testis der $W / W^{\nu}$-Mutante fehlen die Keimzellen und bei der $T f m / Y$-Mutante erreicht die Spermatogenese nur das Stadium der primären Spermatozyten. Nur in der $\mathrm{Insl3}^{-/}$-Mutante ließ sich ein Signal für Insl6 nachweisen. 
Bei Insl3-defizienten und somit kryptorchiden Mäusen ist die Spermatogenese aufgrund der abdominal höheren Temperaturen $\left(37^{\circ} \mathrm{C}\right)$ bereits in der diploiden Phase arretiert und die Spermatogenese erreicht daher nur das Stadium der Pachytän-Spermatozyten. Einige der Spermatozyten erreichen jedoch auch haploide Stadien. Eine mit der Wildtypmaus vergleichbare Expression zeigen die Testes der Mutanten olt/olt und qk/qk, deren Spermatogenese bis zu den Spermatiden reicht.

Diese Ergebnisse haben eindeutig gezeigt, dass Ins16 erst in Pachytän-Spermatozyten exprimiert wird. Eine Übersicht über den jeweiligen Arrest in der Spermatogenese bei den verschiedenen Mausmutanten liefert Abb. 4.3.

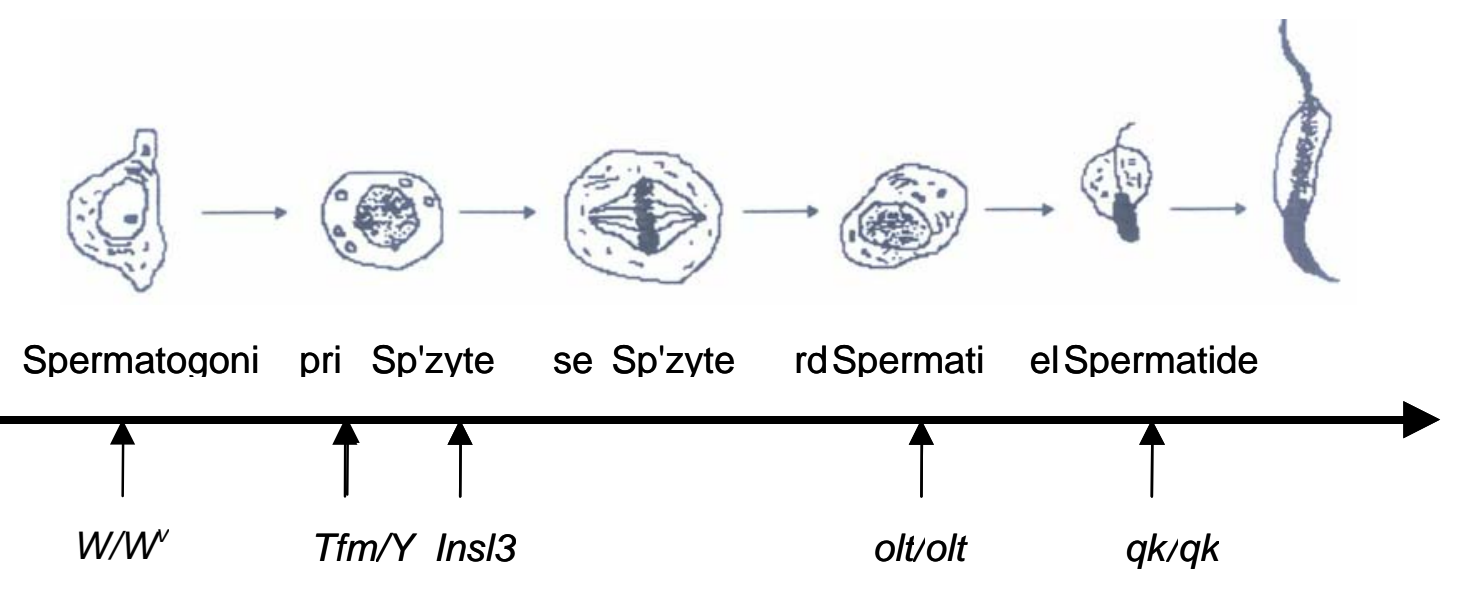

Abb. 4.3: Übersicht über den jeweiligen Arrest in der Spermatogenese der verschiedenen Mausmutanten

prim.Sp'zyte: primäre Spermatozyte, sek.Sp'zyte: sekundäre Spermatozyte, rd: runde Spermatiden, el.: elongierte Spermatiden.

Bei der W/W $W^{\nu}$-Mutante fehlen die Keimzellen, bei Tfm/Y-Mäusen (Testikuläre Feminisierung) endet die Spermatogenese sofort nach Einsetzen des Spermatozytenstadiums (Lyon und Hawkes, 1970), während die knock-out-Mutanten für das Insl3-Gen (Insulin-like Gene 3) einen Arrest in primären Spermatozyten (Pachytän-Spermatozyten) zeigen (Zimmermann et al., 1997). olt/olt-Mutanten (oligotriche) haben eine normale Spermatogenese bis zum Stadium der runden Spermatiden. Die Reifung zu elongierten Spermatiden ist nicht möglich (Moutier, 1976). qk/qk-Mutanten (quaking) weisen einen Defekt in der Spermatidendifferenzierung auf, so dass keine vollständige Spermatidenreifung erfolgen kann. Es kommt zu einem Arrest auf der Ebene der elongierten Spermatiden (Bennett et al., 1971).

Die Lokalisierung der zellulären Expression von Insl6 sollte durch eine immunhistochemische Analyse mit von Prof. Schwabe (USA) zur Verfügung gestellten Anti-Insl6 Antikörpern durchgeführt werden, welche jedoch keine zufriedenstellenden Ergebnisse lieferte. 


\subsection{3}

Funktionsanalyse des Insl6-Gens

Zur Erzeugung Insl6-defizienter Mäuse wurde das Exon 1 mit Hilfe eines knock-outKonstrukts durch homologe Rekombination in embryonalen Stammzellen deletiert (s. Abb. 3.18). Das Exon 1 beinhaltet das ATG Start-Codon und dadurch sollte gewährleistet werden, dass das erwartete Transkript des Insl6-Gens ausgeschaltet und somit eine Nullmutante erzeugt wird. Es wurden ca. 600 ES-Zell-Klone mit der 3'externen Probe hybridisiert, aber es konnte nur ein positiver Klon gefunden werden. Die homolog rekombinanten ES-Zellen wurden zur Generierung von Chimären in Blastocysten injiziert. Es konnten über 25 weibliche und männliche Chimären mit einem Chimärismus zwischen $2-15 \%$, aber nur ein männliche Chimäre mit $35 \%$ Chimärismus erzeugt werden. Keine der Chimären mit 2-15\% Chimärismus konnte das mutierte Allele in ihre Nachkommen transmittieren.

Die männliche Chimäre, in welcher 35\% der Zellen des Körpers das rekombinante Allel enthalten, wurde mit einem Weibchen des Stamms C57BL verpaart. Nach einer viermonatigen Verpaarungszeit stellte sich heraus, dass die männliche Chimäre infertil ist. Für den Nachweis der Infertilität wurde die Zahl der Spermien im Uterus einer Wildtypmaus nach der Verpaarung mit dieser Chimäre bestimmt. Es konnten keine Spermien gefunden werden.

Für den niedrigen Chimärismus gibt es mehrere mögliche Erklärungen:

Erstens könnte „Haploinsuffizienz“ bei Fehlen eines der beiden überlebenswichtigen Allele die Ursache des Todes aller Tiere mit höherem Chimärismus während der embryonalen Entwicklung sein. Als Beispiel hierfür könnte das Spata6-Gen (Oh et al., 2003) angeführt werden. Waren bei Spata6 Chimären mit niedrigem Chimärismus die heterozygoten Spata6 $^{+/-}$-Zellen in wichtigen Organen konzentriert, so starben die betroffenen Embryonen ab. Nachkommen mit einem insgesamt sehr hohen Chimärismus wurden nie geboren. (Oh et al., 2003). Daraus und aus der Expression von Spata6 während der frühen Embryonalentwicklung wurde geschlossen, dass eine hoher Anteil von Spata6 ${ }^{+/}-$Zellen in den chimären Embryonen die Letalität hervorruft (Oh $e t$ al., 2003). Ein ähnliches Phänomen konnte auch bei der Deaktivierung des Ncam-Gens (neuronal cell adhesion molecule) beobachtet werden. Alle von $\mathrm{Ncam}^{+/-}$stammenden Chimären zeigten eine geringe Beteiligung von ES-Zellen, während bei allen Chimären mit hohem ES-Zellanteil zwischen den Embryonaltagen 8.5 und 10.5 eine schwere 
Wachstumsretardierung sowie Defekte der Somiten und des Neuralrohrs auftraten (Rabinowitz et al., 1996). In einem anderen Fall zeigte sich, dass Protamin 1 (Prm1)und 2 (Prm2)-Chimären ebenfalls durch „Haploinsuffizienz“ nachkommenlos blieben. Als Ursache für den niedrigen Chimärismus käme aber auch in Frage, dass eine Vielzahl von homolog rekombinanten Zellen im Testis der Chimären enthalten sind, sich die Spermatozyten aber nicht weiter entwickeln können. Dies wurde beispielsweise für das Afamin-Gen im Institut für Humangenetik in Göttingen nachgewiesen.

\section{3 $\quad \mathbf{I}_{2} \mathbf{I}_{3}$ transgene Mäuse}

Insulin wird in den $\beta$-Zellen des Pankreas (Langerhans Zellen) produziert. Wenn diese Zellen aufgrund eines Autoimmunprozesses zugrundegehen, entsteht der Diabetes mellitus Typ I, der nur durch Injektion von Insulin korrigiert werden kann. Es ist daher attraktiv zu überlegen, ob mithilfe gentechnologischer Verfahren Insulin in anderen Körperzellen produziert und sezerniert werden kann. Die Suche nach Zellen, die dafür geeignet sind, ist schon lange im Gange, war aber bislang nicht eindeutig erfolgreich (z.B. Faradji et al., 2001; Halban et al., 2001).

Adham et al. (2002) haben gezeigt, dass das Leydigzell-spezifische Insulin-ähnliche Hormon Ins13 in $\beta$-Zellen des Pankreas produziert und sezerniert werden kann und auch funktionell ist. Der Phänotyp bei der männlichen Insl3 knock-out Maus, nämlich der abdominale Kryptorchismus, konnte geheilt werden. Bei den männlichen transgenen Mäusen, die $\mathrm{Insl}^{-/-}$und transgen für Insl3 waren, kam es $\mathrm{zu}$ einem vollständigen Descensus testis. Von daher lag der Gedanke nahe zu prüfen, ob die Leydigzellen des Testis von Tieren, die transgen sind für das Insulingen mit vorgeschaltetem Insl3 Promotor, Insulin produzieren und sezernieren können und ein experimentell erzeugter diabetischer Zustand solcher Tiere geheilt werden kann.

\subsubsection{Erzeugung der Fusionskonstrukte $I_{2} I_{3}-0, I_{2} I_{3}-1$ und $I_{2} I_{3}-2$}

In der Arbeitsgruppe wurde bereits früher gezeigt, dass eine 150 bp 5'-flankierende Region des Insl3-Gens ausreicht, um eine spezifische Expression des Reportergens (Chloramphenicolacetyltransferase; CAT) in kultivierten Leydigzellen (MA10-Zellen) 
sicherstellen (Zimmermann et al., 1997; Zimmermann et al., 1999). Später wurde allerdings gezeigt, dass diese 150 bp in vivo nicht für die Expression in Leydigzellen ausreichen. Für die Expression des CAT-Reportergens in den Leydigzellen des Testis waren. 700 bp der 5'-flankierenden Region des Insl3-Gens notwendig (Thamm, 2002).

Im Rahmen der hier durchzuführenden Experimente sollte ja nicht nur die Frage geprüft werden, ob ein Fusionskonstrukt mit dem Insulingen in den Leydigzellen exprimiert wird, sondern es sollte auch festgestellt werden, ob ein entsprechendes Protein produziert und ins Blut sezerniert wird. Um transgenes testikuläres Insulin von dem im Pankreas der Maus produzierten endogenen Maus-Insulin unterscheiden zu können, wurde in das Fusionskonstrukt das menschliche Insulingen eingebaut. Wenn die Leydigzelle in der Lage ist, das Insulingen zu exprimieren, das Präprohormon zu produzieren und Insulin ins Blut $\mathrm{zu}$ sezernieren, sollte dort humanes C-Peptid nachweisbar sein. Dafür stehen spezifische Messverfahren zur Verfügung.

Es wurden zunächst vier $\mathrm{I}_{2} \mathrm{I}_{3}-0$ transgene Mauslinien erzeugt. In das verwendete Fusionskonstrukt ist das menschliche Insulingen mit den 700 bp der 5'-flankierenden Region des Insl3-Gen ligiert. Bei den erzeugten transgenen Mäuse waren die Ergebnisse enttäuschend, denn nur bei einer Linie konnte eine Insulinexpression in Testis gefunden werden, die zudem gering war. Es ist bekannt, dass die Stabilität von mRNA ganz entscheidend von der Interaktion von Einzelstrangbindungsproteinen mit der 3'flankierenden, nicht translatierten Region abhängt (Bernstein et al., 1989). Wir haben daher vermutet, dass eine mangelnde Stabilisierung der Insulin-mRNA in der LeydigZelle auf die Verwendung der 3'-flankierenden Region des Insulin-Gens in unserem transgenen Konstrukt zurückzuführen ist.

Es wurden daher zwei weitere Fusionskonstrukte generiert, in denen jedoch die 3'flankierende Region des Insulingens durch die 3'-flankierende Region des Insl3-Gens ersetzt wurde. Die transgenen Tiere, die mit diesen Konstrukten $\left(I_{2} I_{3}-1\right.$ und $\left.I_{2} I_{3}-2\right)$ erzeugt wurden, zeigten tatsächlich eine verstärkte Expression des menschlichen Insulingens im Testis. Es ist noch nachzutragen, dass auch zwischen diesen beiden Konstrukten Unterschiede bestehen, und zwar bezüglich der 5'-nicht translatierten Region. Das $\mathrm{I}_{2} \mathrm{I}_{3}-1$ Konstrukt beinhaltet alle drei Exons des humanen Insulingens, während bei dem $\mathrm{I}_{2} \mathrm{I}_{3}-2$ Konstrukt das nicht translatierte Exon 1 des Insulingens fehlt. 
Damit sollte bezüglich des $\mathrm{I}_{2} \mathrm{I}_{3}$-2-Konstrukts der Beobachtung Rechnung getragen werden, dass die Distanz des Promotors zum Translations-Startcodon für die Expression von Bedeutung sein kann (Hecht, 1988; Nayernia et al., 1992).

Erzeugung transgener Linien für die Konstrukte $I_{2} I_{3}-0, I_{2} I_{3}-1$ und $\mathbf{I}_{2} \mathbf{I}_{3}-2$

Wie bereits oben dargestellt, wurden für das Konstrukt $\mathrm{I}_{2} \mathrm{I}_{3}-0$ nur vier transgene Linie generiert, diese waren aber wegen der fehlenden bzw. sehr geringen Expression des Transgens für die Arbeit nicht nutzbar. Für die beiden anderen Konstrukte konnten jeweils 6 Founder erstellt werden. Bei den $F_{1}$-Nachkommen dieser Founder stellte sich heraus, dass lediglich Nachkommen von vier Founder für das Konstrukt $\mathrm{I}_{2} \mathrm{I}_{3}-1$ und die Nachkommen von drei Founder für das Konstrukt $\mathrm{I}_{2} \mathrm{I}_{3}-2$ eine relevante Expression des menschlichen Insulingens im Testis zeigten. Wie immer, wenn transgene Linien erzeugt werden, musste jetzt geprüft werden, welche der erzeugten und exprimierenden Linien tatsächlich aufgrund der Zahl der Integrationen des Transgens und der Zahl der integrierten Kopien des Transgens für die Bearbeitung der Fragestellungen geeignet sind.

Mittels Real-Time PCR Analysen konnten die Linien entsprechend charakterisiert werden. Es blieben für das Konstrukt $\mathrm{I}_{2} \mathrm{I}_{3}-1$ zwei Linien (Linie 2 und 12) und für das Konstrukt $\mathrm{I}_{2} \mathrm{I}_{3}-2$ zwei Linien (Linie 10 und 11) übrig. Für diese Linien ergaben sich jeweils eine Integration. Die Zahl der Kopien betrug: Linie 2 mit 16 \pm 1 , Linie 12 mit $3 \pm 1$; Linie 10 mit $5 \pm 1$ und Linie 11 mit $4 \pm 1$. Bei den sich daran anschließenden Experimenten wurde allerdings nicht mit allen Linien weitergearbeitet.

\section{Vergleich der Transkribtion der Fusionskonstrukte für menschliches Insulin mit der Transkribtion des endogenen Insl3-Gens im Testis der transgenen Tiere}

Es ist durch die Arbeiten der Arbeitsgruppe und anderer Autoren hinreichend bekannt, dass das Insl3-Gen ausschließlich in den prä- und postnatalen Leydigzellen des Testis exprimiert wird, auch in geringem Maße in den Thecazellen des postnatalen Ovars 
(Adham et al., 1993; Zimmermann et al., 1997; Balvers et al., 1998). Auch im Corpus luteum und im Trophoblast des Menschen wurde eine geringe Expression des Insl3Gens beschrieben (Tashima et al., 1995; Roche et al., 1996; Bathgate et al., 1996). Im Rahmen dieser Arbeit wurde lediglich das räumliche und zeitliche Expressionsmuster der Fusionskonstrukte und damit des menschlichen Insulingens mit dem für das Insl3Gen verglichen. Es wurde eine eindeutige Übereinstimmung der Expressionsmuster gefunden, sowohl was die Beschränkung der Expression auf Testis und die Leydigzellen betrifft, als auch den Verlauf der Expression während der Testisentwicklung.

Damit ist gezeigt, dass einerseits 700 bp der 5'-flankierenden Region des Insl3-Gens für die Leydigzellspezifische Expression und für die Expression während der Testisentwicklung ausreichen. Das menschliche Insulingen kann also spezifisch in Leydigzellen exprimiert werden. Damit war eine wichtige Forderung, die sich aus unserer Hypothese ergab, erfüllt.

\subsubsection{Zur Frage der Translation der Insulinfusionstranskripte im Testis der transgenen Mäuse}

Es wurden histologische Schnitte von Testis von $\mathrm{I}_{2} \mathrm{I}_{3}$ transgenen männlichen Mäusen hergestellt und mit Antikörper gegen Insulin behandelt. Es konnte eindeutig gezeigt werden (Abb. 3.42), dass in den Leydigzellen Insulin produziert wird. In den $\beta$-Zellen des Pankreas der Mäuse ist - wie auch bei Wildtyptieren - ganz normal Insulin nachweisbar (Abb. 3.41). Der Nachweis der Translation der Insulin mRNA in den Leydigzellen der transgenen Tiere wurde durch die Ergebnisse eines weiteren experimentellen Ansatzes bestätigt.

Proteinextrakte aus Testis und Pankreas von Wildtyp und $\mathrm{I}_{2} \mathrm{I}_{3}-1$ transgenen Mäusen wurden mittels Fluoroimmunoassay mit einem für humanes und murines Insulin und Proinsulin spezifischen Antikörper analysiert. Während die Testisproteinextrakte der Wildtyp-Tiere niedrige Werte zeigten, konnte Insulin in den Extrakten der transgenen Tiere in höheren Konzentrationen nachgewiesen werden (Abb. 3.43). 


\subsection{5}

\section{Zur Prozessierung von Proinsulin in den $\beta$-Zellen des Pankreas und in den Leydigzellen der transgenen Tiere}

Die Biosynthese von Insulin in pankreatischen $\beta$-Zellen verläuft über die PräcursorFormen Präproinsulin und Proinsulin (Steiner et al., 1998; Steiner et al., 2000; Goodge et al., 2000; Steiner et al., 2001). Die effiziente Umwandlung von Proinsulin in aktives Insulin wird durch Splicing-Prozesse an den beiden Enden des die A- und B-Ketten verbindenden C-Peptids bewirkt. Bei der Exocytose werden dann aktives Insulin und freies C-Peptid entlassen. Zuvor sind diese Produkte in den ausgereiften sekretorischen "dense core"-Granula gespeichert. Durch einen geeigneten Stimulus wird die Ausschüttung eingeleitet. Der initiale Spaltungsprozess findet zwischen den Aminosäuren der Positionen 32 und 33 (R $\left.\downarrow_{E}\right)$ und an den Positionen 65 und 66 (R $\downarrow_{\mathrm{G}}$ ) des Proinsulins jeweils an der Verbindung von C-Peptid zur A- bzw. B-Kette statt. Das Erkennen jeder dieser Spaltstellen erfolgt durch Prohormon-Konvertasen PCSK1 und PCSK2 (Seidah et al., 1994; Siezen et al., 1994; Lipkind et al., 1995; Zhou et al., 1999; Steiner et al., 2000; Zhu et al., 2002a). Die beiden Prohormon-Konvertasen wirken hauptsächlich innerhalb der ausgereiften bzw. ausreifenden "dense core"-Granula des regulativen Sekretionswegs (Guest et al., 1995; Daniel et al., 1999).

Um zu überprüfen, ob das translatierte transgene Humaninsulin in den Leydigzellen prozessiert und anschließend sezerniert wird, wurde ein Radio-Immuno-Assay mit Serum von transgenen und Wildtypkontrollmäusen durchgeführt. Dafür wurden sowohl männliche als auch weibliche $\mathrm{I}_{2} \mathrm{I}_{3}-1$ und $\mathrm{I}_{2} \mathrm{I}_{3}-2$ transgene Tiere verwendet. Da nach der Prozessierung von Proinsulin innerhalb der Insulingranula (Daniel et al., 1999) Insulin zusammen mit freiem C-Peptid sezerniert wird und der im Radio-Immuno-Assay verwendete 1. Antikörper spezifisch an humanes C-Peptid bindet, kann im Fall einer Detektion indirekt auf die Sekretion von transgenem testikulärem Insulin geschlossen werden. Wie Abb. 3.44 belegt, konnte humanes C-Peptid im Serum $\mathrm{I}_{2} \mathrm{I}_{3}-1$ transgener Mäuse nachgewiesen werden. Damit wurde gezeigt, dass humanes C-Peptid und somit transgenes Insulin aus den Leydigzellen ins Blut sezerniert werden kann.

Nach Erhalt dieser Ergebnisse war es sinnvoll zu überprüfen, ob die oben genannten Prohormon-Konvertasen im Testis tatsächlich nachweisbar sind. Wie in Abb. 3.45 dargestellt, konnten zumindest auf RT-PCR Ebene und nach Sequenzierung der RTPCR Produkte eindeutig PCSK1 und PCSK2 im Testis nachgewiesen werden. 
Die Prozessierung von Proinsulin in der $\beta$-Zelle vollzieht sich innerhalb von Granula des Transgolginetzwerks (Daniel et al., 1999). Anders als weitere Prohormonkonvertierende Enzyme der Substilisinfamilie wie Furin, PACE4, PC6B und PC7 ließen sich PCSK1, PCSK2 sowie das nur in den Gonaden exprimierte PC4 (Tadros et al., 2001) und PC5/6A besonders in den "dense-core"-Granula des regulativen Sekretionswegs nachweisen (Zhou et al., 1999; Seidah et al., 1999). Bislang gibt es in der Literatur keine Hinweise, dass auch die Leydigzelle über einen solchen Sekretionsweg verfügt.

\subsubsection{Hat das in den Leydigzellen produzierte Insulin auch einen biologischen Effekt?}

Es wurde gezeigt, dass in den Leydigzellen des Testis Insulin produziert, prozessiert und dann auch ins Blut ausgeschüttet werden kann. Damit sollte es auch möglich sein, Mäuse, bei denen die $\beta$-Zellen fehlen oder durch exogene Agentien zerstört worden sind und die dessentwegen eine Diabetes mellitus entwickeln, zu therapieren. Um diese Frage zu prüfen, haben wir einerseits transgene Tiere mit $\mathrm{Pax} 4^{+/-}$-Mäusen verpaart und Nachkommen erzeugt, die hemizygot für das Transgen und Pax4-defizient waren $\left(\mathrm{I}_{2} \mathrm{I}_{3}-1\right.$ T/-, Pax $4^{-/-}$bzw. $\mathrm{I}_{2} \mathrm{I}_{3}-2$ T/-, Pax $4^{-/-}$). Da Pax4 die Differenzierung der $\beta$-Zellen kontrolliert und in $\mathrm{Pax}^{-{ }^{--}}$-Mäuse keine $\beta$-Zellen vorhanden sind (Trucco, 2005) können diese Tiere kein pankreatisches Insulin produzieren, und demsprechend versterben $\mathrm{Pax}^{-/-}$Tiere 1-4 Tage nach der Geburt an den Folge des Diabetes mellitus.

Als exogenes Agens, um $\beta$-Zellen des Pankreas zu zerstören, wird Streptozotocin verwendet. Streptozotocin (STZ) ist ein aus Streptomyces achromogenes isoliertes Antibiotikum. Behandelte Tiere erreichen in der Regel wenige Tage nach Beginn der Behandlung hoch hyperglykämische Zustände, die häufig letal sind.

Bei beiden Versuchsansätzen konnten keine relevanten Effekte erreicht werden. Die Tiere, die für $\mathrm{I}_{2} \mathrm{I}_{3}$ hemizygot und für Pax4 defizient waren, überlebten kaum länger als die Tiere, die Pax4 defizient, aber nicht transgen waren. Generell stiegen die Blutzuckerwerte der getesteten transgenen Tiere sowohl bei den transgenen Tieren mit höherer Kopienzahl (Line 2 und 15) als auch bei denen mit niedriger Kopienzahl des transgenen Allels an. Im Mittel wichen die transgenen Tiere bezüglich ihres zeitlichen 
Glukosespiegelverlaufs nicht signifikant von den Wildtypkontrollen ab (s. Abb. 3.46 und 3.47).

Warum bei den Experimenten - bei nachgewiesener Ausschüttung von Insulin ins Blut - kein relevanter Erfolg bezüglich der Diabetestherapie erzielt werden konnte, ist unklar. Sehr wahrscheinlicher ist die Menge des sezernierten Insulins nicht ausreichend bzw. die Antwort auf die erhöhten Glukosespiegel nicht in geeigneter Weise reguliert. Auf diese letztere Erklärungsmöglichkeit weisen die Ergebnisse der Glukosetoleranztests der mit STZ behandelten transgenen Tiere hin.

Normalerweise kommt es nach intraperitonealer Injektion von Glukoselösung binnen weniger Minuten zu einer Antwort der $\beta$-Zellen in Form einer raschen, quantitativ auf die Zuckerspiegelerhöhung abgestimmten Insulinsekretion. Dies führt $\mathrm{zu}$ einer Normalisierung des Blutglukosespiegels innerhalb einer Stunde. Sinkt der Blutzuckerspiegel, so setzt auch die Insulinsekretion aus, so dass hypoglykämische Zustände vermieden werden. Eine normal verlaufende Blutzuckerkurve nach einer Glukoseinjektion in Abbhängigkeit von der Zeit ist in Abb. 3.48 dargestellt. Alle STZbehandelten Versuchstiere bewegten sich während der Versuchszeit im stark hyperglykämischen Bereich. Daraus ergibt sich, dass bei den diabetisierten transgenen Mäusen durch einen Glukosestimulus nicht ausreichend aktives transgenes Insulin von den Leydigzellen sezerniert werden kann, um den Blutglukosespiegel kurzfristig zu senken, wie dies bei der normalen $\beta$-zellvermittelten Insulinantwort der Fall ist. Aus diesen Ergebnissen ergibt sich auch der Ansatz für weiterführende Experimente. Die Sekretion des Ins13-Hormons aus den Leydigzellen muss anders funktionieren als die des mit dem Insl3-Hormon strukturell eng verwandten Insulins in den $\beta$-Zellen. Die Sekretion des Insl3-Hormons aus den $\beta$-Zellen der transgenen Insl3-Mäuse (diese produzieren Insl3 auch in den $\beta$-Zellen; Adham et al., 2002) ist zwar möglich, aber vermutlich nicht reguliert. Die Insulinsekretion muss reguliert werden, und das ist in den Leydigzellen nicht möglich. In den weiterführenden Experimente geht es darum zu prüfen, ob überhaupt und wenn ja welche molekularen Mechanismen der Insulinsekretion in den $\beta$-Zellen in der Leydigzelle vorhanden sind. 


\subsection{7}

Analyse der Fertilität $\mathbf{I}_{2} \mathbf{I}_{3}-1$ transgener Mäuse

Bei den $\mathrm{I}_{2} \mathrm{I}_{3}-1$ transgenen Mäusen wurde beobachtet, dass die hemizygoten Männchen der Linie 2 und die homozygoten Männchen der Linie 12 mit zunehmenden Alter keine Nachkommen erzeugen konnten. Deshalb wurden die Spermienparameter der männlichen transgenen Tiere unterschiedlicher Altersgruppen untersucht. Es konnte eine signifikante Reduktion in Spermienzahl, Motilität und aller weiteren untersuchten Parameter festgestellt werden. Die histologische Analyse von Testisschnitten dieser Tiere wies auf eine Störung der Spermatogenese hin. Die Untersuchungen haben gezeigt, dass die Keimzellen in 10- $100 \%$ der Tubuli zurückgebildet und die Tubuluslumina vakuolisiert sind. Es fiel auf, dass die Tiere mit einer ausgeprägteren Spermatogenesestörung auch höhere C-Peptidkonzentration im Serum zeigten (s. Tab. 4.1), also das zusätzliche humane Insulin im Serum der transgenen Mäuse zur einer Störung der Keimzellen führt.

Tab. 4.1: Analyse der Spermatogenese und der C-Peptidkonzentrationen im Serum $I_{2} I_{3}-1$ transgener Mäuse

\begin{tabular}{|c|c|c|c|c|}
\hline $\begin{array}{c}\text { Linie } \\
\text { (Alter) }\end{array}$ & $\begin{array}{c}\text { Störung der } \\
\text { Spermatogenese }\end{array}$ & $\begin{array}{c}\text { C-Peptid } \\
\text { Konzentration } \\
\text { in Serum }\end{array}$ & $\begin{array}{c}\text { Spermien } \\
\text {-Motilität } \\
\mathbf{( \% )}\end{array}$ & $\begin{array}{c}\text { Spermienzahl } \\
\text { in Nebenhoden }\end{array}$ \\
\hline $\begin{array}{c}\mathrm{I}_{2} \mathrm{I}_{3}-1 \mathrm{~L} 2 / 68 \\
(15 \text { Monate })\end{array}$ & $\begin{array}{c}\text { schwer: } \\
\text { betrifft } 100 \% \text { der Tubuli }\end{array}$ & $0.6 \mathrm{ng} / \mathrm{ml}$ & 0 & $1.0 \times 10^{5}$ \\
\hline $\begin{array}{c}\mathrm{I}_{2} \mathrm{I}_{3}-1 \mathrm{~L} 12 / \mathrm{C} \\
(7.5 \mathrm{Monate})\end{array}$ & $\begin{array}{c}\text { schwer: } \\
\text { betrifft } 70-80 \% \text { Tubuli }\end{array}$ & $10.0 \mathrm{ng} / \mathrm{ml}$ & 0 & $5.0 \times 10^{3}$ \\
\hline $\begin{array}{c}\mathrm{I}_{2} \mathrm{I}_{3}-1 \mathrm{~L} 2 / 93 \mathrm{~B} \\
(13 \mathrm{Monate})\end{array}$ & $\begin{array}{c}\text { gering: } \\
\text { betrifft } 20-30 \% \text { der Tubuli }\end{array}$ & $0.9 \mathrm{ng} / \mathrm{ml}$ & 16 & $8.8 \times 10^{5}$ \\
\hline $\begin{array}{c}\mathrm{I}_{2} \mathrm{I}_{3}-1 \mathrm{~L} 12 / \mathrm{B} \\
(7.5 \mathrm{Monate})\end{array}$ & $\begin{array}{c}\text { gering: } \\
\text { betrifft } 10 \% \text { der Tubuli }\end{array}$ & $1.1 \mathrm{ng} / \mathrm{ml}$ & 4 & $3.3 \times 10^{4}$ \\
\hline $\begin{array}{c}\mathrm{I}_{2} \mathrm{I}_{3}-1 \mathrm{~L} 2 / 80^{\circ} \\
(4 \mathrm{Monate})\end{array}$ & Keine & $0.13 \mathrm{ng} / \mathrm{ml}$ & 17 & $4.7 \times 10^{6}$ \\
\hline $\begin{array}{c}\mathrm{I}_{2} \mathrm{I}_{3}-12 / 82^{\circ} \\
(4 \mathrm{Monate})\end{array}$ & Keine & $0.0 \mathrm{ng} / \mathrm{ml}$ & 46 & $5.6 \times 10^{6}$ \\
\hline
\end{tabular}


Hyperinsulinämia und die Störung der Spermatogenese wurden auch bei konditionellen knock-out Mäusen (NIRKO), bei denen der Insulin-Rezeptor im Gehirn ausgeschaltet ist, beobachtet (Brüning et al., 2000). Bei diesen Tieren wurde wie auch bei $\mathrm{I}_{2} \mathrm{I}_{3}-1$ Mäusen (s. Abb. 3.46 und 3.47) eine Zunahme des Körpergewichts (ca. 20\%) nachgewiesen.

\subsection{8}

\section{Letalität der homozygoten Mäuse für $\mathbf{I}_{2} \mathbf{I}_{3}-1$ der Linie 2}

In der $\mathrm{F}_{2}$-Generation der $\mathrm{I}_{2} \mathrm{I}_{3}-1$ transgenen Linie 2 war die durchschnittliche Wurfgröße im Gegensatz zu den anderen Linien mit 2.7 \pm 0.87 bedeutend herabgesetzt. Um die hemizygoten und homozygoten $\mathrm{F}_{2}$ transgenen Mäuse unterscheiden zu können, wurden die Tiere mittels Real-Time-PCR genotypisiert. Es konnten keine homozygoten Mäuse identifiziert werden. Für die Reduktion der Wurfgröße gibt es mehrere mögliche Erklärungen:

1. Die Überexpression von Insulin in den $\mathrm{I}_{2} \mathrm{I}_{3}-1$ transgenen Weibchen führt zu einer Störung der Follikelentwicklung bzw. zu einer Reduktion der ovulierten Eizellen.

2. Die Überexpression von Insulin in männlichen Tieren führt zur Störung der Spermatogenese.

3. Das transgene $\mathrm{I}_{2} \mathrm{I}_{3}-1$ Allel wurde innerhalb eines Gens inseriert (und dieses somit ausgeschaltet), dessen Proteinprodukt für die embryonale Entwicklung essentiell ist.

Die durchschnittliche Wurfgröße der Verpaarungen von sowohl männlichen als auch weiblichen transgenen Mäusen mit Wildtyp-Tieren war ebenfalls reduziert. Deshalb kann vermutlich die Insulinüberexpression in den Weibchen oder in den Männchen nicht der Grund für die generelle Abnahme der Wurfgröße sein.

Um zu bestimmen, wann die Embryonen bei den Verpaarungen der hemizygot transgenen Tiere sterben, wurde die Zahl der Embryonen an den Embryonaltagen 7.5, 11.5 und 15.5 bestimmt. Die Zahl der implantierten Embryonen war am Tag E7.5 normal, an E11.5 und E15.5 aber deutlich reduziert. Diese Ergebnisse ließen vermuten, dass die Embryonen nach der Implantation absterben. Um dies zu überprüfen, wurden 
18 Blastocysten isoliert und für fünf Tage in vitro kultiviert. Die tägliche Beobachtung hat gezeigt, dass sich nicht alle Blastocysten normal entwickeln (s. Abb. 4.4). Der Trophoblast aller Blastocysten entwickelte sich normal, aber die innere Zellmasse von 10 dieser 18 Blastocysten prolifierierte nicht weiter. Die Blastocysten wurden mittels PCR genotypisiert. Es stellte sich heraus, dass alle anomalen Blastocysten transgen waren. Die Blastocysten, die sich normal enwickelten, waren genotypisch transgen oder Wildtyp.

Da die Quantität der aus den Blastocysten extrahierten DNA zu gering war, konnte bei Real-Time-PCR-Analysen nicht eindeutig bestimmt werden, ob die Blastocysten homozygot oder hemizygot für das transgene $\mathrm{I}_{2} \mathrm{I}_{3}-1$ Allel waren. Es kann also nicht entschieden werden, ob alle aberanten Blastocysten homozygot für das transgene Allel waren.

Zum jetzigen Zeitpunkt muss offen bleiben, ob die embryonale Letalität in der Linie 2 auf eine Insertionsmutation im homozygoten Zustand oder auf eine Überexpression von Insulin zurückzuführen ist. Es wird notwendig sein, den Integrationsort für das Konstrukt genau festzustellen und dabei herauszufinden, ob ein endogenes Gen betroffen ist. Ein solches Gen sollte dann bei der Maus deletiert werden und der Phänotyp der knock-out Mäuse analysiert werden. Sollte kein endogenes Gen betroffen sein, dann können weiterführende Analysen zur Expression des transgenen Insulins in Blastocysten erfolgen und die Effekte von Insulinapplikationen in der Embryonalentwicklung von Wildtyptieren studiert werden. 
Wildtyp oder Transgen
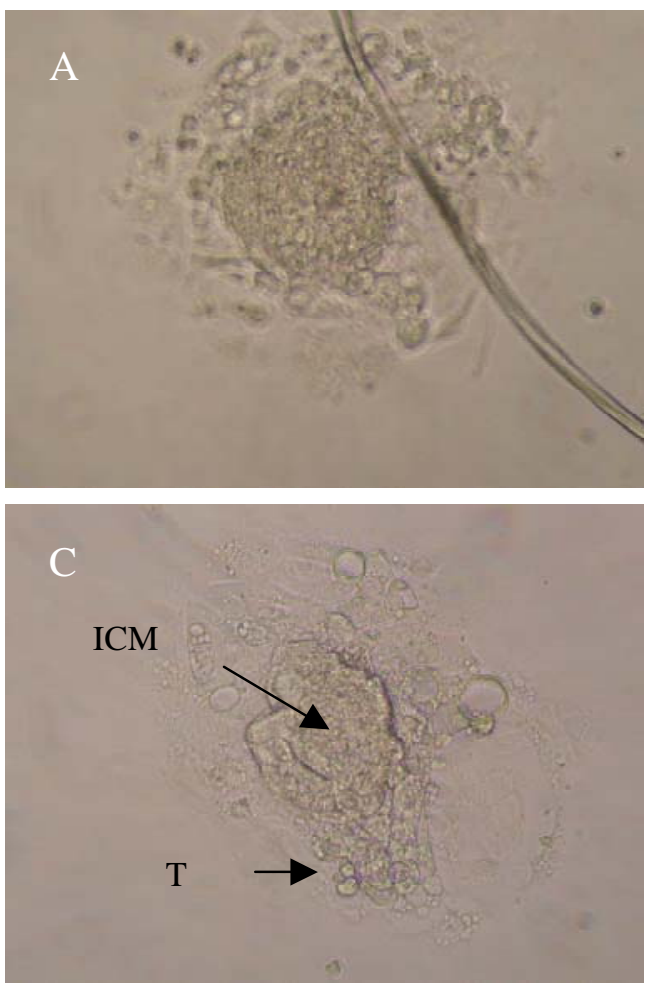

Normale ICM
Transgenes Embryo
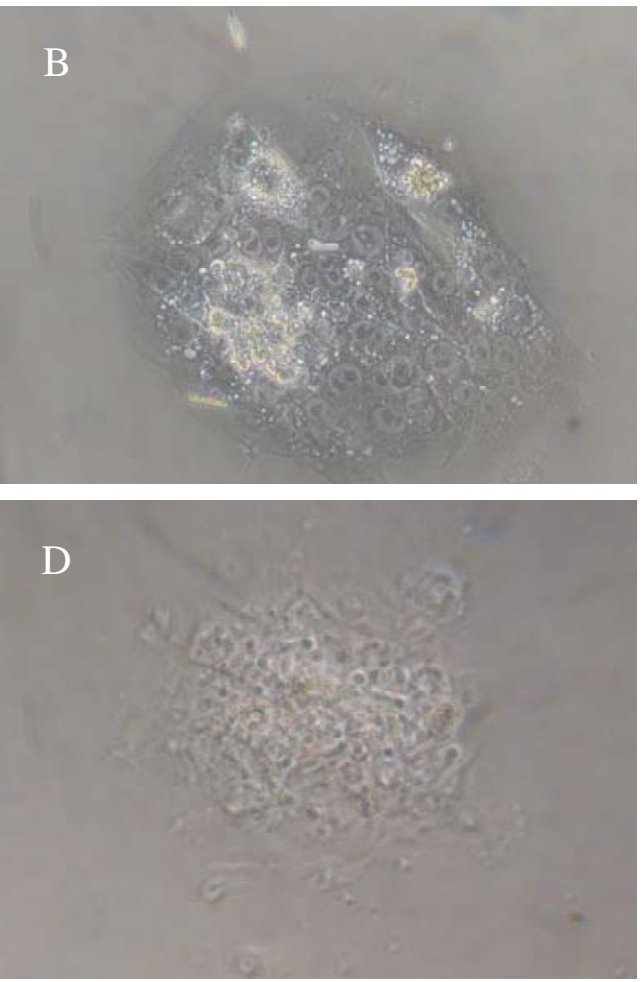

Atrophierte ICM

Abb. 4.4: In vitro Kultivierung der Blastocysten von hemizygoten Verpaarungen der Linie 2. Die inneren Zellmassen der Blastocysten (ICM), die nach 5-tägiger Kultur nicht weiter prolifierierten (B,D) waren alle transgen, wobei aufgrund der Methoden nicht zwischen hemizygot und homozygot transgen unterschieden werden konnte. Im Gegensatz dazu entwickelten sich die ICMs der Wildtyp-Blastocysten normal. Pfeile zeigen die Innere Zellmasse (ICM) bzw. den Trophoblast (T). 


\section{$5 \quad$ ZUSAMMENFASSUNG}

Im Rahmen diese Arbeit wurden die Expression und Funktion von zwei neuen Mitgliedern der Insulinsuperfamilie, Ins15 und Ins16, untersucht.

Anhand einer Northern-Blot-Analyse mit Gesamt-RNA aus unterschiedlichen Organen der adulten Maus konnte gezeigt werden, dass das Insl5-Gen sehr stark im Rektum der Maus exprimiert wird. Die Expression während der embryonalen Entwicklung konnte mittels Northern-Blot nicht nachgewiesen werden und wurde über eine RT-PCRAnalyse an Gesamt-RNA untersucht. Die ersten Transkripte sind in 11.5 Tage alten Embryonen nachweisbar. Es wurde ein knock-out Konstrukt für das Insl5-Gen hergestellt (Deletion im Exon 2). Das Konstrukt wurde in embryonale Stammzellen transfiziert, und durch homologe Rekombination wurden Chimären erzeugt. Die Verteilung der Genotypen in der $\mathrm{F}_{2}$-Generation entsprach den Mendelschen Regeln, was darauf hindeutet, dass die Ins15 ${ }^{-/}$-Mäuse keine Störung der Embryonalentwicklung aufweisen. Die homozygoten Ins15-defizienten Mäuse sind lebensfähig und zeigen keine phänotypischen Auffälligkeiten in Bezug auf Körpergröße, Gewicht oder Fertilität. Northern-Blot-Analysen konnten die Abwesenheit des Insl5-Transkripts in den -/Mäusen bestätigen. Da die Inaktivierung von Insl5 zu keinem erkennbaren aberranten Phänotyp führte, kann auch angenommen werden, dass das Insl5-Gen bei der Maus keine wichtige Funktion besitzt.

Mittels Northern-Blot-Analyse wurde gezeigt, dass das murine Insl6-Gen hauptsächlich im Testis exprimiert wird. Durch RT-PCR-Analyse konnte das Insl6-Transkript ab dem Tag 9.5 der embryonalen Entwicklung nachgewiesen werden. Es sollte der Beginn der Ins16-Expression während der Testisentwicklung der Maus mittels Northern-Blot untersucht werden, um Rückschlüsse auf den exprimierenden Zelltyp ziehen zu können. Ein Transkript konnte schwach ab Tag 15, deutlich ab Tag 20 der postnatalen Entwicklung nachgewiesen werden, was für eine Expression in diploiden und haploiden Keimzellen spricht. Die Expressionsanalyse des Insl6-Gens in den Testes mutanter Mäuse, deren Spermatogenese in verschiedenen Stadien arretiert ist, bestätigte diese Ergebnisse. Ein Insl6-Transkript war nur in Mauslinien detektierbar, deren Spermatogenese das Pachytänstadien erreicht. Mit Hilfe des pPNT-Vektors wurde ein Konstrukt zur Generierung einer Insl6-knock-out Maus hergestellt. Durch homologe 
Rekombination in embryonalen Stammzellen wurde das vollständige Exon 1 auf einem Allel der positiven ES-Zellen durch das Neomycin-Resistenzgen ersetzt. Es konnten nur niedrig-gradige Chimären (2-15\% Chimärismus) erhalten werden. Bei der Verpaarung dieser Chimären wurde das rekombinante Allel nicht an die Nachkommen transmittiert. Eine männliche Chimäre mit 35\% Chimärismus wurde mit Wildtypweibchen verpaart, es wurden keine Nachkommen gezeugt, es konnten auch keine Spermien im Uterus der Weibchen gefunden werden. Daher wird vermutet, dass Haploinsuffizienz die Ursache für den Tod der Tiere mit höherem Chimärismus während der embryonalen Entwicklung ist.

Als weiteres Ziel dieser Arbeit wurden drei verschiedene transgene Konstrukte hergestellt, in denen das humane Insulingen unter die Kontrolle des Leydigzellspezifischen Insl3-Promotors gestellt wurde. Die generierten transgenen Mäuse sollten humanes Insulin im Testes produzieren. Durch Northern-Blot-Analyse konnte die Expression der transgenen Konstrukte in Testis gezeigt werden. Auf der Proteinebene wurde mithilfe des Fluoroimmunoassays und der RIA-Analyse das transgene humane Insulin nachgewiesen. Allerdings konnte das transgene Insulin weder hergestellte diabetische Mäuse (durch Streptozotocin) noch Pax4-defiziente Mäuse retten. Es ist möglich, dass das produzierte Insulin in $\mathrm{zu}$ geringen Mengen und daher nicht ausreichend von den Leydigzellen sezerniert wird. Ob die Sekretionsmechanismen in Leydigzellen vergleichbar sind mit denen in $\beta$-Zellen, ist nicht geklärt. Daher sind weitere Analysen nötig, um zu prüfen, ob und inwieweit Leydigzellen als Ersatz für $\beta$ Zellen des Pankreas in Frage kommen können. 


\section{LITERATURVERZEICHNIS}

Adham IM, Burkhardt E, Benahmed M, Engel W. 1993. Cloning of a cDNA for a novel insulin-like peptide of the testicular Leydig cells. J Biol Chem. 268:26668 -72.

Adham IM, Nayernia K und Engel W. 1997. Spermatozoa lacking Acrosin protein show delayed fertilisation. Mol Rep Dev. 46:370-376.

Adham IM, Emmen JM, Engel W. 2000. The role of the testicular factor INSL3 in establishing the gonadal position. Mol Cell Endocrinol. 160:11-6.

Adham IM, Steding G, Thamm T, Bullesbach EE, Schwabe C, Paprotta I, Engel W. 2002. The overexpression of the insl3 in female mice causes descent of the ovaries.

Mol Endocrinol. 16:244-52.

Agoulnik IU, Krause WC, Bingman WE 3rd, Rahman HT, Amrikachi M, Ayala GE, Weigel NL. 2003. Repressors of androgen and progesterone receptor action.

J Biol Chem. 278:31136-48.

Ausubel FM, Brent R, Kingston RE, Moore DD, Seidman JG, Smith JA und Struhl K. 1994. Current Protocols in Molecular Biology. John Wiley \& Sons Inc., USA.

Balvers M, Spiess AN, Domagalski R, Hunt N, Kilic E, Mukhopadhyay AK, Hanks E, Charlton HM, Ivell R. 1998. Relaxin-like factor expression as a marker of differentiation in the mouse testis and ovary. Endocrinology. 139:2960-70.

Bathgate R, Balvers M, Hunt N, Ivell R. 1996. Relaxin-like factor gene is highly expressed in the bovine ovary of the cycle and pregnancy: sequence and messenger ribonucleic acid analysis. Biol Reprod. 55:1452-7. 
Bathgade RAD, Scott D, Chung S, Ellyard D, Garreffa A, Tregear GW. 2002. Searching the human genome database for novel relaxin-like peptides. Lett Pept Sci.

Bathgate RA, Samuel CS, Burazin TC, Layfield S, Claasz AA, Reytomas IG, Dawson NF, Zhao C, Bond C, Summers RJ, Parry LJ, Wade JD, Tregear GW. 2002.

Human relaxin gene $3(\mathrm{H} 3)$ and the equivalent mouse relaxin (M3) gene. Novel members of the relaxin peptide family. J Biol Chem. 277:1148-57.

Bell GI, Merryweather JP, Sanchez-Pescador R, Stempien MM, Priestley L, Scott J, Rall LB. 1984. Sequence of a cDNA clone encoding human preproinsulin-like growth factor II. Nature. 310:775-7.

Bennett WI, Gall AM, Southard JL und Sidman RL. 1971. Abnormal spermiogenesis in quaking, a myelin-deficient mutant mouse. Biol Reprod. 5:30-58.

Bernstein P, Ross J. 1989. Poly(A), poly(A) binding protein and the regulation of mRNA stability. Trends Biochem Sci. 14:373-7.

Blundell TL, Humbel RE. 1980. Hormone families: pancreatic hormones and homologous growth factors. Nature. 287:781-7.

Boehm, D., Herold, S., Kuechler, A., Liehr, T., Laccone, F. 2004. Rapid detection of subtelomeric deletion/duplication by novel real-time quantitative PCR using SYBRgreen dye. Hum.Mut. 23:368-378.

Bogatcheva NV, Truong A, Feng S, Engel W, Adham IM, Agoulnik AI. 2003. GREAT/LGR8 is the only receptor for insulin-like 3 peptide.

Mol Endocrinol. 17:2639-46.

Bradford MM. 1976. A rapid and sensitive method for the quantitation of microgram quantities of protein utilizing the principle of protein-dye binding.

Anal Biochem. 72:248-254. 
Bradley A, Evans MJ, Kaufman MH und Robertson E. 1984. Formation of germline chimaeras from embryo-derived teratocarcinoma cell lines. Nature. 309:255-256.

Brinster RL, Chen HY, Trumbauer ME, Yagle MK und Palmiter RD. 1985. Factors affecting the efficiency of introducing foreign DNA into mice by microinjecting eggs. Proc Natl Acad Sci U S A. 82:4438-4442.

Bruning JC, Gautam D, Burks DJ, Gillette J, Schubert M, Orban PC, Klein R, Krone W, Muller-Wieland D, Kahn CR. 2000. Role of brain insulin receptor in control of body weight and reproduction. Science. 289:2122-5.

Bullesbach EE, Schwabe C. 2000. The relaxin receptor-binding site geometry suggests a novel gripping mode of interaction. J Biol Chem. 275:35276-80.

Burkhardt E, Adham IM, Brosig B, Gastmann A, Mattei MG, Engel W. 1994.

Structural organization of the porcine and human genes coding for a Leydig cellspecific insulin-like peptide (LEY I-L) and chromosomal localization of the human gene (INSL3). Genomics. 20:13-9.

Chassin D, Laurent A, Janneau JL, Berger R, Bellet D. 1995. Cloning of a new member of the insulin gene superfamily (INSL4) expressed in human placenta.

Genomics. 29:465-70.

Chien A, Edgar DB und Trela JM. 1976. Desoxyribonucleic acid polymerase from extremely thermophile Thermus aquaticus. J Bacteriol. 127:1550-1.

Cho C, Willis WD, Goulding EH, Jung-Ha H, Choi YC, Hecht NB, Eddy EM. 2001. Haploinsufficiency of protamine-1 or -2 causes infertility in mice. Nat Genet. 28:82-6.

Chomczynski P und Sacchi N. 1987. Single step method of RNA isolation by acid guanidine thiocyanate-phenol-chloroform extraction. Anal Biochem. 162:156-159. 
Claasz AA, Bond CP, Bathgate RA, Otvos L, Dawson NF, Summers RJ, Tregear GW, Wade JD. 2002. Relaxin-like bioactivity of ovine Insulin 3 (INSL3) analogues. Eur J Biochem. 269:6287-93.

Clark JM. 1988. Novel non-templated nucleotide addition reactions catalyzed by procaryotic and eucaryotic DNA polymerases. Nucleic Acids Res. 16:9677-9686.

Conklin D, Lofton-Day CE, Haldeman BA, Ching A, Whitmore TE, Lok S, Jaspers S. 1999. Identification of INSL5, a new member of the insulin superfamily. Genomics. 60:50-6.

Cozar-Castellano I, Stewart AF. 2005 Molecular engineering human hepatocytes into pancreatic beta cells for diabetes therapy. Proc Natl Acad Sci U S A. 102:7781-2.

Daniel S, Noda M, Straub SG, Sharp GW. 1999. Identification of the docked granule pool responsible for the first phase of glucose-stimulated insulin secretion.

Diabetes. 48:1686-90.

Denhardt DT. 1966. A membrane-filter technique for the detection of complementary DNA. Biochem Biophys Res Commun. 23:641-646.

Doetschmann T, Gregg RG, Maeda N, Hooper ML, Melton DW, Thomson S und Smithers O. 1987. Targeted correction of a mutant HPRT gene in mouse embryonic stem cells. Nature. 330:576-578.

Faradji RN, Havari E, Chen Q, Gray J, Tornheim K, Corkey BE, Mulligan RC, Lipes MA. 2001. Glucose-induced toxicity in insulin-producing pituitary cells that coexpress GLUT2 and glucokinase. Implications for metabolic engineering.

J Biol Chem. 276:36695-702.

Feinberg AP und Vogelstein B. 1983. A techique for radiolabeling DNA restriction endonuclease fragments to high specific activity. Anal Biochem. 132:6-13. 
Goodge KA, Hutton JC. 2000. Translational regulation of proinsulin biosynthesis and proinsulin conversion in the pancreatic beta-cell. Semin Cell Dev Biol. 11:235-42.

Guest PC, Arden SD, Rutherford NG, Hutton JC. 1995. The post-translational processing and intracellular sorting of carboxypeptidase $\mathrm{H}$ in the islets of Langerhans. Mol Cell Endocrinol. 113:99-108.

Halban PA, Kahn SE, Lernmark A, Rhodes CJ. 2001. Gene and cell-replacement therapy in the treatment of type 1 diabetes: how high must the standards be set? Diabetes. 50:2181-91.

Haskins K, McDuffie M. 1990. Acceleration of diabetes in young NOD mice with a CD4+ islet-specific T cell clone. Science. 249:1433-6.

Hecht NB. 1988. Post-meiotic gene expression during spermatogenesis. Prog Clin Biol Res. 267:291-313.

Hodge R. 1994. Reparation of RNA gel blots. Methods Mol Biol. 28:49-54.

Hosaka T, Yamamoto YL, Diksic M. 1991. Efficacy of retrograde perfusion of the cerebral vein with verapamil after focal ischemia in rat brain. Stroke. 22:1562-6.

Hsu SY. 1999. Cloning of two novel mammalian paralogs of relaxin/insulin family proteins and their expression in testis and kidney. Mol Endocrinol. 13:2163-74.

Hsu SY, Kudo M, Chen T, Nakabayashi K, Bhalla A, van der Spek PJ, van Duin M, Hsueh AJ. 2000. The three subfamilies of leucine-rich repeat-containing G proteincoupled receptors (LGR): identification of LGR6 and LGR7 and the signaling mechanism for LGR7. Mol Endocrinol. 14:1257-71.

Hsu SY. 2003. New insights into the evolution of the relaxin-LGR signaling system. Trends Endocrinol Metab. 14:303-9. 
Hudson P, John M, Crawford R, Haralambidis J, Scanlon D, Gorman J, Tregear G,

Shine J, Niall H. 1984. Relaxin gene expression in human ovaries and the predicted structure of a human preprorelaxin by analysis of cDNA clones. EMBO J. 3:2333-9.

Ivell R, Bathgate RA. 2002. Reproductive biology of the relaxin-like factor (RLF/INSL3). Biol Reprod. 67:699-705.

Joyner A. 1993. Gene Targeting: A practical Approach. Oxford University Press, New York.

Kasik J, Muglia L, Stephan DA, Menon RK. 2000. Identification, chromosomal mapping, and partial characterization of mouse InsI6: a new member of the insulin family. Endocrinology. 141:458-61.

Kinloch RA, Mortillo S und Wassarman PM. 1992. Transgenic mouse eggs with functional hamster sperm receptors in their zona pellucida. Development. 115:937-946.

Koman A, Cazaubon S, Couraud PO, Ullrich A, Strosberg AD. 1996. Molecular characterization and in vitro biological activity of placentin, a new member of the insulin gene family. J Biol Chem. 271:20238-41.

Krajnc-Franken MA, van Disseldorp AJ, Koenders JE, Mosselman S, van Duin M, Gossen JA. 2004. Impaired nipple development and parturition in LGR7 knockout mice.

Mol Cell Biol. 24:687-96.

Laird PW, Zijderwald A, Linders K, Rudnicki MA, Jaenisch R und Berns A. 1991. Simplified mammalian DNA isolation procedure. Nucleic Acids Res. 19:4293.

Larsen JL. 2004. Pancreas transplantation: indications and consequences.

Endocr Rev. 25:919-46. 
Laurent A, Rouillac C, Delezoide AL, Giovangrandi Y, Vekemans M, Bellet D, Abitbol M, Vidaud M. 1998. Insulin-like 4 (INSL4) gene expression in human embryonic and trophoblastic tissues. Mol Reprod Dev. 51:123-9.

Le Bouc Y, Dreyer D, Jaeger F, Binoux M, Sondermeyer P. 1986. Complete characterization of the human IGF-I nucleotide sequence isolated from a newly constructed adult liver cDNA library. FEBS Lett. 196:108-12.

Lemmli UK. 1970. Cleavage of structural proteins during the assembly of the head of bacteriophage T4. Nature. 227:680-685.

Lipkind G, Gong Q, Steiner DF. 1995. Molecular modeling of the substrate specificity of prohormone convertases SPC2 and SPC3. J Biol Chem. 270:13277-84.

Liu C, Eriste E, Sutton S, Chen J, Roland B, Kuei C, Farmer N, Jornvall H, Sillard R, Lovenberg TW. 2003. Identification of relaxin-3/INSL7 as an endogenous ligand for the orphan G-protein-coupled receptor GPCR135. J Biol Chem. 278:50754-64.

Liu C, Chen J, Kuei C, Sutton S, Nepomuceno D, Bonaventure P, Lovenberg TW. 2005. Relaxin-3/insulin-like peptide 5 chimeric peptide, a selective ligand for G proteincoupled receptor (GPCR)135 and GPCR142 over leucine-rich repeat-containing G protein-coupled receptor 7. Mol Pharmacol. 67:231-40.

Liu C, Kuei C, Sutton S, Chen J, Bonaventure P, Wu J, Nepomuceno D, Kamme F, Tran DT, Zhu J, Wilkinson T, Bathgate R, Eriste E, Sillard R, Lovenberg TW. 2005. INSL5 is a high affinity specific agonist for GPCR142 (GPR100).

J Biol Chem. 280:292-300.

Loh EY, Elliott JF, Cwirla S, Lanier LL und Davies MM. 1989. Polymerase reaction with single sided specifity: Analysis of T-cell delta chain. Science. 243:217-220. 
Lok S, Johnston DS, Conklin D, Lofton-Day CE, Adams RL, Jelmberg AC, Whitmore TE, Schrader S, Griswold MD, Jaspers SR. 2000. Identification of INSL6, a new member of the insulin family that is expressed in the testis of the human and rat. Biol Reprod. 62:1593-9.

Lyon MF und Hawkes SG. 1970. X-linkes gene for testicular feminization in the mouse. Nature. 227:1217-1219.

Marban SL, DeLoia JA, Gearhart JD. 1989. Hyperinsulinemia in transgenic mice carrying multiple copies of the human insulin gene. Dev Genet. 10:356-64.

Melton DW. 1994. Gene targeting in the mouse. Bioassays. 16:633-638.

Morgan G, Levinsky RJ, Hugh-Jones K, Fairbanks LD, Morris GS, Simmonds HA. 1987. Heterogeneity of biochemical, clinical and immunological parameters in severe combined immunodeficiency due to adenosine deaminase deficiency.

Clin Exp Immunol. 70:491-9.

Moutier R. 1976. New mutations causing sterility restricted to the male rats and mice. The Laboratory Animal in the Study of Reproduction, Gustav Fischer Verlag, Stuttgart.

Nagy A, Rossent J, Nagy R, Abramow-Newerly W und Roder JC. 1993. Derivation of completely cell-derived mice from early-passage embryonic stem cells. Proc Natl Acad Sci USA. 90:8424-8428.

Nayernia K, Burkhardt E, Beimesche S, Keime S und Engel W. 1992. Germ cellspecific expression of a proacrosin-CAT fusion gene in transgenic mouse testis. Mol Reprod Dev. 31:241-248.

Nef S, Parada LF. 1999. Cryptorchidism in mice mutant for Ins13. Nat Genet. 22:295-9. 
Nishi S, Hsu SY, Zell K, Hsueh AJ. 2000. Characterization of two fly LGR (leucinerich repeat-containing, $\mathrm{G}$ protein-coupled receptor) proteins homologous to vertebrate glycoprotein hormone receptors: constitutive activation of wild-type fly LGR1 but not LGR2 in transfected mammalian cells. Endocrinology. 141:4081-90.

Oh C, Aho H, Shamsadin R, Nayernia K, Muller C, Sancken U, Szpirer C, Engel W, Adham IM. 2003. Characterization, expression pattern and chromosomal localization of the spermatogenesis associated 6 gene (Spata6). Mol Hum Reprod. 9:321-30.

Rabinowitz JE, Rutishauser U, Magnuson T. 1996. Targeted mutation of Ncam to produce a secreted molecule results in a dominant embryonic lethality.

Proc Natl Acad Sci U S A. 93:6421-4.

Robertson E, Bradley A, Kuehn M und Ewans M. 1986. Germ-line transmission of gene introduced cultured pluripotential cells by retroviral vector. Nature. 323:445-448.

Roche PJ, Butkus A, Wintour EM, Tregear G. 1996. Structure and expression of Leydig insulin-like peptide mRNA in the sheep. Mol Cell Endocrinol. 121:171-7.

de Rooij DG, de Boer P. 2003. Specific arrests of spermatogenesis in genetically modified and mutant mice. Cytogenet Genome Res.103:267-76.

Saiki RK, Scharf S, Faloon F, Mullis KB, Horn GT, Ehrlich HA und Arnheim N. 1985. Enzymatic amplification of beta-globin genomic sequence and restriction site analysis for diagnosis of sickle cell anemia. Science. 230:1350-1354.

Sambrook J, Fritsch EF und Maniatis T. 1989. Molecular cloning: A laboratory Manual. 2. Auflage Cold Spring Harbor Laboratory, New York.

Sanger F, Nicklen S und Coulson AR. 1977. DNA sequencing with chain-terminating inhibitors. Proc Natl Acad Sci USA. 74:5463-5467. 
Sapir T, Shternhall K, Meivar-Levy I, Blumenfeld T, Cohen H, Skutelsky E, Eventov-Friedman S, Barshack I, Goldberg I, Pri-Chen S, Ben-Dor L, Polak-Charcon S, Karasik A, Shimon I, Mor E, Ferber S. 2005. Cell-replacement therapy for diabetes: Generating functional insulin-producing tissue from adult human liver cells. Proc Natl Acad Sci USA. 102:7964-9.

Seidah NG, Chretien M, Day R. 1994. The family of subtilisin/kexin like pro-protein and pro-hormone convertases divergent or shared functions. Biochimie. 76:197-209.

Seidah NG, Chretien M. 1999. Proprotein and prohormone convertases: a family of subtilases generating diverse bioactive polypeptides. Brain Res. 848:45-62.

Seipp S und Buselmaier W. 1994. Isolation of glyceraldehyde 3-phosphate dehydrogenase (Gapdh) cDNA from the distal half of mouse chromosome 16: further indication of a link between Alzheimer's disease and glycolysis.

Neurosci Lett. 182:91-94.

Shapiro AM, Lakey JR, Ryan EA, Korbutt GS, Toth E, Warnock GL, Kneteman NM, Rajotte RV. 2000. Islet transplantation in seven patients with type 1 diabetes mellitus using a glucocorticoid-free immunosuppressive regimen. $N$ Engl J Med. 343:230-8.

Sherwood OD. 2004. Relaxin's physiological roles and other diverse actions. Endocr Rev. 25:205-34.

Shier P, Watt VM. 1989. Primary structure of a putative receptor for a ligand of the insulin family. J Biol Chem. 264:14605-8.

Siezen RJ, Creemers JW, Van de Ven WJ. 1994. Homology modelling of the catalytic domain of human furin. A model for the eukaryotic subtilisin-like proprotein convertases. Eur J Biochem. 222:255-66. 
Sosa-Pineda B, Chowdhury K, Torres M, Oliver G, Gruss P. 1997. The Pax4 gene is essential for differentiation of insulin-producing beta cells in the mammalian pancreas. Nature. 386:399-402.

Southern EM. 1975. Detection of specific sequences amoung DNA fragments separated by gel electrophoresis. J Mol Biol. 98:503-517.

Steiner DF. 1998. The proprotein convertases. Curr Opin Chem Biol. 2:31-9.

Steiner DF. 2000. New aspects of proinsulin physiology and pathophysiology. J Pediatr Endocrinol Metab. 13:229-39.

Strachan T und Read AP. 1994. PAX Genes. Curr Opin Genet Dev. 4: 427-438.

Strachan T und Read AP.1996. Molekulare Humangenetik, Spektrum Akademischer Verlag Gmbh, Heidelberg

Strader CH, Weiss NS, Daling JR, Karagas MR, McKnight B. 1988. Cryptorchism, orchiopexy, and the risk of testicular cancer. Am J Epidemiol. 127:1013-8.

Tadros H, Chretien M, Mbikay M. 2001. The testicular germ-cell protease PC4 is also expressed in macrophage-like cells of the ovary. J Reprod Immunol. 49:133-52.

Tan JZ, Lou CF, Zhang GY, Sun BY, Ping YJ. 2003. cDNA cloning and sequence analysis of leginsulin gene in broad bean (Vicia faba). Yi Chuan. 25:168-72.

Tashima LS, Hieber AD, Greenwood FC, Bryant-Greenwood GD. 1995. The human Leydig insulin-like (hLEY I-L) gene is expressed in the corpus luteum and trophoblast. J Clin Endocrinol Metab. 80:707-10.

Thamm T. 2002. Doktorarbeit. Universität Göttingen. Untersuchungen zur Regulation des Insl3 Gens. 
Thomas KR und Cappechi MR. 1987. Site-directed mutagenesis by gene targeting in mouse embryo-derived stem cells. Cell. 51:503-512.

Toppari J, Kaleva M. 1999. Maldescendus testis. Horm Res. 51:261-9.

Trucco M. 2005. Regeneration of the pancreatic beta cell. J Clin Invest. 115:5-12.

Tybulewicz VL, Crawford CE, Jackson PK, Bronson RT und Mulligan RC. 1991. Neonatal lethality and lymphopenia in mice with a homozygous disruption of the c-abl protoncogene. Cell. 65:1153-1163.

Ullrich A, Bell JR, Chen EY, Herrera R, Petruzzelli LM, Dull TJ, Gray A, Coussens L, Liao YC, Tsubokawa M. 1985. Human insulin receptor and its relationship to the tyrosine kinase family of'oncogenes. Nature. 313:756-61.

Vogelstein B und Gillespie D. 1979. Preparative and analytical purification of DNA from agarose. Proc Natl Acad Sci U S A. 76:615-9.

Weber K und Osborn M. 1969. The reliability of molecular weight determinations by dodecyl sulfate-polyacrylamide gel electrophoresis. J Biol Chem. 244:4406-4412.

Wicker LS, Miller BJ, Mullen Y. 1986. Transfer of autoimmune diabetes mellitus with splenocytes from nonobese diabetic (NOD) mice. Diabetes. 35:855-60.

Zhou A, Webb G, Zhu X, Steiner DF. 1999. Proteolytic processing in the secretory pathway. J Biol Chem. 274:20745-8.

Zhu X, Orci L, Carroll R, Norrbom C, Ravazzola M, Steiner DF. 2002. Severe block in processing of proinsulin to insulin accompanied by elevation of des-64, 65 proinsulin intermediates in islets of mice lacking prohormone convertase $1 / 3$.

Proc Natl Acad Sci U S A. 99:10299-304. 
Zimmermann S, Schlötter P, Engel W und Adham IM. 1997. Mouse leydig insulin-like (Ley I-L) gene: structure and expression during testis and ovary development. Mol Reprod Dev. 47:30-38.

Zimmermann S, Steding G, Emmen JM, Brinkmann AO, Nayernia K, Holstein AF, EngelW, Adham IM. 1999. Targeted disruption of the Insl3 gene causes bilateral cryptorchidism. Mol Endocrinol. 13:681-91. 


\section{Danksagung}

Herrn Professor Dr. Wolfgang Engel möchte ich besonders herzlich für das Überlassen des interessanten Themas, die überaus engagierte Betreuung, seine Geduld und die zügigen Korrekturen danken. Er zeigte immer großes Interesse am Fortgang der Versuche und trug mit guten Vorschlägen zum Gelingen dieser Arbeit bei.

Bei Herrn Professor Dr. Rüdiger Hardeland bedanke ich mich für die Übernahme des Korreferates.

Herrn PD Dr. Ibrahim Adham danke ich für seine Betreuung, seine konstruktive Kritik und seine zahlreichen Ideen, die im wesentlichen zum Gelingen dieser Arbeit beigetragen haben.

Professor Schmidt (Würzburg) danke ich für die Anfertigung der FISH-Analysen.

Professor Klonisch (Kanada) danke ich für die histologische Untersuchung der Thymusund Kolon-Gewebe.

Professor Meinhardt (Gießen) danke ich für die Spermatogenese-Analyse.

Dem Tierstall-Team möchte ich herzlich für die Unterstützung bei der Pflege der Mäuse und für die Hilfsbereitschaft danken.

Ich möchte mich in alphabetischer Reihenfolge bei meinen Laborkollegen Betul, Byamba, Ilona, Jin, Khulan, Linda, Oggi, Ozanna, Stefan, Thorsten und Wolfgang für die angenehme Atmosphäre im Labor, für die freundschaftliche Zusammenarbeit und aufmunternden Worte bedanken. Es war eine sehr schöne Zeit mit Euch.

Christian Müller war mir eine unentbehrliche Hilfe bei der Spermienanalyse und Blastocysten-Isolierung, vielen Dank dafür.

Allen Mitarbeitern des Instituts für Humangenetik danke ich für die freundliche Verbundenheit und Hilfe. 
Ich möchte mich bei Leonie, Dirk, Byamba und Stefan für die zum Teil anstrengende Korrekturen bedanken.

Mein größter Dank gilt meiner Familie, die mir das Studium ermöglicht hat. Meine Dankbarkeit lässt sich nicht in Worte fassen, sie haben mich alle immer unterstützt, an mich geglaubt und motiviert. Ohne ihre Liebe hätte ich diese Arbeit nicht geschafft. Besonders meiner Schwester sei gedankt, weil sie immer an meiner Seite war, wenn ich sie brauchte. 